ANDRÉA FRANCO AMORAS MAGALHÃES

AVALIAÇÃO DAS INTOXICAÇÕES EXÓGENAS NO DISTRITO FEDERAL NO PERÍODO DE 2009 A 2013. 


\author{
UNIVERSIDADE DE BRASÍLIA \\ FACULDADE DE CIÊNCIAS DA SAÚDE \\ PROGRAMA DE PÓS-GRADUAÇÃO EM CIÊNCIAS DA SAÚDE
}

ANDRÉA FRANCO AMORAS MAGALHÃES

AVALIAÇÃO DAS INTOXICAÇÕES EXÓGENAS NO DISTRITO FEDERAL NO PERÍODO DE 2009 A 2013.

Tese apresentada como requisito parcial à obtenção do título de Doutor em Ciências da Saúde pelo programa de PósGraduação em Ciências da Saúde da Universidade de Brasília.

Orientadora: Prof. ${ }^{a}$ Dr. ${ }^{a}$ ELOISA DUTRA CALDAS

Brasília 


\title{
AVALIAÇÃO DAS INTOXICAÇÕES EXÓGENAS NO DISTRITO FEDERAL NO PERÍODO DE 2009 A 2013.
}

Aprovado em 14, março, 2017.

\author{
BANCA EXAMINADORA \\ Profa. Dra. Eloisa Dutra Caldas (FCS/UNB) \\ (Presidente) \\ Prof. Dr. Pedro Luíz Tauil (FM/UNB) \\ (Membro Efetivo) \\ Profa. Dra. Rosany Bochner (CICT/FIOCRUZ) \\ (Membro Efetivo)
}

Prof. Dr. Herling Gregorio Aguilar Alonzo (FCM/UNICAMP)

(Membro Efetivo)

Prof $^{a}$. Dra. Laila Salmen Espindola (FCS /UNB)

(Membro Efetivo)

Profa. Dra. Maria da Graça Luderitz Hoefel (DSC/UNB)

(Membro Suplente) 
Ao meu esposo Fernando pelo apoio incondicional. Aos meus filhos, Fernanda, Alissa e André, pela paciência e compreensão. $A$ vocês todo o meu amor. 


\section{AGRADECIMENTOS}

À minha Nossa Senhora de Nazaré.

A minha mãe Edda, pela dedicação, preocupação e amor em todos os momentos. Ao meu pai Walter, pelo incentivo, orientação e principalmente a partir do seu exemplo ter me levado a trilhar os caminhos da saúde pública, com ética e responsabilidade.

Aos meus irmãos, Débora e Walter Junior por todo carinho e estímulo.

À professora Eloísa Caldas por toda a sua orientação e aprendizado ao longo destes anos, pelo incansável apoio, obrigada por estar ao meu lado.

Ao professor Pedro Tauil, que me abriu as portas da UNB, por toda a atenção, carinho e confiança em mim depositada, assim como, por suas fundamentais recomendações.

À todos os membros da banca examinadora por suas valorosas contribuições.

Aos meus colegas de trabalho da área de Medicina Social da UNB, por todo o incentivo, e por me permitirem ser professora voluntária da UNB o que muito me orgulha.

Aos meus colegas de trabalho e estagiários do Centro de Informações Toxicológicas de Brasília, por todo o apoio e compreensão nestes anos, em especial a farmacêutica Sandra Marcia Silva e a enfermeira Luana Nascimento Costa.

Aos meus colegas de trabalho do CEREST, em especial a equipe do ambulatório de Toxicologia ocupacional, que desde 2003, supera desafios a cada dia, por toda a dedicação e empenho em prol dos trabalhadores.

A equipe do Instituto de Medicina Legal/DF - que nos permitiu trabalhar sem restrições, nos dando todo o suporte necessário, em especial nosso agradecimento ao Dr. Aluísio Trindade Filho, perito médico legista e ao Sr. Venilton Siqueira da seção de informática, planejamento e estatística. 
À equipe da Gerência de Informação e Análise de situação de Saúde da SES/DF, em especial ao Sr. Adelson Guimarães da Costa, pelo seu apoio com a coleta dos dados.

Ao estagiário do Laboratório de Toxicologia da UNB- LABTOX, hoje Biomédico, José de Ribamar Ribeiro da Silva Sobrinho, por todo o seu empenho e dedicação com este trabalho.

Ao enfermeiro do CIEVS Linconl Uchoa pelo seu incansável e valioso apoio com o banco de dados.

A farmacêutica do LACEN Fernanda Góes, pela sua prestimosa ajuda com a classificação ATC.

Ao Dr. Tiago Coelho de Sousa Subsecretário da SVS/SES/DF que nos permitiu realizar uma investigação acadêmica sem restrições.

Aos colegas do Laboratório de Toxicologia que me acompanharam nessa caminhada, por todo o apoio recebido.

Aos meus amigos e familiares que me encorajaram a vencer mais esta etapa. 


\section{SUMÁRIO}

LISTA DE FIGURAS $\quad$ ix

LISTA DE QUADROS Xi

LISTA DE TABELAS Xii

LISTA DE ABREVIATURAS E SIGLAS xiii

RESUMO XV

ABSTRACT xvi

1.INTRODUÇÃO

2.REFERENCIAL TEÓRICO 3

2.1. Intoxicações humanas 3

2.1.1. Características da Intoxicação 3

2.1.2. Principais causas de Intoxicações 4

2.1.3. Intoxicações na Infância e adolescência

$\begin{array}{ll}\text { 2.1.4. Tentativas de Suicídio } & 7\end{array}$

2.1.5. Intoxicação Ocupacional 10

2.2 Intoxicação por Agrotóxicos 13

2.2.1. Principais agrotóxicos envolvidos nas intoxicações humanas no Brasil 16

$\begin{array}{ll}\text { 2.2.2 Sintomas Clínicos decorrentes da exposição } & 16 \\ \text { ocupacional a agrotóxicos } & 16\end{array}$

Alterações dermatológicas $\quad 19$

Alterações respiratórias $\quad 21$

Alterações neurológicas $\quad 22$

Alterações reprodutivas $\quad 25$

Alterações genéticas $\quad 27$

2.3. Intoxicações por medicamentos $\quad 27$

2.3.1. Principais medicamentos envolvidos nas
intoxicações

2.4. Sistemas de Informação em vigilância toxicológica no 30
Brasil

2.4.1. Sistema de Informação de Agravos de Notificação-

SINAN. $\quad 32$

2.4.2. Sistema de Informação sobre Mortalidade- SIM 33

Classificação Internacional de Doenças -CID 33

2.4.3. Sistema Nacional de Informações Tóxico

Farmacológicas-SINITOX 35

2.4.4. Centro de Informações Toxicológicas do Distrito
Federal CIT/DF

2.4.5. Instituto de Medicina Legal do Distrito Federal -

IML/DF 39

2.4.6. Centro de Referência em Saúde do Trabalhador do

Distrito Federal CEREST/DF $\quad 40$

2.2.5.O Distrito Federal 41

3.OBJETIVOS 43

ESTRUTURA DA TESE

I. Casos de exposição/intoxicação ocupacionais atendidos

no Centro de Referência em Saúde do Trabalhador do

Distrito Federal entre 2009 e 2013 
II. Exogenous intoxications in the Federal District of Brazil

- data from the Poison Information Center and the

Disease Notification Information System)

III. Óbitos por intoxicação exógena no Distrito Federal entre os anos de 2009 e 2013

REFERENCIAS BIBLIOGRÁFICAS

APENDICE 1- FICHA DE INVESTIGAÇÃO DE CASO- CIT

APENDICE 2- FICHA DE INVESTIGAÇÃO DE CASO -CEREST

ANEXO 1- APROVAÇÃO DO COMITÊ DE ÉTICA

ANEXO 2- MODELO DE DECLARAÇAO DE ÓBITO

ANEXO 3- CAPÍTULO XX (CAUSAS EXTERNAS DE

MORBIDADE E MORTALIDADE) DA CID-10 


\section{LISTA DE FIGURAS}

\section{REFERENCIAL TEÓRICO}

Figura 1. Distribuição das mortes infantis (0-17 anos) por causa no mundo em 2004 de acordo com a Organização Mundial de Saúde (WHO, 2008)

Figura 2. Algumas formas de raticidas ilegais contendo inibidores da acetilcolinesterase

Figura 3. Incidência de intoxicação por agrotóxicos em regiões brasileiras (por 100.000 habitantes) em 2000 e 2010

Figura 4. Número de intoxicações no Brasil em relação a dados nacionais sobre casos registrados de intoxicação humana por agente tóxico de 1999 a 2013.Fonte: FIOCRUZ, 2016

Figura 5. Centros de Informações e Assistência Toxicológica no Brasil

Figura 6. O Distrito Federal e suas regiões administrativas

I. Casos de exposição/intoxicação ocupacionais atendidos no Centro de Referência em Saúde do Trabalhador do Distrito Federal entre 2009 e 2013

Figura 1. Casos de intoxicação ocupacional avaliados no Ambulatório de Toxicologia Ocupacional do CEREST/DF de 2009 a 2013

Figura 2. Principais sintomas relacionados à exposição aos agrotóxicos relatados por agentes de vigilância ambiental e trabalhadores rurais intoxicados atendidos no Ambulatório de Toxicologia Ocupacional do CEREST/DF de 2009 a 2013

II. Exogenous intoxications in the Federal District of Brazil - data from the Intoxication Information Center and the Disease Notification Information System

Figure 1. Summary of the activities performed by the Poison Information Center of the Federal District (PIC-DF) during the period of 2009 to 2013

Figure 2. Poisoning cases reported to SINAM-DF and PIC-DF during the period of 2009 to 2013

Figure 3.Human poisoning cases according to the circumstance $(A)$, the agent involved $(B)$ and the age of the patient (C). Medication includes self-medication, administration error, prescription error and therapeutic use reported to SINAN-DF and PIC-DF from 2009 to 2013.

Figure 4. The main medicines involved with the intoxications reported to the PIC-DF and SINAM-DF from 2009 to 2013.

III. Óbitos por intoxicação exógena no Distrito Federal entre os anos de 2009 e 2013

Figura 1. Distribuição dos códigos CID's reportados (causa básica) no SIM referente a intoxicações exógenas no período de 2009 a 2013 
Figura 2. Agentes (A), circunstâncias (B) e idade (anos) (C) dos indivíduos envolvidos nos 288 casos de óbitos reportados ao SIM-DF, em percentual do total de casos com a informação conhecida, no período de 2009 a 2013

Figura 3. Agentes (A) e idade (B) dos individuos envolvidos nas intoxicações fatais reportadas no IML-DF entre 2009 e 2013

Figura 4. Distribuição de casos de intoxicação fatal (\% dos casos conhecidos), segundo a idade do indivíduo, reportados pelos quatro sistemas de informação, ocorridos no Distrito Federal entre 2009 e 2013

Figura 5. Diagrama de Venn dos 388 casos de óbitos por intoxicação exógena registrados no Distrito Federal reportados aos sistemas SIM, IML, CIT e/ou SINAN, 2009 a 2013

Figura 6. Distribuição dos 338 óbitos por intoxicação exógena ocorridos no Distrito Federal, em número de casos, no período de 2009 a 2013

Figura 7. Distribuição dos 335 óbitos por intoxicação exógena com idade conhecida ocorridos no Distrito Federal, de acordo com a idade do indivíduo, em\% do número de casos, no período de 2009 a 2013 


\section{LISTA DE QUADROS}

\section{REFERENCIAL TEÓRICO}

Quadro 1. População exposta de acordo com o agrotóxico utilizado em diversas regiões do Brasil relatados na literatura.

Quadro 2. Principais vias de absorção na exposição a agrotóxicos e fatores de risco de ocorrência de intoxicação.

Quadro 3. Resumo dos efeitos neurotóxicos causados por alguns agrotóxicos.

Quadro 4. Resumo dos sistemas de toxicovigilância no Brasil.

Quadro 5. Principais capítulos, agrupamentos e categorias relacionados com a morbi-mortalidade por intoxicação exógena. 


\section{LISTA DE TABELAS}

\section{REFERENCIAL TEÓRICO}

Tabela 1. Classificação Toxicológica dos Agrotóxicos (Portaria №. 3/1992). De acordo com a DL 50 oral aguda em ratos.

Tabela 2. Tipo e frequência de sintomas relatados por exposição ocupacional a agrotóxicos relatados na literatura.

\section{ESTRUTURA DA TESE}

I. Casos de exposição/intoxicação ocupacionais atendidos no Centro de Referência em Saúde do Trabalhador do Distrito Federal entre 2009 e 2013.

Tabela 1. Características dos indivíduos atendidos no Ambulatório de Toxicologia Ocupacional do CEREST/DF de 2009 a 2013.

Tabela 2. Indivíduos atendidos, segundo grupo ocupacional e agente envolvido na exposição no Ambulatório de Toxicologia Ocupacional do CEREST/DF de 2009 a 2013.

Tabela 3. Principais agrotóxicos, atividades envolvidas e resultados do exame de butirilcolinesterase nos indivíduos expostos a estes agentes, nos casos atendidos no Ambulatório de Toxicologia Ocupacional do CEREST/DF de 2009 a 2013.

II. Exogenous intoxications in the Federal District of Brazil - data from the Intoxication Information Center and the Disease Notification Information System.

Table 1. Poisoning cases involving rodenticides and pesticides reported to the SINAM-DF and PIC-DF from 2009 to 2013.

Table 2. Poisoning cases involving children (up to 9 years) reported to the SINAM-DF and PIC-DF from 2009 to 2013.

Table 3. Lethal poisoning cases reported to the SINAM-DF and PIC-DF from 2009 to 2013.

III. Óbitos por intoxicação exógena no Distrito Federal entre os anos de 2009 e 2013.

Tabela 1. Óbito por causas externas e por intoxicação exógena, reportados ao SIM-DF, 2009 a 2013.

Tabela 2. Óbitos registrados nos Sistemas de informação de acordo com, sexo, circunstância e agente tóxico no DF, 20092013.

Tabela 3. Características dos 388 casos de óbitos por intoxicações exógenas ocorridos no Distrito Federal no período de 2009 a 2013.

Tabela 4. Registros de óbitos por sistema de informação e agente causador relatados na literatura. 


\section{LISTA DE ABREVIATURAS E SIGLAS}

AAPCC American Association of Poison Control Centers

AChE Acetil-colinesterase Eritrocitária

ANVISA Agência Nacional de Vigilância Sanitária

ATO Ambulatório de Toxicologia Ocupacional

ATSDR Agency for Toxic Substances and Disease Registry

BChE Butirilcolinesterase

CAT Comunicação de Acidente de Trabalho

CIAT Centro de Informação e Assistência Toxicológica

CENEPI Centro Nacional de Epidemiologia

CEREST Centro de Referência em Saúde do Trabalhador

CDC Centers for Disease Control and Prevention

CID Classificação Internacional de Doenças

CIT Centro de Informação Toxicológica

CLT Consolidação das Leis do Trabalho

DATASUS Departamento de Informática do Sistema Único de Saúde

DISAT Diretoria de Saúde do Trabalhador

EPI Equipamento de Proteção Individual

FIOCRUZ Fundação Oswaldo Cruz

IBAMA Instituto Brasileiro de Meio Ambiente

IARC International Agency for Research on Cancer

IBE Indicador Biológico de Efeito

IBMP Indicador Biológico Máximo Permitido

IBGE Instituto Brasileiro de Geografia e Estatística

ICICT Instituto de Comunicação e Informação Científica e 


$\begin{array}{ll}\text { IML } & \begin{array}{l}\text { Tecnológica em Saúde } \\ \text { Instituto de Medicina Legal }\end{array} \\ \text { INSS } & \text { Instituto Nacional de Seguridade Social } \\ \text { LACEN } & \text { Laboratório Central de Saúde Pública } \\ \text { MB } & \text { Monitorização Biológica } \\ \text { NIOSH } & \text { National Institute for Occupational Safety and Health } \\ \text { NOST } & \text { Norma Operacional de Saúde do Trabalhador } \\ \text { NR } & \text { Norma Regulamentadora do Ministério do Trabalho e Emprego } \\ \text { OIT } & \text { Organização Internacional do Trabalho } \\ \text { OMS } & \text { Organização Mundial da Saúde } \\ \text { OPAS } & \text { Oficina Pan Americana de Saúde } \\ \text { PCP } & \text { Pentaclorofenol } \\ \text { RENACIAT } & \text { Rede Nacional de Centros de Informação e Assistência } \\ \text { SES } & \text { Soxicológica } \\ \text { SINAN } & \text { Sistema Nacional de Agravos de Notificação } \\ \text { SIM } & \text { Sistema de Informação sobre Mortalidade } \\ \text { SINITOX } & \text { Sistema Nacional de Informação Tóxico-Farmacológica } \\ \text { SIS } & \text { Sistema de Informação em Saúde } \\ \text { SNC } & \text { Sistema Nervoso Central } \\ \text { SPSS } & \text { Statistical Package for the Social Sciences } \\ \text { SVS } & \text { Secretaria de Vigilância em Saúde } \\ \text { SUS } & \text { Sistema Único de Saúde } \\ \text { UNICAMP } & \text { Universidade Estadual de Campinas } \\ \text { USEPA } & \text { United States Environmental Protection Agency } \\ \text { World Health Organization }\end{array}$




\section{RESUMO}

Magalhães, Andrea Franco Amoras. Avaliação das intoxicações exógenas no Distrito Federal no período de 2009 a 2013. Brasília, 2017.Tese de Doutorado em Ciências da Saúde, Universidade de Brasília, Brasília 2017.

As intoxicações exógenas são importantes causas de morbidade e mortalidade, sendo consideradas um problema de saúde pública no mundo todo. Os objetivos deste estudo foram analisar as informações relativas às intoxicações exógenas ocorridas no Distrito Federal de 2009 a 2013. Com este fim, foram avaliados os casos de exposição ocupacional atendidos pelo ambulatório do Centro de Referência Estadual em Saúde do Trabalhador (CEREST-DF), o perfil epidemiológico das intoxicações exógenas registradas no Centro de Informação Toxicológica (CIT-DF) e do Sistema de Informação de Agravos Notificáveis (SINAN-DF), e as intoxicações fatais registradas nestes dois sistemas e ainda no Sistema de Informação de Mortalidade (SIM) e no Instituto Médico Legal (IML-DF). A maioria dos 382 trabalhadores expostos a produtos químicos atendidos no CEREST era do sexo masculino $(66,7 \%)$, faixa etária de 30-39 anos, 46,3\% cursaram até o ensino médio, $81 \%$ não utilizavam equipamento de proteção individual e 55,2\% trabalhavam na atividade por até 9 anos. A partir da investigação ocupacional, clínica e laboratorial, $57,3 \%$ foram diagnosticados como intoxicados, principalmente após exposição a agrotóxicos $(61,6 \%)$. Durante o período do estudo, foram registrados 3622 casos de intoxicação no CIT e 5702 casos no SINAN. Em ambos os sistemas, as mulheres foram mais acometidas (52-54\%), e 53\% dos casos reportados ao CIT envolveram crianças de até 9 anos. A intoxicação acidental foi a principal circunstância $(66,7 \%$ no CIT e $48 \%$ no SINAN). Os medicamentos foram o principal agente tóxico em ambos os sistemas ( $40 \%$ dos casos); outros agentes incluíram produtos de limpeza, drogas de abuso, raticidas (incluindo 0 chumbinho) e os agrotóxicos, que foram os agentes mais letais $(3,4 \%$ dos 263 casos no CIT). Em relação as intoxicações fatais, 288 casos foram reportados ao SIM, 18 ao SINAN, 29 ao CIT e 101 casos foram identificados no IML. Quando eliminadas as duplicidades de casos nos sistemas, 338 casos de intoxicação fatal foram identificados, dos quais $73,4 \%$ foram reportados em apenas um sistema (principalmente o SIM), e apenas 1 caso foi reportado pelos quatro sistemas. Os medicamentos $(48,7 \%)$ e os agrotóxicos ou chumbinho $(29,9 \%)$ foram os principais agentes envolvidos, e as circunstâncias foram acidental $(50,8 \%)$ ou suicídio $(47,7 \%)$. Onze casos envolveram crianças de até 6 anos. Este estudo mostrou que as notificações de casos de intoxicação exógena nos sistemas de vigilância do Distrito Federal são deficientes, com subnotificação importante e baixa completude dos dados, demandando atenção das autoridades de saúde para seu aprimoramento para subsidiar ações de prevenção destas ocorrências, principalmente com crianças.

Palavras chaves: exposição ocupacional, Intoxicação exógena, toxicovigilância, sistemas se informação. 


\section{ABSTRACT}

Magalhães, Andrea Franco Amoras. Evaluation of exogenous intoxications that occurred in the Federal District, Brazil, from 2009 to 2013. Brasília, 2017. PhD Thesis in Health Sciences, University of Brasilia, Brasilia, 2017.

Exogenous intoxications are important causes of morbidity and mortality, being a worldwide public health problem. The objective of this study was to evaluate the exogenous intoxications that occurred in the Federal District from 2009 to 2013. In order to reach this objective we evaluated the cases of individuals occupationally exposed to chemicals who received care at the ambulatory of the Centro de Referência Estadual em Saúde do Trabalhador (CEREST-DF), investigated the profile of the exogenous intoxications reported to the Poison Information Center (PIC-DF) and to the Disease Notification Information System (SINAN-DF), and the fatalities reported in these systems, in addition to the Mortality Information System (SIM) and the Legal Medical Institute (IML-DF). Most the 382 workers that were seen at the CEREST were men (66.7\%), aged 30 to 39 years, $46.3 \%$ attended up to high school, $81 \%$ did not use any individual protection device and $55.2 \%$ worked in the relevant activity for up to 9 years. Occupational, clinical and laboratory investigation concluded that $57.3 \%$ of the exposed workers were intoxicated during labor, mainly from pesticide exposure (61.6\%). During the study period, 3622 intoxication cases were reported to the PIC and 5702 cases to SINAN. Most the cases involved women (52-54\%), with $53 \%$ of the PIC cases involving children up to 9 years old. Most of the cases were accidental (66.7\% in the PIC and $48 \%$ in the SINAN). Medicines were the main agent involved ( 40\% of the cases), in addition to household products, drugs of abuse, rodenticides (including chumbinho), and pesticides, which were the most lethal agent (3.4\% of the 263 cases reported to PIC). A total of 288 cases of fatal intoxications were reported to SIM, 18 to SINAN, 29 to PIC and 101 were identified in the IML records. After eliminating the case duplicities, 338 cases of fatal intoxications were identified to have occurred in the region, from which $73.4 \%$ were reported to only one system (mostly the SIM), and only one case was reported to all four. Medicines $(48.7 \%)$ and pesticides or chumbinho $(29.9 \%)$ were the main agents involved, accidentally $(50.8 \%)$ or by suicide $(47.7 \%)$. Eleven cases involved children up to 6 years. This study indicated a high sub-notification rate of the intoxication records in the systems, and a lack of completeness of the data, mainly of SINAN fatal cases. These results demand attention from the health authorities to improve the vigilance systems and to provide sound data that could be used in prevention actions to decrease the actual number of intoxications that occur in the region, mainly involving children.

Keywords: Exogenous intoxication, occupational exposure, toxicovigilance, information systems 


\section{INTRODUÇÃO}

O ser humano convive desde os primórdios com vários agentes ou substâncias tóxicas. O uso milenar de venenos animais e extratos de plantas como arma de caça e guerra e para causar homicídios e suicídios são bem conhecidos, e muito cedo o homem teve que aprender a distinguir uma planta venenosa de uma planta que pudesse servir de alimento para a sua sobrevivência (ANDRADE FILHO; CAMPOLINA; DIAS, 2013). Além destes componentes naturais do planeta, há um crescente desenvolvimento de novos produtos químicos utilizados pela sociedade moderna com potencial risco para a saúde humana, incluindo os agrotóxicos de uso agrícola ou domiciliar, os domissanitários, os medicamentos e os produtos de uso industrial (SCHWARTZMAN, 2001). Porém, os riscos advindos da exposição a esses produtos têm sido, em muitos casos, negligenciados.

A toxicologia, além da ciência do veneno, é cada vez mais a ciência da segurança e da avaliação do risco. O conhecimento da probabilidade de a substância causar um efeito adverso no homem e no ambiente (risco) ou não (segurança), é fundamental para o estabelecimento de uma política racional de proteção da sociedade (SCHWARTZMAN, 2001).

As intoxicações exógenas podem ser definidas como a condição médica ou social inaceitável de um indivíduo como consequência da exposição a uma substância numa dose considerada muito alta para este indivíduo (UGES, 2001). O risco de um efeito indesejado decorrente de uma exposição a um agente químico depende de vários fatores, incluindo as propriedades intrínsecas e a toxicidade do agente, a via de exposição, a dose, a frequência de exposição e a susceptibilidade individual, que inclui aspectos genéticos, nutricionais e de saúde (THORNE, 2013). A Organização Mundial de Saúde (OMS) estima que 1,5 a $3 \%$ da população intoxicam-se todos os anos (WHO, 1990). Para o Brasil, esta estimativa representaria aproximadamente 4.800 .000 casos novos a cada ano, dos quais entre 0,1 e $0,4 \%$ das intoxicações resultariam em óbito (ZAMBOLIM et al., 2008). Entretanto, há forte indício que estes dados sejam subnotificados, a OMS estimou que para caso registrado existam pelo menos 50 subnotificados (WHO, 2002).

No mundo todo, a principal fonte de dados de intoxicações são os 
sistemas de informação toxicológica (BENTUR et al., 2008; MOWRY et al., 2015; OSTAPENKO et al., 2001; VEALE et al., 2013; WANANUKUL et al., 2007). No Brasil, o Sistema Nacional de Informações Tóxico-Farmacológica (SINITOX) compila desde a década de 80 as informações dos Centros de Informação (e Assistência) Toxicológica (CIT/CIAT) localizados nos estados e no Distrito Federal (DF). Estes Centros têm como função fornecer informação e orientação sobre o diagnóstico, prognóstico, tratamento e prevenção das intoxicações e envenenamentos, e atendem tanto os profissionais de saúde quanto o público em geral (ANVISA, 2005). Entre 1985 e 2010, o SINITOX registrou 692.098 casos de intoxicação no País, com 9.753 óbitos (BOCHNER, 2013). Estes casos referem-se principalmente aos casos de intoxicações agudas, e as intoxicações crônicas estão provavelmente subnotificadas.

Além do sistema CIT/CIAT/SINITOX, outras fontes de dados de intoxicações exógenas no Brasil incluem o Sistema de Informação de Agravos de Notificação (SINAN), o Sistema de Informação sobre Mortalidade (SIM) e os bancos de dados dos institutos médico legais nos estados e no Distrito Federal (IML). Uma investigação detalhada destes dados no Distrito Federal, poderá fornecer um panorama das intoxicações ocorridas na região, indicar potenciais fontes de subnotificação e servir de subsídios para aperfeiçoar as ações de prevenção, além da assistência e recuperação da saúde de pacientes expostos. 


\section{REFERENCIAL TEÓRICO}

\subsection{Intoxicações humanas}

A Toxicologia é a ciência que tem como objeto de estudo o efeito nocivo decorrente da interação entre um agente tóxico e um sistema biológico, com a finalidade principal de prevenir o aparecimento desse efeito, ou seja, estabelecer condições seguras de exposição a essas substâncias (EATON; GILBERT, 2013).

As intoxicações agudas são responsáveis por parte significativa dos atendimentos de emergência e internações em unidades de terapia intensiva, seja envolvendo pacientes adultos ou pediátricos, tanto em países desenvolvidos como nos em desenvolvimento. As estimativas são de que 3 a $7 \%$ dos pacientes que procuram as emergências apresentam algum agravo à saúde relacionado à exposição a agentes tóxicos (BRENT, 2005).

A intoxicação humana abrange uma ampla variedade de processos fisiopatológicos relacionados com a interação entre um agente químico ou biológico e o organismo. A condição primária para que a intoxicação aconteça consiste na exposição ao agente tóxico, o qual deverá alcançar o sítio-alvo após vencer as barreiras impostas pelo organismo. A expressão da toxicidade de uma substância sobre um sistema biológico dependerá de inúmeros fatores, como as propriedades físico-químicas do agente tóxico, as condições de exposição e, fundamentalmente, de seu comportamento toxicocinético e toxicodinâmico (GREGUS, 2013).

\subsubsection{Características da intoxicação}

As principais vias de exposição humana às substâncias tóxicas são a via gastrintestinal (ingestão), respiratória (inalação) e cutânea. As vias pulmonares e cutâneas são mais importantes na Toxicologia Ocupacional e Ambiental, e a via gastrintestinal em Toxicologia de Alimentos e de Medicamentos, e nas intoxicações intencionais suicídios e homicídios (THORNE, 2013).

Adicionalmente, têm-se as vias endovenosa, intraperitoneal, subcutânea, intramuscular e intradérmica, que se referem principalmente a medicamentos, e normalmente ocorrem em ambientes hospitalares/ ambulatoriais, e por isto são mais controláveis (LAURENCE et al., 2010). Uma exceção importante refere-se 
ao uso abusivo de substancias psicoativas, principalmente pela via intravenosa.

A dose, o tempo e a frequência de exposição ao agente tóxico são importantes para determinar o efeito tóxico. Na exposição em curto prazo (aguda), a dose pode ser única ou múltipla num período de tempo não superior a 24 horas. Na exposição em médio prazo, as exposições são frequentes ou repetidas num período de um mês ou menos (subaguda) ou no período de um a três meses (subcrônica). A exposição em longo prazo (crônica) pode se estender por um longo período de tempo (meses, anos ou toda a vida) (LAURENCE et al., 2010).

A exposição única a um agente tóxico que produz um efeito drástico pode resultar em manifestações de menor intensidade ou não produzir efeitos se a mesma dose ou concentração total for fracionada. Isto ocorre quando a substância é rapidamente excretada e o efeito tóxico causado pela substância for parcial ou totalmente revertido antes da exposição seguinte. Do contrário, o aumento da frequência poderá resultar em efeitos crônicos (GREGUS, 2013).

Para algumas substâncias, os efeitos tóxicos observados nas exposições agudas são diferentes daqueles produzidos por exposições repetidas. Por exemplo, a principal manifestação tóxica aguda do benzeno é a depressão do sistema nervoso central, enquanto exposições repetidas podem resultar em toxicidade para a medula óssea com aumento do risco para o desenvolvimento de leucemia. Nas exposições agudas, substâncias químicas rapidamente absorvidas levam a efeitos imediatos. Entretanto, podem ocorrer efeitos retardados, similares ou não aos efeitos produzidos nas exposições em longo prazo (LAURENCE et al., 2010).

\subsubsection{Principais causas de intoxicações}

As principais causas das intoxicações humanas diferem entre os países. No Brasil, a última publicação do SINITOX referente ao ano de 2013 indica que $28,5 \%$ das intoxicações notificadas pelos CIAT's se referem a medicamentos, e as intoxicações envolvendo agrotóxicos de uso agrícola são as mais letais (FIOCRUZ, 2016).

Nos Estados Unidos, os medicamentos ou produtos farmacêuticos foram responsáveis por 57\% das intoxicações ocorridas em 2014, seguidas de cosméticos/produtos de cuidado pessoal (9\%) e produtos domissanitários $(9 \%)$ 
(MOWRY et al., 2015). Na Africa do Sul, agrotóxicos (34.8\%) e medicamentos (35,2\%) foram os agentes mais envolvidos em 2008/2009 (VEALEet al., 2013). $\mathrm{Na}$ Tailândia, os agrotóxicos foram os agentes mais envolvidos nas intoxicações humanas, responsáveis por $41,5 \%$, dos casos entre 2001 e 2004 (WANANUKUL et al., 2007).

Em Israel, os medicamentos foram responsáveis por $44,2 \%$ dos 26.738 casos de intoxicação ocorridos em 2007 e os produtos químicos por $37,9 \%$ dos casos (BENTUR et al., 2008). O número de casos de intoxicações agudas em Moscou e grandes cidades russas aumentaram quase duas vezes num período de quinze anos. Os principais agentes tóxicos envolvidos foram os medicamentos (até 63,1\%), álcool (até 49,3\%) e corrosivos (até 21,8\%) (OSTAPENKO et al., 2001).

\subsubsection{Intoxicações na infância e adolescência}

As intoxicações exógenas agudas apresentam-se como um dos principais acidentes pediátricos (crianças e jovens de 0 a 19 anos), respondendo por aproximadamente $7 \%$ de todos os acidentes em crianças menores de cinco anos (MENDONÇA et al., 2016). As intoxicações estão implicadas em cerca de $4,0 \%$ de todas as mortes na infância no mundo, e dentre os jovens de 15-19 anos, o envenenamento é classificado como a $13^{\mathrm{a}}$ maior causa de morte, de acordo com os dados da OMS divulgada em 2008 (HOLDER et al., 2008; TOWNER; SCOTT, 2008) (Figura 1). 


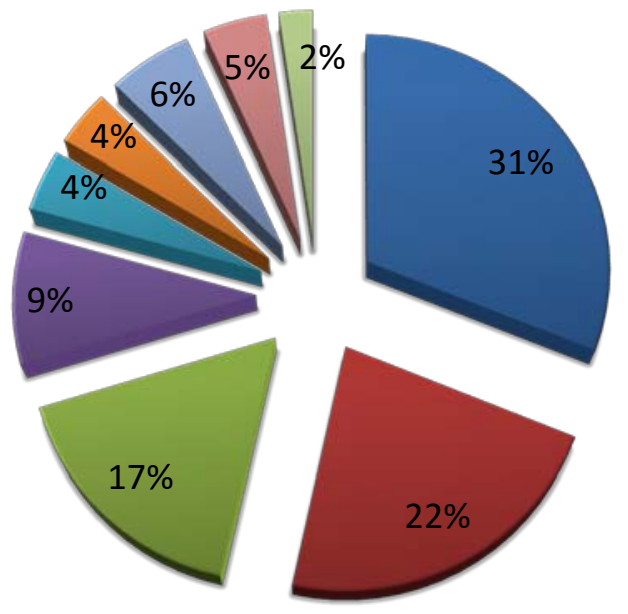

Q Outro não intencional

Lesões no trânsito

$\square$ Afogamento

Queimadura por fogo

$\square$ Quedas

๑Intoxicação

$\square$ Homicídios

$\square$ Lesões auto provocadas

$\square$ Guerras

Figura 1. Distribuição das mortes infantis (0-17 anos) por causa no mundo em 2004 de acordo com a Organização Mundial de Saúde (WHO, 2008). Outro não intencional inclui sufocamento, asfixia, choque, picadas de animais venenosos, hipotermia e hipertermia e desastres naturais.

As intoxicações, geralmente são decorrentes de situações facilitadoras relativas ao ambiente doméstico e no cuidado com a criança, das características peculiares às fases de desenvolvimento da criança, do pouco incentivo às medidas preventivas, da frágil política nacional de medicamentos e do uso indiscriminado de medicamentos, sendo desta forma, em sua maioria acidental e preveníeis (MINTEGI et al., 2006; NEGREIROS, 2006; SHANNON, 2000). Em Israel, 45\% dos casos de intoxicação registrados em 2007 envolveram crianças menores de 6 anos de idade (BENTUR et al., 2008).

Estudo realizado na Espanha mostrou que $75 \%$ dos acidentes com crianças ocorreram nas residências; em $26 \%$ dos casos, a família relatou armazenar produtos de limpeza doméstica em recipientes não originais e em $15,6 \%$ dos casos os medicamentos eram armazenados em locais inseguros (AZKUNAGA et al., 2013). Na Inglaterra e Canadá, estima-se que os medicamentos respondam por mais de um terço das intoxicações com crianças e adolescentes registrados (LAl et al., 2006). Nos Estados Unidos, mais de 2 milhões de atendimentos foram reportados pelos 56 centros de informações toxicológicas em 2014, sendo que 50\% envolveram crianças de até 5 anos. Nesta faixa etária, os cosméticos e os produtos de higiene pessoal foram a primeira causa de exposição (15\%), seguido pelos produtos de limpeza (11\%) e analgésicos (10\%); as principais causas de óbito registradas foram gases e 
vapores e analgésicos (15,4\% cada), e produtos de limpeza (7,7\%) (MOWRY et al., 2015).

Em Salvador (Bahia) no período de 2008 a 2012, 53,1\% das intoxicações atendidas no Hospital Geral Roberto Santos e pelo Centro Antiveneno da Bahia em crianças com idade inferior a 4 anos, sendo os medicamentos o principal agente tóxico (MENDONÇA et al., 2016).

No Brasil, dados do SINITOX indicam que no período de 2009 a 2013 foram registradas 451.308 intoxicações humanas, sendo que $22,8 \% \quad(N=$ 103.057) envolveram crianças de até 4 anos de idade. As principais causas de intoxicação foram medicamentos $(36,6 \%)$, domissanitários $(21,8 \%)$ e produtos químicos industriais $(9,1 \%)$. No mesmo período, foram registrados 1775 óbitos, sendo 119 em crianças de até 4 anos, principalmente por agrotóxicos de uso agricola $(31,9 \%)$, medicamentos $(16,8 \%)$ e domissanitários $(3,3 \%)$. Vale ressaltar que desde 2008 alguns CITs não reportam seus dados ao SINITOX de forma sistemática, sendo que em 2013 só 16 dos 34 existentes o fizeram, gerando uma subnotificação importante no País (FIOCRUZ, 2016).

Medidas de prevenção de intoxicações em crianças, como a instituição de Embalagem Especial de Proteção à Criança (EEPC), implementada nos Estados Unidos e Canadá, são eficazes (RAMOS et al., 2005). A introdução das embalagens de medicamentos seguras de aspirina reduziu a incidência de até $55 \%$ de ingestão acidental deste medicamento por crianças nos Estados Unidos (CLARKE; WALTON, 1979). No Brasil o Projeto de Lei № 530, em tramitação no Congresso Nacional desde 2003, visa à adoção da embalagem especial de medicamentos e produtos químicos de uso doméstico, de maneira a dificultar seu manuseio por crianças. A aprovação desse projeto poderia impactar as estatísticas de eventos tóxicos causados por medicamentos e produtos químicos que vitimam um grande número de crianças e adolescentes brasileiros, entretanto o projeto foi arquivado em 2008 (BRASIL, 2008).

\subsubsection{Tentativa de suicídio}

As tentativas de suicídio são um trágico fenômeno social que ocorre por diversos métodos em diferentes comunidades, com aumento da sua taxa global estimados em $60 \%$ nos últimos 45 anos; em alguns países, o suicídio está entre as dez causas mais frequentes de morte, e a terceira entre jovens e 
adolescentes (AZIZPOUR et al., 2016; MEDEIROS et al., 2012; MELOSANTOS et al., 2005). De acordo com a OMS estima-se que 804000 mortes por suicídio ocorreram no mundo em 2012, representando uma taxa de suicídio de 11,4 por 100000 habitantes (15,0 para o sexo masculino e 8,0 para as mulheres). No entanto, o suicídio pode muitas vezes ser erroneamente classificado como um acidente ou outra causa de morte (WHO, 2014).

$\mathrm{O}$ custo do suicídio, estimado em termos de anos de vida ajustados às limitações, representou $1,8 \%$ do gasto total com doenças em todo o mundo em 1998 (WHO, 2000). Isso equivaleu ao dispêndio com guerras e homicídios, sendo similar aos custos de internação por trauma e asfixia neonatal e o dobro do custo com diabetes.

A história pregressa de tentativa de suicídio é um importante preditor do suicídio e de novas tentativas por um indivíduo. Aproximadamente $1 \%$ das pessoas que tentam, suicida-se no ano seguinte, uma taxa que se mantém após vários anos da tentativa inicial, e que é 100 vezes superior à observada na população geral. Seguimentos mais longos mostram que $10 \%$ das pessoas que tentam o suicídio terminam se matando. A mortalidade por causas naturais e por acidentes também é maior nesse grupo. Por outro lado, metade das pessoas que cometem o suicídio já o haviam tentado anteriormente (WHO, 2000).

O Brasil é o oitavo país em número de suicídios (5.8 por 100 mil habitantes), com 11.821 mortes registradas em 2012, 78\% envolvendo homens. Entre 2000 e 2012, houve um aumento de 10,4\% desses eventos, principalmente de mulheres no mundo (WHO, 2014).

Estima-se que as tentativas de suicídio sejam subnotificadas, aparecendo sob a forma eufêmica de acidente ou violência externa, e muitas vezes omitida pelo embaraço familiar (WHO, 2014). A partir de uma revisão sistemática, Gunnel et al. (2007) estimaram que cerca de 30\% de suicídios no mundo ocorrem pela ingestão de agrotóxicos, percentual que varia entre $4 \%$ na região europeia para mais de 50\% na região do Pacífico Oriental. A ingestão de agrotóxicos foi implicada em 62\% dos suicídios na China entre 1996 e 2000 (ZHANG et al., 2009). Estudo realizado no Iran de 1993 a 2003 analisando 6.794 casos de tentativas de suicídio por intoxicação indicou um percentual de incidência anual de $87,3 \%$, envolvendo principalmente mulheres jovens e 
solteiras, e homens desempregados (AZIZPOUR et al., 2016).

Estimativas mostram que ocorrem entre 234 mil e 326 mil suicídios com agrotóxicos todo ano, contribuindo com aproximadamente um terço de todos os suicídios no mundo (WHO, 2008). No Brasil, os registros do SIH/SUS (Sistema de Informações Hospitalares do Sistema Único de Saúde) mostram que ocorreram 3.082 internações devido ao envenenamento por agrotóxicos em 2004, com um coeficiente de 1,8 internações/ 100 mil habitantes (FARIA et al., 2007). Os organofosforados estiveram envolvidos em mais de $80 \%$ dos suicídios que ocorreram entre 1992 a 2002, em uma região rural do estado de Mato Grosso do Sul (PIRES et al., 2005).

A OMS identificou três tipos principais de intervenções comunitárias promissoras na prevenção do suicídio causado por agrotóxicos armazenamento mais seguro dos produtos (na família e na comunidade), a educação e intervenções psicossociais (WHO, 2008). A regulamentação dos agrotóxicos utilizados na prática agrícola do Sri Lanka mostrou que a proibição dos agrotóxicos mais tóxicos resultou em uma redução global do número de mortes por envenenamento intencional por estes produtos (GUNNELL et al., 2007a).

Destaca-se no Brasil a importância do chumbinho, um produto comercializado ilegalmente no País contendo inseticidas para uso agrícola, responsável por envenenamentos acidentais, suicídios e homicídios, acarretando um grave problema de saúde pública (CRUZ et al., 2013; MAGALHÃES, 2001). Tradicionalmente, o chumbinho é um "fracionamento" do inseticida carbamato contendo aldicarbe (vendido pela empresa Bayer com o nome comercial de Temik), de alta toxicidade aguda (SOLOMON, 2000). $\mathrm{Na}$ tentativa de diminuir o número de acidentes com este produto, a Anvisa solicitou à Bayer o acréscimo de um amargante e de um emético à formulação do Temik (ANVISA, 2017). Em 2012, a empresa suspendeu a comercialização do produto no Brasil, e o chumbinho comercializado atualmente no País contém outros agrotóxicos, principalmente inseticidas organofosforados.

Em uma série de 66 casos estudados pelo Centro de Informações Toxicológicas de Campinas/SP, as principais circunstâncias que levaram ao envenenamento foram intencionais, com $92.1 \%$ de tentativas de suicídio. $\mathrm{Na}$ maioria das amostras de plasma e urina coletadas no momento da admissão 
foi detectado o metabólito aldicarbe sulfóxido, indicando o uso do chumbinho (BUCARETCHI et al., 2012). Os autores encontraram aldicarbe em $50 \%$ das amostras de chumbinho analisadas (Figura 2), além dos carbamatos carbofurano e metomil, e dos organofosforados terbufós, forato e monocrotofós.

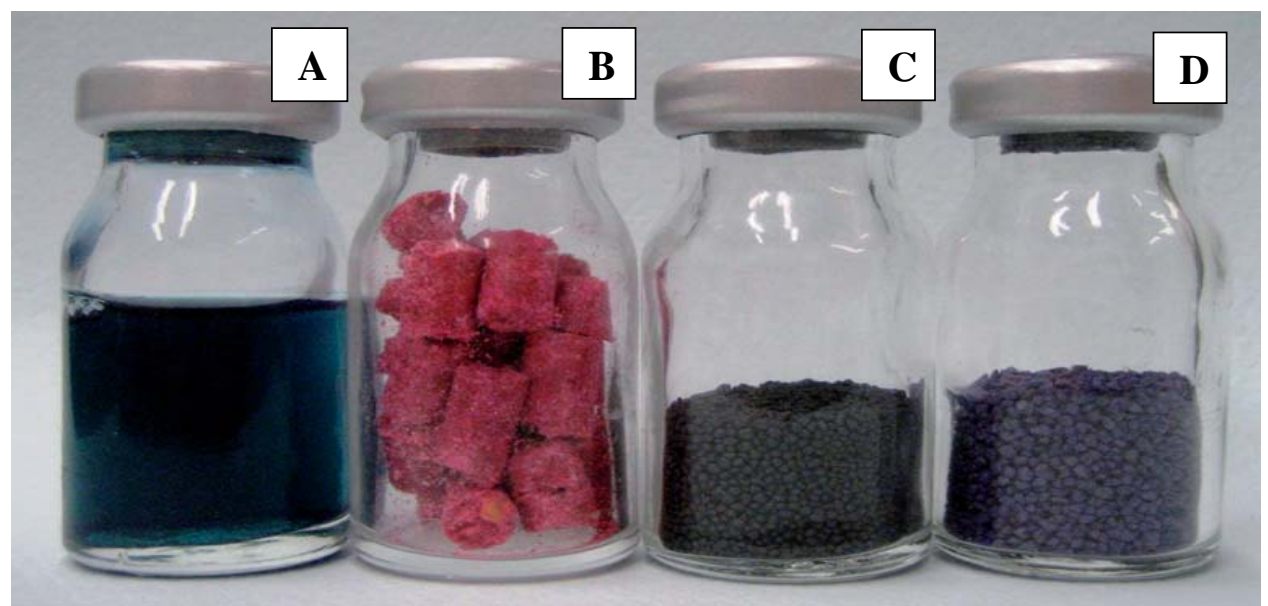

Figura 2. Algumas formas de raticidas ilegais contendo inibidores da acetilcolinesterase. A: forma líquida; B: pellet semelhante ao raticida a base de cumarínicos; C: grânulos cinzento-escuros; D: grânulos roxos. As formas C e D são conhecidas popularmente no Brasil como "chumbinho". Fonte: BUCARETCHI et al., 2012 (adaptado).

Em um estudo realizado no Hospital Antônio Pedro, no Rio de Janeiro, 40 pacientes expostos ao chumbinho foram atendidos, sendo $95 \%$ casos de tentativa de suicídio (SILVA; ALVES, 2007). Em estudo realizado por Werneck et al. (2006) no Hospital Geral no Rio de Janeiro, o chumbinho, foi responsável por cerca de um terço das ocorrências de tentativa de suicídio.

\subsubsection{Intoxicação ocupacional}

Os trabalhadores compartilham os perfis de adoecimento e morte da população em geral em função de sua idade, gênero, grupo social ou inserção social em grupo específico de risco. Além disso, os trabalhadores podem adoecer ou morrer por causas relacionadas ao trabalho, como consequência da profissão que exercem ou exerceram, ou pelas condições adversas em que seu trabalho é ou foi realizado (MENDES; OLIVEIRA, 2013). No mundo, cerca de $50 \%$ da força de trabalho é empregada na agricultura e a exposição destes 
trabalhadores aos agrotóxicos representa o risco ocupacional mais importante em todo o mundo. A Organização Internacional do Trabalho (OIT) estima que anualmente haja 70.000 casos de intoxicações agudas e crônicas entre os trabalhadores rurais (ILO, 2005).

No Brasil a população rural representou $16 \%$ da população em 2010 , dos quais $47,8 \%$ só na região nordeste (IBGE, 2010). Existem cerca de 6,4 milhões de trabalhadores rurais assalariados no País e 60\% - cerca de 2,4 milhões - atuam na informalidade (IBGE, 2010). Ferreira-de-Sousa e Sousa Santana (2016), utilizando dados do SIM, estimaram que 8.923 óbitos relacionados a atividade agropecuária ocorreram no Brasil entre 2000 e 2010

A natureza e a magnitude dos riscos para a saúde associados com a exposição ocupacional a qualquer produto químico dependem da sua toxicidade intrínseca e das condições de exposição (SILVEIRA; LUCCA, 2013). Porém, há pouca informação disponível sobre os efeitos na saúde da maioria dos produtos químicos envolvidos na atividade ocupacional. Entre os milhões de compostos conhecidos pela ciência, apenas cerca de 100.000 estão listados no Registro de Efeitos Tóxicos de Substâncias Químicas (ATSDR) publicados pelo Instituto Nacional de Segurança e Saúde Ocupacional dos Estados Unidos (NIOSH). Entre essas substâncias, menos de 5.000 tem estudos de toxicidade relativos aos seus potenciais efeitos carcinogênicos ou reprodutivos em animais ou seres humanos (BLANC et al., 2012).

As doenças do trabalho causadas por exposição a produtos químicos ainda são pouco reconhecidas, seja por deficiência de diagnóstico médico ou por dificuldades de suporte do poder público, incluindo o apoio laboratorial especializado. A monitorização biológica é a medida de avaliação de agentes químicos e/ou de seus produtos de biotransformação, ou do produto da interação entre o agente e uma molécula ou célula-alvo, que seja mensurável em um compartimento biológico, como tecidos, secreções, excreções, ar exalado ou alguma combinação destes (AMORIM, 2003). O risco à saúde advindo da exposição ao agente químico pode então ser avaliado comparando os níveis desses marcadores biológicos com uma referência apropriada, ou limites biológicos de exposição (THORNE, 2013).

Os biomarcadores podem ser classificados em três tipos de exposição, efeito e susceptibilidade (Amorim, 2003). Os biomarcadores de exposição 
podem ser usados para confirmar e avaliar a exposição individual ou de um grupo a uma substância, estabelecendo uma ligação entre a exposição externa e a quantificação da exposição interna. Os biomarcadores de efeito podem ser usados para documentar as alterações pré-clínicas ou efeitos adversos à saúde decorrentes da exposição e absorção da substância química. Dessa forma, a ligação dos biomarcadores entre exposição e efeitos contribui para a definição da relação dose-resposta. Os biomarcadores de suscetibilidade podem refletir fatores genéticos ou adquiridos que influenciam na resposta do organismo a uma determinada exposição química (Amorim, 2013).

No Brasil, a Norma Regulamentadora № 7 (BRASIL, 2013) traz os biomarcadores de exposição e/ou de efeito para algumas substâncias químicas presentes no ambiente de trabalho (Índice Biológico Máximo Permitido, IBMP), e inclui também valores de referência para indivíduos não expostos ocupacionalmente (Valor de referência). A norma também traz a possibilidade de diagnóstico das intoxicações ocupacionais, baseados nos dados laboratoriais dos biomarcadores e nos sinais e sintomas apresentados pelos trabalhadores. Esta norma faz referência ao monitoramento biológico da exposição aos agrotóxicos dos grupos dos organofosforados e carbamatos, e também para outros agentes químicos, incluindo o chumbo, mercúrio, arsênico, cromo, fenol, flúor, anilina e monóxido de carbono.

Para agrotóxicos, a norma estabelece como biomarcadores de efeito a dosagem da atividade da enzima acetil-colinesterase eritrocitária (AChE) e da colinesterase plasmática ou butirilcolinesterase (BChE), ou de ambas no sangue. O valor de referência é determinado a partir da atividade préocupacional. Os Índice Biológico Máximo Permitido (IBMP) são: 30\% de depressão da atividade inicial de AChE; 50\% de depressão da atividade inicial de BChE, e $25 \%$ de depressão da atividade inicial da colinesterase no sangue. Segundo a norma, além de mostrar uma exposição excessiva a inseticidas inibidores da colinesterase, o IBMP tem também significado clínico ou toxicológico próprio, ou seja, pode indicar doença, estar associado a um efeito ou a uma disfunção do sistema biológico avaliado.

No Brasil, foram registrados no Ministério do Trabalho e Previdência Social em 2014 cerca de 704,1 mil acidentes do trabalho. Neste período, os principais CID's (Classificação Internacional de Doenças) relacionados com 
intoxicação ocupacional foram: intoxicação por drogas, medicamentos e substancias biológicas (T36 a T50; $\mathrm{N}=134$ ), efeitos tóxicos de substâncias de origem predominantemente não medicinal (T51 a T65; $N=455$ ), e contato com animais e plantas venenosos (X20 a X29; $\mathrm{N}=166$ ) (BRASIL, 2016).

Dados do SINITOX referente ao período de 1999 a 2013 mostram 1.341 .687 casos de intoxicação no Brasil, sendo $6,3 \%$ dos casos referentes a intoxicação ocupacional, principalmente envolvendo agrotóxicos agrícolas $(24,3 \%)$, animais peçonhentos, serpentes $(19,8 \%)$ e produtos químicos industriais (15,8\%) (FIOCRUZ, 2016).

O diagnóstico das intoxicações ocupacionais é um grande desafio, tanto pelo arsenal de novas substâncias, quanto ao diagnóstico, principalmente relativo às intoxicações crônicas. Enquanto os efeitos adversos após a exposição aguda a produtos químicos são claros, o diagnóstico da exposição crônica, como ocorre de forma sistemática no ambiente ocupacional, é difícil de ser estabelecido, já que os sintomas são inespecíficos na maioria dos casos e a relação causa-efeito nem sempre é bem definida. Adicionalmente, existe um tempo de latência entre exposição e aparecimento dos sintomas para algumas doenças, que também podem ter caráter multifatorial (THORNE, 2013).

\subsection{Intoxicação por agrotóxicos}

No Brasil, o termo "agrotóxico" substituiu "defensivo agrícola" após grande movimento da sociedade civil organizada para deixar em evidência a toxicidade desses produtos à saúde humana e ao meio ambiente. A Lei №. 7802 DE 18 de junho de 1989, regulamentada pelo №. 4.074/2002, em seu Artigo 1ํ, Inciso IV, define o termo AGROTÓXICOS E AFINS como:

os produtos e os agentes de processos físicos, químicos ou biológicos destinados ao uso nos setores de produção, armazenamento e beneficiamento de produtos agrícolas, nas pastagens, na proteção de florestas nativas ou implantadas e de outros ecossistemas e também em ambientes urbanos, hídricos e industriais, cuja finalidade seja alterar a composição da flora e da fauna, a fim de preservá-las da ação danosa de seres vivos considerados nocivos (BRASIL, 1989);[bem como] substâncias e produtos empregados como desfolhantes, dessecantes, estimuladores e inibidores do crescimento (BRASIL, 1989). 
A venda de agrotóxicos globais mostrou a partir de 2004 sinais de recuperação depois de um período de 5 anos de depressão, atingindo um mercado em torno de US $\$ 52$ bilhões em 2013, com uma projeção de US \$ 76 bilhões até 2019 (CALDAS, 2016). O Brasil se destaca no cenário mundial entre os maiores consumidores de agrotóxicos, respondendo na América Latina por $86 \%$ dos produtos, e em 2013, atingiu US \$11,45 bilhões em comercialização, um aumento de 18\% em relação a 2012 (CALDAS, 2016).

No Brasil, a Portaria № 3 de 16 de abril de 1992 do Ministério da Saúde estabelece critérios para a classificação toxicológica dos agrotóxicos que são classificados como: Classe I-Extremamente Tóxico, Classe II-Altamente Tóxico, Classe III-Medianamente tóxico e Classe IV-Pouco Tóxico.

A portaria determina a obrigatoriedade de apresentar nos rótulos dos produtos comercializados, uma faixa colorida indicativa de sua classe toxicológica (Tabela 1). Esta classificação reflete a toxicidade aguda e tem como alvo a população exposta ocupacionalmente. Associada a esta classificação, os produtos devem incluir pictogramas e orientações de uso de equipamento de proteção individual pelos trabalhadores.

Tabela 1.Classificação Toxicológica dos Agrotóxicos (Portaria №. 3/1992). De acordo com a DL 50 oral aguda em ratos.

\begin{tabular}{c|c|c|c|}
\hline CLASSE & TOXICIDADE & LíQUIDA & SÓLIDA \\
\hline I & Extremamente tóxico & $\leq 20 \mathrm{mg} / \mathrm{kg}$ & $\leq 5 \mathrm{mg} / \mathrm{kg}$ \\
\hline II & Altamente tóxico & $20-200 \mathrm{mg} / \mathrm{kg}$ & $5-50 \mathrm{mg} / \mathrm{kg}$ \\
\hline III & Medianamente tóxico & $20-2000 \mathrm{mg} / \mathrm{kg}$ & $50-500 \mathrm{mg} / \mathrm{kg}$ \\
\hline IV & Pouco tóxico & $>2.000 \mathrm{mg} / \mathrm{kg}$ & $>500 \mathrm{mg} / \mathrm{kg}$ \\
\hline
\end{tabular}

No Brasil, até fevereiro de 2017, 467 ingredientes ativos de agrotóxicos foram registrados na ANVISA (2017), incluindo agentes químicos, feromônios, produtos biológicos e óleos vegetais, para uso na agricultura, tratamento de madeira, controle em ambientes urbanos e uso doméstico. Dentre estes ingredientes, 386 têm importância toxicológica. No total, 1764 produtos agrícolas formulados com agentes químicos foram registrados no Ministério da Agricultura (AGROFIT, 2017), dos quais $35,4 \%$ são classificados como 
extremamente tóxico (Classe I) e 15,2\% como altamente tóxica (classe II).

MALASPINA et al. (2011) avaliaram as intoxicações por agrotóxicos no Brasil notificadas no Sistema de Informação de Agravos de Notificação (SINAN) de 1995 a 2010. Observou-se prevalência do sexo masculino e de indivíduos de 15 a 49 anos. Entre os homens, a principal circunstância foi ocupacional, e entre as mulheres, a tentativa de suicídio.

Segundo Caldas (2016), considerando os dados do SINITOX, a incidência de casos de intoxicação (por 100.000 habitantes) envolvendo agrotóxicos agrícolas no Norte, Nordeste e Centro-Oeste do Brasil aumentou no período 2000/2010, enquanto houve uma queda na região Sul (Figura 3). Não houve correlação entre a taxa de utilização de agrotóxicos e a incidência envenenamento. Enquanto a região Sul teve a maior taxa de uso agrícola $(8,8$ $\mathrm{kg}$ ha em 2012), o Centro-Oeste (6,5 kg ha) teve a maior incidência de casos (8,5 casos em 2010) (CALDAS, 2016).

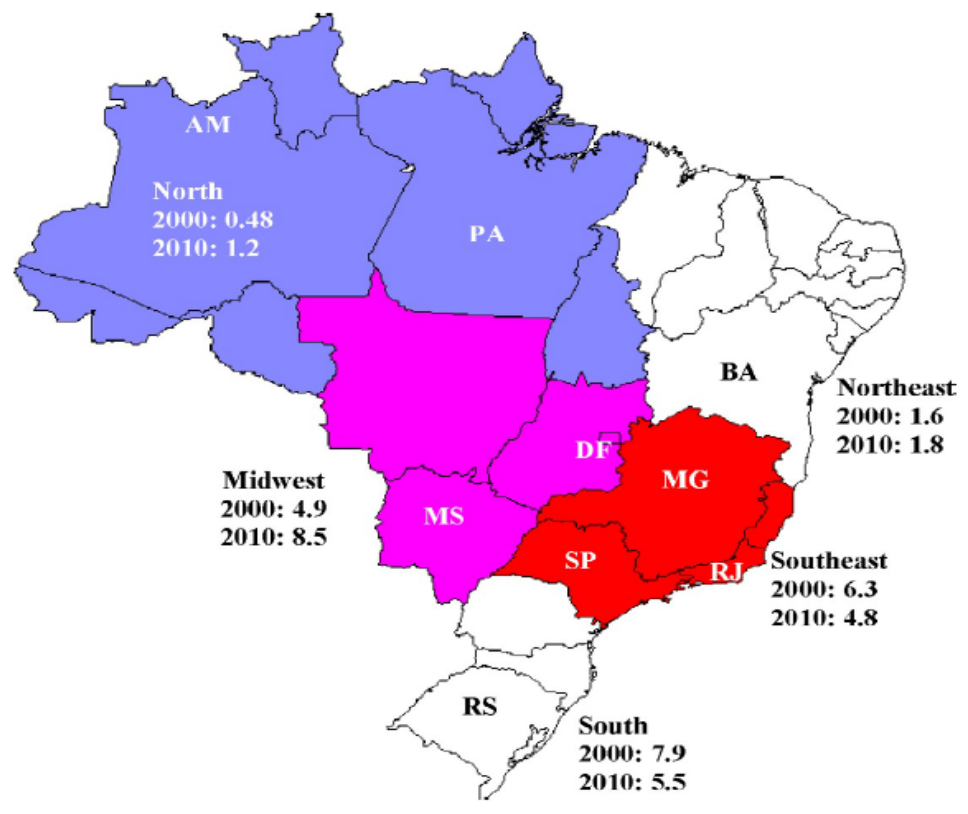

Figura 3. Incidência de intoxicação por agrotóxicos em regiões brasileiras (por 100.000 habitantes) em 2000 e 2010. Os dados de intoxicação foram obtidos do SINITOX e os dados populacionais do Instituto Brasileiro de Geografia e Estatística (CALDAS, 2016). 


\subsubsection{Principais agrotóxicos envolvidos nas exposições e intoxicações humanas no Brasil}

Vários estudos com as mais diversas populações e regiões no Brasil avaliaram a situação de exposição e dos casos de intoxicação a agrotóxicos no País, inclusive os casos letais (Quadro 1). A maioria dos estudos reportou o envolvimento dos inseticidas organofosforados (incluindo metamidofós, monocrotofós, malation) ou carbamatos (carbofuran, aldicarbe), piretroides (incluindo deltametrina), e chumbinho.

\subsubsection{Sintomas clínicos decorrentes da exposição ocupacional a agrotóxicos}

Os trabalhadores que utilizam agrotóxicos na atividade ocupacional incluem os agricultores e aquele responsáveis pelo controle de pragas e vetores de doenças em ambientes urbanos. A exposição individual torna-se menor, e consequentemente o uso de agrotóxicos mais seguros, à medida que procedimentos de proteção são adotados e as regras de segurança obedecidas (DELGADO; PAUMGARTTEN, 2004).

A toxicidade aguda refere-se aos efeitos imediatos, sendo que os sintomas mais frequentes incluem cefaleia, náuseas, vômitos, dor abdominal, irritação dos olhos e pele, opressão torácica, crises de asma, coriza, diarreia, sialorréia, sudorese intensa, visão turva, lacrimejamento, dificuldade respiratória, edema agudo do pulmão, cãibras, fasciculações musculares, arritmias cardíacas, coma e convulsão (THORNE, 2013).

Os fatores de risco da ocorrência de intoxicação com agrotóxicos pelas diferentes vias de absorção estão mostrados no Quadro 2. 
Quadro 1. População exposta de acordo com o agrotóxico utilizado em diversas regiões do Brasil relatados na literatura.

\begin{tabular}{|c|c|c|}
\hline Referência & População & Agrotóxico \\
\hline $\begin{array}{l}\text { CAMPOS et al., } \\
\qquad 2016\end{array}$ & $\begin{array}{l}\text { Trabalhadores } \\
\text { rurais de Don } \\
\text { Feliciano, RS }\end{array}$ & $\begin{array}{c}\text { Vários, principalmente } \\
\text { organofosforados, carbamatos, } \\
\text { glifosato, fungicidas dicarboximide } \\
\text { (incluindo iprodiona) }\end{array}$ \\
\hline $\begin{array}{l}\text { PICCOLI et } \\
\text { al.,2016 }\end{array}$ & $\begin{array}{l}\text { Trabalhadores } \\
\quad \text { rurais de } \\
\text { Farroupilha, RS }\end{array}$ & $\begin{array}{c}\text { Organoclorados persistentes, incluído } \\
\text { endrin, dieldrin, heptacloro epóxido e } \\
\text { DDT; endosulfan }\end{array}$ \\
\hline $\begin{array}{l}\text { PASIANI et al., } \\
2012\end{array}$ & $\begin{array}{l}\text { Trabalhadores } \\
\text { rurais do DF e GO }\end{array}$ & Carbamatos e organofosforados \\
\hline $\begin{array}{l}\text { CAMPELO \& } \\
\text { CALDAS, } 2010\end{array}$ & $\begin{array}{l}\text { Óbitos registrados } \\
\text { no IML -DF }\end{array}$ & Chumbinho e outros pesticidas \\
\hline $\begin{array}{l}\text { CALDAS et al., } \\
\text { 2008; } \\
\text { REBELO et al., } \\
2011\end{array}$ & $\begin{array}{c}\text { Pacientes } \\
\text { atendidos pelo CIT- } \\
\text { DF e pelos } \\
\text { hospitais públicos } \\
\text { do DF }\end{array}$ & $\begin{array}{c}\text { Chumbinho, } \\
\text { Cumarinicos: brodifacoum, } \\
\text { bromadiolone, } \\
\text { Piretroides: cipermetrina, deltametrina } \\
\text { Organofosforados: clorpirifós, } \\
\text { diclorvós, } \\
\text { Carbamatos: carbofuran, aldicarbe }\end{array}$ \\
\hline $\begin{array}{l}\text { ARAÚJO et al., } \\
2007\end{array}$ & $\begin{array}{l}\text { Trabalhadores } \\
\text { rurais do RJ }\end{array}$ & $\begin{array}{l}\text { Metamidofós, mancozeb, paraquat, } \\
\text { clorotalonil, sulfato de cobre, } \\
\text { piretroides }\end{array}$ \\
\hline $\begin{array}{l}\text { RECENA et al., } \\
2006\end{array}$ & & $\begin{array}{l}\text { Inseticidas: monocrotofós, } \\
\text { metamidófos, malation, carbofuran }\end{array}$ \\
\hline $\begin{array}{l}\text { PIRES, et al., } \\
2005\end{array}$ & CIVITOX-MS & $\begin{array}{l}\text { Herbicidas: glifosato, 2,4D, trifluralins, } \\
\text { imazaquim, paraquat, diquat }\end{array}$ \\
\hline $\begin{array}{l}\text { MAGALHÃES, } \\
2005\end{array}$ & $\begin{array}{l}\text { Pacientes } \\
\text { atendidos no } \\
\text { CEREST-DF }\end{array}$ & $\begin{array}{l}\text { Organoclorado, organofosforado, } \\
\text { carbamato, piretroide, fosfina, } \\
\text { bipiridílio, glifosato }\end{array}$ \\
\hline $\begin{array}{l}\text { DELGADO; } \\
\text { PAUMGARTTE, } \\
2004\end{array}$ & $\begin{array}{l}\text { Trabalhadores } \\
\text { rurais no RJ }\end{array}$ & $\begin{array}{c}\text { Organofosforado: metamidofós, } \\
\text { vamidotion } \\
\text { Carbamato: carbofurano, carbaril } \\
\text { Piretroide: permetrina, deltamertrina } \\
\text { Abamectina } \\
\text { Fungicida: clorotalonil,mancozeb } \\
\text { Acaricida: tetradifon }\end{array}$ \\
\hline
\end{tabular}


Quadro 2. Principais vias de absorção na exposição a agrotóxicos e fatores de risco de ocorrência de intoxicação.

\begin{tabular}{|c|c|c|c|}
\hline Dérmica & Ocular & Respiratória & Oral \\
\hline Manuseio em geral & $\begin{array}{c}\text { Manuseio em } \\
\text { geral }\end{array}$ & $\begin{array}{c}\text { Vapores, pós e } \\
\text { gases voláteis. }\end{array}$ & $\begin{array}{c}\text { Armazenar em } \\
\text { vasilhame incorreto }\end{array}$ \\
\hline $\begin{array}{c}\text { Característica da } \\
\text { formulação }\end{array}$ & Respingos & $\begin{array}{c}\text { Partículas } \\
\text { mínimas } \\
\text { durante } \\
\text { pulverização }\end{array}$ & $\begin{array}{l}\text { Limpar bicos ou abrir } \\
\text { embalagens com a } \\
\text { boca }\end{array}$ \\
\hline $\begin{array}{c}\text { Altas temperaturas } \\
\text { Umidade do ar }\end{array}$ & & $\begin{array}{c}\text { Pulverização } \\
\text { em locais } \\
\text { fechados }\end{array}$ & $\begin{array}{c}\text { Comer, beber ou } \\
\text { fumar durante o } \\
\text { manuseio do produto. }\end{array}$ \\
\hline
\end{tabular}

Fonte: SOLOMON, 2000 (adaptado).

O diagnóstico da toxicidade crônica aos agrotóxicos é mais complexo, já que a relação causa-efeito nem sempre é bem definida. Os sintomas são de início lento e insidioso num tempo muito longo (meses ou anos), com sinais e sintomas sutis e inespecíficos, e geralmente acarreta danos irreversíveis. Dentre estes efeitos podem-se ressaltar as desordens reprodutivas (oligoespermia, esterilidade e aborto), dano neurológico (parestesias, neurite periférica, déficit motor, impotência), neurocomportamentais (alucinações, nervosismo, insônia, irritabilidade, labilidade emocional) e alterações pulmonares, renais, cardiovasculares, dermatológicas ou endócrinas (SOLOMOM, 2000). Num estudo de revisão sistemática, Mostafalou e Abdollahi (2016) reportaram associações entre a exposição a agrotóxicos e os efeitos adversos a saúde, incluindo carcinogenicidade, neurotoxicidade, toxicidade reprodutiva, toxicidade metabólica, pulmotoxicidade e toxicidade para o desenvolvimento

$\mathrm{Na}$ avaliação de um grupo de indivíduos excessivamente expostos a agrotóxicos ou outras substancias químicas, são fundamentais para o diagnóstico: o histórico de exposição (anamnese ocupacional), avaliação clínica (anamnese clínica, exame clínico, a caracterização dos sinais e 
sintomas) e diagnóstico laboratorial (exames clínicos e toxicológicos específicos). No estudo de um grupo de indivíduos intoxicados, a avaliação clínica será sempre soberana e determinante; já na avaliação de um grupo de casos suspeitos o histórico da exposição é o fator mais importante para a caracterização do caso (SILVA et al., 2003).

\section{Alterações dermatológicas}

As reações dermatológicas devido a exposição a agrotóxicos podem ocorrer em qualquer área da superfície corpórea, incluindo as áreas cobertas, principalmente se o produto embebe completamente a vestimenta do trabalhador. As áreas descobertas são as mais comumente afetadas, como mãos, braços, pescoço e face. Há relatos clínicos dos agrotóxicos como causadores de irritação dérmica, dermatite alérgica de contato, fotodermatite e porfiria cutânea tardia (CDC, 2009). As reações são geralmente mais severas quando ocorrem na pele previamente lesada (O' MALLEY, 1997; RICE; MAURO, 2013).

Os fungicidas são particularmente conhecidos pelo seu potencial de sensibilização dérmica, entre eles os ditiocarbamatos, compostos que contêm enxofre na sua estrutura, tais como o manebe, o mancozebe, o zinebe $(\mathrm{KOCH}$, 1996). O enxofre, também um agrotóxico, é um dos produtos mais comumente relatados de reações da pele entre trabalhadores da agricultura. Este composto é um irritante da pele, mas pode também causar dermatite alérgica. $O$ agrotóxico biológico Bacillus thuringienis também tem sido relatado como indutor de sensibilização dérmica em trabalhadores expostos (BERNSTEIN et al, 1999). Os piretroides podem causar dermatite alérgica e alopecia como resultado da exposição crônica (BUDAVARI, 1996; FUORTES, 1999; MITSCHE et al., 2000; RAY, 1991; RICE; MAURO, 2013).

A Tabela 2 mostra alguns estudos publicados na literatura que reportaram alguns sintomas clínicos descritos indivíduos expostos ocupacionalmente a agrotóxicos, principalmente trabalhadores rurais. 
Tabela 2. Tipo e frequência de sintomas relatados por exposição ocupacional a agrotóxicos relatados na literatura.

\begin{tabular}{|c|c|c|}
\hline Sintomas & $\begin{array}{l}\text { Frequência de } \\
\text { ocorrência }\end{array}$ & $\begin{array}{c}\text { País } \\
\text { (Referência) }\end{array}$ \\
\hline $\begin{array}{l}\text { Irritação, cansaço, } \\
\text { cefaleia, ansiedade e } \\
\text { depressão }\end{array}$ & $47,4-27,6 \%$ & $\begin{array}{c}\text { Argentina } \\
\text { (BUTINOF et al., 2015) }\end{array}$ \\
\hline $\begin{array}{l}\text { Lacrimejamento, tosse e } \\
\text { expectoração, visão turva, } \\
\text { coriza, náuseas, vômitos e } \\
\text { diarreia }\end{array}$ & $12,3-20,2 \%$ & $\begin{array}{c}\text { Argentina } \\
\text { (MATOS et al., 2008) }\end{array}$ \\
\hline $\begin{array}{l}\text { Dermatite de contato, } \\
\text { parestesias, hiperemia } \\
\text { ocular, hepatomegalia e } \\
\text { esplenomegalia, hiper- } \\
\text { reatividade brônquica. }\end{array}$ & $16,2 \%$ & $\begin{array}{c}\text { Brasil } \\
\text { (FIGUEIREDO et al., 2011) }\end{array}$ \\
\hline $\begin{array}{l}\text { Irritação ocular, } \\
\text { lacrimejamento, cefaleia, } \\
\text { tontura, dermatites }\end{array}$ & $18,5-20,4 \%$ & $\begin{array}{c}\text { Brasil } \\
\text { (FARIA et al.,2009) }\end{array}$ \\
\hline $\begin{array}{l}\text { Efeitos muscarínicos, } \\
\text { efeitos nicotínicos, efeitos } \\
\text { no sistema nervoso } \\
\text { central, distúrbios } \\
\text { cognitivos e } \\
\text { neurocomportamentais }\end{array}$ & $72,5-64,7 \%$ & $\begin{array}{c}\text { Brasil } \\
\text { (ARAÚJO et al.,2007) }\end{array}$ \\
\hline Sintomas depressivos & $10,4 \%$ & $\begin{array}{l}\text { Correia do Sul } \\
\text { (KIM et al., 2013) }\end{array}$ \\
\hline $\begin{array}{l}\text { Dermatite, prurido, } \\
\text { diarreia, vômitos, náuseas, } \\
\text { falta de apetite, dor } \\
\text { muscular, tosse, dispneia, } \\
\text { diplopia, arritmia e } \\
\text { taquicardia }\end{array}$ & $8,8 \%$ & $\begin{array}{c}\text { China } \\
\text { (ZHANG et al., 2011) }\end{array}$ \\
\hline $\begin{array}{l}\text { Dor, irritação e inflamação } \\
\text { ocular, tontura, náuseas, } \\
\text { tosse, dor torácica, } \\
\text { dispneia }\end{array}$ & $38,0-18,0 \%$ & $\begin{array}{c}\text { EUA } \\
\text { (CALVERT et al.,2007) }\end{array}$ \\
\hline $\begin{array}{l}\text { Insônia, depressão, fadiga, } \\
\text { cefaleia, dor abdominal, } \\
\text { náuseas, eczema, } \\
\text { fraqueza muscular }\end{array}$ & $16,7-37,2 \%$ & $\begin{array}{c}\text { Índia } \\
\text { (JAMAL et al.,2016) }\end{array}$ \\
\hline $\begin{array}{l}\text { Alterações respiratórias } \\
\text { Tosse seca, tosse } \\
\text { produtiva, hemoptise }\end{array}$ & $36,7 \%$ & $\begin{array}{c}\text { Índia } \\
\text { (FAREED,2013) }\end{array}$ \\
\hline
\end{tabular}




\begin{tabular}{ccc}
\hline Sintomas & $\begin{array}{c}\text { Frequência de } \\
\text { ocorrência }\end{array}$ & $\begin{array}{c}\text { País } \\
\text { (Referência) }\end{array}$ \\
\hline $\begin{array}{c}\text { Avaliação Cognitiva } \\
\text { Depressão e ansiedade }\end{array}$ & $88,7 \%$ & $\begin{array}{c}\text { Inglaterra } \\
\text { (HARRISON E ROSS, } \\
\text { Dor de cabeça, coceira e } \\
\text { tonturas }\end{array}$ \\
$\begin{array}{c}\text { Cefaleia, tosse, fraqueza, } \\
\text { tonteira, dermatite de } \\
\text { contato }\end{array}$ & $38 \%$ & $\begin{array}{c}\text { México (CORTÉS- } \\
\text { GENCHI et al., 2008) }\end{array}$ \\
\hline
\end{tabular}

\section{Alterações respiratórias}

O principal alvo do herbicida paraquat é o pulmão. Este agrotóxico é seletivamente levado ao pulmão e causa danos oxidativos, que se apresentam como edema pulmonar agudo, hemorragia, evoluindo para fibrose pulmonar. A falência respiratória pode ocorrer após uma exposição exclusivamente dérmica (CDC, 2013)

A inibição da AChE pelos inseticidas organofosforados e carbamatos pode causar constrição brônquica e aumento de secreções, podendo levar à insuficiência respiratória. Um estudo transversal com quase dois mil fazendeiros em Saskatchewan, Canadá, mostrou uma associação significativa entre o diagnóstico de asma e relato do uso de agrotóxicos inibidores da colinesterase (SENTHILSELVAN et al., 1992). Porém, a exposição a fungos e pólen são fatores de confundimento que não pode ser completamente controlado. Alguns estudos relatam outros efeitos respiratórios dos agrotóxicos, incluindo a hemossiderose pulmonar, infiltrados pneumônicos, bronquite crônica, fibrose pulmonar, granulomatose de Wegener, e enfraquecimento da musculatura pulmonar (DUNA et al., 1997; KAYSER et al., 1998; KOSSMANN et al., 1997; LEIKAUF, 2013).

Estudo realizado a partir do Sistema de Notificação de agravos por agrotóxicos da Califórnia de 2000-2008 identificou que a maioria das intoxicações agudas por piretroides era de baixa severidade (85\%) e $34 \%$ estavam relacionadas com o trabalho, e os efeitos respiratórios foram os sintomas mais relatados dos casos (48\%) (HUDSON et al., 2014).

Os piretroides, piretrinas, enxofre, diversos organofosforados e 
metilcarbamatos, foram relatados como causadores de asma ocupacional, por meio de relato de casos e testes de broncoconstrição. Estes produtos parecem ter um efeito semelhante à metacolina sobre o pulmão (BOX; LEE, 1996). Um estudo de caso descreveu uma jovem que desenvolveu hemosiderose pulmonar difusa, quatro dias depois que aplicou uma combinação de três piretroides (deltametrina, cialotrina e bensultap, esse proibido no Brasil) em uma plantação de morango (KAYSER et al., 1998). O início repentino do desenvolvimento da doença com dispneia e hemoptise grave, requereu transfusão sanguínea. $O$ raios- $X$ de tórax mostrou infiltrados difusos bilaterais e o lavado bronco-alveolar revelou macrófagos com hemossiderina. Todos os anticorpos eram negativos. A síndrome respondeu bem a ciclofosfamida. Um grupo de pesquisadores propõe a existência, após uma exposição prolongada a agrotóxicos, do "pulmão biocida", síndrome caracterizada por infiltrado pulmonar intermitente, seguido pela fibrose crônica (LEIKAUF, 2013)

\section{Alterações neurológicas}

Os agrotóxicos podem afetar o sistema nervoso central (SNC) e o sistema nervoso periférico (SNP) de animais e seres humanos por meio de uma variedade de mecanismos. Os efeitos da neurotoxicidade podem ser avaliados pelos neurotransmissores, alterações celulares e do comportamento, incluindo efeitos sutis na função visual, na concentração, relação-tempo, aprendizagem e memória (MOSER, 2013). Em estudo conduzido no Rio Grande do Sul, CAMPOS et al. (2016) encontraram uma associação significativamente positiva entre o relato de intoxicação com agrotóxicos e desordem mental comum ( $\mathrm{OR}=2.63 ; 95 \% \mathrm{IC}, 1.62-4.25)$ e relato de depressão $(\mathrm{OR}=2.62 ; 95 \% \mathrm{IC}, 1.63-4.21)$. Os efeitos agudos dos organofosforados $\mathrm{e}$ carbamatos, desenvolvidos para danificar especificamente a função neurológica nos insetos, são os mesmos nos seres humanos por causa das similaridades na função nervosa dos mesmos (DE DUFFARD; DUFFARD, 1996).

Há uma evidência crescente que uma proporção elevada de casos de doença de Parkinson pode estar associada com fatores ambientais, incluindo a exposição ao paraquate, organofosforados, dieldrin, e aos fungicidas manebe e mancozebe (FERRAZ et al., 1998; FLEMING et al., 1994; LANGSTON, 1998). 
Taxas mais elevadas do que as previstas de determinados polimorfismos da glutationatransferase, da 2-N-acetiltransferase, e a hidroxilação lenta do debrisoquina (substrato seletivo da CYP 2D6 29B+) foram relatadas nos pacientes com Parkinson. Estas variações genéticas podem aumentar o risco na exposição ambiental, retardando a detoxificação de compostos exógenos (HUBBLE et al., 1998; MENEGON et al., 1998; VELDMAN, 1998).

Evidências sugerem que a exposição cumulativa a agrotóxicos ao longo da vida pode gerar efeitos tóxicos e duradouros sobre o sistema nervoso central e contribuir para o desenvolvimento da doença de Alzheimer. Estudo de meta-análise realizado por Yan et al. (2016) analisou mais de 40 artigos e sugeriu uma associação positiva entre a exposição a agrotóxicos e Alzheimer, confirmando a hipótese de que a exposição a agrotóxicos é um fator de risco para a doença.

Os organofosforados e carbamatos inibidores da AChE interferem com a transmissão do impulso nas neuropatias periféricas e os efeitos crônicos da exposição podem incluir alterações sensoriais, motoras e neuropatias autonômicas (MOSER,2013). As manifestações clínicas são o resultado da hiperestimulação colinérgica que ocorre por inibição da AChE e consequente acúmulo de acetilcolina na fenda sináptica. De acordo com os sítios receptores onde a acetilcolina atua, as manifestações podem ser muscarínicas, nicotínicas ou no SNC (MOSER, 2013).

A estimulação parassimpática pós-ganglionar produz efeitos muscarínicos, que incluem bradicardia, miose, diurese aumentada, lacrimejamento e sialorréia, náusea, vômito, dor abdominal, hipersecreção brônquica e hipotensão. A estimulação neuromuscular esquelética produz efeitos nicotínicos, incluindo hiperestimulação ocorre fasciculações musculares, cãibras, fraqueza muscular e tremores. A estimulação pré-ganglionar simpática e parassimpática produz estimulação na glândula adrenal e glândulas sudoríparas assim como em muitos músculos lisos dos olhos, coração e glândulas salivares, levando à taquicardia, hipertensão, palidez e hiperglicemia. A estimulação dos receptores da acetilcolina cerebral afeta o SNC, manifestando sonolência, fadiga, letargia, confusão mental, cefaleia, ataxia, dispneia, convulsões e coma (COSTA, 2013)

Os compostos organofosforados podem causar, além da síndrome 
colinérgica aguda, outras síndromes neurológicas, neuroquímicas e psiquiátricas subagudas e crônicas, incluindo a neuropatia retardada induzida por organofosforados (organophosphate induced delayed polyneuropathy OPIDN) e uma série de manifestações neurológicas e psiquiátricas agrupadas sob o termo de síndrome neuropsiquiátrica crônica induzida por organofosforado (chronic organophosphate induced neuropsychiatric disorder COPIND) (JOKANOVIC et al., 2011; JAMAL,1997).

A OPIDN tem como alvo molecular uma enzima no sistema nervoso conhecida como NTE (neuropathy target esterase) e ocorre de 2 a 5 semanas após uma intoxicação aguda, e no caso de intoxicação crônica, há menos previsibilidade do período para o início do quadro. A síndrome caracteriza-se por parestesias das extremidades e membros inferiores, podendo evoluir para uma paralisia flácida que pode persistir por semanas ou anos. O quadro inicial apresenta sonolência, formigamento, frio e fraqueza em membros inferiores, pontadas nas solas dos pés e dor muscular ao frio e fraqueza em membros inferiores (JOKANOVIC et al., 2011; MOSER, 2013).

Em alguns casos, o indivíduo pode desenvolver uma síndrome intermediária 24 a 96 horas após o envenenamento agudo com organofosforado. O principal sintoma é uma fraqueza muscular afetando predominantemente os músculos comandados pelos nervos cranianos, nervos flexores do pescoço, músculos proximais das pernas e músculos respiratórios. Ao contrário da OPIDP, esta síndrome apresenta o risco de morte devido à depressão respiratória (BLEECKER; NEUCKER; COLARDYN, 1993; COSTA, 2013).

Os agrotóxicos podem atravessar a barreira hematoencefálica, exercendo efeitos no cérebro, causando disfunção da captação de oxigênio e nutrientes, hormônios e neurotransmissores. As áreas do cérebro mais geralmente afetadas incluem o sistema límbico, o hipocampo, o gânglio basal e o cerebelo. A evidência de déficits neuropsicológicos associados é baseada primeiramente em estudos dos trabalhadores com intoxicação aguda ou exposição crônica aos agrotóxicos organofosforados, embora alguns relatos de caso impliquem também alguns carbamatos (SOLOMON, 2000). O Quadro 3 resume os efeitos neurotóxicos causados por alguns agrotóxicos. 
Quadro 3. Resumo dos efeitos neurotóxicos causados por alguns agrotóxicos.

\begin{tabular}{|c|c|c|}
\hline Agrotóxico & $\begin{array}{c}\text { Sistema Nervoso } \\
\text { Central }\end{array}$ & $\begin{array}{c}\text { Sistema Nervoso } \\
\text { Periférico }\end{array}$ \\
\hline $\begin{array}{l}\text { Organofosforados: } \\
\text { clorpirifós, malation, } \\
\text { temefos. }\end{array}$ & $\begin{array}{l}\text { Transtornos de } \\
\text { Cognição; } \\
\text { percepção. }\end{array}$ & $\begin{array}{c}\text { Neuropatia } \\
\text { Periférica, } \\
\text { Síndrome } \\
\text { Intermediária; }\end{array}$ \\
\hline Carbaril & $\begin{array}{c}\text { Déficits de memória; } \\
\text { deficiência visual; } \\
\text { fadiga }\end{array}$ & $\begin{array}{c}\text { Neuropatia } \\
\text { sensitivo motora }\end{array}$ \\
\hline $\begin{array}{l}\text { Fumigantes: dissulfeto de } \\
\text { carbono, dicloropropano, } \\
\text { brometo de metila }\end{array}$ & $\begin{array}{l}\text { Déficits cognitivos, } \\
\text { dificuldade de } \\
\text { concentração e } \\
\text { sintomas piramidais. }\end{array}$ & $\begin{array}{l}\text { Diminuição dos } \\
\text { reflexos, } \\
\text { diminuição da } \\
\text { força motora distal. }\end{array}$ \\
\hline $\begin{array}{l}\text { Fungicidas } \\
\text { ditiocarbamatos: zineb, } \\
\text { mancozebe, mancozebe }\end{array}$ & $\begin{array}{l}\text { Deficiências } \\
\text { respiratórias, } \\
\text { arritmias, } \\
\text { possibilidade de } \\
\text { Parkinson. }\end{array}$ & $\begin{array}{c}\text { Redução da } \\
\text { condução nervosa }\end{array}$ \\
\hline $\begin{array}{c}\text { Piretroides: cipermetrina, } \\
\text { esfenvalerate }\end{array}$ & $\begin{array}{l}\text { Redução da } \\
\text { atividade motora }\end{array}$ & $\begin{array}{c}\text { Parestesia cutânea } \\
\text { e dormências }\end{array}$ \\
\hline
\end{tabular}

Fonte: Pesticides and Human Health, 2000.

\section{Alterações reprodutivas}

Os agrotóxicos podem afetar a reprodução humana pela toxicidade direta aos órgãos reprodutivos ou pela interferência na função hormonal. As alterações podem incluir anormalidades menstruais, infertilidade masculina e feminina e distúrbios hormonais. A toxicidade pode resultar em aborto espontâneo, retardo do crescimento, defeitos de nascimento estruturais, ou déficit funcional, sendo frequente um maior período de vulnerabilidade durante o desenvolvimento fetal e a infância (FOSTER; GRAY, 2013).

O uso do clordecone foi interrompido nos Estados Unidos após a evidência de alterações espermáticas, com diminuição da mobilidade e 
viabilidade, além dos efeitos neurológicos (FOSTER; GRAY, 2013). O herbicida 2,4-ácido diclorofexiacético (2,4-D) é espermatotóxico em animais de laboratório e uma correlação entre a exposição aumentada a 2,4-D e a densidade diminuída do esperma junto com a porcentagem aumentada do esperma anormal foi relatada nos aplicadores de agrotóxicos (SOLOMON, 2000). Um estudo com oitocentos casais, submetidos à fertilização in vitro, revelou que homens com exposição moderada ou elevada a agrotóxicos no trabalho tiveram significativa diminuição da fertilidade, quando comparados com não expostos, efeitos que persistiram após o ajuste para fatores de confundimento, como incluindo fumo, álcool, cafeína e o outros produtos químicos (TIELEMANS et al.,1999).

Estudos relatam uma taxa aumentada de aborto espontâneo e de natimortos nas mulheres trabalhadoras da agricultura (DE COCK et al., 1994; TIELEMANS et al., 1999). Numerosos relatos epidemiológicos associam exposição do agrotóxico no trabalho com risco aumentado de vários tipos de malformações congênitas, incluindo fissura palatina e labial, com risco associado à exposição durante 0 primeiro trimestre; malformações cardiovasculares, particularmente veia pulmonar anômala; espinha bífida e hidrocefalia; criptorquidia e hipospádia (FOSTER; GRAY, 2013; GARCÍARODRÍGUEZ et al., 1996; KRISTENSEN et al., 1997). Os fungicidas vinclozolina e o iprodiona são anti-androgênios, bem como alguns herbicidas, como a atrazina, que interferem indiretamente com o estrógeno (HOYER; FLAWS, 2013).

O pentaclorofenol (PCP), um preservativo de madeira, pode se ligar ao hormônio tireoestimulante (TSH) e reduzir a tiroxina (T4). Outros agrotóxicos atualmente usados, incluindo o dicofol e o bromoxinil, têm efeitos similares sobre a tiroxina. Os efeitos nos animais incluem níveis circulantes alterados de hormônios, desenvolvimento nos machos de hipospádia, criptorquidia, qualidade diminuída do sêmen e alteração da maturidade sexual (CDC, 2009; HOYER; FLAWS, 2013; VAN DEN BERG, 1990; VAN RAAIJ et al., 1994;). Trabalhadores de fábrica de agrotóxicos na China expostos aos organofosforados paration etílico e metamidofós, tiveram anormalidades significativas em seus perfis hormonais reprodutivos. A exposição aumentada de agrotóxicos foi correlacionada positivamente com os níveis séricos dos 
hormônios FSH (hormônio folículo estimulante) e LH (hormônio luteinizante), e negativamente com os níveis séricos de testosterona. Além disso, os trabalhadores com exposição elevada mostraram um risco maior para parâmetros anormais do sêmen (PADUNGTOD et al., 1998).

\section{Alterações genéticas}

Os agrotóxicos têm sido considerados agentes mutagênicos químicos potenciais (BOLOGNESI, 2003). Em estudo realizado no Paquistão com trabalhadores expostos ao malation na indústria de transformação do agrotóxico por 13-25 anos tinham significativamente maior comprimento da cauda de DNA (7,04 milímetros) do que o grupo controle $(0,94 \mathrm{~mm})$. Trabalhadores no grupo exposto também tiveram maior contagem de células brancas e menor contagem de células vermelhas no sangue, e menores níveis de hemoglobina corpuscular média e volume corpuscular médio (ARSHAD et al., 2016). Apesar do malation não ser considerado genotóxico, seus metabólitos isomalation e malaoxon podem causar alterações cromossômicas (USEPA, 2002). Ferreira Filho (2013) detectou anormalidades cromossômicas em 11 dos 43 trabalhadores rurais expostos a agrotóxicos no Ceará, utilizando células-tronco hematopoiéticas coletadas por aspirado da medula óssea.

\subsection{Intoxicações por medicamentos}

Segundo a OMS, "um medicamento ou droga é um produto farmacêutico, usado no organismo humano com o fim de prevenir, diagnosticar ou tratar uma doença, ou para modificar uma função fisiológica" (WHO, 2016). O efeito do medicamento se deve a uma ou mais substâncias ativas com propriedades terapêuticas reconhecidas cientificamente, que fazem parte da composição do produto, denominadas fármacos, drogas ou princípios ativos. Os medicamentos seguem a normas rígidas para poderem ser utilizados, desde a sua pesquisa e desenvolvimento, até a sua produção e comercialização (BRASIL, 2010).

O amplo uso de medicamentos sem orientação médica, quase sempre acompanhada do desconhecimento dos malefícios que pode causar, é apontado como uma das causas de estes constituírem o principal agente tóxico responsável pelas intoxicações humanas registradas no Brasil (MOTA et al.,2012; BOCHNER, 2008). Góes et al. (2016), utilizando os dados da 
Pesquisa de Orçamentos Familiares 2008-2009, reportaram que a aquisição de medicamentos foi reportada por $81,2 \%$ dos domicílios brasileiros, com média nacional de 2,4 medicamentos por domicilio e 0,72 medicamento por habitante, sendo maiores nas regiões Sul e Sudeste (0,81 e 0,79 medicamento/habitante, respectivamente). As classes de medicamentos mais adquiridas foram aqueles para o Sistema nervoso, Sistema cardiovascular e Aparelho digestivo/metabolismo, segundo o primeiro nível da classificação ATC (Anatomical Therapeutic Chemical). Domicílios de baixa renda, que se localizam principalmente em regiões com condições sanitárias mais precárias, adquiriram mais medicamentos da classe de antiparasitários.

A partir de 1994, os medicamentos assumiram a primeira posição no conjunto de agentes tóxicos reportados ao SINITOX. Entre 1999 e 2013, foram registradas 1.341 .687 de intoxicações humanas, sendo 379.096 por medicamentos (28,2\%) (Figura 4; BRASIL, 2016). O decréscimo acentuado do número de intoxicações em 2013 se deveu principalmente, principalmente, ao menor número de CIT/CIATs que enviaram dados ao SINITOX. Em 2009, existiam 36 CIT/CIATs no País, número que diminuiu para 34 em 2012. Porém, a participação dos Centros nos dados do SINITOX tem diminuído nos últimos anos, de 25 em 2009 para somente 16 em 2013.

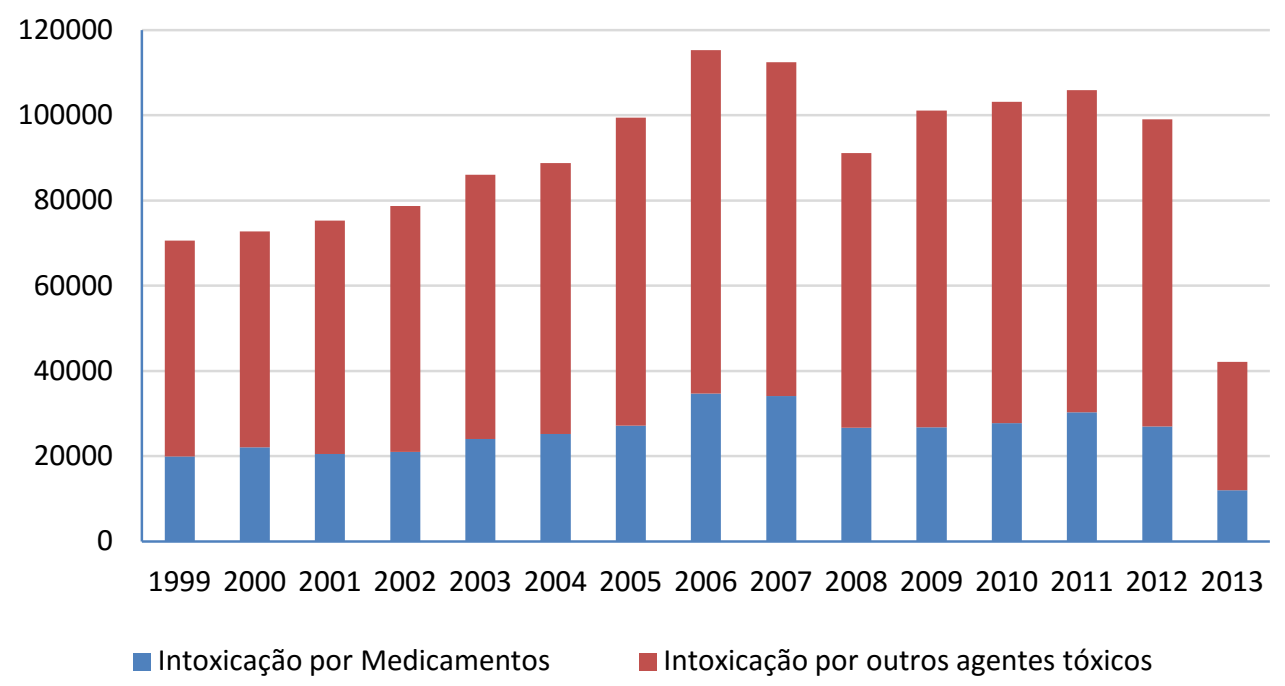

Figura 4. Número de intoxicações no Brasil em relação a dados nacionais sobre casos registrados de intoxicação humana por agente tóxico de 1999 a 2013.Fonte: FIOCRUZ, 2016. 
O uso racional de medicamentos pode diminuir as intoxicações por medicamentos, sendo um processo que compreende a prescrição apropriada, a disponibilidade oportuna e a preços acessíveis, a dispensação em condições adequadas, o consumo nas doses e pelo período de tempo indicados e nos intervalos definidos de medicamentos eficazes, seguros e de qualidade (GAVIOLI; NICOLELLA, 2007; SANTOS, 2004). Estudo realizado no Distrito Federal por Almeida et al. (2011) com funcionários e clientes de drogaria, funcionários e pacientes de hospitais e população geral ( $N=997)$, mostrou que a aquisição de medicamentos sem receita é uma prática generalizada, principalmente entre funcionários de drogaria. Cerca de $1 / 3$ deles reconhecem que estes produtos fazem mal a saúde, principalmente inibidores de apetite, antibióticos e "remédios para dormir".

\subsubsection{Principais medicamentos envolvidos nas intoxicações}

Souza et al. (2014) ao avaliar a morbi-mortalidade relacionada a medicamentos por meio de revisão sistemática de 45 trabalhos realizados no Brasil, observaram que os principais envolvidos foram os medicamentos que atuam no sistema nervoso central, no sistema respiratório, os anti-infecciosos para uso sistêmico, e os medicamentos cardiovasculares. As populações com maiores prevalências de danos ocasionados por medicamentos foram os idosos e as crianças.

Mota et al. (2012) avaliaram o perfil da mortalidade por intoxicação com medicamentos de 1996 a 2005 no Brasil, a partir de dados do Sistema de Informações sobre Mortalidade (SIM). Foi constatado que a maior parte dos óbitos foi devido a tentativa de suicídio por anticonvulsivantes, sedativos, antiparkinsonianos e psicotrópicos. A maior mortalidade ocorreu na região sudeste, que tem o maior consumo de medicamentos, e tem quase metade das farmácias e drogarias existentes oficialmente no Brasil.

Em 2014 o CIT do Rio Grande do Sul registrou 24.510 atendimentos destes, 10.456 por medicamentos, sendo que benzodiazepínicos, antidepressivos, analgésicos/antiperéticos, anticonvulsivantes foram as principais classes de medicamentos envolvidas (CIT/RS, 2014).

Lessa e Bochner (2008) analisaram as internações hospitalares registradas pelo SIH nos anos de 2003 a 2005 com crianças menores de um 
ano relacionadas a intoxicações e efeitos adversos de medicamentos. Os antiepilépticos, sedativos-hipnóticos e antiparkinsonianos foram responsáveis por $15,2 \%$ das internações de menores de um mês idade e $21,1 \%$ em crianças de um a onze meses. Os antibióticos sistêmicos responderam para essas mesmas faixas etárias por $12,6 \%$ e $18,5 \%$ das internações, respectivamente. Os analgésicos, antitérmicos e anti-reumáticos não opiáceos representaram $7,3 \%$ das internações para menores de um mês e $6,6 \%$ para crianças de um a onze meses.

Nos EUA, ocorreram 2.165.142 intoxicações humanas em 2014, sendo que as substâncias mais frequentemente envolvidas foram os medicamentos, principalmente analgésicos (11,3\%), sedativos /hipnóticos/ antipsicóticos $(5,9 \%)$ e antidepressivos $(4,4 \%)$. A classe dos sedativos foi a que apresentou o maior aumento em número de casos e gravidade nos últimos anos 13 anos $(12,2 \%)$ principalmente entre os adultos com mais de 20 anos (MOWRY et al.,2015) .Handley e Flanagan (2014), ao avaliar os dados de óbitos por intoxicação na Inglaterra e País de Gales de 2000 a 2011, observaram que os óbitos por paracetamol diminuíram, os por codeína e tramadol aumentaram, e os por inibidores da recaptação da serotonina se mantiveram estáveis ao longo dos anos.

\subsection{Sistemas de informação em vigilância toxicológica no Brasil}

A toxicovigilância representa o conjunto de ações que buscam eliminar ou minimizar as situações capazes de afetar a integridade física, mental e social dos indivíduos pela exposição às substâncias químicas (DIAS; ARAÚJO, 1997). Para que a toxicovigilância seja efetiva é necessária uma integração das atuações governamentais da vigilância epidemiológica, vigilância sanitária, vigilância ambiental e vigilância laboratorial. Entretanto as vigilâncias necessitam dos sistemas de informação em saúde para realizar suas ações de detecção de agravos à saúde e prevenção danos (LIMA,2010).

A OMS define Sistema de Informação em Saúde (SIS) como um mecanismo de coleta, processamento, análise e transmissão da informação necessário para se planejar, organizar, operar e avaliar os serviços de saúde. Considera-se que a transformação de um dado em informação exige, além da análise, a divulgação, e recomendações para a 
ação. Os SIS's utilizam programas operacionais informatizados que apoiam as funções técnicas, gerenciais e de tomada de decisão de interesse em saúde (BRASIL, 2009). Ascaracterísticas desejáveis de um sistema de informação incluem boa cobertura, exatidão das informações, e disponibilidade em tempo hábil.

No Brasil, os principais sistemas que agregam informações para a área de toxicologia são o Sistema de Informação de Agravos de Notificação (SINAN), o Sistema de Informação sobre Mortalidade (SIM), o Sistema Nacional de Informação Tóxico - Farmacológica (SINITOX) e os centros de informação (assistência) toxicológica (CIT/CIAT's). Adicionalmente, os institutos médicos legais dos estados e do Distrito Federal podem agregar informações importantes relativas às intoxicações fatais. O Quadro 4 resume a atuação desses sistemas. Outros sistemas do Brasil são o Sistema de Internações Hospitalares do SUS SIH/SUS e o Sistema de Informações Ambulatoriais do SUS SIA/SUS, que não serão abordados neste estudo.

Quadro 4. Resumo dos sistemas de toxicovigilância no Brasil.

\begin{tabular}{|c|c|c|c|}
\hline SISTEMA & EVENTO & $\begin{array}{c}\text { INSTRUMENTO DE } \\
\text { COLETA }\end{array}$ & FLUXO \\
\hline SINAN & $\begin{array}{c}\text { Agravos de } \\
\text { notificação }\end{array}$ & $\begin{array}{c}\text { Ficha de notificação e } \\
\text { investigação }\end{array}$ & $\begin{array}{c}\text { Unidades } \\
\text { de Saúde }\end{array}$ \\
\hline SIM & Óbito & Declaração de óbito & $\begin{array}{c}\text { Cartórios } \\
\text { Regionais }\end{array}$ \\
\hline SINITOX & Intoxicações & $\begin{array}{c}\text { Ficha de informação } \\
\text { toxicológica dos } \\
\text { CIT/CIAT }\end{array}$ & CIT/CIAT \\
\hline CIT/CIAT & $\begin{array}{c}\text { Intoxicações } \\
\text { Prontuário } \\
\text { CIT-ONLINE }\end{array}$ & $\begin{array}{c}\text { Unidades } \\
\text { estaduais, municipais e } \\
\text { federais }\end{array}$ \\
\hline IML & $\begin{array}{c}\text { Pédicias } \\
\text { em vivos e } \\
\text { mortos }\end{array}$ & Laudos periciais & Delegacias \\
& & & IML \\
\hline
\end{tabular}

CIT/CIAT: Centros de Informação (Assistência) toxicológica;

IML: Instituto Médico Legal. 


\subsubsection{Sistema de Informação de Agravos de Notificação- SINAN}

O SINAN foi desenvolvido no início da década de 90 tendo como objetivo a coleta e processamento dos dados sobre agravos de notificação no território nacional, fornecendo informações para a análise do perfil da morbidade e contribuindo para a tomada de decisões nos níveis municipal, estadual e federal (SINAN, 2005). A concepção do SINAN foi norteada pela padronização de conceitos de definição de caso, pela transmissão de dados a partir da organização hierárquica das três esferas de governo, pelo acesso à base de dados necessários à análise epidemiológica e pela possibilidade de disseminação rápida dos dados gerados na rotina do Sistema Nacional de Vigilância Epidemiológica do Sistema Único de Saúde - SUS (LAGUARDIA et al., 2004).

O SINAN foi implantado, de forma gradual, a partir de 1993. No entanto, esta implantação foi realizada de forma heterogênea nas unidades federadas e municípios, não havendo uma coordenação e acompanhamento por parte dos gestores de saúde, nas três esferas de governo. Em 1998, o Centro Nacional de Epidemiologia (CENEPI) retoma este processo e constitui uma comissão para desenvolver instrumentos, definir fluxos e um novo software para o sistema, além de definir estratégias para sua imediata implantação em todo o território nacional. O uso do SINAN foi regulamentado (Portaria Funasa/MS № 073 de 9/3/98), tornando obrigatória sua alimentação regular pelos municípios, estados e Distrito Federal, bem como designando o CENEPI como gestor nacional do Sistema, responsabilidade que foi transferida para a Secretaria de Vigilância em Saúde (SVS) em 2003 (SINAN,2005).

Desde 1997 somente as intoxicações por agrotóxicos eram notificadas ao SINAN. A partir da Portaria nº 777 de 2004, as intoxicações exógenas por substâncias químicas, incluindo agrotóxicos, gases tóxicos e metais pesados passou a ser compulsória, tratadas como um agravo à saúde do trabalhador. $A$ Portaria GM/MS N. ำ 2.472, de 31 de agosto de 2010 e a Portaria GM/MS № 104, de 25 de janeiro de 2011, determinam a relação de doenças, agravos e eventos em saúde pública de notificação compulsória em todo o território nacional e estabelece fluxo, critérios, responsabilidades e atribuições aos profissionais e serviços de saúde, ampliando as notificações das intoxicações exógenas para outras circunstâncias que não só a ocupacional. Esta portaria 
ainda ressalta no seu artigo $7^{\circ}$ que a notificação compulsória é obrigatória a todos os profissionais de saúde (médicos, enfermeiros, odontólogos, médicos veterinários, biólogos, biomédicos, farmacêuticos e outros no exercício da profissão), bem como os responsáveis por organizações e estabelecimentos públicos e particulares de saúde e de ensino, em conformidade com os arts. $7^{\circ}$ e 8o, da Lei oㅜ 6.259, de 30 de outubro de 1975. A ficha de Notificação e Investigação de Intoxicação Exógena do SINAN é o instrumento padronizado de coleta de dados e está disponível nos serviços de saúde envolvidos diretamente com as ações de assistência e vigilância: os serviços de urgências e emergências, de atenção primária, de vigilância epidemiológica e de farmácia hospitalar. Vale ressaltar que existe uma ficha específica para a Notificação e Investigação de Acidentes por Animais Peçonhentos no SINAN.

\subsubsection{Sistema de Informação sobre Mortalidade - SIM}

O Sistema de Informação sobre Mortalidade (SIM), desenvolvido pelo Ministério da Saúde em 1975, é produto da unificação de mais de quarenta modelos de instrumentos utilizados ao longo dos anos para coletar dados sobre mortalidade no País. Possui variáveis que permitem, a partir da causa básica atestada pelo médico, construir indicadores e processar análises epidemiológicas que contribuam para a eficiência da gestão em saúde (MELLO JORGE et al., 2010; SIM, 2014)

O documento básico e essencial à coleta de dados da mortalidade no Brasil é a Declaração de Óbito, emitida pelo médico, conforme prevê o artigo 115 do Código de Ética Médica, Artigo 1ำ da Resolução no 1779/2005 do Conselho Federal de Medicina e a Portaria SVS no 116/2009. Os óbitos registrados no SIM encontram-se categorizados segundo a Classificação Internacional de Doenças (CID-10 a partir de 1996).

\section{Classificação Internacional de Doenças - CID}

A Classificação Estatística Internacional de Doenças e Problemas Relacionados com a Saúde, frequentemente designada pela sigla CID (International Statistica IClassification of Diseases and Related Health Problems, ICD) fornece códigos relativos à classificação de doenças e de uma grande variedade de sinais, sintomas, aspectos anormais, queixas, 
circunstâncias sociais e causas externas para ferimentos ou doenças (DATASUS, 2008).

A classificação propriamente dita, assim chamada LISTA TABULAR, é formada por categorias, isto é, códigos de três caracteres (uma letra e dois algarismos) e subcategorias (quando a uma categoria é atribuída um outro número, tem-se as subdivisões de três caracteres iniciais acrescidos de um ponto e de outro número). Um conjunto de categorias que contém doenças semelhantes constitui um agrupamento. Vários agrupamentos constituem um capítulo (DATASUS,2008) (Quadro 5).

Nessa classificação, são relevantes para agravos relacionados com as intoxicações exógenas o Capítulo XIX (Lesões, envenenamento e algumas outras consequências de causas externas) e o Capítulo XX (Causas externas de morbidade e mortalidade).

Quadro 5. Principais capítulos, agrupamentos e categorias relacionados com a morbi-mortalidade por intoxicação exógena.

\begin{tabular}{|c|c|c|}
\hline Capítulo & Agrupamento & Categorias \\
\hline XIX & $\begin{array}{l}\text { Lesões, } \\
\text { envenenamentos } \\
\text { e algumas outras } \\
\text { consequências de } \\
\text { causas externas. }\end{array}$ & $\begin{array}{c}\text { T20-T32- Queimaduras e corrosões, } \\
\text { T36-T50-Intoxicações por drogas, medicamentos e } \\
\text { substâncias biológicas; } \\
\text { T51-T65 - Efeitos tóxicos de substâncias de } \\
\text { origem predominantemente não medicinal } \\
\text { T90-T98-Sequelas de traumatismos, de } \\
\text { intoxicações e de outras consequências das } \\
\text { causas externas }\end{array}$ \\
\hline$X X$ & $\begin{array}{c}\text { Causas externas } \\
\text { de morbidade e de } \\
\text { mortalidade }\end{array}$ & $\begin{array}{c}\text { X 20- X29 -Contato com animais e plantas } \\
\text { venenosas } \\
\text { X40-X49- Envenenamento [intoxicação] acidental } \\
\text { por e exposição à substancias nocivas } \\
\text { X60-X84 - Lesões autoprovocadas } \\
\text { intencionalmente, } \\
\text { X85-Y09 - Agressões } \\
\text { Y10-Y34-Eventos fatos cuja a intenção é } \\
\text { indeterminada, } \\
\text { Y40-Y57-Efeitos adversos de drogas, } \\
\text { medicamentos e substâncias biológicas usadas } \\
\text { com finalidade terapêutica. }\end{array}$ \\
\hline
\end{tabular}




\subsubsection{Sistema Nacional de Informações Tóxico-Farmacológicas - SINITOX}

O reconhecimento do problema das intoxicações e a necessidade de meios especializados para tratá-las, assim como a existência de um núcleo de profissionais de saúde dedicados à toxicologia humana, constituíram o requisito básico para a criação dos centros de informação toxicológica. Esses serviços têm como principal função prestar informação e assessorar sobre diagnóstico, prognóstico, tratamento e prevenção das intoxicações, tanto para os profissionais de saúde quanto para o público em geral (OMS, 1998).

Os primeiros centros a que se tem registro estavam localizados na Europa. Em 1949 já havia em Budapeste (Hungria) uma enfermaria especializada com 100 leitos dedicados à toxicologia clínica e, quase ao mesmo tempo, um serviço de informação foi criado na Enfermaria do Hospital Geral de Leeds, na Inglaterra. Em 1964, foi criada a Associação Europeia de Centros de Controle de Intoxicação, e em 1970, 22 países europeus possuíam programas de controle de intoxicações, sendo que a maioria apresentava um serviço permanente de informação e tratamento (GOVAERTS, 1970; HUNGRIA, 2016).O primeiro centro nos Estados Unidos foi inaugurado em novembro de 1953, em Chicago. Outras cidades dos EUA seguiram esse exemplo e, em 1958, os 17 Centros existentes fundaram a American Association of Poison Control Centers (AAPCC). No Canadá, o primeiro centro surgiu em 1957, e atualmente conta com 13 centros regionais que atendem a diversas províncias e 5 centrais que fazem parte da Associação Canadense de Centros Anti-Veneno (CAPCC, 2016).

$\mathrm{Na}$ América do Sul, a Argentina foi pioneira, contando com um centro desde 1962 (ARGENTINA, 2016; BAROUD, 1985), seguido do Uruguai, que inaugurou seu primeiro centro em dezembro de 1975 (COMSTOCK et al., 1981; URUGUAI, 2016). Em 1992, vários países latino-americanos possuíam centros (ZAMBRONE, 1992). No Brasil, como em vários outros países, a iniciativa de criar centros partiu de pediatras. Em 1963, em São Paulo, os médicos Eduardo Marcondes e Samuel Schwartzman formaram o primeiro serviço de pediatria para atendimento da criança intoxicada (CALDAS et al., 1996). Instalado no Hospital Municipal Dr. Arthur Ribeiro de Saboya, o serviço tornou-se um centro de referência em 1971, sob a denominação de Centro de Controle de Intoxicações (SÃO PAULO, 2016). 
Em 1972, já existia em Belo Horizonte, no Hospital João XXIII, um núcleo de toxicologia, que utilizava fichas manuais com informações sobre substâncias e condutas médicas para orientações em casos de intoxicação. Porém, o Serviço de Toxicologia só foi criado em 1982. Em 1976, foi criado pelo Dr. Alberto Furtado Rahde o Centro de Informação Toxicológica do Rio Grande do Sul e em 1980, o Centro de Informação Anti-Veneno da Bahia (BORTOLETTO, 1993; MARQUES et al., 1995).

Em 1980, dada a necessidade de ampliar o número de centros, de produzir conhecimento sobre intoxicações e envenenamentos e de gerar informação epidemiológica com base na consolidação dos casos registrados pelos centros já existentes no País, foi constituído o Sistema Nacional de Informações Tóxico-Farmacológicas. Em fevereiro de 1989 passou a denominar-se Programa Nacional Integrado de Informação FármacoToxicológica, que hoje é denominado Sistema Nacional de Informações TóxicoFarmacológicas (SINITOX). Esse sistema é coordenado e administrado pela Fundação Oswaldo Cruz (FIOCRUZ), por meio de seu Instituto de Comunicação e Informação Científica e Tecnológica em Saúde (ICICT). O SINITOX tem como principal atribuição coordenar o processo de coleta, compilação, análise e divulgação dos casos de intoxicação e envenenamento notificados no País, registrados pela Rede Nacional de Centros de Informação e Assistência Toxicológica (RENACIAT), localizados nas diversas regiões do País (FIOCRUZ, 2016).

Alguns centros prestam apenas orientação toxicológica (CIT's), ou seja, seus esforços estão voltados para informar e esclarecer aos serviços de saúde e à população em geral quanto aos riscos das substâncias químicas e biológicas, assim como medidas preventivas, diagnóstico e tratamento das intoxicações, de forma não presencial, preferencialmente pelo telefone. Outros, por sua vez, prestam também assistência toxicológica (CIAT's), e seus profissionais de saúde desenvolvem atividades presencialmente no atendimento ao paciente intoxicado (ANVISA, 2005). Atualmente no Brasil existem 34 Centros de Informação (e Assistência) toxicológica públicos espalhados em 19 estados brasileiros (Figura 5). Os Centros funcionam em hospitais universitários, Secretarias Estaduais e Municipais de Saúde e fundações. 


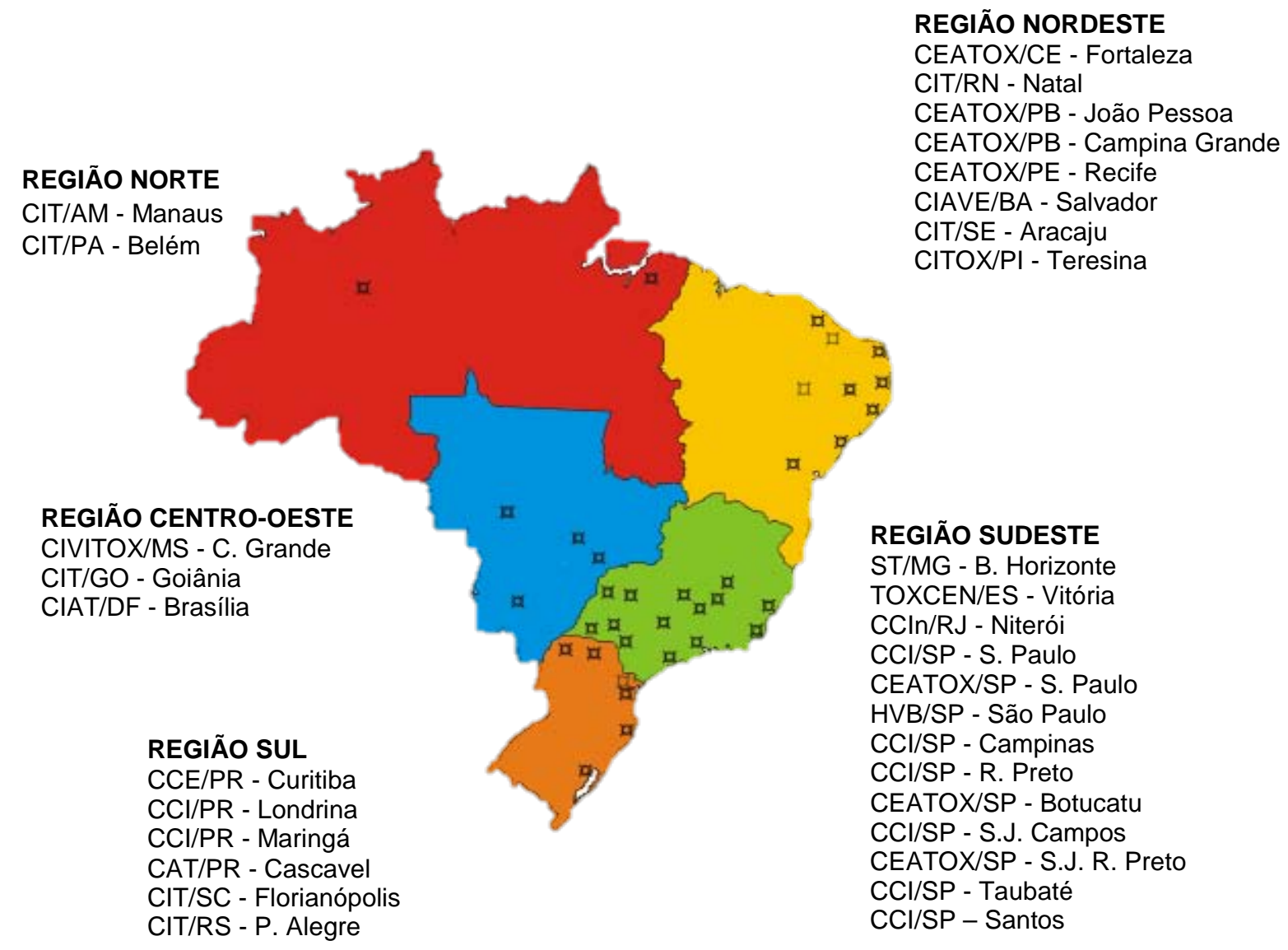

Figura 5. Centros de Informações e Assistência Toxicológica no Brasil.

Fonte: FIOCRUZ, 2016.

Em 2005, foi criada a RENACIAT Rede Nacional dos Centros de Assistência Toxicológica pela ANVISA ao qual alguns centros do Brasil ainda participam. Em 2006, a ANVISA criou o Disque- Intoxicação um 0800 nacional interligado com todos os centros do País para um melhor atendimento da população, a ligação é direcionada para o centro mais próximo da região onde a chamada foi originada. O número 8006226001 está grafado nas embalagens, rótulos e bulas de medicamentos, agrotóxicos, saneantes e cosméticos registrados pela ANVISA (ANVISA,2006).

Ao longo dos anos, a Ficha de Notificação e de Atendimento dos Centros passou por várias revisões/atualizações, sendo seu modelo e manual de preenchimento atual divulgado em janeiro de 2001, servindo de base para a criação do modelo utilizado pelo SINAN na notificação de intoxicação exógena realizada a partir de 2007 (SINAN, 2013). A coleta primária dos dados pelos centros é realizada no momento em que se faz o registro do atendimento. 


\subsubsection{Centro de Informações Toxicológicas do Distrito Federal - CIT-DF}

O Centro de Informação Toxicológica do Distrito Federal (CIT-DF) foi instituído em 1983, por um grupo de médicos intensivistas no Hospital de Base do DF, funcionando até 1985 . Em fevereiro de 2004, o Centro foi novamente reaberto, a partir de uma iniciativa de médicos e enfermeiros Laboratório Central de Saúde Pública (LACEN-DF), subordinado a Subsecretaria de Vigilância a Saúde da Secretaria de Estado da Saúde do Distrito Federal e tendo como proposta prestar assessoria e orientação frente à ocorrência de acidentes tóxicos no Distrito Federal (DISTRITO FEDERAL, 2012).

Nos seus 12 anos de existência, o CIT-DF realizou mais de 30.000 atendimentos relativos a pacientes vítimas de intoxicação exógena, apoiando políticas públicas relativas à Vigilância Epidemiológica, Vigilância Sanitária e Vigilância Ambiental na questão toxicológica no DF. O CIT-DF mantém cooperação técnica com centros similares do Brasil por meio da RENACIAT e da Rede de Toxicologia em Latino América e no Caribe (RETOXLAC).

O CIT-DF presta assessoria e orientação em acidentes tóxicos, em caráter de emergência e em regime de plantão permanente (24 horas/dia) aos profissionais de saúde por meio do telefone 0800644 6774, de maneira que estes possam aperfeiçoar o atendimento (diagnóstico e tratamento). O CIT-DF também fornece orientações à população em geral sobre condutas frente a esses agravos no Distrito Federal e em outras unidades da federação, por meio de um telefone 0800 nacional. Os agentes envolvidos incluem agrotóxicos agrícolas ou domésticos, substâncias químicas de uso doméstico ou industrial, plantas tóxicas, animais peçonhentos, medicamentos de uso humano ou animal, drogas lícitas e ilícitas, ou qualquer outro agente potencialmente tóxico. O CIT-DF possui uma equipe multidisciplinar de profissionais de saúde (médicos, enfermeiros e farmacêuticos) e estagiários do curso de graduação de Medicina, Enfermagem e Farmácia. O prontuário eletrônico do CIT-DF registra a história clínica da exposição/intoxicação, o agente tóxico envolvido, evolução clínica do paciente e o desfecho final de cada caso assistido. O CIT-DF encaminha anualmente seu relatório de atendimento ao SINITOX. 


\subsubsection{Instituto de Medicina Legal do Distrito Federal}

A toxicologia forense é uma ciência multidisciplinar que busca mostrar a verdade de um fato perante a lei, mas também identificar e quantificar os efeitos prejudiciais associados a produtos tóxicos, ou seja, qualquer substância que pode provocar danos ou produzir alterações no organismo, no seguimento de solicitações processuais de investigação criminal (ALCÂNTARA, 2006).

Até o século XX, a toxicologia forense limitava-se a estabelecer a origem tóxica de um determinado crime; o "toxicologista" atuava diretamente no cadáver com a mera intenção da pesquisa e identificação do agente. Atualmente, o campo de ação desta ciência é mais vasto, estendendo-se desde as perícias no vivo e no cadáver até circunstâncias de saúde pública, tais como aspectos da investigação relacionados a eventual falsificação ou adulteração de medicamentos e de acidentes químicos de massa (ALVES, 2005).

No caso de morte por intoxicação tem grande relevância a colaboração entre a Patologia Forense e a Toxicologia Forense, uma vez que essa possibilita a identificação e quantificação de determinada substância química, de forma a deliberar se a quantidade encontrada da mesma é compatível com a conclusão de morte por intoxicação ou, se adequa a concentrações terapêuticas, subjacentes às características patológicas do caso em estudo (ALCÂNTARA, 2006; PEREIRA,2009).

O Instituto de Medicina Legal do Distrito Federal (IML-DF), órgão pertencente ao Departamento de Polícia Técnica da Policia Civil do Distrito Federal, realiza perícias médicas, por solicitação das autoridades policiais e judiciárias. Na sua estrutura, a Divisão de Perícia no Morto (Tanatologia Forense) é responsável pela realização dos exames cadavéricos em vítimas de mortes por causas externas. A Seção de Laboratório Forense é responsável pelos exames laboratoriais e histopatológicos que os peritos julguem necessários para complementação de seus laudos, incluindo exames toxicológicos e alcoolemia em cadáveres, investigação de envenenamentos e análise histopatológica de vísceras. O Banco de dados do IML é construído a partir do programa de registro de casos da Polícia Civil do DF, onde são inseridos os laudos periciais e os resultados de exames laboratoriais, com 0 objetivo de responder aos quesitos oficiais, relativo aos laudos cadavéricos. 
2.4.6. Centro de Referência em Saúde do Trabalhador do Distrito FederalCEREST-DF

O setor público de saúde do DF, considerando a construção do SUS e coerente com a NOST-SUS Portaria no. 3.908, de 10 de outubro de 1998, implantou em 2000 a Diretoria de Saúde do Trabalhador (DISAT/SES-DF), instituída como parte da reforma administrativa da Secretaria de Estado de Saúde do DF, em substituição às antigas estruturas de atendimento à saúde do trabalhador. As ações da DISAT têm como área de cobertura principal o DF e a área de abrangência do Instituto Nacional de Seguridade Social (INSSBrasília), para atendimento assistencial ou concessão de benefício. Porém, na prática, trabalhadores de estados próximos como Goiás, Minas Gerais e Bahia também procuram atendimento. Em observação a nova Política Nacional de Saúde do Trabalhador e da Trabalhadora (Portaria do Ministério da Saúde 1.823 de 2012), o DISAT foi substituído pelo CEREST. Esta Política tem como finalidade definir os princípios, as diretrizes e as estratégias a serem observados pelas três esferas de gestão do SUS para o desenvolvimento da atenção integral à saúde do trabalhador, com ênfase na vigilância, visando a promoção e a proteção da saúde dos trabalhadores e a redução da morbimortalidade decorrente dos modelos de desenvolvimento e dos processos produtivos

O CEREST tem como atribuições coordenar as ações de saúde do trabalhador no DF, sendo responsável, entre outros, por inserir ações, metas e indicadores de saúde do trabalhador no Plano Estadual de Saúde e na Programação Anual de Saúde, organizar as ações de promoção, vigilância e assistência à saúde do trabalhador no DF, garantir a implementação nos serviços públicos e privados, da notificação compulsória dos agravos à saúde relacionados ao trabalho, promover a formação e capacitação em saúde do trabalhador para os profissionais de saúde do SUS e desenvolver estratégias de comunicação e divulgação de informações do perfil produtivo e epidemiológico relativos à saúde dos trabalhadores (RENAST,2016; BRASIL,2012). O CEREST também possui como atribuição ser referência em especialidades médicas dos agravos relacionados ao trabalho. Com este intuito foi criado em abril de 2003 o Ambulatório de Toxicologia Ocupacional (ATO), tendo como suporte laboratorial, o Laboratório Central de Saúde Pública 
(LACEN), da Secretaria de Saúde do Distrito Federal. São atribuições do ATO, a identificação e controle dos fatores de risco à saúde presentes nos ambientes e condições de trabalho para, a partir de um diagnóstico, propor tratamento e prevenção dos danos, lesões ou doenças provocadas pelo trabalho, no indivíduo ou no coletivo de trabalhadores (MAGALHÃES, 2005).

Até 2010 o acesso de pacientes no ATO poderia se dar por três vias: pela Rede pública de serviços de saúde, que após o primeiro atendimento, na atenção básica e nas diversas clínicas especializadas, encaminha os trabalhadores considerados suspeitos de intoxicação ocupacional, ou já com alguma sintomatologia de intoxicação para confirmação diagnóstica; pela Gerência de Vigilância à Saúde do Trabalhador, com pacientes de risco ou provável risco de intoxicação ocupacional, após inspeção técnica do ambiente de trabalho e do processo de trabalho; e por demanda espontânea. Atualmente, somente são atendidos no ATO pacientes encaminhados pela rede pública de saúde.

\subsection{O Distrito Federal}

O Distrito Federal (DF) é uma das e a menor das 27 unidades federativas do Brasil. Situado na Região Centro-Oeste, o DF é em 31 regiões administrativas (Figura 6), totalizando uma área de $5779,999 \mathrm{~km}^{2}$. Em seu território, está localizada a capital federal do Brasil, Brasília, que é também a sede do governo do Distrito Federal. O crescimento demográfico do DF se situa em 2,8\%/ano, com densidade média de $410,8 \mathrm{hab} . / \mathrm{km}^{2}$ e uma das mais altas taxas de urbanização do País, alcançando 94,7\% (IBGE,2010).

Relativamente ao desenvolvimento socioeconômico são significativos os valores dos seguintes indicadores: mortalidade infantil de 17,8 por mil nascimentos; taxa de analfabetismo alcança $4,7 \%$ entre pessoas acima de 15 anos, 3.777 leitos hospitalares disponíveis, e quase a totalidade da população tem acesso à água corrente e à rede de esgoto (IBGE,2010) 


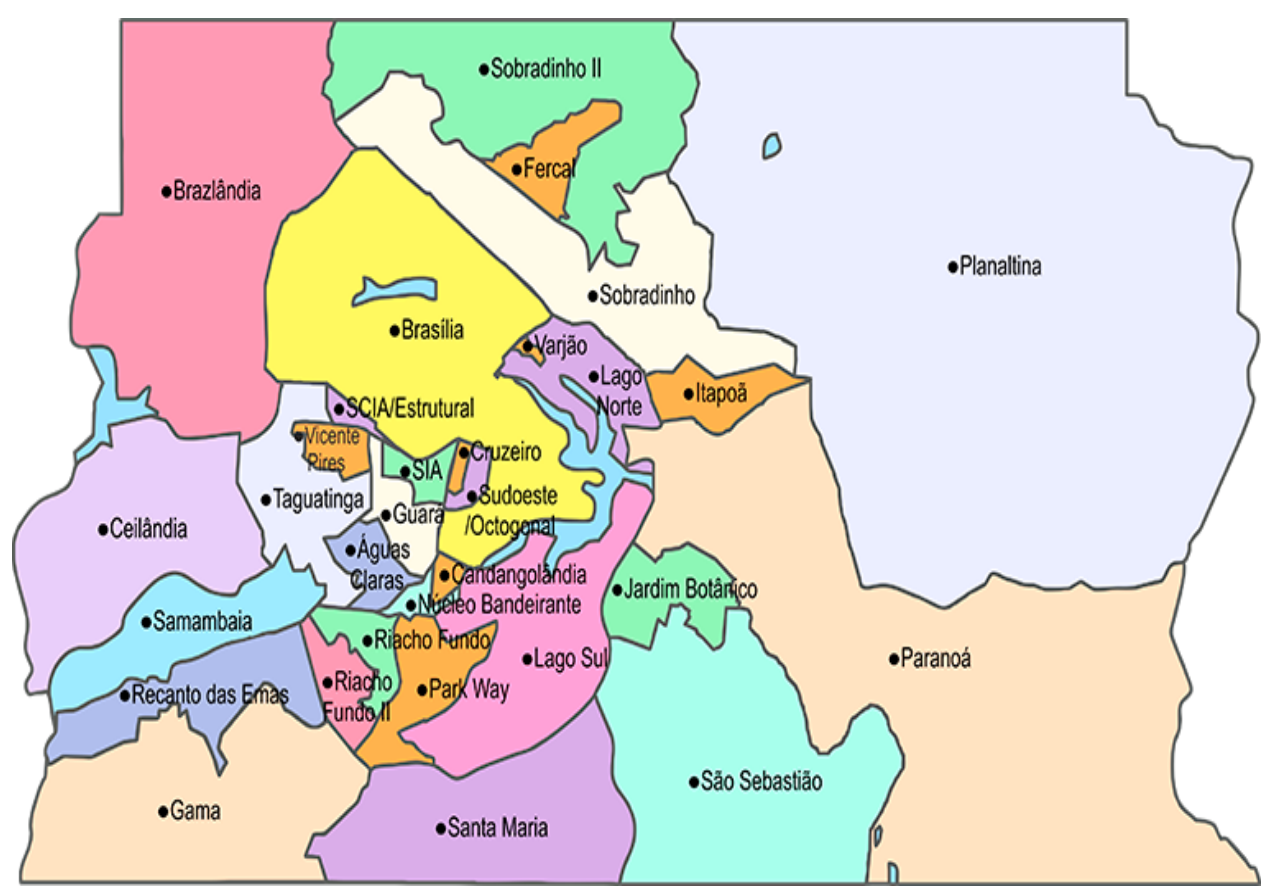

Figura 6. O Distrito Federal e suas regiões administrativas

Além de abrigar o centro político, Brasília, o DF também é um importante centro econômico, sendo a sétima unidade federativa com o maior produto interno bruto (PIB) do País ( $R$ \$ 171,2 bilhões em 2012) e o maior PIB per capita do país ( $R \$ 64.653)$. A economia do DF sempre teve como principais bases a construção civil e o varejo, além da agricultura e agropecuária ocupam lugar de destaque na economia brasiliense (IBGE, 2012).

Um cinturão verde na Região Integrada de Desenvolvimento do Distrito Federal e Entorno abastece a cidade e exporta alimentos para outros locais, com culturas permanente (abacate, banana, café, goiaba, laranja, limão, mamão, manga, maracujá, tangerina, urucum e uva) e temporária (abacaxi, algodão, alho, amendoim, arroz, batata-doce, batata-inglesa, cana-de-açúcar, cebola, feijão, mandioca, melancia, milho, soja, tomate e trigo). A pauta de exportação em 2012 foi baseada principalmente em carne de aves $(64,04 \%)$ e soja $(8,24 \%)$ (IBGE, 2010). 


\section{OBJETIVOS}

\section{Geral}

Avaliar as informações relativas às intoxicações exógenas no Distrito Federal, no período de 2009 a 2013.

\section{Específicos}

1. Avaliar a evolução clínico-epidemiológica dos casos de intoxicação atendidos pelo Ambulatório de Toxicologia Ocupacional do Centro de Referência Estadual em Saúde do Trabalhador do DF (CEREST-DF)

2. Avaliar o perfil epidemiológico das intoxicações exógenas do Distrito Federal baseado nos dados do Centro de Informação Toxicológica do Distrito Federal (CIT-DF) e do Sistema de Informação de Agravos de Notificação (SINAN)

3. Identificar os fatores associados aos óbitos por intoxicação exógena registrados pelo CIT-DF, SINAN, Sistema de Informação sobre de Mortalidade (SIM), e Instituto Médico Legal do DF

4. Identificar as inconsistências dos registros oficiais e subnotificações das intoxicações exógenas, onde elas mais ocorrem e suas possíveis causas. 


\section{ESTRUTURA DA TESE}

Os métodos e resultados desse trabalho serão apresentados em três capítulos distintos, todos em formato de artigo.

O primeiro capítulo (I. Casos de exposição/intoxicação ocupacionais atendidos no Centro de Referência em Saúde do Trabalhador do Distrito Federal entre 2009 e 2013) se refere a evolução clínica dos casos de intoxicação atendidos pelo Ambulatório de Toxicologia Ocupacional do Centro de Referência Estadual em Saúde do Trabalhador do DF (CEREST-DF). Este estudo atende ao objetivo 1 deste trabalho.

O segundo capítulo (II. Exogenousintoxications in the Federal District of Brazil - data from the Poison Information Center and the Disease Notification Information System) se refere a análise do perfil epidemiológico das intoxicações exógenas do Distrito Federal baseado nos dados do CIT-DFe do SINAN-DF. Este estudo atende ao objetivo 2 e 4 deste trabalho.

O Terceiro capítulo (III. Óbitos por intoxicação exógena no Distrito Federal entre os anos de 2009 e 2013) avalia os óbitos por intoxicação exógena a partir dos dados registrados pelo CIT-DF, SINAN-DF, SIM-DF, e IML-DF. Este estudo atende ao objetivo 3 e 4 deste trabalho. 


\section{Casos de exposição/intoxicação ocupacionais atendidos no Centro de}

Referência em Saúde do Trabalhador do Distrito Federal entre 2009 e 2013

\section{Resumo}

A exposição ocupacional a produtos químicos no ambiente de trabalho acarreta o risco de efeitos adversos à saúde humana. Este é um estudo retrospectivo que utilizou dados de dados de 382 trabalhadores residentes no Distrito Federal expostos ocupacionalmente a produtos químicos e atendidos no Ambulatório de Toxicologia Ocupacional do CEREST-DF nos anos de 2009 a 2013. Os prontuários foram analisados com o intuito de se verificar os aspectos epidemiológicos, clínicos e laboratoriais dos trabalhadores, assim como a ocorrência de intoxicações. Cerca de dois terços dos trabalhadores eram homens, predominantemente entre 30 e 39 anos; 46,3\% cursaram até o ensino médio. A maioria trabalhava na atividade por até 9 anos $(55,2 \%)$, e $81 \%$ relataram não usar equipamento de proteção individual durante o trabalho. Quase 60\% dos atendimentos foram de agricultores e agentes de vigilância ambiental, expostos predominantemente a agrotóxicos, produtos que estiveram envolvidos em $63,0 \%$ dos casos investigados. Cerca de $40 \%$ dos casos com exposição a agrotóxicos envolveram inseticidas organofosforados, principalmente o temefós. Entre os indivíduos que realizaram exame de colinesterase, $68 \%$ apresentaram resultados alterados, principalmente agricultores (85,9\%). Baseados em critérios ocupacionais, clínicos e epidemiológicos, $57,3 \%$ dos indivíduos foram considerados intoxicados, a maioria por agrotóxicos (61,6\%), e afastados do trabalho por pelo menos 10 dias.

Palavras-chave: Intoxicação ocupacional, atendimento ambulatorial, agrotóxicos, Distrito Federal. 


\section{Introdução}

O homem convive desde os primórdios com vários agentes tóxicos de origem química e biológica, incluindo aqueles ubíquos na natureza, como bactérias e metais pesados. A partir da revolução industrial e da modernização da atividade agrícola, novos agentes foram inseridos na sociedade com potencial risco para a saúde humana, incluindo os agrotóxicos e os produtos de uso industrial (ATSDR, 2014). Indivíduos envolvidos com estes agentes na atividade laboral constituem a população mais crítica, já que o nível de exposição é maior comparado com a população geral, e consequentemente maiores são os riscos de danos à saúde (CDC, 2009).

De acordo com o Sistema Nacional de Informações TóxicoFarmacológica que compila dados de intoxicações humanas registrados pelos centros de informações toxicológicas do País, 72,3\% das ocorrências reportadas entre 2009 e 2013 foram de acidentes individuais e tentativa de suicídio, e 5,8\% de causa ocupacional. Em 2009, existiam 36 CIT/CIAT's no País, número que diminuiu para 35 em 2012. Porém, a participação dos Centros nos dados do SINITOX tem diminuído nos últimos anos, com $25 \mathrm{em}$ 2009 e somente 16 em 2013.

Dados do CIT-DF, mostra um percentual menor no Distrito Federal (2,4\%; dados não publicados), o que pode ser explicado pela pouca atividade industrial e agrícola na região comparada com outras regiões do País ou pela não investigação de casos expostos ocupacionalmente. Sousa e Santana (2016) identificaram no Sistema de Informações sobre Mortalidade (SIM), 8.923 óbitos por acidentes de trabalho no Brasil no período de 2000 a 2010 sendo que os agrotóxicos estavam envolvidos em $2,3 \%$ dos casos.

Intoxicações com agrotóxicos são importantes principalmente em Países em desenvolvimento e emergentes (CALDAS, 2016; MALASPINA, ZINILISE, BUENO, 2011). Desde 2008, o Brasil está entre os três maiores usuários de agrotóxicos no mundo, com mais de 500 mil toneladas de produtos comercializados no País em 2014 (IBAMA,2016). A exposição ocupacional a agrotóxicos ocorre principalmente no campo, mas também é importante em ambientes urbanos no controle de vetores e nas desinsetizações domésticas.

No Brasil, a principal estratégia de atenção à saúde do trabalhador no Sistema Único de Saúde (SUS) é a Rede Nacional de Atenção à Saúde do 
Trabalhador (RENAST), instituída pela Portaria GM № 1679/2002 para articular as instituições da rede de serviços do Sistema. Nesse contexto, foram criados os Centros de Referência em Saúde do Trabalhador (CEREST), os quais têm como atribuições coordenar as ações de saúde do trabalhador e ser referência em especialidades médicas de doenças relacionadas ao trabalho. Suas competências se inserem nas diretrizes da Política Nacional de Saúde do Trabalhador e da Trabalhadora (BRASIL, 2012). O Ambulatório de Toxicologia Ocupacional do CEREST-DF foi criado em 2003 em parceria com o CIT-DF, tendo como suporte o Laboratório Central de Saúde Pública (LACEN) da Secretaria de Saúde do Distrito Federal.

Este estudo tem como objetivo avaliar os casos de intoxicação por produtos químicos atendidos no Ambulatório de Toxicologia Ocupacional do CEREST-DF entre 2009 e 2013.

\section{Método}

Este é um estudo retrospectivo descritivo, que teve como fonte primária o prontuário médico dos pacientes atendidos no CEREST-DF. Os critérios de inclusão no estudo foram pacientes residentes no DF, com exposição ocupacional a produtos químicos, com idade igual ou maior que 18 anos cujo primeiro atendimento ocorreu entre 01 de janeiro de 2009 a 31 de dezembro de 2013. O estudo só contabilizou o primeiro atendimento, não sendo consideradas as consultas de retorno no número total de casos. As informações extraídas do prontuário dos pacientes foram: data do $1^{\circ}$ atendimento, identificação do paciente (sexo, idade, escolaridade, ocupação atual e anterior), zona de ocorrência, circunstância, tempo e via de exposição, agente tóxico (classe, nome comercial e princípio ativo), uso dos equipamentos de proteção individual (EPI), sinais e sintomas clínicos relatados e observados no exame clínico, exames laboratoriais, diagnóstico final e evolução do caso (Apêndice 2). O diagnóstico final foi baseado em critérios ocupacionais, clínicos e laboratoriais/toxicológicos. De acordo com o protocolo de atendimento que existia no período do estudo, foram solicitados a todos trabalhadores atendidos exames laboratoriais de rotina, que incluíram hemograma, para verificar função da medula óssea, AST (Transaminase Aspartato Aminotransferase) e ALT (Transaminase Alanina Aminotransferase) para avaliar a função hepática, ureia 
e creatinina para avaliar função renal, e avaliação da função tireoidiana (T3, T4 e TSH). Exames de ecografia abdominal e radiografia do tórax também foram solicitados.

Trabalhadores expostos a agrotóxicos fizeram análise de colinesterase plasmática, indicador de exposição a inseticidas organofosforados e carbamatos, segundo a Norma Regulatória do Programa de Controle Médico de Saúde Ocupacional do Ministério do Trabalho (NR-7) (BRASIL, 1978). As análises foram realizadas no Núcleo de Toxicologia do LACEN-DF utilizando kit comercial DiaSys (Diagnostic Systems $\mathrm{GmbH}$ ), que indica valores de referência para mulheres (3930 a $10800 \mathrm{U} / \mathrm{L}$ ) e para homens (4620 a $11500 \mathrm{U} / \mathrm{L}$ ). Foram consideradas alteradas as dosagens que tinham atividade enzimática abaixo da faixa inferior de referência do Kit. Ressalta-se que os trabalhadores não possuíam dosagem de atividade pré-ocupacional. Indivíduos que apresentaram alterações clínicas compatíveis com a exposição, com ou sem alteração da colinesterase plasmática, foram considerados intoxicados.

Os dados dos prontuários foram transferidos para o Programa Statistical Package for the Social Sciences V. 20 (SPSS Inc., Chicago, Estados Unidos) para análise. Esse estudo utilizou um banco de dados secundários com a garantia do sigilo e anonimato dos pacientes, de acordo com a Resolução 466/2012 do Conselho Nacional de Saúde. O estudo foi aprovado pelo Comitê de Ética em Pesquisa da Fundação de Ensino e Pesquisa do Distrito Federal parecer no 1076808 (CAEE 36189714.2.0000.5553) (Anexo 1).

\section{Resultados}

Este estudo incluiu 382 trabalhadores residentes no Distrito Federal expostos ocupacionalmente a produtos químicos atendidos no Ambulatório de Toxicologia Ocupacional do CEREST-DF no período de 2009 a 2013 para fins de avaliação clínico-toxicológica. Todos trabalhadores foram encaminhados pela rede de saúde pública do DF. O número de atendimentos diminuiu drasticamente ao longo do período, de 93 casos em 2009 para 50 em 2013. A Tabela 1 mostra as características dos indivíduos atendidos no Ambulatório. A maioria dos indivíduos eram homens $(66,7 \%)$, chegando a representar mais de $80 \%$ dos casos em 2009; $28,5 \%$ tinham entre 30 e 39 anos, e $7,6 \%$ deles mais de 60 anos. Quase a metade dos indivíduos (45,3\%) estudaram até o ensino 
fundamental, 5,8\% com ensino superior completo e dois agricultores se auto declararam sem grau de instrução. Enquanto $46,5 \%$ dos agricultores possuía apenas o ensino fundamental, a maioria dos agentes de vigilância ambiental $(87,0 \%)$ possuía o ensino médio (dados não mostrados). A maioria dos atendidos trabalhavam na sua ocupação por até 9 anos (55,2\%) e 6,5\% foram atendidos devido a um quadro agudo com até 24 horas de exposição (Tabela 1).

Tabela 1. Características dos indivíduos atendidos no Ambulatório de Toxicologia Ocupacional do CEREST/DF de 2009 a 2013.

\begin{tabular}{|c|c|c|}
\hline Parâmetro & $\mathbf{N}$ & Percentual \\
\hline \multicolumn{3}{|l|}{ Sexo } \\
\hline Homens & 255 & 66,7 \\
\hline Mulheres & 127 & 33,3 \\
\hline \multicolumn{3}{|l|}{ Idade (anos) } \\
\hline 18 a 29 & 56 & 14.7 \\
\hline 30 a 39 & 109 & 28.5 \\
\hline 40 a 49 & 95 & 24.7 \\
\hline 50 a 59 & 93 & 24.3 \\
\hline 60 ou mais & 29 & 7.6 \\
\hline \multicolumn{3}{|l|}{ Escolaridade } \\
\hline Sem escolaridade & 2 & 0.5 \\
\hline Fundamental I & 85 & 22.3 \\
\hline Fundamental II & 88 & 23.0 \\
\hline Ensino médio & 177 & 46.3 \\
\hline Superior incompleto & 8 & 2.1 \\
\hline Superior completo & 22 & 5.8 \\
\hline \multicolumn{3}{|l|}{ Tempo de exposição } \\
\hline Até 24 hs & 25 & 6,5 \\
\hline $0-4$ anos & 111 & 29,1 \\
\hline 5-9 anos & 100 & 26,2 \\
\hline 10-14 anos & 44 & 11,5 \\
\hline $15-19$ anos & 36 & 9,4 \\
\hline 20-30 anos & 42 & 11 \\
\hline Mais de 30 anos & 23 & 6 \\
\hline
\end{tabular}


A Tabela 2 mostra a distribuição dos trabalhadores atendidos pelo Ambulatório em subgrupos conforme a atividade ocupacional e agente químico envolvido na exposição. Quase $60 \%$ dos atendimentos foram de agricultores rurais e agentes de vigilância ambiental (AVA). Os AVA são funcionários da Secretaria de Saúde do DF que realizam atividades de combate a vetores de doenças utilizando os agrotóxicos que são determinados pelo Ministério da Saúde. Entre as atividades de trabalho dos AVA estão a aplicação de larvicida durante as visitas domiciliares, aplicação de inseticidas por pulverização com aplicadores costais e pulverização de inseticidas com o carro fumacê. Nessa estão incluídos os guardas de endemias da antiga SUCAN (Superintendência de Campanhas de Saúde Pública) hoje FUNASA (Fundação Nacional de Saúde).

A terceira atividade ocupacional mais importante mostrada na Tabela 2 é de auxiliar de limpeza/diarista ( $9,4 \%$ dos atendimentos), que envolveu principalmente mulheres $(66,7 \%)$. Nenhuma mulher atendida pertencia aos grupos pintor/mecânico automotivo, técnico de metalurgia e pedreiro, refletindo a predominância de homens nessas atividades (Tabela 2).

A maioria dos casos atendidos no Ambulatório envolveu a exposição a agrotóxicos (63,0\% dos indivíduos), seguido de produtos químicos industriais (24,6\%; Tabela 2). Os auxiliares de limpeza/diarista estiveram expostos principalmente a saneantes (26 casos), com produtos contendo principalmente hipoclorito de sódio, soda cáustica e amoníaco.

A múltipla exposição ocupacional a produtos de várias classes esteve presente em 48 trabalhadores $(12,5 \%$ do total), principalmente produtos químicos industriais e metais $(77,0 \%)$, seguido por raticidas e agrotóxicos utilizados em campanhas de saúde pública (10,4\%). Em todos os casos de exposição a metais e raticidas, houve co-exposição a outro agente químico (Tabela 2). 
Tabela 2. Indivíduos atendidos, segundo grupo ocupacional e agente envolvido na exposição no Ambulatório de Toxicologia Ocupacional do CEREST/DF de 2009 a 2013.

\begin{tabular}{|c|c|c|c|c|c|c|c|}
\hline Grupo & $\begin{array}{l}\text { Total } \\
\text { N (\%) }\end{array}$ & $\begin{array}{c}\text { Homens } \\
\%\end{array}$ & $\begin{array}{l}\text { Agrotóxicos } \\
\qquad \mathrm{N}\end{array}$ & $\begin{array}{l}\text { PQI } \\
\text { N }\end{array}$ & $\begin{array}{c}\text { Metais } \\
\mathrm{N}\end{array}$ & $\begin{array}{c}\text { Saneantes } \\
\mathrm{N}\end{array}$ & $\begin{array}{c}\text { Raticidas } \\
\text { N }\end{array}$ \\
\hline Agricultor $^{1}$ & $\begin{array}{c}113 \\
(29,6)\end{array}$ & 92,9 & 113 & - & 1 & - & - \\
\hline $\begin{array}{l}\text { Agente de } \\
\text { vigilância } \\
\text { ambiental }^{2}\end{array}$ & $\begin{array}{c}108 \\
(28,3)\end{array}$ & 57,4 & 106 & - & - & - & 7 \\
\hline $\begin{array}{l}\text { Auxiliar de } \\
\text { limpeza/ } \\
\text { diarista }\end{array}$ & $\begin{array}{c}36 \\
(9,4)\end{array}$ & 33,3 & 5 & 2 & 2 & 26 & 1 \\
\hline $\begin{array}{l}\text { Pintor/mec. } \\
\text { automotivo }\end{array}$ & $\begin{array}{c}15 \\
(3,9)\end{array}$ & 100 & - & 15 & 13 & - & - \\
\hline $\begin{array}{l}\text { Técnico de } \\
\text { metalurgia }\end{array}$ & $\begin{array}{c}13 \\
(3,4)\end{array}$ & 100 & - & 8 & 8 & - & - \\
\hline $\begin{array}{l}\text { Servidor } \\
\text { público }^{3}\end{array}$ & $\begin{array}{c}10 \\
(2,6)\end{array}$ & 20 & 5 & 5 & 3 & - & - \\
\hline $\begin{array}{l}\text { Frentista de } \\
\text { posto }\end{array}$ & $\begin{array}{c}7 \\
(1,8)\end{array}$ & 57,1 & - & 7 & - & - & - \\
\hline $\begin{array}{l}\text { Técnico de } \\
\text { laboratório }\end{array}$ & $\begin{array}{c}7 \\
(1,8)\end{array}$ & 71,4 & 1 & 6 & 1 & - & - \\
\hline Pedreiro & $\begin{array}{c}6 \\
(1,6)\end{array}$ & 100 & - & 5 & 1 & - & - \\
\hline Outros $^{4}$ & $\begin{array}{c}67 \\
(17,5)\end{array}$ & 46,3 & 11 & 46 & 26 & - & 2 \\
\hline Total & $\begin{array}{c}382 \\
(100)\end{array}$ & $\begin{array}{c}255 \\
(66,7)\end{array}$ & $\begin{array}{c}241 \\
(63,1)\end{array}$ & $\begin{array}{c}94 \\
(24,6)\end{array}$ & $\begin{array}{c}56 \\
(14,6)\end{array}$ & $\begin{array}{c}26 \\
(6,8)\end{array}$ & $\begin{array}{c}10 \\
(2,6)\end{array}$ \\
\hline
\end{tabular}

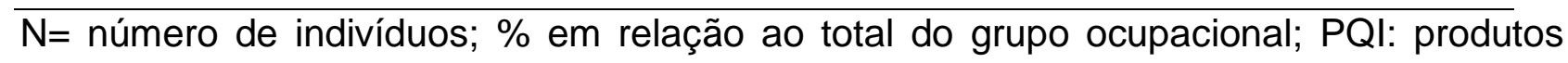
químicos industrias; 'inclui 2 tratoristas rurais e 1 técnico agrícola; 2inclui 8 motoristas da vigilância ambiental; ${ }^{3}$ intoxicados no ambiente de trabalho; ${ }^{4}$ inclui trabalhador de firma de desinsetização, caseiro, motorista de ônibus, garimpeiro, serigrafista, dentre outros. 
Entre os trabalhadores avaliados, as principais vias de exposição foram cutânea e respiratória (87,2\% dos casos). Ao avaliar a adesão dos trabalhadores ao equipamento de proteção individual (EPI), observou-se que $81,7 \%$ relataram não usar qualquer tipo de proteção $(73,0 \%$ entre os agentes de vigilância ambiental e $78,7 \%$ entre os agricultores). Entre os trabalhadores que usaram algum EPI ( $N=70)$, luva foi o equipamento mais utilizado, e $32,8 \%$ reportaram o uso de máscara e luva. Somente $1,4 \%$ relataram a utilização de EPI completo (bota, chapéu, avental ou roupa impermeável, luva, máscara e óculos).

Os $241(63,1 \%)$ indivíduos expostos a agrotóxicos estiveram envolvidos em atividades diversas, incluindo carga e descarga de produtos (motoristas e encarregados de depósito de inseticidas), preparo e aplicação de agrotóxicos (atividades agropecuárias, campanhas de saúde pública e desinsetizadores), comercialização de agrotóxicos, e manutenção de áreas verdes e jardins. Todos relataram exposição a mais de um produto agrotóxico, mas $23,6 \%$ deles não identificaram o grupo ou o nome do produto.

Entre os 184 casos com exposição a agrotóxicos com o grupo químico identificado, mais da metade (96 casos) teve o envolvimento de inseticidas organofosforados, principalmente o temefós por agentes de vigilância ambiental, e o metamidofós por agricultores/trabalhadores rurais (Tabela 3). Vinte e um casos envolveram os inseticidas piretroides (Tabela 3), dos quais 17 com deltametrina, sozinha (12) ou associada com glifosato (5), que esteve envolvido em outros 22 casos, sendo $19 \mathrm{com}$ trabalhadores rurais. O inseticida diflubenzuron esteve envolvido em 9 casos com agentes de vigilância (Tabela 3). Outros agrotóxicos incluem o inseticida clofenapir (5 casos) e o herbicida paraquat ( 3 casos), além de outros 15 agrotóxicos de várias classes.

Apesar de terem sido solicitados exames laboratoriais de rotina (sangue e urina), radiologia de tórax e ecografia do abdômen para todos os 382 indivíduos atendidos no Ambulatório, na grande maioria dos casos (93,7\%) pelo menos 1 exame solicitado não foi realizado, principalmente devido a deficiências do sistema de saúde em atender esta solicitação no prazo máximo de 90 dias depois da primeira consulta.

Dos 241 indivíduos expostos a agrotóxicos, 128 (53,1\%) foram submetidos a análise da colinesterase plasmática, dos quais 71 agricultores e 
51 agentes de vigilância ambiental, além de 6 outros indivíduos envolvidos em outras atividades. Dentre os trabalhadores que realizaram este exame, $68 \%$ apresentaram resultados que foram considerados alterados, com maior percentual de exames alterados entre os agricultores (Tabela 3).

Tabela 3. Principais agrotóxicos, atividades envolvidas e resultados do exame de butirilcolinesterase nos indivíduos expostos a estes agentes, nos casos atendidos no Ambulatório de Toxicologia Ocupacional do CEREST/DF de 2009 a 2013.

\begin{tabular}{cc}
\hline Agrotóxico & $\begin{array}{c}\text { Número de casos } \\
\text { (Ocupação principal) }\end{array}$ \\
\hline Temefós & 80 (79 agentes de vigilância) \\
Metamidofós & $(11$ agricultores $)$ \\
Piretroides & $21(15$ agricultores, 5 agentes de vigilância $)$ \\
Glifosato & $27(19$ agricultores $)$ \\
Diflubenzuron & 9 (agentes de vigilância) \\
\hline Butirilcolinesterase & Exames realizados (\% alterados) \\
Agricultor & $71(85,9)$ \\
Agente de vigilância ambiental & $51(43,1)$ \\
Outras atividades & $6(66,7)$ \\
\hline
\end{tabular}

Dos 382 indivíduos atendidos, 219 (57,3\%) foram considerados intoxicados pelo agente ao qual eles foram expostos, sendo 135 por agrotóxicos (Figura 1), correspondendo a $61,6 \%$ do total de intoxicados e $56,0 \%$ dos expostos a agrotóxicos. No total, 47 casos envolveram intoxicação com inseticidas organofosforados, $17 \mathrm{com}$ glifosato e $9 \mathrm{com}$ piretroides (inclui dois casos de exposição concomitante a deltametrina e glifosato; Figura 1). Os 74 trabalhadores rurais foram intoxicados principalmente com glifosato e metamidofós, mas $47,3 \%$ dos casos não tiveram o agente identificado (Figura 1). Os 48 agentes de vigilância ambiental se intoxicaram principalmente com 0 temefós 35 casos (Figura 1), dos quais 62,8\% apresentaram colinesterase plasmática alterada. Produtos químicos industriais estiveram envolvidos em 75 intoxicações, como agente único (principalmente solventes) ou associado a metais (Figura 1), principalmente chumbo. 


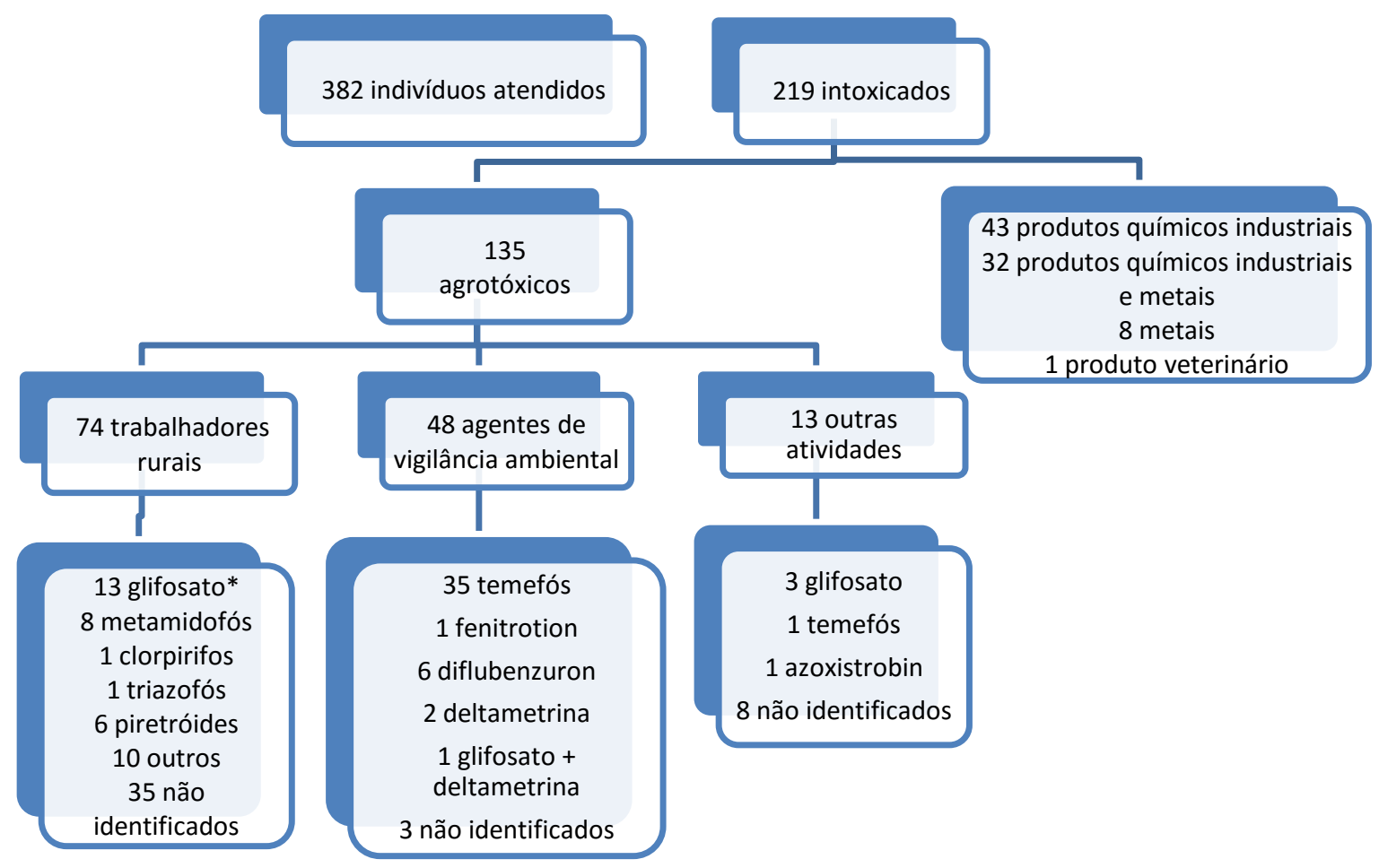

Figura 1. Casos de intoxicação ocupacional avaliados no Ambulatório de Toxicologia Ocupacional do CEREST/DF de 2009 a 2013. *1 caso de intoxicação com glifosato + deltametrina

Os agentes de vigilância e trabalhadores rurais intoxicados relataram sinais e sintomas diversos no momento da consulta, principalmente cefaleia, visão turva, prurido e náusea (Figura 2). Dispneia, tosse seca lacrimejamento e hiperemia ocular foram sintomas mais importantes entre os trabalhadores rurais (Figura 2). 


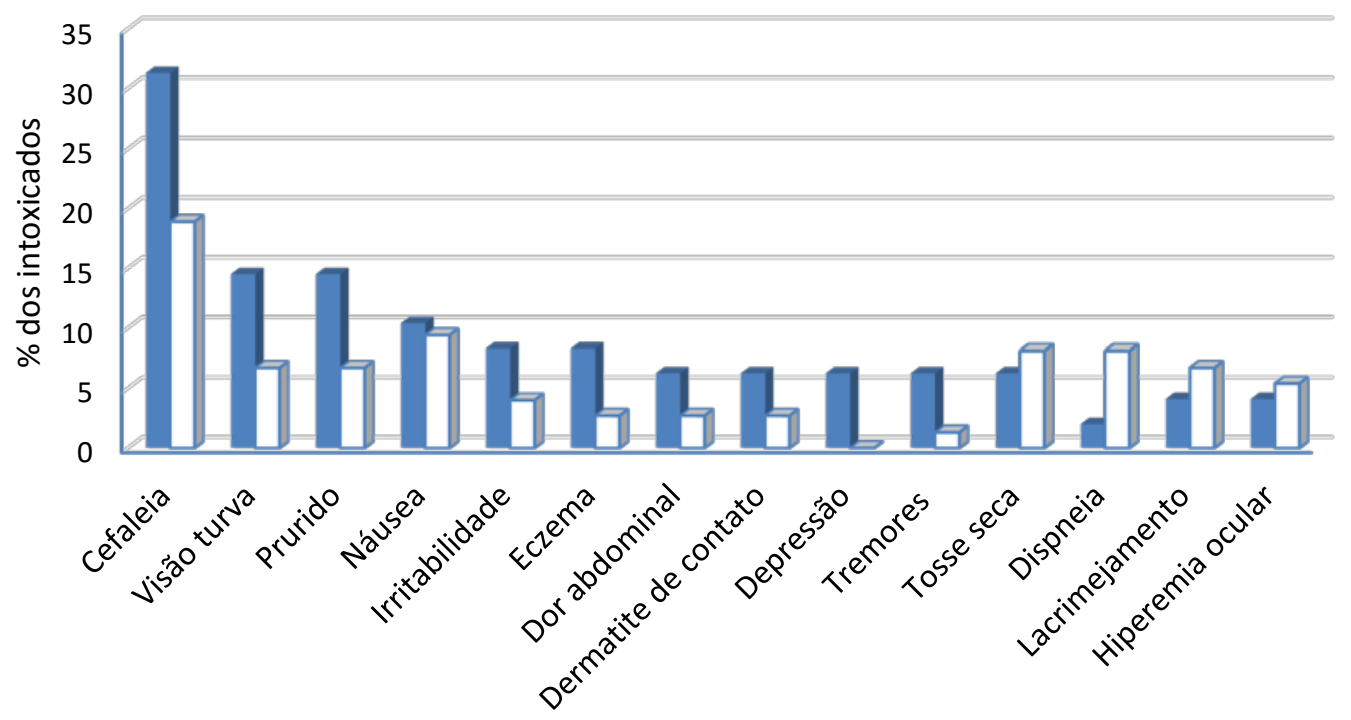

- Agente de vigilância ambiental , N=48 $\square$ Trabalhador rural, N=74

Figura 2. Principais sintomas relacionados à exposição aos agrotóxicos relatados por agentes de vigilância ambiental e trabalhadores rurais intoxicados atendidos no Ambulatório de Toxicologia Ocupacional do CEREST/DF de 2009 a 2013.

Dentre os 135 trabalhadores considerados intoxicados por agrotóxicos, constatou-se que as hemácias estavam alteradas em 9,5\% dos 115 resultados disponíveis, hemoglobina em 3,9\% (101 resultados), leucócitos em 4,5\% (115 resultados), e plaquetas alterada em 1 trabalhador (94 resultados). Dentre os 89 resultados reportados para ALT e AST, 4,4\% e 5,5\% estavam alterados, respectivamente, todos agentes de vigilância ambiental. Dos 109 pacientes com resultados de ecografia abdominal, 7 apresentaram resultados alterados, sendo 2 trabalhadores de saúde púbica e 2 trabalhadores rurais, indicando alterações hepáticas, confirmada por alterações de AST e ALT. Todos os 77 trabalhadores que realizaram $\mathrm{RX}$ de tórax apresentaram laudos normais.

Para os trabalhadores intoxicados foi preenchida a Comunicação de Acidente de Trabalho (CAT) para trabalhadores regidos pela CLT (Consolidação das leis do trabalho), ou fornecido laudo médico para o órgão de origem para servidores públicos visando à caracterização da relação de quadro clínico com a exposição ocupacional. A duração média dos afastamentos foi de 60 dias, com extremos entre 10 dias e 120 dias, conforme a necessidade de 
cada caso. Entre os trabalhadores com exames de colinesterase alterados, só houve retorno ao trabalho após normalização dos níveis enzimáticos. Quando necessário, os trabalhadores avaliados foram referenciados para as especialidades médicas dentro do sistema assistencial da Rede Pública de Saúde do DF para a investigação e tratamento das patologias específicas. Nenhum óbito ocorreu entre os pacientes atendidos no Ambulatório durante o período do estudo. Todos os casos de intoxicação foram notificados ao SINANDF.

\section{Discussão}

No período do estudo (2009-2013), o Ambulatório do CEREST-DF atendeu 382 novos pacientes, com média de 6,3 por mês, menor do que a média de atendimentos ocorrida entre abril de 2003 e julho 2005 (222 atendimentos, 8 por mês) (MAGALHÃES, 2005). A queda do número de indivíduos atendidos no Ambulatório desde 2005, observada no período do presente estudo, era esperada, já que ao longo dos anos o Ambulatório foi se firmando como referência de especialidade, atendendo apenas pacientes encaminhados da rede assistencial pública do DF. Até 2007/2008 os pacientes chegavam até o Ambulatório também por intimação da Gerência de Vigilância em Saúde do Trabalhador ao empregador, após vistoria em ambiente de trabalho com risco químico, e por demanda espontânea. Esses dois segmentos representaram $28,4 \%$ dos atendimentos realizados pelo Ambulatório entre 2003 e 2005 (MAGALHÃES, 2005). Outro fator foi da criação do Projeto VIGITOX pelo CEREST, onde os atendimentos são realizados pela equipe do ambulatório diretamente na área rural junto a unidade de Saúde da Família, com foco no agricultor rural. Estes atendimentos não estão incluídos no estudo, pois os prontuários não ficam sob a guarda do CEREST, e sim nas unidades do Saúde da Família.

Quase $60 \%$ dos atendimentos foram de agricultores e agentes de vigilância ambiental, expostos predominantemente a agrotóxicos. Este perfil é diferente do observado no estudo anterior (MAGALHÃES, 2005), onde cerca de $71 \%$ dos atendidos no Ambulatório eram de agentes de vigilância, e apenas $8,6 \%$ eram de agricultores. Naquele período, as mulheres foram a maioria dos atendidos (53\%), principalmente entre os agentes de vigilância $(67,5 \%)$, 
enquanto no estudo atual predominaram os homens. O maior percentual de mulheres atendida no período de 2003-2005 se deve principalmente ao perfil dos agentes de vigilância naquele período $(67,5 \%$ mulheres) (MAGALHÃES, 2005) comparado com o investigado no presente estudo (42,6\% mulheres).

A baixa escolaridade dos agricultores atendidos pelo Ambulatório no presente estudo, com quase a metade possuindo apenas o ensino fundamental, também foi relatado no estudo anterior (MAGALHÃES, 2005) e em estudos de campo com trabalhadores rurais no Brasil (PASIANI et al., 2012; SOARES et al., 2005). No Núcleo Rural Taquara (DF) (PASIANI et al., 2012), cerca da metade dos trabalhadores tinha o ensino fundamental incompleto e $6 \%$ não tinha nenhuma escolaridade, situação que representou $17,6 \%$ dos agricultores de Culturama (Mato Grosso do Sul) (RECENA et al., 2006). Estudo recente realizado no sul do País, mostrou que $83 \%$ dos 869 agricultores tinha apenas o ensino fundamental (CAMPOS et al., 2016). Esta baixa escolaridade pode comprometer a leitura e compreensão dos rótulos de agrotóxicos e as orientações de uso seguro, e aumentar as chances de intoxicação (WAICHMAN et al., 2007).

O perfil educacional dos trabalhadores rurais no Brasil é similar ao encontrado em outros países em desenvolvimento, como a China (ZHANG, 2011), mas bastante diverso daquele dos agricultores nos Estados Unidos, onde $90 \%$ dos 57,310 indivíduos avaliados tinham pelo menos 12 anos de estudo (BONNER et a., 2016). O percentual de pessoas de 25 anos ou mais sem instrução ou com o fundamental incompleto na área rural no Brasil tem diminuído ao longo dos anos, caindo de $90,3 \%$ para $79,6 \%$ de 2000 para 2010 (IBGE, 2010), e espera-se que o perfil do trabalhador neste aspecto mude no futuro.

Por outro lado, mais de $80 \%$ dos agentes de vigilância ambiental atendidos no Ambulatório tinham pelo menos o ensino médio, grau de escolaridade mínimo necessário para o concurso público nesta ocupação. Esses agentes são trabalhadores de campanhas de saúde pública da Secretaria de Estado de Saúde do DF nas ações de controle de vetores de doença e guardas de endemias da Fundação Nacional de Saúde (FUNASA).

A exposição a saneantes foi exclusiva dos auxiliares de limpeza/diarista, e incluiu produtos contendo hipoclorito de sódio. Esse agente também foi o 
principal envolvido em intoxicações com saneantes clandestinos em Maringá (PR) (SANTOS, 2011). As intoxicações ocupacionais por domissanitários representaram $6,6 \%$ das intoxicações ocupacionais registradas pelo SINITOX de 2009 a 2013 (FIOCRUZ, 2016). Em estudo realizado por Correa (CORRÊA, 2005) para avaliar a exposição de 159 empregadas domésticas a saneantes, $39,0 \%$ referiram alterações de saúde durante sua manipulação e $16,1 \%$ foram efetivamente afastadas por motivo de doença relacionada com a exposição a esses produtos.

$O$ uso de EPI tem como objetivo minimizar o risco e diminuir a ocorrência de intoxicações e outros acidentes de trabalho, e o Capítulo V da Consolidação das Leis do Trabalho (CLT; Lei 6514 de dezembro de 1977) estabelece que estes equipamentos devem ser fornecidos pelo empregador gratuitamente ao trabalhador. No presente estudo, $81,7 \%$ dos indivíduos atendidos relataram não usar qualquer EPI durante a atividade ocupacional, sendo que a não adesão atingiu $73 \%$ entre os agentes de vigilância. Situação mais crítica foi observada no estudo anterior conduzido no Ambulatório, onde 147 dos 157 agentes receberam o EPI, mas 93,9\% deles relataram não os usarem, principalmente por serem incômodos (MAGALHÃES, 2005).

O uso de EPI no campo por trabalhadores rurais é mais necessário em pequenas propriedades, onde os agricultores usam equipamentos de baixa tecnologia na aplicação destes insumos, como aplicadores costais e tratores de cabine aberta (PASIANI et al., 2012; RECENA et al., 2006). Diferentes taxas de adesão a estes equipamentos têm sido reportadas nos estudos conduzidos no País. Enquanto que $78,7 \%$ dos atendidos no Ambulatório no presente estudo não utilizavam quaisquer $\mathrm{EPI}$, alta adesão $(78,6 \%)$ foi observada entre os 370 trabalhadores expostos a agrotóxicos atendidos em 2006 e 2007 no ambulatório de toxicologia do Hospital das Clínicas da UNICAMP (FIGUEIREDO et al, 2011). Pasiani et al., (2012) mostraram que $44,4 \%$ dos agricultores do DF declararam usar EPI completo (bota, chapéu, luvas, máscara e roupa impermeável) pelo menos em algumas ocasiões, e somente $7,2 \%$ deles nunca usava esses equipamentos. Por outro lado, mais de $80 \%$ dos agricultores do Mato Grosso do Sul afirmaram não usar EPI (RECENA et al., 2006), embora conhecessem esses equipamentos e considerassem que deveriam usá-los (RECENA; CALDAS, 2008). As principais causas referidas 
pelos agricultores nesse estudo incluem o desconforto e o próprio "desleixo" (FIGUEIREDO et al., 2011). O não uso regular do EPI também foi identificado por $70 \%$ dos trabalhadores agrícolas avaliados em Nova Friburgo (RJ) (ARAÚJO et al., 2007) e por $40 \%$ dos agricultores paranaenses (NERILO, 2014). Em Bento Gonçalves, mais de $90 \%$ dos fruticultores familiares declararam usar EPI (FARIA et al., 2009). É provável que temperaturas mais quentes, encontradas em algumas regiões do País, desfavoreçam o uso de EPI pelos trabalhadores pelo desconforto que podem causar, principalmente relacionado ao uso de botas e roupas impermeáveis.

Todos os trabalhadores expostos a agrotóxicos avaliados no presente estudo relataram exposição a múltiplos compostos deste grupo, mesmo que somente uma parte deles soube identificar os produtos envolvidos. A exposição concomitante a vários agrotóxicos é comum no campo e tem sido relatada por outros autores no Brasil (ARAÚJO et al., 2007; CAMPOS et al., 2016; FIGUEIREDO et al., 2011) e em outros países (KACHURI et al., 2013). Em Nova Friburgo (RJ) (ARAÚJO et al., 2007), os agricultores relataram o uso concomitante de organofosforados, piretroides, herbicidas e fungicidas como uma prática comum. A múltipla exposição a agrotóxicos tem sido relacionada com o aumento da incidência de várias doenças, inclusive o câncer (KACHURI et al., 2013).

$\mathrm{Na}$ avaliação de um grupo de indivíduos expostos a agrotóxicos e potencialmente intoxicados, apoia-se sobre o mesmo tripé: histórico de exposição, avaliação clínica e diagnóstico laboratorial. No presente estudo, mais da metade dos trabalhadores $(57,3 \%)$ foram considerados intoxicados segundo os critérios clínicos e laboratoriais. Entre os indivíduos expostos a agrotóxicos, este percentual foi de $56 \%$, maior que o encontrado no estudo anterior com os dados do Ambulatório de 2003 a 2005 (22,9\%), baseado em critérios similares, mas envolvendo predominantemente agentes de vigilância ambiental (MAGALHÃES, 2005). Por exemplo, um trabalhador que aplicou agrotóxicos sem EPI e evoluiu com cefaleia intensa, dermatite de contato, prurido e vermelhidão ocular e tosse seca, mas apresentou exame de colinesterase normal foi considerado intoxicado baseado na clínica. Em outro caso, trabalhador com exposição repetida a agrotóxicos referia cefaleia leve e dosagem de colinesterase alterada foi considerado intoxicado baseado no 
exame laboratorial. No estudo com dados ambulatoriais de agricultores expostos a agrotóxicos por no mínimo um ano realizado por Figueiredo et al. (2011), foram estabelecidos dois diagnósticos: "exposição a longo prazo" para aqueles que não apresentaram alteração no exame físico ou laboratorial, e "provável efeito à saúde", para trabalhadores cujo exame físico ou laboratorial apresentou alterações. Cerca de $21 \%$ dos 370 trabalhadores avaliados (77) foram diagnosticados como tendo provável efeito à saúde, bem menor que o encontrado neste estudo para esta população (65.5\%). Os inseticidas organofosforados estiveram envolvidos na maioria dos casos com agente identificado, principalmente o temefós, envolvido em 35 casos de intoxicação de agentes de vigilância ambiental. Esse larvicida foi o único utilizado no combate a vetores no Distrito Federal até novembro de 2011, quando foi substituído pelo diflubenzuron (OPAS, 2016), envolvido em 6 casos de intoxicações com agentes de vigilância. Em 2014, o diflubenzuron foi substituído pelo pyriproxyfen, recomendado e considerado seguro pela Organização Mundial de Saúde (OPAS, 2016).

O organofosforado metamidofós esteve envolvido em 12 casos, todos com agricultores/trabalhadores rurais, dos quais 8 foram considerados intoxicação. O metamidofós teve seu registro cancelado no Brasil em 2011, quando a maioria dos seus produtos no Brasil era classificado como extrema ou altamente tóxicos (COSTA, 2013).

Os organofosforados são inseticidas que inibem a enzima acetilcolinesterase, levando ao aumento do neurotransmissor acetilcolina nos sítios colinérgicos, causando hiperestimulação da transmissão colinérgica póssináptica (COSTA,2013). As manifestações clínicas da exposição podem se iniciar em alguns minutos a algumas horas, com miose, sudorese, sialorréia, bradicardia e hipersecreção brônquica, resultado da ação nos receptores muscarínicos. O aumento da atividade nos receptores nicotínicos, menos comuns, incluem fasciculações, hipertensão arterial, arritmias cardíacas e insuficiência respiratória. Manifestações do sistema nervoso central incluem ansiedade, cefaleia, convulsões e coma (COSTA,2013).

Dentre os 47 intoxicados com inseticidas organofosforados identificados no presente estudo, $71,7 \%$ não reportaram o uso do EPI e $47,8 \%$ referiram pelo menos um sintoma neurológico, principalmente cefaleia. Adicionalmente, 
mereceram destaque a cefaleia a visão turva e o prurido. A irritação da pele(dermatite de contato) é um sintoma local que, em menor ou maior grau, pode ser causado por quase todos os agrotóxicos. Os sintomas encontrados foram semelhantes aos citados por Delgado e Paumgartten (2004) no trabalho realizado em Pati do Alferes, Rio de Janeiro.

O mecanismo de neurotoxicidade dos piretroides, envolvidos em 9 casos de intoxicação, envolve a inibição dos canais de sódio, cálcio e cloreto voltagem dependentes, podendo prejudicar a atividade motora de mamíferos (COSTA,2013). Exposição a piretroides é comum, e causa principalmente reações alérgicas, mas intoxicação ocupacional grave é rara. A exposição crônica pode causar dermatite alérgica, alopecia, disestesia facial, alterações de personalidade, sensitivo motora, polineuropatia, déficits de memória e concentração (BRADBERRY et al., 2005). Os agricultores de Nova Friburgo $(R J)$ expostos a piretroides reportaram rubor facial, lacrimejamento, irritação ocular e dermatite de contato (ARAÚJO et al., 2007). No presente estudo, nenhum dos trabalhadores intoxicados com piretroides apresentou efeitos dermatológicos, mas 6 apresentaram efeitos neurológicos. Apenas três usavam algum EPI durante o trabalho.

O glifosato esteve envolvido em 22 casos, principalmente com trabalhadores rurais, com 17 intoxicações confirmadas. O glifosato é um herbicida sistêmico de amplo espectro, e o mais utilizado no mundo, inclusive no Brasil (IBAMA, 2016). O glifosato foi classificado recentemente pela Agência Internacional de Pesquisa de Câncer da OMS (IARC) como provável cancerígeno para os seres humanos (Grupo 2A) (GUYTON et al., 2015), o que tem levado vários países a reavaliarem seu uso, inclusive o Brasil (BRASIL, 2015).A toxicidade dos produtos à base de glifosato está provavelmente ligada aos surfactantes presentes na formulação (MESNAGE et al., 2015). Apenas 4 dos indivíduos intoxicados com este produto usavam algum EPI durante 0 trabalho, e seis apresentaram sintomas neurológicos diversos.

A maioria dos trabalhadores expostos a agrotóxicos e submetidos ao exame de colinesterase plasmática, tiveram resultados alterados de acordo com os critérios estabelecidos (abaixo da faixa inferior de normalidade estabelecida pelo fabricante do kit de análise). $\mathrm{Na}$ avaliação dos trabalhadores rurais atendidos no ambulatório do Hospital das Clínicas da UNICAMP 
alterações laboratoriais foram encontradas em $29,7 \%$ dos pacientes, dos quais $37,2 \%$ apresentavam alteração no exame da colinesterase, sendo $78 \%$ com alteração na colinesterase plasmática e $22 \%$ na colinesterase eritrocitária (FIGUEIREDO et al. 2011). O critério estabelecido para indicar alteração não está claro no estudo.

Vários estudos conduzidos no campo avaliaram os níveis enzimáticos dos agricultores rurais. Pasiani et al. (2012) mostraram que os níveis de colinesterase plasmática encontrados entre os 64 trabalhadores da agricultura familiar do Distrito Federal foram significantemente menores durante o período de exposição no campo comparado com o período de não exposição e ao grupo controle. Porém, somente um dos 60 agricultores avaliados teve inibição enzimática maior que 50\% comparado ao período de não exposição, situação que pode indicar doença e estar associado a um efeito ou uma disfunção do sistema, segundo a NR-7 (BRASIL, 2013).

Adicionalmente, familiares dos agricultores, não diretamente envolvidos na aplicação de agrotóxicos, também apresentaram atividade enzimática deprimida comparado ao controle (PASIANI et al., 2012). No estudo conduzido por Araújo et al. (2007), 20\% dos trabalhadores de Nova Friburgo (RJ) tiveram os níveis de colinesterase plasmática reduzido (10ํำ percentil em relação à curva de distribuição de atividade enzimática do grupo controle). Nenhum dos 173 hortifruticultores do Paraná avaliados por Nerilo et al. (2014) tiveram atividade da colinesterase plasmática inibida mais de 50\% em relação ao controle. A comparação dos resultados encontrados no presente estudo com outros conduzidos no País é limitada devido aos diferentes critérios utilizados para definir o nível de atividade enzimática ou de inibição relevante.

A maioria dos outros estudos avaliou também os níveis de acetilcolinesterase, ou colinesterase eritrocitária (CORRÊA, 2005; FIGUEIREDO et al., 2011; NERILO, 2014; PASIANI et al., 2012), exame que não foi realizado nos pacientes atendidos no Ambulatório do CEREST-DF. Esse indicador biológico está diretamente relacionado ao efeito tóxico de exposição a organofosforados e carbamatos (COSTA, 2013; NERILO, 2014; PASIANI et al., 2012), está previsto na legislação brasileira (BRASIL, 1978) e deve ser incluído nas avaliações futuras dos trabalhadores atendidos pelo Ambulatório para auxiliar na identificação de casos de intoxicação. 
A Política Nacional de Saúde do Trabalhador e da Trabalhadora (BRASIL, 2012) estabelece que "cabem aos CEREST's ações diretas de vigilância, somente em caráter complementar ou suplementar para situações em que o Município não tenha condições técnicas e operacionais, ou para aquelas definidas como de maior complexidade". Costa et al. (2013) questionam a capacidade dos CEREST's de desenvolver competência própria para cumprir seu papel no âmbito da rede, já que dependem de outras instâncias que não têm a prevenção ao risco ocupacional como foco de atuação. Segundo dados da RENAST, existem atualmente 220 CEREST's instalados no País, regionais e estaduais (RENAST, 2016), porém não está claro quantos têm ambulatórios instalados e em atividade, e como estes funcionam. O CEREST de Ribeirão Preto (SP), por exemplo, lista na sua página internet sete ambulatórios de saúde do trabalhador, dos quais seis em unidades básicas ou centros de saúde (BRASIL, 2016). A avaliação da atuação do Ambulatório do CEREST-DF em relação a ambulatórios de outros Centros no País é bastante limitada. SILVA et al. (2006) avaliaram os dados de 218 prontuários de pacientes atendidos de janeiro a setembro de 2004 no CEREST/Jequié-BA, envolvidos principalmente com a atividade industrial.

Este estudo tem limitações que devem ser ressaltadas. A primeira delas é relacionada ao número de atendimentos realizados no Ambulatório, que pode não refletir o número de trabalhadores em situação de risco devido à exposição a produtos químicos no Distrito Federal. Muitos desses trabalhadores não procuram a rede pública de saúde e quando o fazem, os sintomas relatados podem não ser identificados pelo profissional como relacionado à atividade ocupacional. Adicionalmente, a maioria dos profissionais de saúde não questiona sobre a atividade exercida pelo paciente durante a consulta, não formando hipótese de nexo causal do adoecimento em questão com o trabalho exercido, portanto não ocorrendo o encaminhamento ao Ambulatório.

Outra limitação se deve ao desconhecimento do próprio trabalhador quanto à qual produto químico ele está exposto, o que pode dificultar 0 diagnóstico. Uma limitação do estudo que comprometeu de maneira importante a avaliação dos casos foi a incompletude dos dados no prontuário, principalmente relacionado aos exames laboratoriais. Adicionalmente, o teste de atividade da colinesterase utilizado atualmente pelo CEREST-DF e sua 
interpretação devem ser reavaliados, pois não refletem o conhecimento científico do tema, e nem atende a legislação brasileira, explicitada na NR-7.

\section{Conclusão}

O perfil da população atendida no ambulatório de Toxicologia Ocupacional do CEREST no período do estudo foi de homens, predominantemente de 30-39 anos, que não utilizavam EPI. A maioria dos atendidos foi diagnosticado como intoxicados, principalmente por agrotóxicos.

Este estudo é relevante devido à escassez de dados ambulatoriais de pacientes expostos ocupacionalmente a produtos químicos no País, principalmente relacionados aos agentes de vigilância ambiental. Espera-se que as limitações identificadas no estudo, principalmente com relação a incompletude dos dados laboratoriais nos prontuários dos pacientes, possam auxiliar os agentes envolvidos, incluindo os gestores, a aprimorar os procedimentos do CEREST-DF para melhor atender a população ocupacional no DF. 


\section{Exogenous intoxications in the Federal District of Brazil - data from the Poison Information Center and the Disease Notification Information System}

\section{Abstract}

Exogenous intoxication is a worldwide public health problem that involves individuals of all age ranges in a wide range of chemicals. In this study, exogenous intoxication cases that occurred in the Federal District from 2009 to 2013 were investigated using data from the Poison Information Center (PIC-DF) and the Disease Notification Information System (SINAN-DF). A total of 3622 cases were reported to PIC-DF and 5702 cases were reported SINAN-DF during the period of the study. Most of the cases occurred with women, and while most of the cases reported to PIC-DF occurred with children up to 9 years old (53\%), in the SINAN-DF, 53\% of the cases involved individuals aging 15 to 49 years. Accidental intoxication was involved in over $66,7 \%$ of the cases in PIC-DF, and accounted for $48 \%$ of the cases in SINAN. Medicine accounted for over $40 \%$ of the cases in both systems, mainly involving clonazepam and other benzodiazepines. Others agents involved included cleaning products $(16,3 \%$ in PIC-DF) and drugs of abuse (12.2\% in SINAN-DF), rodenticides (about 9-10\%, including the illegal chumbinho), industrial chemicals (10.5\% in PIC-DF) and plants (6.1\% in PIC-DF). Pesticides were the most lethal agents involved in the intoxication cases (3.4\% of the 263 cases in PIC-DF). Although PIC-DF clearly underestimate the number of intoxications that occurred in the Federal District during the period, both systems were important to properly describe the epidemiology of intoxication cases within the population.

Keywords: exogenous intoxication, Federal District, poisoning information center, SINAN 


\section{Introduction}

The massive expansion of the availability and use of chemicals during the past decades, including pharmaceuticals, has increased the concern over the human exposure worldwide, representing an important public health issue. Exogenous intoxication is one of the main 13 causes of fatal deaths among adolescents 15 to 19 years, and accidental poison death rates per 100,000 children and adolescents aged 0 to 17 years was estimated to be 1.8 globally, ranging from 0.5 in high-income countries to 2 in low and middle-income countries (WHO, 2008). An estimated 804000 suicide deaths occurred worldwide in 2012, with pesticides involved in about one third of all suicides globally (WHO, 2014).

A major source of intoxication data in any country are the intoxication information centers (PICs), which have the main function of providing information and advice concerning the diagnosis, prognosis, treatment, and prevention of intoxication, on the toxicity of chemicals and other agents and the risks they pose to human and animals (IPCS, 1997). The National Poison Data System of the United States (NPDS) compiles data from PICs since 1982; in 2014 over 2 million human exposure cases were reported in the country, corresponding to 6.7 exposures per 1000 individuals (MOWRY et al., 2015). In Brazil, the National Toxicological Information System (SINITOX) started its activities in 1985, with 102,822 human intoxication cases reported to the system in 2012 (FIOCRUZ, 2016), an incidence of 0.52 cases per 1000 individuals. Most likely this incidence is highly underestimated, as only 15 of the 34 PICs provided data to the system in 2012.

The Disease Notification Information System (SINAN) coordinated by the Brazilian Ministry of Health, collects morbidity information from the public and private health system of about $70 \%$ of the Brazilian states and the Federal District (SINAN, 2005). As the PIC and the SINAN have different objectives and mechanisms of data collection, one intoxication event might not be reported to both systems and the data collected may vary substantially among them. This lack of a sound unified data makes it difficult to assess the real extent of the exogenous intoxication problem in Brazil. A detailed investigation of the data from the different sources can provide a more realistic intoxication scenario in the country, indicate potential sub-notification sources, provide information to 
improve data collection and actions that could promote and prevent these events and optimize the costs invested in the actions. It was estimated that in USA, for each 1 US\$ spent in PIC can save almost US\$8 on medical spending (GALVÃO et al., 2012).

This study aimed at investigating the human exogenous intoxication cases that occurred in the Federal District region, using data from the Poison Information Center (PIC-DF) and the Disease Notification Information System (SINAN-DF) from January $1^{\text {st }} 2009$ to December $31^{\text {st }} 2013$.

\section{Methods}

This is a retrospective and descriptive study related to exogenous intoxication cases reported by the health system of the Federal District to the PIC-DF and SINAN during the period of 2009 to 2013.

The PIC-DF, which is part of the Health Department of the Federal District, started its activities in July 2003, responding to calls related to human and animals exposure to chemical substances, plants, venomous and nonvenomous animals. The calls are made by health professionals from public and private clinics and hospitals primarily from the Federal District, and also from Brazilian states. Additionally, the PIC-DF responds to information calls from the community, supplying basic care information, when necessary. The calls are managed by medical doctors, pharmacists and nurses who have received specialized training to assess and monitor poison cases. The data collected are entered in an electronic system, from where the information provided in this study were collected. In this system, even if more than one agent is involved in the intoxication/intoxication case, in most cases, only the most relevant was included in the electronic system. Only the PIC-DF cases that occurred and/or were treated in the Federal District were considered in this study.

The Disease Notification Information System (SINAN) is part of the Brazilian Ministry of Health and has the objective of collecting and processing disease data in the country, providing information on diseases, injuries and public health events, including exogenous intoxication, notified by public and private health systems in all Brazilian territory. The data is reported to the SINAN NET online/DATASUS system, and compiled by the health department of the 27 Brazilian states and the Federal District, and in some cases, by the 
municipalities. The SINAN data related to the cases that were reported by the hospitals/clinics of the Federal District were provided by the Health Department of the Federal District, and are referred in this study as SINAN-DF.

Both databases were checked for inconsistencies, such as classifying a medicine as a pesticide or vice-versa or imputing the circumstance of suicide attempt to a child less than 5 years old. This study was approved by the Ethical Committee of the Foundation for Research and Education of the Federal District (FEPECS), maintaining the anonymity of the data (Annex 1).

\section{Results}

Intoxication data

During the period of 2009 to $2013,12,303$ calls were made to the PIC-DF (Figure 1), mainly from health professionals (89.7\%), especially medical doctors (81.2\%); $37 \%$ occurred between $6 \mathrm{pm}$ and mid-night. About $42 \%$ of the calls $(10,169)$ were related to human exposure, but the majority $(56.2 \%)$ were calls asking for information related to a variety of agents. Most of the human exposure cases (55.8\%) were confirmed as intoxication case, from which about $75 \%$ received medical care in the Federal District (Figure 1). From these cases, 3,622 were exogenous intoxications (chemicals or plants) and will be the focus of investigation in this study. Other agents include venomous animals (558; $46 \%$ scorpions), non-venomous animals and bacteria food intoxication (Figure 1).

A total of 5,702 exogenous intoxication cases were reported to the SINAN-DF, with the number of cases reported increasing in both systems during the period of study, but mainly after 2010 in the SINAN-DF (Figure 2). 


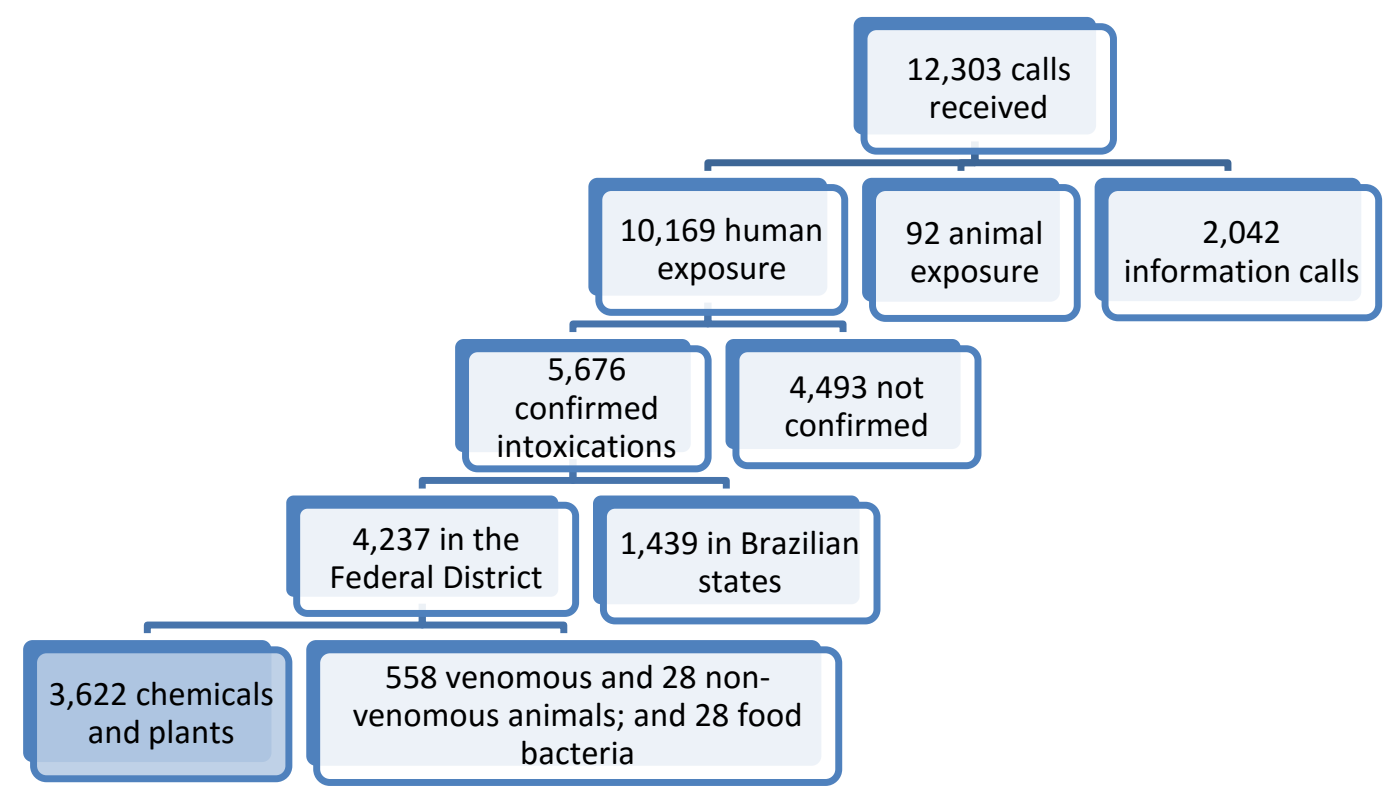

Figure 1. Summary of the activities performed by the Poison Information Center of the Federal District (PIC-DF) during the period of 2009 to 2013.

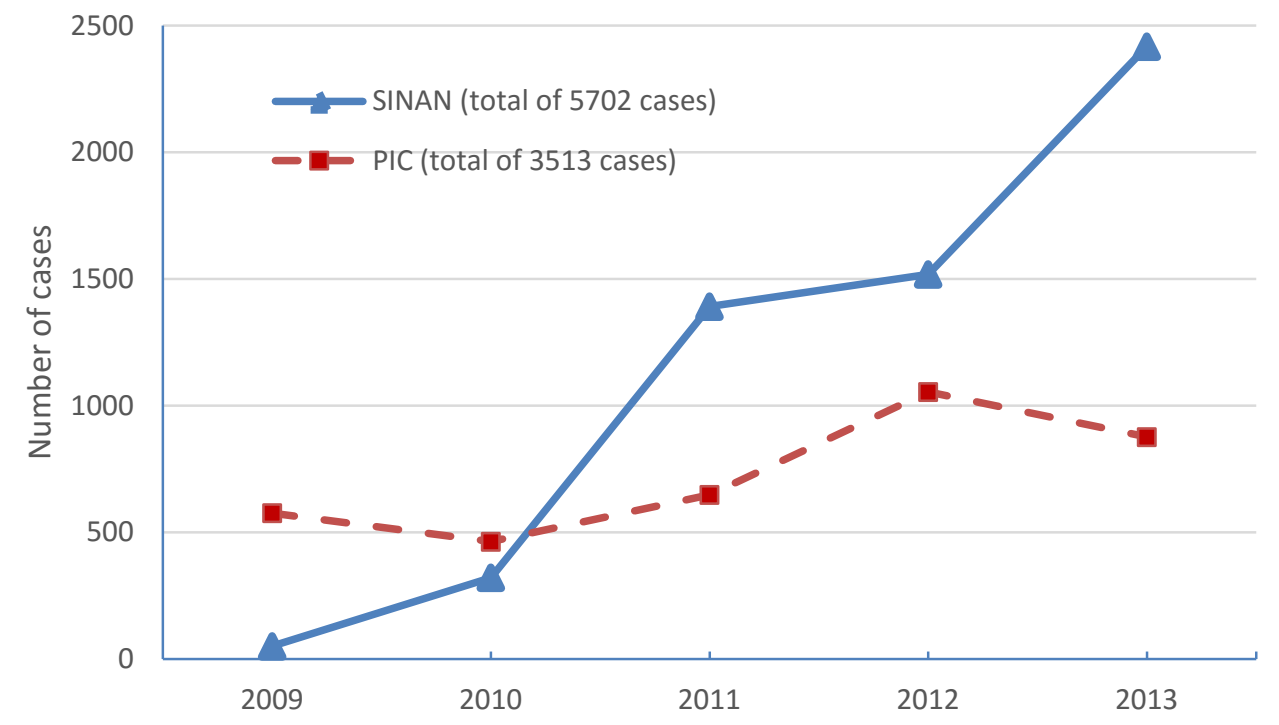

Figure 2. Poisoning cases reported to SINAN-DF and PIC-DF during the period of 2009 to 2013. 
Figures 3 to 4 show the profile of the cases in both systems. As the number of cases with missing data is high, mainly in the SINAN, the results (in\%) presented in the figures, tables and in the text are given in relation to the cases where each information was provided (known cases). In the SINAN-DF, missing data is mainly related to the circumstance of the event $(29.2 \%)$, outcome of the event $(51.8 \%)$, chemical or plant involved (17.7\%), exposure route $(12.6 \%)$ and agent involved (10\%). In the PIC-DF, the highest rate of missing data referred to the agent involved (4\%).

Ingestion was the main route of intoxication cases reported to the SINAN-DF and PIC-DF, accounting for $87.5 \%$ and $88.6 \%$ of the cases, respectively, followed by inhalation/nasal $(9.0 \%$ and $6.8 \%)$, and dermal contact (3.0 and 2.4\%). In both systems, most of the intoxication cases involved women (54.9\% in the SINAN-DF and $51.4 \%$ in the PIC-DF).

Accidental intoxication was the circumstance most involved in the intoxications, accounting for $64.5 \%$ of the PIC-DF cases and for $48 \%$ of the SINAN-DF cases with known circumstances (Figure 3A). In absolute numbers, more accidental intoxications were also reported to the PIC-DF compared to the SINAN-DF (2242 and 1786, respectively). Suicide attempt was the second circumstance most involved in the cases, accounting for $34.4 \%$ in the SINANDF (Figure 3A). Occupational exposure was only reported to the PIC-DF (88 cases).

Medicines were the agent most involved in the intoxications (45.8-48.1\% of the known cases), followed by household cleaning products (16.2\% by the PIC-DF) or drugs of abuse (13.2\% in the SINAN-DF) (Figure 3B). Rodenticides and pesticides accounted for 16.5 and $15.1 \%$ in the SINAN-DF and PIC-DF, respectively. Furthermore, the proportion of cases involving industrial chemicals and plants were higher in the PIC data.

The distribution of the individual's age involved in the cases varied among the systems (Figure $3 \mathrm{C}$ ). Although the number of cases involving children up to 4 years old in both systems was similar (1639 in the PIC-DF and 1667 in the SINAN-DF), they were more important in the PIC data (Figure 3C). About $35 \%$ of SINAN-DF cases occurred with individuals from 20 to 39 years old, while this age range accounted for $21.5 \%$ of the cases in the PIC-DF (Figure 3C). 

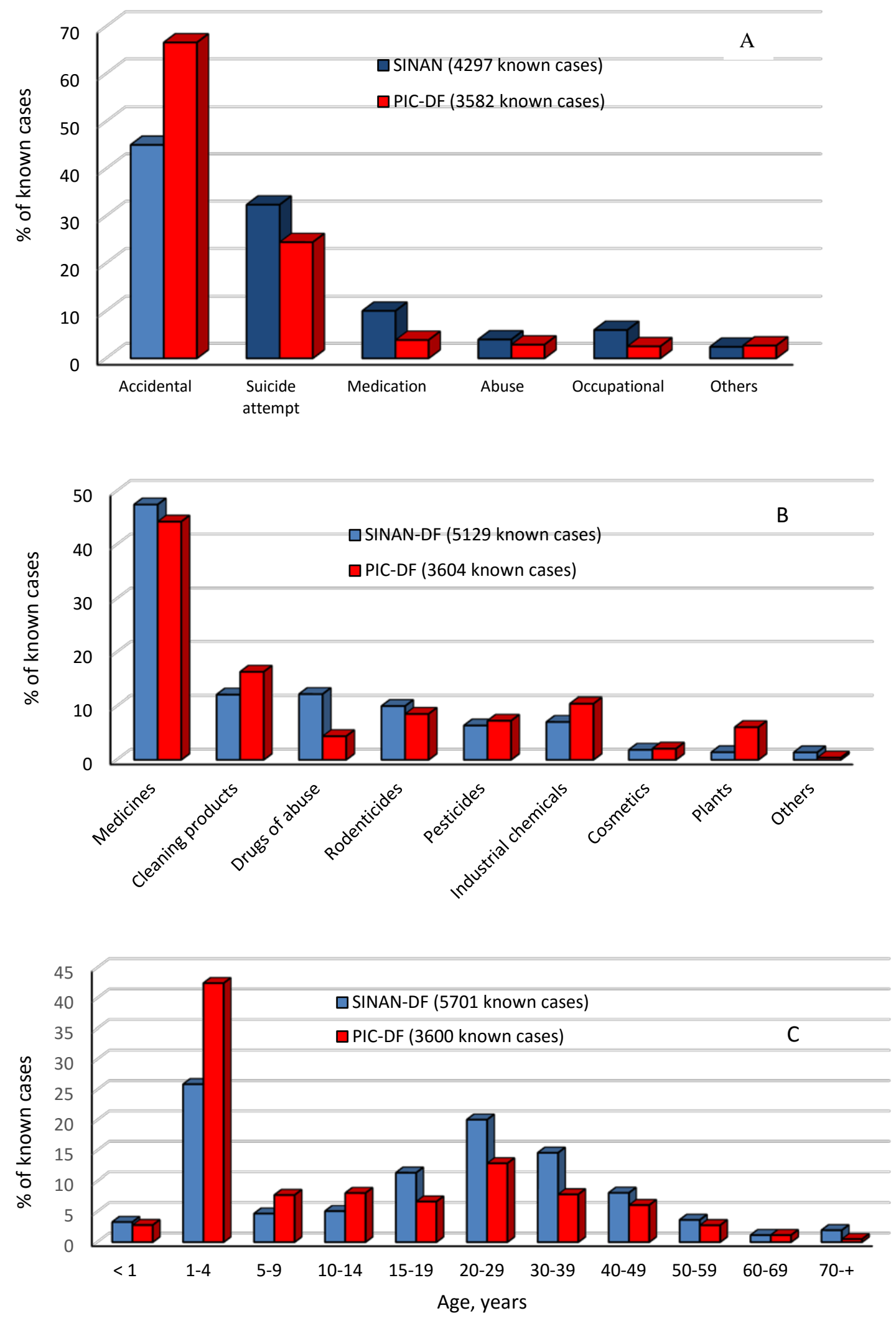

Figure 3. Human poisoning cases according to the circumstance $(A)$, the agent involved (B) and the age of the patient (C). Medication includes self-medication, 
administration error, prescription error and therapeutic use reported to SINANDF and PIC-DF from 2009 to 2013.

Although the percentage of known cases due to suicide attempt is different, the profile of the individuals and agents involved was similar in the systems. About $70 \%$ of the cases involved women, $66-67 \%$ involved individuals from 20 to 40 years old and 6.2 to $6.5 \%$ from 10 to 14 years. Medicines were involved in most of these cases (56.6 and 66.5\% in the PIC-DF and SINAN-DF, respectively), followed by pesticides/rodenticides (31.2 and 24.9\%, respectively).

\section{Medicines}

A total of 1596 cases reported to the PIC-DF involved medicines, mainly under accidental circumstances (60\%, from which $68.5 \%$ involving children up to 4 years) and suicide attempt (30.1\%, from which $67.2 \%$ involving individuals aged 20 to 49 years). From the 2436 medicine cases from the SINAN-DF, the circumstance was known in 1927 cases, from which $47.7 \%$ were accidental and $40.5 \%$ suicide attempts.

Figure 4 shows the main medicine drugs involved in the cases reported to the PIC-DF and SINAN-DF. In about $10 \%$ of the SINAN-DF cases, the drug was not reported, while this represented $1 \%$ in the PIC-DF. In both databases, clonazepam and paracetamol were the drugs most reported, although proportionally, clonazepam was more reported in the SINAN-DF cases $(16 \%$ of the known cases), as well as diazepam, fluoxetine, ibuprofen, amoxicillin and diclofenac (proportionally, at least two times more than PIC-DF). Naphazoline and cyproheptadine intoxications were more relevant in the PIC-DF, as they occur mostly with children. One characteristic of the SINAN-DF data is that many cases involving medicines include drugs from different classes and/or other agents. For example, $69 \%$ of the cases involving fluoxetine had association with other medicines, mainly clonazepam. Furthermore, 36.4\% of the cases with clonazepam was associated with other medicines and/or drugs of abuse (alcohol and crack cocaine). In the PIC-DF, only 10 cases include more than one drug. 


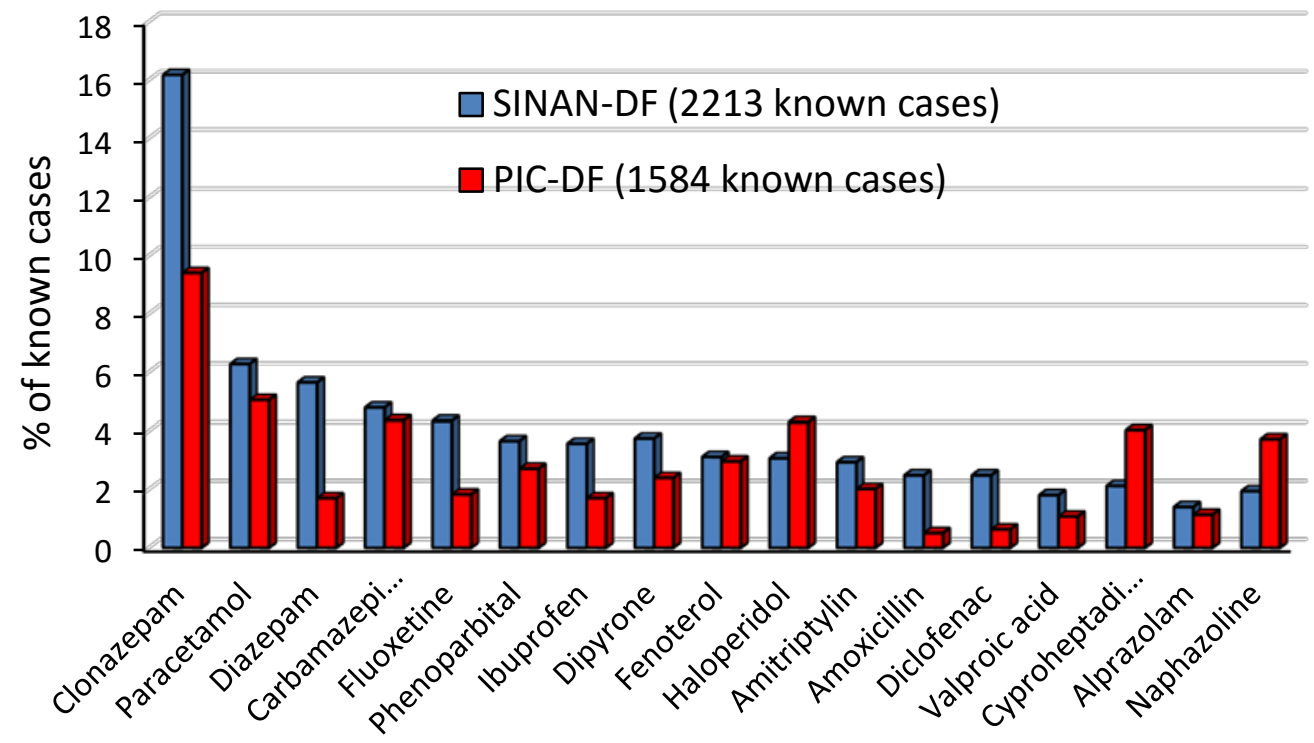

Figure 4. The main medicines involved with the intoxications reported to the PIC- and SINAN-DF from 2009 to 2013.

Cleaning products and drugs of abuse

Cleaning products represented 12.1 and $16.8 \%$ of the SINAN-DF and PIC-DF cases, respectively (Figure 3B), mostly involving accidental cases with children 1 to 4 years (53.9 and $61 \%$ of the cases, respectively). The main product in this category in both database was sodium hypochlorite (43.7 and $37.8 \%$ of the cases, respectively).

A total of 625 cases involving drugs of abuse were reported to the SINAN-DF (12.2\%; Figure 3B), mostly with alcohol (66.6\%), from which 84 cases were associated with medicines and/or other drugs. In the PIC-DF, only $4.5 \%$ of the cases involved drugs of abuse (Figure 3B), from which $45.9 \%$ with alcohol. Other drugs in both systems include cannabis and cocaine/crack. About $52 \%$ of the cases with drugs of abuse in both systems involved individuals aged 15 to 29 years.

\section{Pesticides and rodenticides}

Table 1 summarizes the information concerning the cases involving rodenticides and pesticides. Chumbinho, an illegal rodenticide, was involved in 
over $60 \%$ of the cases in both systems; broadifacoum and bromadiolone, which are 4-hydroxycoumarin vitamin $\mathrm{K}$ antagonist anticoagulants, were the main legal rodenticides involved. Almost $25 \%$ of the rodenticide cases in SINAN-DF did not have the name of the compound involved, and $41.3 \%$ were associated with medicines, alcohol and/or cocaine.

Insecticides were the main class of pesticides involved in the cases in both systems, mainly pyrethroids, followed by herbicides, mainly glyphosate. The chemical involved in $24 \%$ of the SINAN-DF pesticide cases was unknown, and most of the cases involved different pesticides.

Table 1. Poisoning cases involving rodenticides and pesticides reported to the SINAN-DF and PIC-DF from 2009 to 2013.

\begin{tabular}{|c|c|}
\hline SINAN-DF & PIC-DF \\
\hline \multicolumn{2}{|l|}{ Rodenticides } \\
\hline 515 cases $^{*} ; 10 \%$ of known cases & 309 cases; $8.6 \%$ of known cases \\
\hline 337 chumbinho & 195 chumbinho \\
\hline $\begin{array}{l}55 \text { anticoagulants ( } 65 \% \text { brodifacoum or } \\
\text { bromadiolone) }\end{array}$ & $\begin{array}{l}98 \text { anticoagulants ( } 58.2 \% \text { brodifacoum } \\
\text { or bromadiolone) }\end{array}$ \\
\hline 123 ignored & 16 ignored \\
\hline \multicolumn{2}{|l|}{$\begin{array}{l}\text { *213 cases associated with medicines, } \\
\text { alcohol and/or cocaine }\end{array}$} \\
\hline \multicolumn{2}{|l|}{ Pesticides } \\
\hline 329 cases $* 6.4 \%$ of known cases & 263 cases; $7.5 \%$ of known cases \\
\hline $\begin{array}{l}204 \text { insecticides ( } 41.7 \% \text { pyrethroids, } \\
31.4 \% \text { acetylcholinesterase inhibitors) }\end{array}$ & $\begin{array}{l}228 \text { insecticides ( } 58.8 \% \text { pyrethroids, } \\
26 \% \text { acetylcholinesterase inhibitors) }\end{array}$ \\
\hline 43 herbicides ( $74.4 \%$ glyphosate) & 26 herbicides (76.9\% glyphosate) \\
\hline 17 other classes & 1 fungicide \\
\hline 79 ignored & 8 ignored \\
\hline $\begin{array}{l}\text { *include associations among the } \\
\text { classes }\end{array}$ & \\
\hline
\end{tabular}

Other agents

Industrial chemicals were involved in 364 cases in SINAN-DF $(7.1 \%$ of the known cases) and in 380 cases in PIC-DF (10.9\% of the cases) (Figure 3B). Volatile hydrocarbons (liquid) were the main product involved, accounting for 
about one third of the cases in this category in both systems (31 and 33.3\%). Other chemicals include formaldehyde (49 cases in SINAN-DF and 36 cases in PIC-DF) and naphthalene (20 cases in each system).

A total of 73 cases involved toxic plants in the SINAN-DF system (19 cases with unknown specie), mostly $(76.7 \%)$ with children up to 9 years. Among the 21 differents species reported were Dieffenbachia seguine (an ornamental plant known as comigo-ninguém-pode; 17 cases) and Jatropha sp (gossypiifolia and curcas, known as pinhão roxo and branco/manso, respectively), with 14 cases. In the PIC-DF system, 220 cases with plants were reported (20 species reported), from which 109 involved a mixture of plants containing urticanting trichomes, known in Brazil as pó-de-mico, all from a single 2009 group event. $D$. seguine and Jatropha $s p$ were also reported (33 and 17 cases, respectively).

Other agents shown in Figure 3B include metals, veterinary drugs and carbon monoxide. In the SINAN-DF, 71 cases were included in this category. Among the 39 cases with veterinary drugs, 16 were products containing either cypermethrin or deltamethrin; 16 cases involved metals (mercury, lead, arsenic, cupper and thallium). Carbon monoxide was involved in 6 cases. Only 15 cases were included in the Others category in the PIC-DF, 6 involving mercury, 5 veterinary drugs and 4 cases with carbon monoxide.

\section{Cases involving children}

Most of the cases (53\%) reported to the PIC-DF involved children up to 9 years old, while in the SINAN-DF this population accounted for one third of the cases (33.4\%); most of the cases in both systems occurred with children from 1 to 4 years (Figure $3 \mathrm{C}$ ). All cases in both systems were accidental, except for one case involving an 8 years old child that was reported in the SINAN-DF as suicide attempt. Table 2 shows the cases according to the agent involved. The\% of known cases are similar in both systems for all agents, with almost half of the cases involving medicines ( 49\%), followed by cleaning products ( 22\%). 
Table 2. Poisoning cases involving children (up to 9 years) reported to the SINAN-DF and PIC-DF from 2009 to $2013^{*}$.

\begin{tabular}{lcc}
\hline & SINAN-DF, N = 1935 & PIC-DF, N=1921 \\
\hline Medicines & $879(49.2)$ & $928(48.5)$ \\
Cleaning products & $384(21.5)$ & $416(21.8)$ \\
Industrial chemicals & $189(10.6)$ & $229(12.0)$ \\
Pesticides/rodenticides & $60 / 101(9.0)$ & $89 / 86(9.2)$ \\
Cosmetics & $77(4.3)$ & $67(3.5)$ \\
Plants & $56(3.1)$ & $79(4.1)$ \\
Drugs of abuse & $7(0.4)$ & $9(0.5)$ \\
Others & $31(1.7)$ & $9(0.5)$ \\
Unknown & 151 & 9 \\
\hline
\end{tabular}

* In parenthesis, the\% of known cases

\section{Lethal cases}

The outcome of the intoxication was unknown in $51.8 \%$ of the SINAN-DF, and 18 fatal cases were reported in this system. In the PIC-DF, 2.2\% of the cases had unknown outcome, and 29 fatalities were reported. Most of the cases in both systems involved men, and suicide was the main circumstance (Table 3). Three lethal cases in the SINAN-DF involved children, all males, two aged below 1 year who ingested azithromycin or sodium hypochlorite, and one with a 6 year old child who ingested paracetamol. The three fatal cases involving children from PIC-DF occurred with males aged 1 to 4 years, after ingestion of the deltamethrin, benzydamine or dipyrone. Other medicines involved in the fatal cases were stanozolol, levomepromazine, phenobarbital, amitriptyline, amlodipine, and carbamazepine.

Chumbinho was involved in 5 cases in each system, and pesticides accounted for $31 \%$ of the PIC-DF lethal cases (deltamethrin, cypermethrin, glyphosate, methamidophos and carbofuran). 
Table 3. Lethal poisoning cases reported to the SINAN-DF and PIC-DF from 2009 to $2013^{*}$.

\begin{tabular}{lcc}
\hline & SINAN-DF, N = 19 & PIC-DF, N=29 \\
\hline Male & $11(57.9 \%)$ & $18(62 \%)$ \\
Suildren up to 9 & $3(15.8 \%)$ & $3(10.3 \%)$ \\
& $11(57.8 \%)$ & $18(62 \%)$ \\
& 3 chumbinho & 4 chumbinho \\
& 2 pesticides & 4 medicines \\
& 1 unknown & 7 pesticides \\
Accidental/medication & 5 sodiumhydroxide \\
& 2 medicines & 1 unknown \\
& 2 drugs of abuse & 7 medicines \\
& 1 sodium & 1 glycerin \\
hypochlorite & \\
Other circumstances & $3(15.7 \%)$ & $4(13.8 \%)$ \\
& 1 drugsof abuse & 2 drugs of abuse \\
& 2 unknown & 1 chumbinho \\
& & 1 formaldehyde \\
& &
\end{tabular}

\section{Discussion}

The Federal District is located in the Midwest region of Brazil, with a total area of $5,779,999 \mathrm{~km}^{2}$, including the capital Brasilia, and a population of $2,570,163$ inhabitants in 2010 (IBGE, 2016). During the period from 2009 to 2013, the PIC-DF received 12,033 calls, $16.6 \%$ of them information calls. This profile is different from that reported by the PIC-RS (Rio Grande do Sul State, 10,693,929 inhabitants in 2010), where information calls corresponded only to $6.3 \%$ of the 109777 calls received during the same period, with $90 \%$ of the calls related to human exposure (Nicolella et al., 2013). The number of calls received in relation to the population is similar in both PICs (9.4 and 10.2 calls per 1000 inhabitants in the DF and RS, respectively), but both centers receive 
calls from other states through a national hotline. In USA, over 2.8 million exposure cases were reported to the NPDS in 2014, 23\% information calls (MOWRY et al., 2015). In the United Kingdom, information calls accounted for less than $10 \%$ of all activities of the National Poisons Information Service in 2013/2014 (NPIS, 2014).

In this study, only confirmed human exogenous intoxication cases that received care in the public and private health hospitals of the Federal District were considered from the PIC-DF database, so the data could be compared with the SINAN-DF. Except for the years 2009 and 2010, the number of cases in the SINAN-DF was much larger, with 2190 more cases than the PIC-DF during the period. In 2011, notification of exogenous intoxications under circumstance other than occupational became compulsory in the SINAN (Brazil, 2011), what explain the important increase of cases reported in this and subsequent years in the system.

The lower number of cases in the PIC-DF is explained by the characteristics of poison information centers, to which the calls are voluntarily made by health professionals seeking, primarily, for advice on first aid, and management of the intoxication. As reporting is not mandatory, the PIC-DF frequently promotes campaigns to increase awareness among health professionals and the general public over the importance of the service provided. Indeed, the number of calls received increased substantially since the Center started its activities, from 476 calls in 2004 to 5679 in 2013 (data not shown).

Most of the intoxication cases that occurred in the Federal District involved females, similar of what was found in other PIC-RS in 2013 (55\% females; NICOLELLA et al., 2013), in Paraiba state from 2009-2013 (56.1\%; DA SILVA NÓBREGA et al., 2015), as well as in other countries (52\% in Israel, BENTUR et al., 2008; $57.6 \%$ in South Africa, VEALE et al., 2013). In both DF systems, this distribution varied according to the age population, with females accounting for $45-47 \%$ among children, $63-65 \%$ among adolescents (10-19 years), and $57 \%$ among adults (data not shown). Similar distribution was found in the exposure cases reported to the USA NPDS (MOWRY et al., 2015).

Medicines were the main agent involved in the intoxications in both systems, accounting for over $40 \%$ of the cases, similar to what was reported to 
PIC-RS (NICOLELLA et al., 2012; 2013), and to SINITOX (2016). On the other hand, in the Paraiba state, $53 \%$ of the intoxication cases were scorpion accidents, with medicines being the main agent involving in the exogenous intoxications (DA SILVA NOBREGA et al., 2015). Medicines were also the main agent involved in intoxication in the Korea (65.5\%; KIM et al., 2016), United States (57\%; MOWRY et al., 2015), Israel (44.2\%; BENTUR et al., 2008) and Russia (up to 63\%; OSTAPENKO et al., 2001). In the United Kingdom, 70\% of all telephone enquiries to the TOXBASE in 2013/14 were related to pharmaceuticals (NPIS, 2014). In South Africa, medicines and pesticides accounted each for about 35\% of the cases (VEALE et al., 2013), while in Thailand $41.4 \%$ of the 15,016 cases reported to Ramathibodi Poison Center involved pesticides, followed by household products and medicines ( $20 \%$ each) (WANANUKUL et al., 2007).

Accidental exposure was the main circumstance involved in the intoxication cases, corresponding to over $60 \%$ of the cases in the PIC-DF. The absolute number of cases was also higher in this database compared to SINAN-DF, mainly due to the higher number of accidental events involving children reported to the Center, mostly from 1 to 4 years (44\% of the cases). Lower proportions of cases involving children 1 to 4 were reported in Rio Grande do Sul in 2012-2013 (about 36\%; NICOLELLA et al., 2012; 2013) and nationally (28.2\%; SINITOX, 2016). Pediatric exogenous intoxication generally is a consequence of facilitating situations and the specific characteristics of this population. Children under five years of age tend to touch, test and explore their surroundings, getting in contact with toxic chemicals that are unsafely stored (WHO, 2004), mainly medicines and cleaning products. Indeed, these were the main agents involved in the intoxication cases with this population in this study and elsewhere (SHANON, 2000; MINTEGl et al., 2006; ALIJE et al., 2014). Almeida et al. (2011) showed that only $13 \%$ of the 997 participants in a Federal District study to evaluate the risk perception of medicaments storage these products out of the children reach.

Suicide attempt was the second major circumstance involved in the intoxication events, with a higher percentage reported to the SINAN-DF. This was expected as they occur mainly with adults $(74.7 \%)$, subpopulation involved in most of the cases reported to this system, mostly with individuals from 20 to 
39 years (54.2\%). Santos et al. (2013), however, reported more suicide attempt cases from exogenous exposure retrieved from the PIC of the State of Rio de Janeiro from 2008 to 2008 compared to the SINAN system (907 and 447 cases, respectively). Suicide attempt is a tragic social phenomenon that affects all countries at various rates, with populations using different self-harm methods. Gunnell et al. (2007) estimated that, globally, about one third of all suicides occurred after pesticide ingestion, a rate that ranges from $4 \%$ in Europe up to over $50 \%$ in the Western Pacific Region.

PIC-DF data show that $10.4 \%$ of the suicide attempts involved pesticide and $56.6 \%$ medicines, while in SINAN-DF data the rates were 4.4 and $66 \%$, respectively). Similar rates were found at national level in 2012 (14.3 and 66\%, respectively; SINITOX, 2016), while PIC-RS data showed $78 \%$ of the suicide attempt cases involving medicines (NICOLELLA et al., 2012; 2013). Unlike in the Federal District, the profile of PIC and SINAN data from the State of Rio de Janeiro (2006-2008) were distinct, with pesticides proportionally involved in less suicide attempt cases in the PIC-RJ (43\% against 49\%) and more in the SINAN system (50.2\% against 34\%) (SANTOS et al., 2013).

While medicine was the main agent involved in the intoxication cases, pesticides was the most lethal product. The lethality rates for medicines were 0.5 and $0.2 \%$ for the PIC-DF and SINAN-DF databases, respectively, in the same range of what was reported at National level $(0.25 \%$; SINITOX, 2016). For pesticides, the lethality rate at the PIC-DF was $3.4 \%$, involving pyrethroids, the carbamate carbofuran, the organophosphate metamidophos, and glyphosate. This rate was similar to the national data $(3.1 \%)$, primarily with pesticides of agricultural use (FIOCRUZ, 2016). Albuquerque et al. (2015) compared the data related to pesticides poisoning in the state of Pernambuco registered from 2008 to 2012 in the SINAN and the PIC (CEATOX). The number of cases (2970 and 2449 , respectively) and the profile of age and sex were similar in both systems, and suicide attempt accounted for 66 and $75 \%$ of the cases, respectively. The overall mortality rate from pesticide poisoning was about $8 \%$, much higher than the National and DF rates.UK NPIS data from 2004 to 2013 showed 81 cases of severe toxicity involving pesticides, from which 38 cases were fatal, mostly suicide with the herbicides paraquat, diquat and glyphosate (PERRY et al., 
2014). Most of the UK pesticide poisoning cases were accidental involving children up to 4 years old.

One toxic agent that is characteristic of the Federal District and other Brazilian regions is the illegal rodenticide chumbinho, widely sold in street markets around the country. This product is formulated with agricultural insecticides, mainly the carbamate aldicarb, but may also contain other carbamates, organophosphates and even cumarinic compounds (VIEIRA et al., 2006). Bucaretchi et al. (2012) investigated 76 poisoning cases that occurred in 2009/2010 in Campinas, state of Sao Paulo, involving illegal rodenticides containing cholinesterase inhibitors. Most of the cases were suicide attempt, with aldicarb the sole component in the eight samples of chumbinho brought for identification. Subsequent analysis of plasma, urine and/or gastric lavage material of 59 patients identified aldicarb and/or its metabolites in 55 cases, carbofuran in 2 cases, aldicarb and carbofuran in 1 case, and no active component in a further case. No organophosphates or coumarins were detected in the samples. The manufacturer stopped commercializing aldicarb in Brazil in 2012, and most likely, chumbinho may currently contain primarily other insecticides. A similar product, called tres-pasitos, was involved in various poisoning cases in USA, brought into the country mainly from Dominican Republic (WASEEM et al., 2010).

Both carbamates and organophosphates are acetyl cholinesterase inhibitors, and intoxication with these agents can be fatal if appropriate medical care is not provided immediately after ingestion of high doses (VALE; LOTTI, 2015). In this study, PIC-DF shows 195 cases of chumbinho intoxication during the period of 2009 to 2013 , similar to what was previously retrieved from the same data base for the period of 2004 to 2007 (194 cases; CALDAS et al., 2008), mostly after suicide attempt (57-60\%). An additional 142 cases were reported to SINAN-DF, also mostly suicide attempt, associated with medicines, drugs, and/or pesticides. Five chumbinho fatal cases were retrieved for the current study, with a fatality rate up to $2.5 \%$, which was half than that previously reported for this product by Caldas et al. (5.2\%). This decrease in fatality rate may be due to a better training of health personal over the years in the management of patients with cholinergic symptoms. 
Clonazepam was the main medicine involved in the intoxications, accounting for $16 \%$ in the SINAN-DF, mostly suicide attempt (55.8\%); in the PIC-DF, clonazepam cases were mostly accidental/medication (62\%). Diazepam and alprazolam were also one of the major medicines involved in the intoxication (5.6\% and $1.4 \%$ of the medicine cases in the SINAN-DF), but none of the cases were reported to be lethal. Clonazepam was also the main drug involved in the intoxication cases reported to PIC-RS, accounting for $16 \%$ of the medicines cases (NICOLELLA et al., 2012; 2013). Benzodiazepines are commonly prescribed worldwide for anxiety, stress and insomnia (WHO, 1996). Although they are generally considered safe, their extensive use can lead to cognitive decline, sleep disturbances and psychiatric disorders, mainly in older adults, and are identified as a contributing factor in suicides and poisoning deaths (MURPHY et al., 2016).

Paracetamol (acetaminophen) was the second medicine most involved in the intoxication cases in both systems (5.0 - 6.2\%), including a 6 year old child fatal case reported to SINAN-DF. This was also the case in Rio Grande do Sul, where about $9 \%$ of the cases reported to the PIC involved this medicine. In UK, this drug was the main medicine inquired in TOXBASE, accounting for about $30 \%$ of the cases (NPIS, 2013). In USA, paracetamol alone or in combination with other drugs accounted for about $10 \%$ of all lethal intoxications in 2014 (MOWRY et al., 2015). Rajanayagam et al. (2015) reported that 14 of 54 cases of pediatric acute liver failure admitted to New Zealand and Queensland Pediatric Liver Transplant Services (2002-2012) were attributed to paracetamol; the majority were secondary to medication errors, and 12 children were under the age of 5 years, of which 3 underwent transplant and one died.

Dipyrone was another analgesic involved in the intoxications, which ingestion was fatal to a child bellow 4 years old. Analgesics were indeed the main group of medicines acquired by Brazilian families in 2008/2009 Brazilian Household Survey, obtained by $22.9 \%$ of the all households and by $25.3 \%$ of households with children up to 5 years old (GOES et al., 2016). As discussed previously, a safe storage of medicines in the household can prevent many cases of medicine intoxication in this subpopulation. Overall, analgesics was the main agent involved in all human exposure cases in USA (11.3\%; MOWRY et al., 2015). 
Cleaning products were a major agent involved in the intoxication cases, with sodium hypochlorite (bleaching) the main product. This product was involved in $7.7 \%$ of all cases with children up to 4 years old reported to PIC-DF, similar to the incidence in Rio Grande do Sul (NICOLELLA et al., 2014), with one fatal case (below 1 year of age) reported to SINAN-DF. Intoxication and fatal cases involving sodium hypochlorite have also been reported in other countries, including USA (MURPHY et al., 2015), Mali (DIALLO et al., 2013) and Republic of Macedonia (CHIBISHEV et al., 2012).

One substance involved in the intoxications that should be pointed out is formaldehyde, which solution is used as a preservative for biological tissues in hospitals and laboratories, but also widely used in Brazil in hair-straightening products, not legally registered by the health authority. Intoxication with this substance was the only fatal occupational event reported in the systems (CITDF).

\section{Conclusions}

In general, both systems indicate that most of exogenous intoxication cases in the Federal District were accidental, involving medicines and individuals of all age range, mainly women. The benzodiazepines were the main medicine class involved in the cases and pesticides were the most fatal agent. This study showed that although the PIC-DF is an important source of exogenous intoxication data, it underestimates the number of cases that occurs in the region compared with the data reported to SINAN. However, it can capture more efficiently accidental cases occurring with children, and has a considerably higher rate of data completeness compared to SINAN. Although both systems were important to properly describe the epidemiology of intoxication cases within the population, the lack of personal information on the PIC-DF data (name of the individual and of the mother) did not allow the identification of duplicate cases and the determination of the total number of cases that actually occurred in the Federal District during the period. This was a major limitation of this study. 


\section{III. Óbitos por intoxicação exógena no Distrito Federal entre os anos de}

2009 e 2013.

\section{Resumo}

Este é um estudo retrospectivo e descritivo, que utilizou dados de óbitos por intoxicação exógena que ocorreram no Distrito Federal entre 2009 e 2013, registrados no Sistema de Informação sobre Mortalidade (SIM), no Sistema de Informação de Agravos de Notificação (SINAN), no Centro de Informação Toxicológica (CIT), e no Instituto de Medicina Legal (IML). No período do estudo, houveram 288 casos reportados ao SIM, 18 ao SINAN, 29 ao CIT e 101 casos foram identificados no IML. Sem considerar as duplicidades, 338 casos de intoxicações fatais ocorreram no DF neste período, dos quais $73,4 \%$ foram reportados em apenas um dos sistemas (principalmente o SIM), 24,0\% foram reportados em 2 sistemas, 8 casos em três apenas 1 caso foi reportado pelos quatro sistemas A maior parte dos óbitos envolveu medicamentos (48,7\%), seguido de agrotóxico/raticida (29,9\%), incluindo chumbinho. Os óbitos ocorreram principalmente por intoxicação acidental $(50,8 \%)$ e suicídio $(47,7 \%)$. Os adultos na faixa etária entre 20 e 39 anos corresponderam a $46,6 \%$ dos casos. Este estudo mostra subnotifição importante dos óbitos por intoxicação exógena ocorridos entre 2009 e 2013 no DF registrados nos sistemas SINAN, CIT e IML, indicando a necessidade da uniformização do registro de dados que permitiria uma toxicovigilância efetiva, visando tornar mais efetivas e ágeis as medidas de controle de eventos adversos à saúde.

Descritores: Intoxicação humana, envenenamento, sistemas de informação, toxicovigilância. 


\section{Introdução}

As informações sobre causas de mortalidade de uma população são importantes para o planejamento e gestão de políticas de ação em saúde. Para isto é necessário que estas informações sejam fidedignas, e acessíveis sob a óptica da legislação e das normas éticas existentes (MELO JORGE et al., 2010; MENDONÇA et al., 2010). A principal fonte de dados de mortalidade no Brasil é o Sistema de Informação sobre Mortalidade (SIM), criado pelo Ministério da Saúde em 1975 para a obtenção regular de dados de forma abrangente e confiável, para embasar os diversos níveis de gerenciamento em suas ações de saúde. O SIM é alimentado com dados da Declaração de Óbito (DO), emitida pelo médico, que deve registrar a causa do óbito do ponto de vista médico e permitir o diagnóstico da causa jurídica do óbito, seja por causas externas (homicídio, suicídio, acidente) ou a morte chamada natural (BRASIL, 2011). Adicionalmente, outros sistemas também permitem obter dados de óbitos por intoxicação exógena no País, incluindo o Sistema de Informação de Agravos de Notificação (SINAN), os centros de informações toxicológicas (CIT) e os institutos de medicina legal (IML).

O SINAN foi desenvolvido no início da década de 90 tendo como objetivo a coleta e processamento dos dados sobre agravos de notificação no território nacional, fornecendo informações para a análise do perfil da morbidade e contribuindo para a tomada de decisões nos níveis municipal, estadual e federal (SINAN, 2005). A Portaria no 777 de 2004 incluiu a notificação compulsória ao SINAN de agravos relacionados ao trabalho, incluindo as intoxicações exógenas por substâncias químicas, e a Portarias GM/MS N. 2.472, de 31 de agosto de 2010 e № 104, de 25 de janeiro de 2011, estenderam a compulsoriedade destas notificações envolvendo circunstâncias não ocupacionais.

O Centro de Informação Toxicológica do Distrito Federal (CIT-DF) é um órgão subordinado à Subsecretaria de Vigilância a Saúde da Secretaria de Estado da Saúde. Inaugurado em fevereiro de 2004, o CIT-DF presta assessoria e orientação em acidentes tóxicos, em caráter de emergência e em regime de plantão permanente (24 horas/7 dias) aos profissionais de saúde por meio do telefone 0800644 6774, de maneira que estes possam aperfeiçoar o atendimento (diagnóstico e tratamento) de pacientes vitimados por exposições 
exógenas em geral. Adicionalmente, a população geral pode entrar em contato com o Centro para obter informações e relatar casos de intoxicação, e, se necessário, serem encaminhados à rede de atenção à saúde.

O IML-DF é vinculado à Polícia Civil do Distrito Federal, e responsável por todas as perícias médico-legal do DF. Define-se perícia médico-legal como "um conjunto de procedimentos médicos e técnicos que têm como finalidade o estabelecimento de um fato do interesse da Justiça, ou como um ato pelo qual a autoridade procura conhecer, por meios técnicos e científicos, a existência ou não de certos acontecimentos, capazes de interferir na decisão de uma questão judiciária ligada à vida ou à saúde do homem ou que com ele tenha relação" (DE FRANÇA, 2013).

Como cada uma dessas fontes de dados tem objetivos diferentes e são administrados por diferentes instâncias do setor público, é esperado que nenhum sistema seja capaz de captar todos os eventos fatais de intoxicação exógena no País, e cada um tenha algum nível de subnotificação. Este estudo tem como objetivo investigar os casos de óbitos causados por intoxicações exógenas registrados nos bancos de dados do Distrito Federal - CIT-DF, SIMDF, SINAN-DF e no IML-DF entre 2009 e 2013.

\section{Método}

Este é um estudo epidemiológico retrospectivo descritivo referentes aos óbitos por intoxicação exógena que ocorreram no Distrito Federal (DF) entre 2009 e 2013. Os dados foram obtidos a partir de quatro fontes: o Sistema de Informação sobre Mortalidade (SIM-DF), o Sistema de Informação de Agravos de Notificação (SINAN-DF), o Centro de Informação Toxicológica (CIT-DF), e o Instituto de Médico Legal (IML-DF). Os critérios de inclusão no estudo foram de óbitos de residentes no Distrito Federal ou que ocorreram em hospitais do DF, com confirmação de intoxicação exógena.

SIM-DF: Neste estudo utilizou-se como fonte primária as informações fornecidas pela Secretaria de Saúde do DF obtidas no sistema SIM online/DATASUS, que têm como base a Declaração de óbito (BRASIL, 2008). $\mathrm{Na}$ DO (Anexo 2), o médico deve descrever as condições e causas que levaram à morte, que contribuíram para a mesma, ou estiveram presentes no momento do óbito, segundo a Classificação Internacional de Doenças (CID-10 
a partir de 1996). Na parte I do DO, existem quatro campos para preenchimento com o código CID-10: 1-Causa imediata ou terminal, 2-Causa intermediária, 3-Causa intermediária e 4-Causa básica da morte, estabelecendo-se uma sequência, de baixo para cima, até a causa terminal ou imediata. Neste estudo, foi considerado a classificação inserida no campo da causa básica, com códigos do Capítulo XX (Causas externas de morbidade e mortalidade) do CID-10 (Anexo 3). Além do código CID, as variáveis avaliadas em cada caso foram ano do óbito e identificação do paciente (nome, nome da mãe, nome do pai, sexo e idade/data de nascimento).

SINAN-DF: Os dados utilizados neste estudo foram fornecidos pela Secretaria de Saúde do DF e tiveram como fonte primária as fichas de intoxicação exógena registradas no sistema SINAN NET online/DATASUS. A ficha de Notificação e Investigação de Intoxicação Exógena do SINAN (Anexo 4) é o instrumento padronizado de coleta de dados e está disponível nos serviços de saúde envolvidos diretamente com as ações de assistência e vigilância: os serviços de urgências e emergências; de atenção primária; de vigilância epidemiológica e de farmácia hospitalar. Para este estudo foram selecionados os casos de intoxicação exógena fatais, e as variáveis avaliadas foram ano da intoxicação, identificação do paciente (nome, nome da mãe, nome do pai, sexo e idade/data de nascimento), circunstância, via de exposição e agente (s) tóxico (s).

CIT-DF: A coleta dos dados teve como fonte primária o prontuário eletrônico do CIT online(Apêndice 1).Para este estudo foram avaliados os dados das intoxicações fatais registrados no sistema com relação ao ano do óbito, identificação do paciente (nome, nome da mãe, sexo e idade/data de nascimento), circunstância, via de exposição e agente tóxico. O diagnóstico de intoxicação no CIT-DF é baseado em critérios clínicos e laboratoriais(Cap. II).

IML-DF: Utilizou-se como fonte primária as informações dos laudos cadavéricos de vítimas de mortes por causas externas inseridos no banco de dados do IML-DF.Com o objetivo de responder aos quesitos oficias do laudo cadavérico, a causa básica do óbito é subdividida em: causa médica (como traumatismo crânio-encefálico, infarto agudo do miocárdio, pneumonia, intoxicação e envenenamento), causa jurídica (homicídio, suicídio, acidente) e instrumento jurídico (incluindo atropelamento, meio físico, meio químico, 
cortante, perfurante). Os casos de fatalidades por intoxicação exógena foram selecionados a partir do cruzamento destas variáveis e dos resultados dos exames toxicológicos. A partir deste filtro, as variáveis selecionadas foram: ano, data do óbito, identificação do paciente (nome, nome da mãe, sexo e idade/data de nascimento), causa básica, circunstância, agente tóxico e resultado do exame toxicológico.

Os dados foram transferidos para o Programa Statistical Package for the Social Sciences V. 20 (SPSS Inc., Chicago, Estados Unidos) para análise. Esse estudo utilizou um banco de dados secundários com a garantia do sigilo e anonimato dos pacientes, de acordo com a Resolução 466/2012 do Conselho Nacional de Saúde. O estudo foi aprovado pelo Comitê de Ética em Pesquisa da Fundação de Ensino e Pesquisa do Distrito Federal parecer ㄲo 1076808 (CAEE 36189714.2.0000.5553) (Anexo 1).

\section{Resultados}

SIM-DF

Foram identificados 288 óbitos por intoxicação exógena registrados pelo SIM-DF entre 2009 e 2013 e classificados nos CID's relevantes. A Tabela 1 mostra a distribuição dos ao longo dos anos e em relação ao número de óbitos por causas externas ocorridas no período. Em relação ao total, 4,6\% dos óbitos ocorreram por intoxicação, com menor percentual em 2012 (3,8\%).

Tabela 1. Óbito por causas externas e por intoxicação exógena, reportados ao SIM-DF, 2009 a 2013.

\begin{tabular}{cccc}
\hline Ano & $\begin{array}{c}\text { Causas } \\
\text { externas }\end{array}$ & Intoxicação exógena & $\%$ \\
\hline 2009 & 1213 & 56 & 4,6 \\
2010 & 1133 & 74 & 6,5 \\
2011 & 1206 & 65 & 5,4 \\
2012 & 1275 & 48 & 3,8 \\
2013 & 1182 & 47 & 4.0 \\
\hline TOTAL & $\mathbf{6 2 9 8}$ & $\mathbf{2 9 0}$ & $\mathbf{4 , 6}$ \\
\hline
\end{tabular}




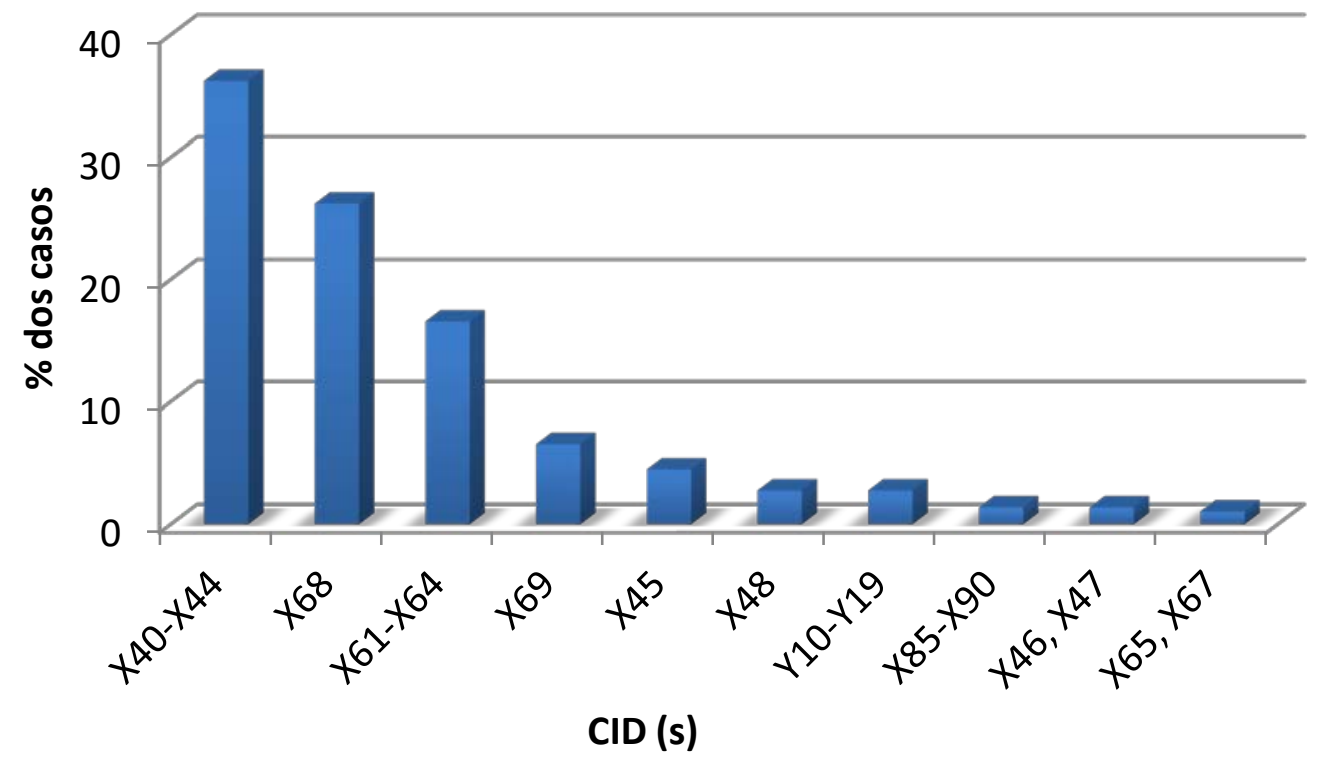

Figura 1. Distribuição dos códigos CID's reportados (causa básica) nos 288 reportados ao SIM referente a intoxicações exógenas no período de 2009 a 2013.

Nota: $\mathrm{X} 40$ a X44 = Envenenamento [intoxicação] acidental por e exposição à substâncias nocivas (medicamentos ou outras drogas); X68= Autointoxicação por e exposição, intencional, a agrotóxicos e raticidas; $\mathbf{X 6 9 =}$ Autointoxicação por e exposição, intencional, a outros produtos químicos e substâncias nocivas não especificadas; X61-X64= Autointoxicação por e exposição, intencional, a medicamentos ou outras drogas; $X 45=$ Envenenamento [intoxicação] acidental por e exposição por exposição ao álcool; $X 46=$ Envenenamento [intoxicação]acidental por e exposição por exposição a solventes orgânicos e hidrocarbonetos halogenados e seus vapores; Y10-Y19= Eventos (fatos) cuja intenção é indeterminada; $X 85-X 90=$ agressões provocadas por substancias quimicas; $X 46=$ Envenenamento (intoxicação) acidental por e exposição a solventes orgânicos e hidrocarbonetos halogenados e seus vapores; X47= Intoxicação acidental por exposição a outros gases e vapores; X65= Autointoxicação voluntária por álcool, X67= Auto-intoxicação intencional por outros gases e vapores; 
A Figura 1 mostra os códigos de classificação do Capítulo XX nos casos reportados durante o período de estudo. Mais de um terço dos casos $(34,8 \%)$ foram classificados como X40 a X44 (Envenenamento [intoxicação] acidental por e exposição à medicamentos), principalmente envolvendo narcóticos e psicodislépticos (alucinógenos) (X42, 69,5\%). O código X68 (Autointoxicação por e exposição, intencional, a agrotóxicos e raticidas) classificou $26,4 \%$ dos casos. Dentre as Autointoxicação por e exposição, intencional, a medicamentos (X61-X64), casos envolvendo anticonvulsivantes (antiepilépticos) sedativos, hipnóticos (X61) representaram 72,9\%. A maioria dos óbitos envolveu homens (54,5\% dos casos).

A Figura 2 mostra a distribuição dos óbitos reportados no SIM-DF de acordo com o agente envolvido, circunstância e idade do indivíduo. A maioria dos casos envolveu medicamentos (59,2\% dos casos com esta informação) e intoxicação intencional (51,8\%). Quase a metade dos óbitos (46\%) envolveram indivíduos entre 20 e 39 anos.

\section{SINAN-DF e CIT-DF}

Durante o período de estudo 5.703 casos de intoxicação exógena foram reportados ao SINAN-DF, com 18 óbitos (Cap. II). A maioria dos óbitos ocorreu com homens $(57,9 \%)$ e $47.4 \%$ com indivíduos entre 20 e 49 anos. A principal circunstância dos óbitos foi suicídio (10 casos), 8 casos envolveram agrotóxico ou chumbinho, e 5 envolvendo medicamentos.

Dentre os 3.622 casos de intoxicação exógena reportados ao CIT-DF no período do estudo, 29 foram fatais (Cap. II). Destes, 62,0\% ocorreram com homens, $62 \%$ por indivíduos entre 20 e 49 anos e $62 \%$ por suicídio. Quase a metade dos óbitos envolveu agrotóxicos ou chumbinho (48,3\%) e 27,6\% por medicamentos. O único caso de exposição ocupacional foi causado por um produto cosmético a base de formaldeído, utilizado para fazer escova progressiva. 

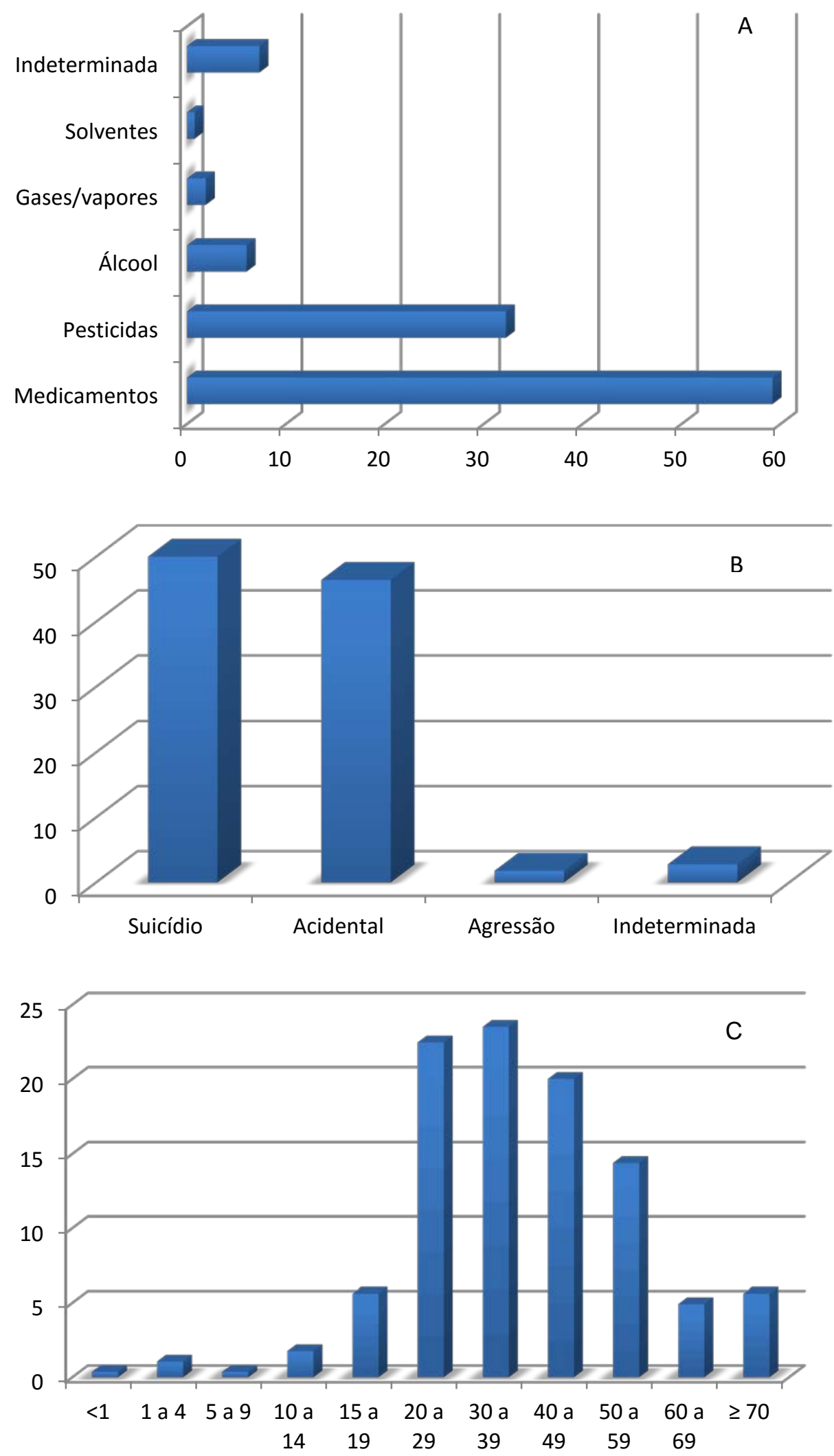

Figura 2. Agentes (A), circunstâncias (B) e idade (anos) (C) dos indivíduos envolvidos nos 288 casos de óbitos reportados ao SIM-DF, em percentual do total de casos com a informação conhecida, no período de 2009 a 2013. 


\section{IML-DF}

O IML-DF realizou no período de 2009-2013, 15.413 perícias em mortos com a posterior emissão de laudos cadavéricos. Este número está distribuído de maneira homogênea ao longo dos anos (cerca de 3 mil por ano). Óbitos por causas externas e violentas representaram $41,2 \%$ dos casos, 19,6\% dos óbitos foram de causas naturais e $7,4 \%$ de causas a esclarecer e $2,3 \%$ de causas indeterminadas e $29,5 \%$ outras causas.

Nos laudos cadavéricos do IML-DF foram identificados, primeiramente, 35 óbitos por intoxicação, sendo estes diagnosticados logo após a necropsia sem a necessidade de posterior investigação laboratorial, e 12 casos como envenenamento. Adicionalmente, foram selecionados para investigação mais detalhada 4.082 casos a esclarecer, casos de suicídio e meio químico. Destes, 2.285 foram descartados por envolverem causas não relevantes para o estudo, e 1.797 casos foram examinados, juntamente com o boletim de ocorrência policial e informações do atendimento hospitalar, quando existente. Neste processo, foram recuperados mais 54 casos de intoxicação exógena, resultando num total de 101 óbitos onde a intoxicação foi confirmada. Vale ressaltar que 43 casos com história clínica ou policial de envenenamento, mas sem confirmação laboratorial, não foram considerados.

A Figura 3 mostra os agentes e a idade dos indivíduos envolvidos nos 101 óbitos registrados no IML. Agrotóxico ou chumbinho estiveram envolvidos em 35,6\% dos casos e drogas de abuso (álcool ou cocaína), em 47,6\% dos casos. Nenhum caso reportado envolveu indivíduos menores que 15 anos, e $28,9 \%$ deles envolveu indivíduos entre 30 e 39 anos. A circunstância do óbito (causa jurídica) não está especificada em 53,4\% dos laudos cadavéricos do IML-DF. Dos 47 casos com esta informação, a maioria ocorreu acidentalmente (55,3\%), e 44,7\% por suicídio. 

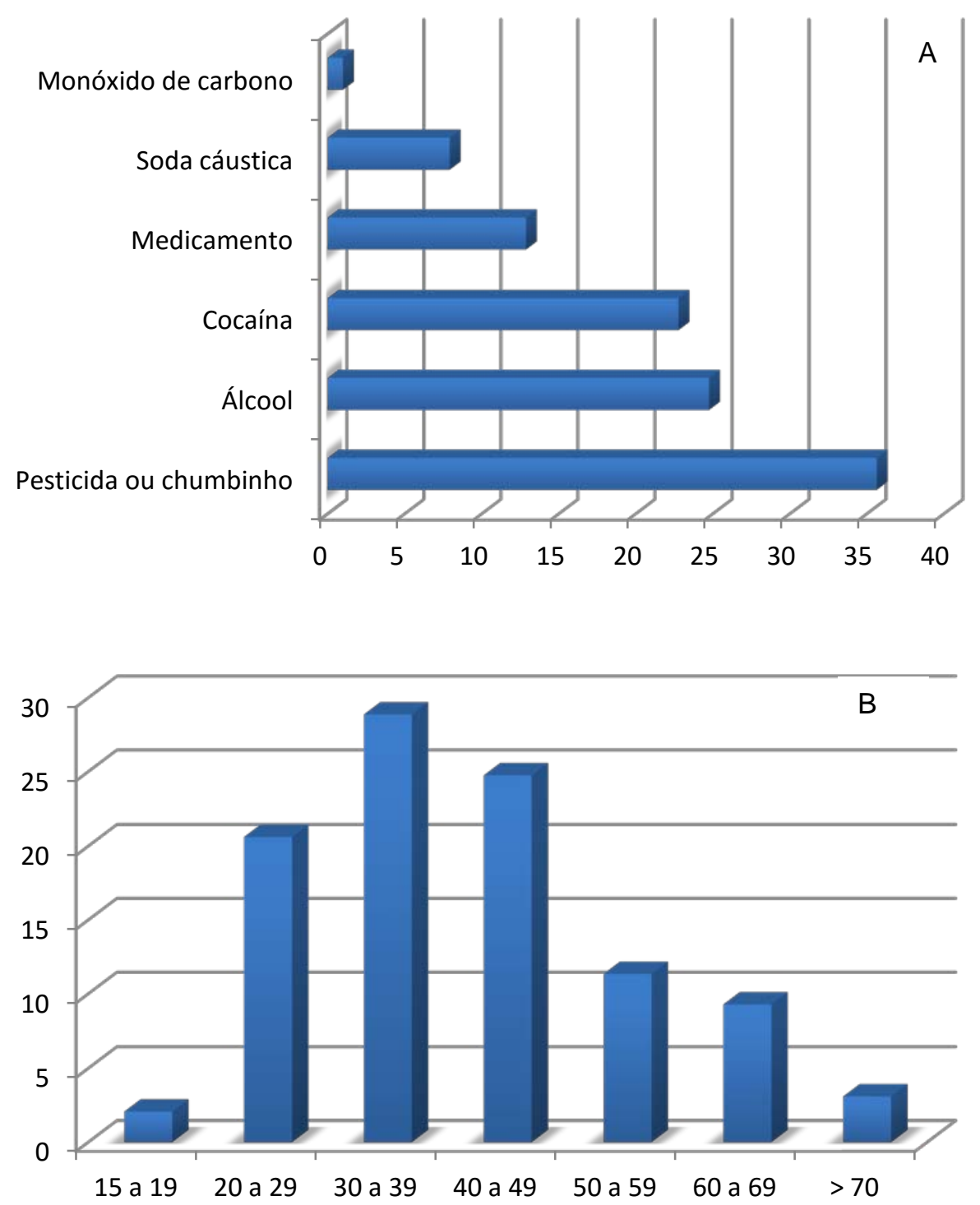

Figura 3. Agentes (A) e idade (B) dos individuos envolvidos nas intoxicações fatais reportadas no IML-DF entre 2009 e 2013 


\section{Comparação entre os casos óbitos por intoxicação exógena reportados no SIM-DF, SINAN-DF, CIT-DF e IML-DF.}

Não é possível identificar no banco de dados do SIM a substância envolvida na intoxicação, mas somente o agente envolvido, já que a codificação CID-10 não traz esta informação. A classe à qual um medicamento pertence é especificado em alguns códigos, como (X61) Auto-intoxicação por e exposição, intencional, a drogas anticonvulsivantes (antiepilépticos) sedativos, hipnóticos, e se a circunstância foi acidental (X40-X49) ou intencional (X60 a X84) (Anexo 3).

A Tabela 2 resume as principais características dos casos de intoxicação fatal reportadas no SIM-DF, SINAN-DF, CIT-DF e IML-DF. Em todos os sistemas, a maioria dos casos ocorreu com homens, com um percentual maior para os casos do IML (70,3\%). Com exceção do IML, o suicídio foi a principal circunstância envolvida nas fatalidades com circunstância conhecida.

Os medicamentos envolvidos nas fatalidades incluem azitromicina (antibiótico), benzodiazepínicos e amitriptilina (antidepressivos), fenobarbital (antiepiléptico), benzimidamina e dipirona (analgésico/antinflamatório) e anlopidino (antihipertensivo). Adicionalmente, o CIT identificou 2 casos de acidentes letais pelo uso parenteral usados para alteração de aparência, um com estanozolol (anabolizante) e outro com glicerina (Tabela 2).

Casos com chumbinho foram identificados em todos os sistemas, com exceção do SIM, onde os códigos CID X48 e X68 se referem a agrotóxicos e raticidas, sem especificação do agente. Os agrotóxicos envolvidos nos casos pertenciam principalmente à classe dos inseticidas carbamatos, organofosforados e piretroides, com um caso com o herbicida glifosato reportado ao CIT.

Dados do IML mostram 25 casos envolvendo álcool etílico, dos quais 3 envolvendo também medicamentos, e 15 reportados como acidental (Tabela 2); 22 desses casos foram reportados como intoxicação etílica. Com exceção de um caso (que reportou a ingestão de 9 comprimidos de diazepam $10 \mathrm{mg}$ e 2 garrafas de vinho), o teor de álcool etílico foi determinado no sangue colhido nas câmaras cardíacas dos indivíduos, variando entre 4 a 8,2 g/L. Casos envolvendo álcool também foram reportados no SIM (14) e SINAN (2), mas não no CIT. O IML também reportou o maior número de casos envolvendo cocaína 
(20), incluindo um caso associado com chumbinho envolvendo um homem de 50 anos. Este caso foi reportado como acidental, mas a ingestão acidental de chumbinho por um adulto não é esperada. Somente um outro caso indicando cocaína foi reportado (CIT-DF, Tabela 2).

A Figura 4 mostra o número de casos em cada banco de dados segundo a idade dos envolvidos. Importante ressaltar que a subnotificação dos casos nos outros sistemas comparado ao SIM-DF ocorreu em todas as faixas etárias. Nenhum caso do IML envolveu indivíduos menores que 15 anos, e nenhum caso do SINAN envolveu indivíduos maiores que 59 anos. O CIT só não fez registro dos casos de 5 a 9 anos de 10 a 14 anos e acima de 69 anos.

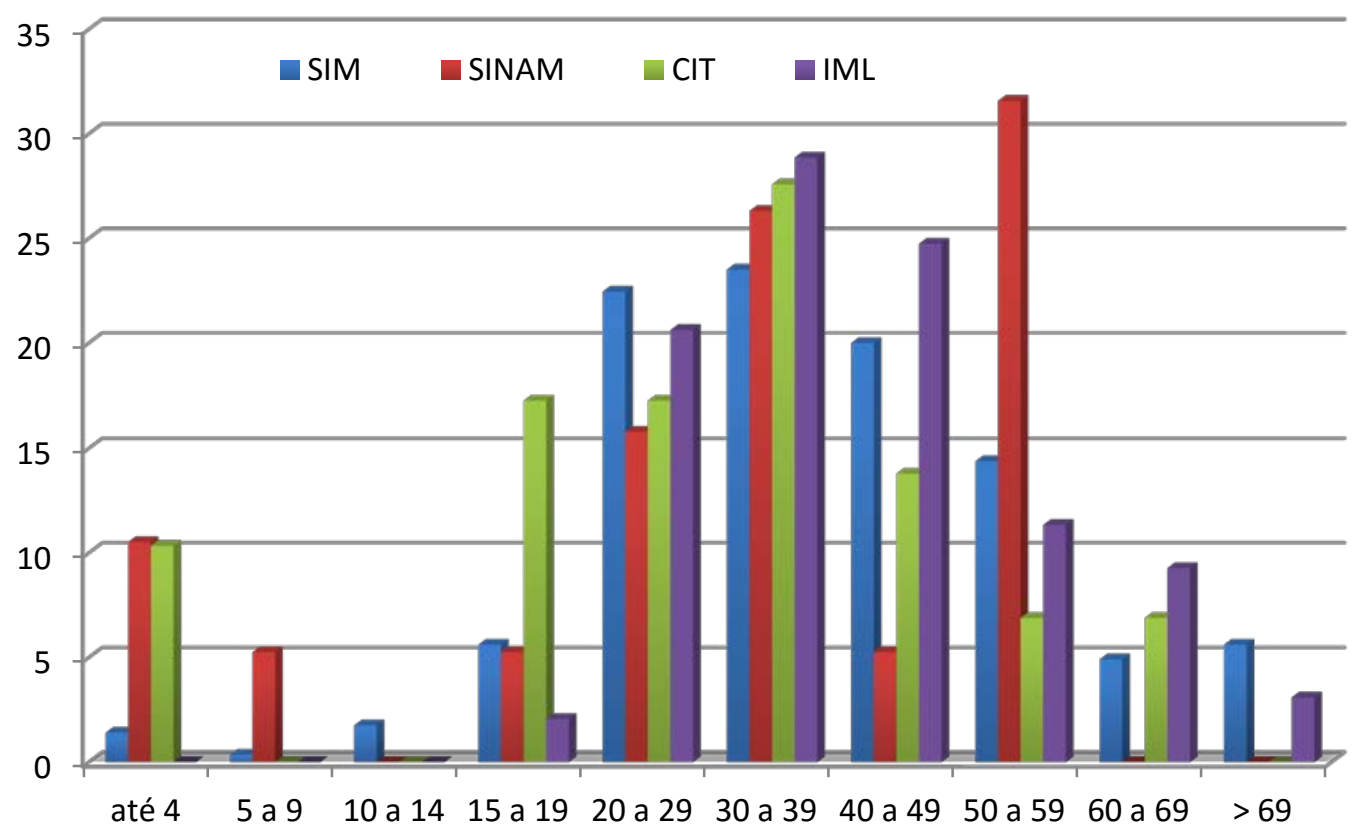

Figura 4. Distribuição de casos de intoxicação fatal (\% dos casos conhecidos), segundo a idade do indivíduo, reportados pelos quatro sistemas de informação, ocorridos no Distrito Federal entre 2009 e 2013. 
Tabela 2. Óbitos registrados nos Sistemas de informação de acordo com, sexo, circunstância e agente tóxico no DF, 2009 a 2013*.

\begin{tabular}{|c|c|c|c|c|}
\hline & SIM N=288 & SINAN N=18 & $\mathrm{CIT} N=29$ & IML N=101 \\
\hline Homens & $54,50 \%$ & $57,90 \%$ & $62 \%$ & $70,30 \%$ \\
\hline \multirow[b]{2}{*}{ Suicídio } & $50,30 \%$ & $57,80 \%$ & $62 \%$ & $44,70 \%$ \\
\hline & $\begin{array}{c}76 \text { pesticidas ou raticidas } \\
48 \text { medicamentos: } 35 \\
\text { antiepilépticos/sedativos/ } \\
\text { hipnóticos/antiparkinsonianos/ } \\
\text { psicotrópicos, } \\
3 \text { narcóticos/ psicodislépticos, } 4 \text { de } \\
\text { ação sobre o sistema nervoso } \\
\text { autônomo, (6 ignorados), } \\
2 \text { gases/vapores, } 1 \text { álcool19 ignorados }\end{array}$ & $\begin{array}{c}5 \text { chumbinhos } \\
\text { agrotóxicos: cipermetrina, } \\
\text { deltametrina+malation1 } \\
3 \text { medicamentos: amitriptilina, } \\
\text { anlopidino, (1 ignorado) } \\
2 \text { ignorado }\end{array}$ & $\begin{array}{c}4 \text { chumbinhos, } \\
7 \text { agrotóxicos: glifosato, } \\
\text { deltametrina, cipermetrina, } \\
\text { carbofuram, metamidofós } \\
4 \text { medicamentos } \\
2 \text { sodas causticas, } \\
2 \text { ignorados }\end{array}$ & $\begin{array}{c}7 \text { chumbinhos } \\
5 \text { agrotóxicos: } 2 \text { organofosforados, } \\
2 \text { carbamatos, } 1 \text { carbofuram, } \\
1 \text { chumbinho + medicamento, } \\
6 \text { sodas causticas, } \\
1 \text { ignorado }\end{array}$ \\
\hline \multirow{3}{*}{ Acidental } & $45,10 \%$ & $26,30 \%$ & $24,10 \%$ & $25,70 \%$ \\
\hline & $\begin{array}{c}105 \text { medicamentos: } 72 \\
\text { narcóticos/psicodélicos, } 12 \\
\text { antiepilépticos/sedativos/ } \\
\text { hipnóticos;2analgésicos/antipiréticos/antire } \\
\text { umáticos, não-opiáceos, } 2 \text { ação sobre o } \\
\text { sistema nervoso autônomo, } 16 \text { ignorado8 } \\
\text { pesticidas, } 13 \text { álcool, } \\
2 \text { solventes, } 2 \text { gases }\end{array}$ & $\begin{array}{c}2 \text { medicamentos: acetaminofen, } \\
\text { azitromicina, } \\
2 \text { drogas de abuso: } \\
\text { álcool,ignorado, } \\
1 \text { hipoclorito de sódio }\end{array}$ & $\begin{array}{l}4 \text { medicamentos: estanozolol } \\
\text { (parenteral), dipirona, } \\
\text { benzimidamina, amitriptilina, } \\
1 \text { glicerina (parenteral) }\end{array}$ & $\begin{array}{c}15 \text { álcool etílico, } 5 \text { cocaína, } \\
2 \text { medicamentos, } 2 \text { chumbinhos, } \\
1 \text { chumbinho + cocaína, } \\
1 \text { monóxido de carbono }\end{array}$ \\
\hline & $4,50 \%$ & $15,70 \%$ & $13,80 \%$ & $53,50 \%$ \\
\hline $\begin{array}{l}\text { Outras } \\
\text { circunstân- } \\
\text { cias } \\
\text { ou } \\
\text { ignorada }\end{array}$ & $\begin{array}{l}\text { Agressão: } 1 \text { medicamento, } 2 \text { pesticidas, } 1 \\
\text { indeterminado8 ignorada }\end{array}$ & $\begin{array}{l}1 \text { droga de abuso: álcool + } 1 \\
\text { chumbinho, } 1 \text { ignorado }\end{array}$ & $\begin{array}{c}2 \text { drogas de abuso: } 1 \text { cocaína, } 1 \\
\text { ignorado), } \\
1 \text { chumbinho } \\
\text { (violência/homicídio), } \\
1 \text { formaldeído (ocupacional- } \\
\text { respiratória) }\end{array}$ & $\begin{array}{c}16 \text { cocaínas, } 14 \text { chumbinhos, } \\
6 \text { medicamentos: azitromicina, } \\
\text { benzimidamina, benzodiazepinico, } \\
7 \text { álcool etílico,3 álcool etílico + } \\
\text { medicamento: clonazepam, diazepam, } \\
\text { fenobarbital, } 2 \text { carbamato e } \\
\text { organofosforado, } 1 \text { inseticida e raticida, } \\
1 \text { carbamato e benzodiazepínico, } \\
1 \text { carbofuram,2 soda caustica, } \\
1 \text { ignorado }\end{array}$ \\
\hline
\end{tabular}


Óbitos por intoxicação exógena no Distrito Federal entre 2009 e 2013 dados consolidados

Os 436 casos de óbitos por intoxicação exógena no Distrito Federal reportados nos quatro sistemas (288 no SIM, 18 no SINAN, 29 no CIT e 101 no IML) foram reavaliados considerando o nome do indivíduo, a idade e/ou data de nascimento, e o nome da mãe de cada caso para identificação de duplicidades entre os sistemas. Adicionalmente, dois casos classificados no SIM como X84 (Lesão autoprovocada intencionalmente por meios não especificados) e R99 (Outras causas mal definidas e as não especificadas de mortalidade) foram reclassificadas para CID's X68 e X44 a partir de informações obtidas no SINAN e IML, respectivamente.

No total, eliminando-se as duplicidades dos casos e acrescentando-se os dois casos adicionais identificados no SIM, foram identificados 338 casos fatais por intoxicação exógena ocorridas no DF entre 2009 e 2013. A maioria envolvendo homens (227 casos, 67,2\%).

Considerando-se a população total do DF em 2010 (2.570.160 pessoas segundo o censo IBGE), estimou-se a uma incidência anual média de 2,63 casos por 100.000 habitantes. A população masculina, que corresponde a $47,9 \%$ da população do DF, teve uma incidência maior que a feminina (3,7 e 1,6 por 100.000 habitantes/ano, respectivamente).

A Figura 5 mostra a distribuição dos 338 casos em todos os sistemas. A maioria $(248 ; 73,4 \%)$ destes casos foram reportados em apenas um dos sistemas, 81 casos foram reportados em 2 sistemas (64 pelo SIM e IML), 8 casos foram reportados por 3 sistemas, e apenas 1 caso foi reportado em todos os sistemas, relativo a uma jovem de 22 anos que se suicidou em 2011 pela ingestão de chumbinho.

A Figura 6 mostra a distribuição dos 338 casos de acordo com o ano de ocorrência do óbito, com o maior número de casos reportado em 2010, decrescente até o final do período do estudo. 


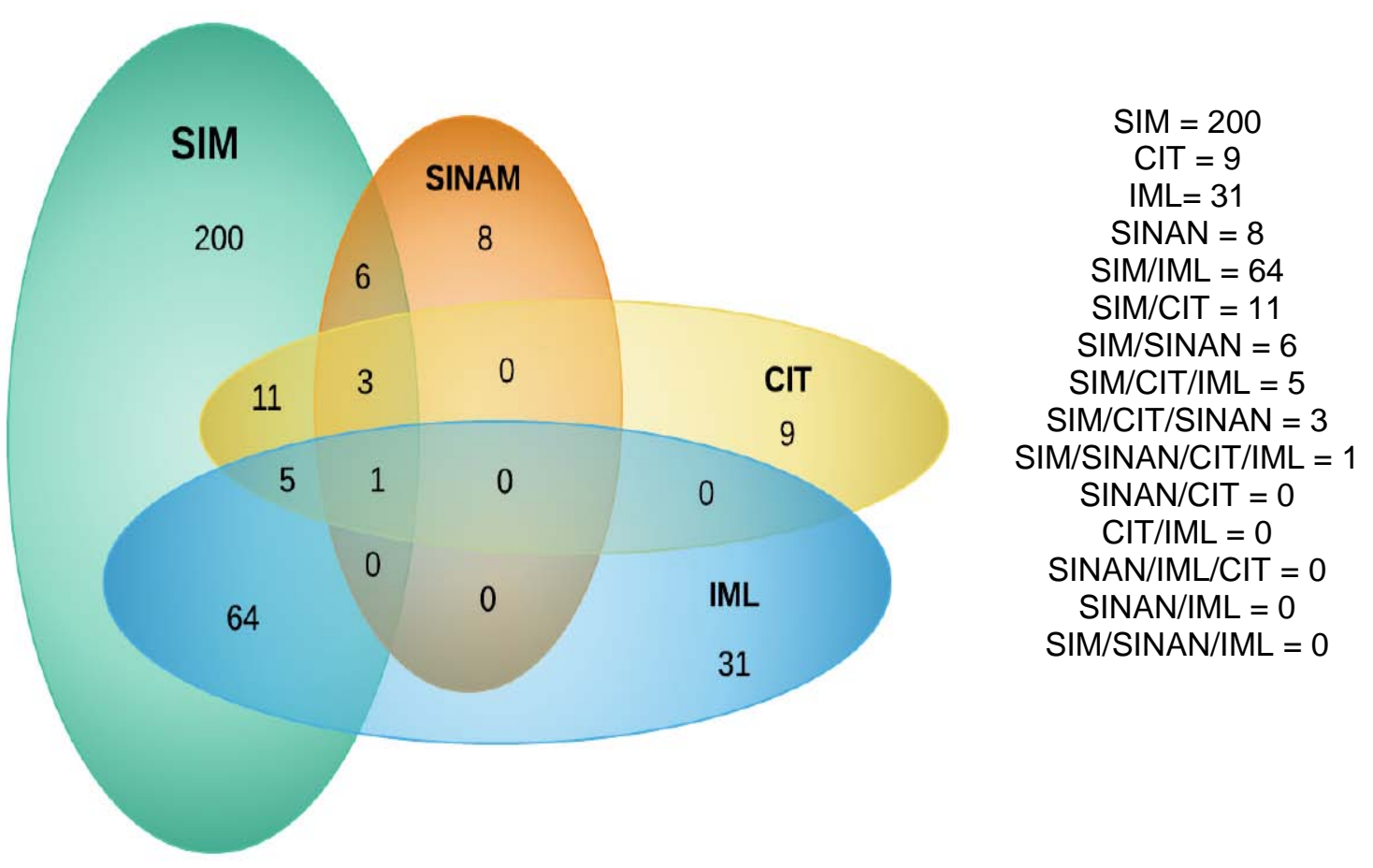

Figura 5. Diagrama de Venn dos 338 casos de óbitos por intoxicação exógena registrados no Distrito Federal reportados aos sistemas SIM, IML, CIT e/ou SINAN, 2009 a 2013.

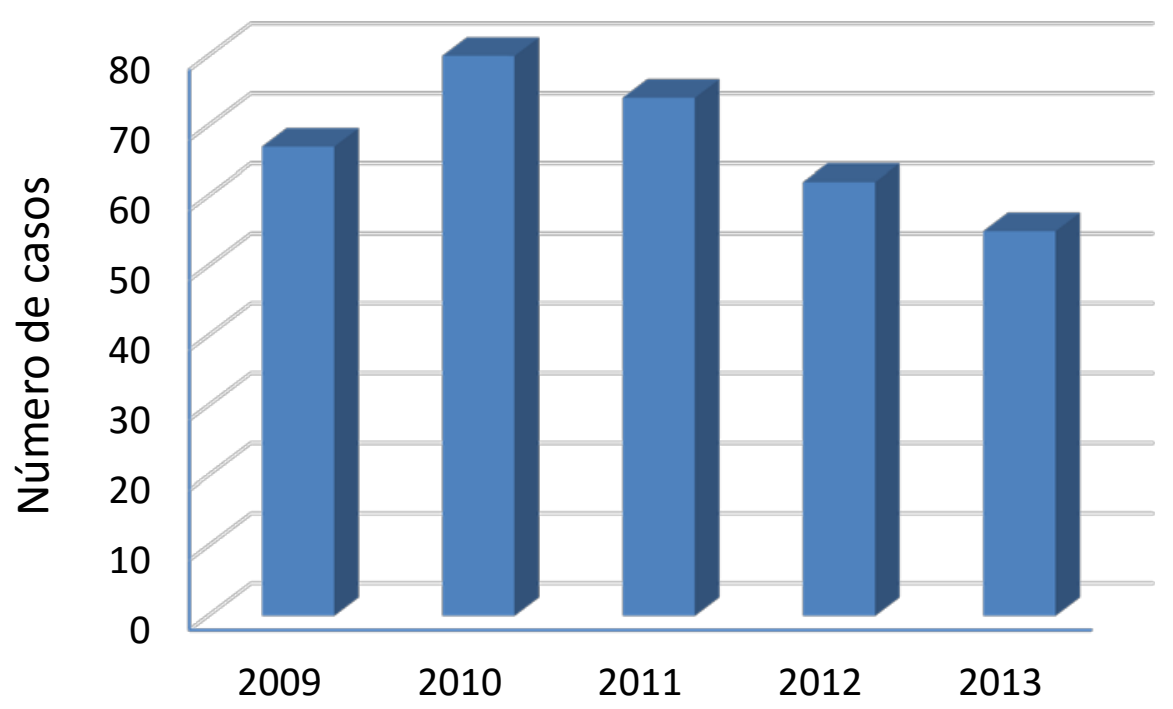

Figura 6. Distribuição dos 338 óbitos por intoxicação exógena ocorridos no Distrito Federal, em número de casos, no período de 2009 a 2013. 
A Figura 7 mostra a distribuição dos óbitos de acordo com a idade do indivíduo (5 casos com idade não reportada). Quase 10\% dos casos ocorreram com crianças até 6 anos, e nenhum ocorreu com indivíduos entre 7 e 12 anos de idade. A principal faixa etária correspondeu a indivíduos entre 30 e 39 anos (23,9\%).

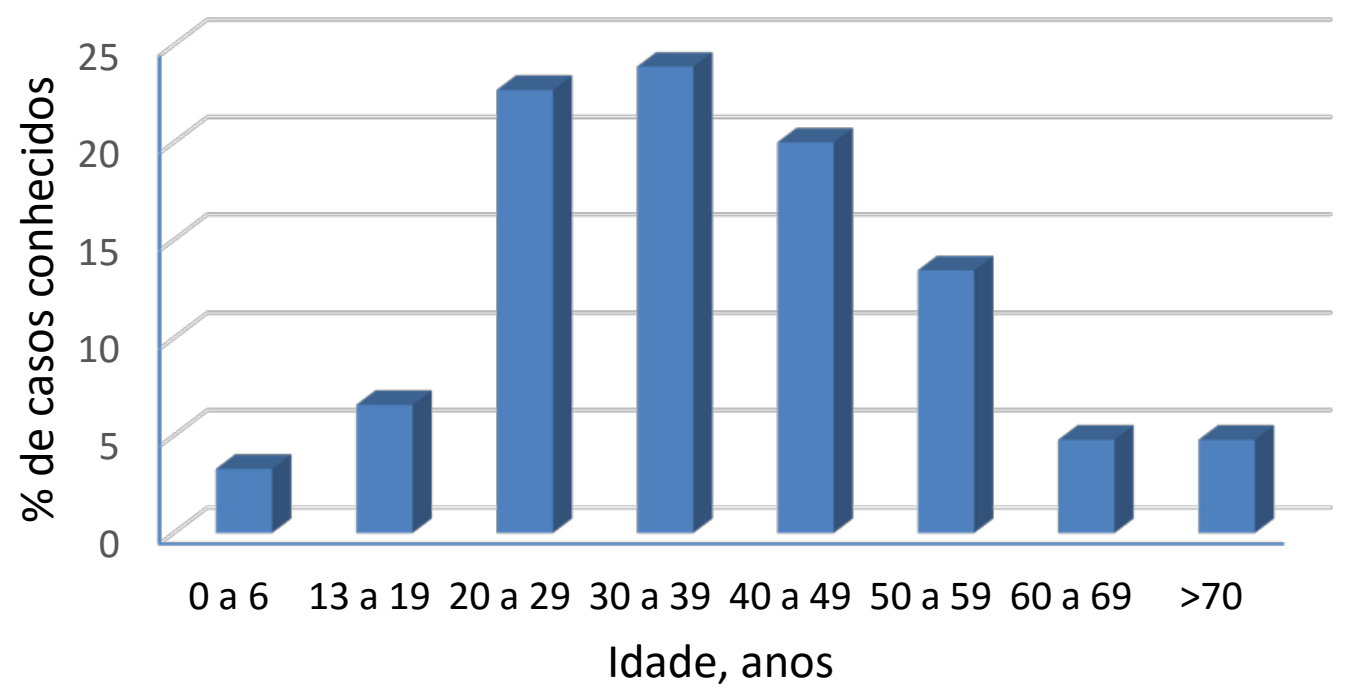

Figura 7. Distribuição dos 335 óbitos por intoxicação exógena com idade conhecida ocorridos no Distrito Federal, de acordo com a idade do indivíduo, em\% do número de casos, no período de 2009 a 2013.

Após a identificação dos 338 óbitos reportados nos quatro sistemas, procurou-se consolidar as informações de maneira a identificar discrepâncias e complementar informações que foram dadas apenas por um deles. Por exemplo, o SIM não indica especificamente óbitos por ingestão de cocaína, mas esta informação estava incluída para o mesmo caso em pelo menos um dos outros sistemas. Da mesma maneira, vários códigos do SIM não identificam a classe à qual a substância pertence (X69, X90 e Y19), ou o agrotóxico/raticida envolvido (X47 e X67), e esta informação foi obtida em outro sistema.

No total, foram encontrados 13 casos inconsistentes, seja pelo agente envolvido (agrotóxico/raticida ou medicamento) e/ou pela circunstância (suicídio ou acidente), todos entre o SIM e um dos outros sistemas avaliados. Nestes casos, considerou-se a informação indicada pelo SIM. Todos os casos 
envolvendo chumbinho ocorreram com adultos, e mesmo se a circunstância reportada tenha sido acidental ou desconhecida, considerou-se como suicídio. Da mesma maneira, casos com adultos envolvendo álcool e cocaína foram considerados acidentais. Casos reportados pelo IML no qual aldicarbe foi detectado no material gástrico foi classificado como intoxicação por chumbinho, mesmo quando esta informação não pode ser confirmada em outro sistema. A Tabela 3 mostra as características dos casos 338 casos consolidados com as informações dos 4 sistemas. A maioria dos casos foi acidental, seguido por suicídio. A incidência anual média de suicídios por intoxicação exógena na população do DF foi 1,2 casos /100.000 indivíduos (1,09 para mulheres e 1,32 para homens).

Tabela 3. Características dos 338 casos de óbitos por intoxicação exógena ocorridos no Distrito Federal no período de 2009 a 2013.

\begin{tabular}{lcc}
\hline & $\mathbf{N}$ & $\%^{\mathrm{a}}$ \\
\hline Circunstância & 164 & 50,8 \\
Acidental & 154 & 47,7 \\
Suicídio & 5 & 1,5 \\
Agressão/ocupacional & 15 & \\
Ignorada & & \\
Agente & $155^{\mathrm{b}}$ & 48,7 \\
Medicamento & $95^{\mathrm{c}, \mathrm{d}}$ & 29,9 \\
Agrotóxico/raticida & $35^{\mathrm{e}}$ & 11,0 \\
Álcool & $22^{\dagger}$ & 6,9 \\
Cocaína/outras drogas & 8 & 2,5 \\
Soda caustica & 5 & 1,6 \\
Gases/vapores & 3 & 0,9 \\
Solvente/glicerina & 1 & 0,3 \\
Hipoclorito de sódio & 20 & \\
Não especificado & \\
\hline relação ao total conhecido; b. Inclui 5 associações com álcool ou \\
ico; c. inclui 3 associações com medicamento ou cocaína; d. inclui 27 \\
mbinho; e. 4 associações com medicamento/droga; f. Uma associação \\
mbinho;
\end{tabular}




\section{Discussão}

A exposição humana a substâncias tóxicas representa um problema de saúde pública no mundo todo. Estimativas da Organização Mundial de Saúde (OMS) indicaram que a exposição acidental levou a 300.000 mortes em 2000, sendo mais de $20 \%$ envolvendo crianças de até 14 anos (IPCS, 2004). As intoxicações estão implicadas em cerca de $4,0 \%$ de todas as mortes na infância no mundo, e dentre os jovens de 15-19 anos, o envenenamento é classificado como a 13 maior causa de morte (HOLDER et al., 2008; TOWNER e SCOTT, 2008). Handley e Flanagan (2014) reportaram que 0,5\% de todos os óbitos que ocorreram na Inglaterra e País de Gales no período de 2000 a 2011 foram devido a intoxicações fatais, com cerca de 3 mil casos por ano. No Brasil, entre 300 e 500 óbitos por intoxicação foram reportados ao Sistema Nacional de Informações Toxico-Farmacológicas durante o mesmo período (FIOCRUZ, 2017). Estes números são reconhecidamente subestimados, principalmente por que vários CIT's deixaram de enviar seus dados para o Sistema nos últimos anos.

O presente estudo mostrou que a maioria dos envenenamentos fatais no DF ocorreram por acidente e $47,7 \%$ por suicídio. O suicídio é um trágico fenômeno mundial, e em 2012, 75\% deles ocorreram em países classificados como de renda baixa ou media, sendo também a segunda causa mais frequente de morte entre indivíduos de 15 a 29 anos (WHO, 2014). Dentre os adultos jovens estima-se que as tentativas de suicídio sejam subnotificadas, aparecendo sob a forma eufêmica de acidente ou violência externa, e muitas vezes omitida pelo embaraço familiar (WHO,2014). No Iran (AZIZPOUR et al., 2016), a incidência de suicídio por envenenamento entre 1993 a 2013 foi de 2.17 por 100.000 habitantes (1.9 mulheres e 2.4 homens), mais alta que 0 encontrado neste estudo para o Distrito Federal. A principal faixa etária envolvida nos casos iranianos foi de 15 a 24 anos, correspondendo a 58,9\% dos 160 casos, perfil distinto do encontrado no DF, que envolveu principalmente indivíduos acima de 30 anos ( $77 \%$ dos casos).

Gunnell et al. (2007) estimaram que cerca de $30 \%$ de suicídios no mundo ocorrem pela ingestão de agrotóxicos, percentual que varia entre 4\% na região europeia para mais de 50\% na região do Pacífico Oriental. A ingestão de 
agrotóxicos foi implicada em $62 \%$ dos suicídios por envenenamento na China entre 1996 e 2000 (ZHANG et al., 2009). Estimativa nacional do SINITOX mostram que 151 óbitos por intoxicação com agrotóxicos/raticidas ocorreram em 2012, correspondendo a cerca de $45 \%$ dos óbitos por intoxicações ocorridas, porém não é possível identificar quantos destes se referiram a suicídio. No presente estudo, $\sim 30 \%$ das intoxicações fatais envolveram agrotóxicos/raticidas, dos quais $85,2 \%$ por suicídio.

Dados do IML-DF de 2006 a 2008 mostram que, de um total de 8.736 exames realizados em material gástrico ou urina, $21,7 \%$ foram positivos para pelo menos um composto investigado, incluindo agrotóxicos, anfetaminas, benzodiazepínicos, barbitúricos, tetra-hidro-canabinol (THC), cocaína e opiáceos. Agrotóxicos foram encontrados em 13,3\% dos 188 casos investigados, principalmente adicarbe (CAMPELO; CALDAS, 2010). Aldicarbe é o principal componente do chumbinho, raticida comercializado ilegalmente no Brasil contendo inseticidas para uso agrícola (VIEIRA et al., 2006; BUCARETCHI et al., 2012). Neste estudo, o chumbinho teve um papel relevante entre as intoxicações letais, estando envolvido em pelo menos 27 casos de suicídio de adultos.

Os medicamentos foram o principal agente envolvido nas intoxicações fatais do DF, estando presente em quase a metade dos casos, incluindo associações com agrotóxico ou drogas de abuso. Este perfil difere do cenário nacional reportado pelo SINITOX, em que $44,9,0 \%$ da 334 intoxicações fatais com agente conhecido em 2012 se referiram a agrotóxicos e 30,2\% a medicamentos (FIOCRUZ, 2017). Mais da metade dos casos fatais no DF foram acidentes, incluindo 5 casos com crianças até 5 anos. Quase $70 \%$ dos casos envolveram medicamentos classificados pelo SIM como narcóticos e psicodislépticos (alucinógenos) ou anticonvulsivantes (antiepilépticos), sedativos, hipnóticos, e 18 casos tiveram o fármaco identificado nos outros sistemas, principalmente benzodiazepínicos, e dois casos com paracetamol.

No total, 57 casos com álcool e cocaína foram reportados, principalmente pelo IML (43 casos), subsidiado com a análise toxicológica. Além do efeito clinico, principalmente depressão do sistema nervoso e parada respiratória, o nível alcoólico no sangue é a principal ferramenta do médico 
legista para caracterizar a alcoolemia fatal (LAHTI et al., 2011). Vinte e dois casos do IML cuja causa morte foi identificada como alcoolemia fatal $(21,8 \%$ dos casos neste sistema) mostraram níveis de álcool no sangue de até $8,2 \mathrm{~g} / \mathrm{L}$. Níveis similares foram encontrados por Li et al. (2017) quando avaliou os 149 casos que ocorreram em Maryland (EUA) entre 2004 e 2012, com níveis alcoólicos mais baixos para indivíduos obesos. Dezesseis casos de alcoolemia foram reportados pelo SIM (5,6\% dos casos), classificados nos CID's X45, X61 e Y15. Lahti et al. (2011) concluíram que a classificação CID-10 subestima o número de alcoolemias fatais, principalmente quando associada a outras drogas, mesmo quando o médico legal indica o álcool como o componente mais importante. Os autores reportaram que em 2005, 631 alcoolemias fatais ocorreram na Finlândia (concentração média de 2,9 g/L), correspondendo a $27 \%$ das mortes com resultado positivo para álcool no sangue ( $\geq 0,5 \mathrm{~g} / \mathrm{L})$.

O número de casos envolvendo cocaína também pode estar subestimado neste estudo, principalmente no SIM, onde casos classificados como Envenenamento (intoxicação) acidental por e exposição a narcóticos e psicodislépticos (alucinógenos) (X42) foram identificados em outros sistemas como cocaína, mas 62 permaneceram sem a identificação do agente envolvido. A cocaína foi a única subsância de abuso ilegal envolvida nas intoxicações no DF. Este perfil difere de países do hemisfério norte, onde os opioides (incluindo heroína, morfina e metadona) são os principais agentes envolvidos (MOWRYet al., 2014; SIMONSENet al., 2015).

A Tabela 4 sumariza os dados de alguns estudos publicados na literatura que reportaram óbitos por intoxicação exógena no Brasil. 
Tabela 4. Registros de óbitos por sistema de informação e agente causador relatados na literatura.

\begin{tabular}{|c|c|c|}
\hline $\begin{array}{l}\text { Sistema de } \\
\text { Informação }\end{array}$ & $\begin{array}{l}\text { Agente causador } \\
\text { Frequência }\end{array}$ & Referência \\
\hline & $\begin{array}{c}\text { SINAN } \\
\text { Medicamentos } 72,2 \%\end{array}$ & \\
\hline SINAN e SIM /MG & $\begin{array}{l}\text { Raticidas } 18,2 \% \\
\text { SIM } \\
\text { CID X80.0- X83.9 }\end{array}$ & RIBEIRO, 2016 \\
\hline IML/PE & $\begin{array}{l}\text { Organofosforados } 10,6 \% \\
\text { Carbamatos } 6,4 \%\end{array}$ & VIEIRA et al.,2016 \\
\hline IML/MG & Medicamento $12,2-27,8 \%$ & $\begin{array}{c}\text { BATISTA E } \\
\text { GOMES, } 2016\end{array}$ \\
\hline SIM/BRASIL & Agrotóxicos uso ocupacional & BOCHNER, 2015 \\
\hline IML/RJ & Álcool etílico & CRUZ et al., 2014 \\
\hline $\begin{array}{l}\text { CCIN-NITERÓI } \\
\text { SIM/SINAN RJ }\end{array}$ & $\begin{array}{l}\text { Medicamentos } 11,1-34,4 \% \\
\text { Agrotóxicos } 46,9-68,7 \% \\
\text { Produtos químicos } 6,2-18,4 \%\end{array}$ & SANTOS, 2013 \\
\hline SIM/BRASIL & Agrotóxicos uso ocupacional & $\begin{array}{l}\text { SANTANA et al., } \\
2013\end{array}$ \\
\hline SIM/ BRASIL & $\begin{array}{c}\text { Álcool } 84,9 \% \\
\text { Fumo } 11,3 \% \\
\text { Outras substâncias psicoativas } \\
1,8 \% \\
\text { Cocaína } 0,8 \%\end{array}$ & CNM, 2012 \\
\hline SIM/BRASIL & Medicamentos & MOTA et al., 2012 \\
\hline IML/DF & $\begin{array}{c}\text { Álcool } 47,4 \% \\
\text { Cocaína } 21,6 \% \\
\text { THC 17,5\% } \\
\text { Agrotóxicos 13,3\% } \\
\text { Benzodiazepínicos 4,6\% }\end{array}$ & $\begin{array}{l}\text { CAMPELO e } \\
\text { CALDAS, } 2010\end{array}$ \\
\hline IML/MG & $\begin{array}{c}\text { Etanol } 66,5 \% \\
\text { Carbamatos } 11,2 \% \\
\text { Medicamentos } 9,7 \%\end{array}$ & MONTEIRO, 2010 \\
\hline
\end{tabular}

Este estudo mostrou claramente que os óbitos por intoxicação exógena são subnotificados no Distrito Federal, principalmente no SINAN. Santos et al. (2013) avaliaram o número de suicídios por intoxicação exógena no Rio de Janeiro entre 2006 e 2008, identificando 33 casos no CIT, 23 casos no SINAN e 180 casos no SIM, com razão em relação aos dados do SIM 
(CIT/SINAN/SIM) de 0,18/0,13/1. No Distrito Federal, a subnotificação foi ainda maior, com razão de 0,1/0,06/1, sendo o dobro de subnotificação no SINAN, comparado ao estudo do Rio de Janeiro. O número de casos fatais por intoxicação exógena no estado de Pernambuco num período de 5 anos (2008 a 2012) é bem maior que os dados do DF e RJ, com 552 casos envolvendo agrotóxicos reportados pelo SIM, 237 pelo SINAN e 201 pelo CEATOX (Centro de Assistência Toxicológica) (Albuquerque et al., 2015), e uma razão CEATOX/SINAN/SIM de 0,36/0,43/1.

No DF, a principal causa da subnotificação de óbitos no SINAN é a incompletude dos dados referente a evolução do caso (mais de $50 \%$ dos casos de intoxicação exógena não possuem esta informação, Cap. II), provavelmente por falta de acompanhamento dos casos que deram entrada no Sistema. Os profissionais de saúde, incluindo os gestores, na sua grande maioria desconhecem que as notificações para o SINAN são uma obrigação legal não uma escolha.

No CIT, por outro lado, a notificação dos casos é espontânea, sendo realizada principalmente por profissionais de saúde que buscam informações acerca do diagnóstico e tratamento. Entretanto, a notificação pode ser aumentada a partir de um maior reconhecimento dos profissionais de saúde sobre o serviço prestado, e a carência de capacitação regular sobre intoxicações junto aos profissionais de saúde, estudantes e a comunidade. Adicionalmente, é necessário modernizar os recursos para o registro da informação, que hoje ocorre apenas via telefônica, visando ampliar a possibilidade de notificação,

O SIM é o principal sistema de registro de óbitos do País com uma cobertura de $97 \%$ no Distrito Federal. Porém, 48 casos de intoxicações fatais ocorridas no período do estudo não foram notificados no SIM. Esse sistema tem como fonte de dados a Declaração de Óbito, cuja responsabilidade do preenchimento é do profissional médico (Resolução CFM no 1931, 2009), e não está sujeita ao sigilo profissional. Erros, imprecisões e omissões verificados no preenchimento da DO podem, porém, conduzi-lo às penalidades previstas no Código Penal e na legislação dos Conselhos de Medicina (SILVEIRA, 2001). Pedrosa et al. (2002) avaliaram a qualidade da informação sobre causa básica 
de óbitos neonatais em Maceió ( $A L$ ) registrado no SIM, e concluíram ser necessário o treinamento dos profissionais no preenchimento da DO para que os dados do SIM possam ser utilizadas em sua plenitude. Mendonça et al. (2010) reportaram que os principais problemas apontados por médicos e epidemiologistas de Belo Horizonte sobre o preenchimento da DO foram o próprio formulário (grande número de campos a serem preenchidos); falhas na disseminação de instruções para preenchimento; falta de informações suficientes para registrarem o óbito; necessidade de melhorias no nível de conhecimento dos médicos sobre o adequado detalhamento das possíveis causas de morte, principalmente no que diz respeito à causa básica; desconhecimento por parte dos médicos da importância do adequado e completo preenchimento do formulário para a veracidade e consistência das informações coletadas pelo SIM. Todas estas circunstâncias podem levar a uma classificação equivocada da CID-10.

Neste estudo, conseguimos identificar entre os óbitos por causas externas reportadas ao SIM (os únicos aos quais tivemos acesso), dois casos com classificação CID equivocada. Adicionalmente, é possível óbitos não tenham sido classificados no sistema como de causa externa no SIM, e que o total número de óbitos na região no período do estudo esteja subnotificado.

No IML, as informações do laudo de necropsia, que incluem resultados dos exames toxicológicos, quando existentes, anatomopatológicos, e da investigação policial, são transcritos na DO que é enviada para a secretaria de saúde para a codificação e seleção da causa básica, e posterior alimentação do SIM. A alegação de desconhecimento e temor de implicações legais são as justificativas mais comuns dos médicos legistas para a ausência do registro das circunstâncias do óbito nas DO, levando ao um número excessivo de óbitos classificados como acidentes não especificados ou lesões de intencionalidade ignorada (MOTA et al., 2007). Realmente, o número de laudos de necropsia com causa mortis "indeterminada", ou a "esclarecer" na suspeita de intoxicação exógena/envenenamento nos laudos de necropsia emitidos pelo IML-DF foi considerável. Matos et al. (2007) relataram que a deficiências nos laudos das necropsias de mortes violentas em Belo Horizonte foram devidas, principalmente à ausência de resultados de exames toxicológicos e à falta de 
padronização na emissão dos registros. Simões e Reichenheim (2001) também encontraram deficiências importantes nos laudos de necropsia dos óbitos por causas externas em menores de 18 anos em Duque de Caxias (RJ), comprometendo a qualidade da DO.

Em muitos casos, uma análise toxicológica adequada pode identificar o agente envolvido nas intoxicações exógenas. Porém, a impossibilidade de respostas laboratoriais rápidas e a necessidade de liberação da DO para que o corpo possa ser sepultado, pode impedir a conclusão do caso. O Laboratório de Toxicologia do IML-DF realiza exames toxicológicos para complementar a investigação diagnóstica do óbito, incluindo a análise de substâncias entorpecentes e psicoativas (anfetaminas, barbitúricos, opiáceos, benzodiazepínicos, maconha, cocaína e drogas sintéticas) e alcoolemia. Porém, é importante ressaltar que um achado laboratorial positivo pode não estar relacionado diretamente com causa básica do óbito. Quando se analisa os resultados dos exames toxicológicos realizados no período do estudo, verifica-se que $26,7 \%$ dos 15.413 laudos cadavéricos do período do estudo apresentaram resultado positivo para pelo menos um xenobiótico analisado (dados não mostrados). A não confirmação laboratorial se deve a vários fatores, incluindo o tempo entre o óbito e a necropsia, que compromete a qualidade da amostra biológica, o método analítico inadequado, e o entendimento do médico perito acerca do caso.

A qualidade dos dados é tema recorrente nas avaliações dos sistemas de informação em saúde. Critérios são apontados para a sua avaliação, tais como a subnotificação, consistência, incompletude e confiabilidade (LIMA, 2010). A incompletude (do campo) é a proporção de informação em branco ou preenchido como ignorada (ROMERO; CUNHA, 2002). Segundo esses autores, a completitude pode ser classificada como excelente quando 0 percentual de campos preenchidos é superior a $90 \%$, regular de 70 a $89 \%$, e ruim quando abaixo de $70 \%$.

A análise da incompletude dos dados avaliados nesse estudo mostrou que o desempenho dos campos das fichas apresenta uma grande variação, não só quanto ao preenchimento como também o preenchimento correto dos dados. Nos bancos de dados do CIT-DF, SIM-DF e IML-DF, a completude ficou 
entre excelente e bom. Contudo, ao examinar os dados do SINAN, observaram-se campos com completude excelente e outros ruim, principalmente com relação ao desfecho do caso (Cap. II), o que pode explicar o baixo número de óbitos reportados neste sistema

\section{Conclusão}

Os óbitos por intoxicação que ocorreram no DF no período do estudo, registrados no SIM, SINAN, CIT e IML ocorreram principalmente devido a acidente ou suicídio, causados por medicamentos, pesticidas e chumbinho, atingindo principalmente adultos jovens. A subnotificação foi mais presente no SINAN e ficou evidente a dificuldade de caracterização do óbito por intoxicação pelo IML.

Apesar dos sistemas SINAN, SIM, CIT e IML serem diferentes em termos de cobertura, abrangência, qualidade e agilidade na disponibilidade de dados, entre outras peculiaridades, e de apresentarem falhas operacionais que necessitam serem corrigidas, os dados obtidos foram complementares para se desenhar um panorama dos agentes envolvidos nas intoxicações fatais e 0 perfil da população envolvida.

Os sistemas de toxicovigilância devem ser avaliados periodicamente, visando tornar mais efetivas e ágeis as medidas de controle de eventos adversos à saúde. O treinamento dos profissionais de saúde (principalmente médicos e enfermeiros) é fundamental para que eles percebam a importância da notificação para a manutenção ou mudanças das políticas de saúde. 


\section{CONCLUSÕES FINAIS}

O presente estudo teve como ponto de partida a investigação dos casos de intoxicação exógena disponíveis nos sistemas de registros oficiais que compõem a toxicovigilância do Distrito Federal. Foram utilizados dados do Centro de Informações Toxicológicas (CIT-DF), do Sistema de Informação de Notificação de Doenças (SINAN-DF), do Sistema de Informações sobre Mortalidade (SIM-DF), do Centro de Referência em Saúde do Trabalhador (CEREST-DF) e do Instituto de Medicina legal do DF (IML-DF) no período de 2009 a 2013.

Com a finalidade de se identificar as intoxicações ocorridas no exercício da atividade laboral, foram avaliados 382 prontuários de trabalhadores expostos a produtos químicos atendidos no ambulatório de toxicologia ocupacional do CEREST. A amostra foi constituída principalmente por homens na faixa etária de 30-39 anos, que cursaram até o ensino médio (46,3\%), e trabalhavam na atividade por até 9 anos. Mais de $80 \%$ dos trabalhadores não utilizavam equipamento de proteção individual durante o trabalho, e a maioria $(57,3 \%)$ foi diagnosticado como intoxicado, principalmente por agrotóxicos. Apesar de estes dados serem importantes para a região, a incompletude das informações nos prontuários, principalmente relacionado aos exames laboratoriais, comprometeu uma avaliação mais aprofundada dos casos atendidos. Esta incompletude se deve principalmente às dificuldades dos pacientes em realizar exames básicos na Secretaria de Saúde do DF. Adicionalmente, foi identificada a necessidade da reavaliação do teste da colinesterase utilizado atualmente na rotina do laboratório, bem como a implantação de testes toxicológicos mais específicos com o intuito de fortalecer a investigação e o diagnóstico correto dos casos.

Durante o período do estudo, foram registrados 3.622 casos de intoxicação exógena no CIT e 5.702 casos no SINAN. Em ambos os sistemas a maioria dos casos ocorreu com mulheres. No CIT, a maioria dos casos reportados envolveram foram crianças de até 9 anos, enquanto no SINAN a principal população foi de adultos. A maioria das intoxicações foi acidental. Enquanto os medicamentos foram o principal agente envolvido nas 
intoxicações ( 40\%), os agrotóxicos foram os mais letais $(3,4 \%$ dos 263 casos no CIT). Outros agentes incluíram produtos de limpeza, drogas de abuso, raticidas, incluindo o chumbinho, produtos químicos industriais e plantas. Apesar de o CIT subestimar os casos de intoxicação ocorridos, os dois sistemas se complementam na descrição dos casos de intoxicações do DF. Porém é necessário aprimorar a capacitação do profissional de saúde, aumentando a conscientização da importância da notificação para as ações de vigilância sanitária, e melhorar preenchimento dos formulários visando diminuir a incompletude dos dados, principalmente no SINAN.

De 2009 a 2013, 288 casos de intoxicação fatal foram reportados ao SIM, 18 ao SINAN, 29 ao CIT e 101 casos foram identificados no IML. Sem considerar as duplicidades, 338 casos de intoxicações fatais ocorreram no DF neste período, dos quais apenas 1 caso foi reportado pelos quatro sistemas. Quase a metade dos óbitos envolveu medicamentos, seguido de agrotóxico ou chumbinho, em circunstâncias acidentais ou por suicídio, envolvendo indivíduos acima de 15 anos, e 11 casos com crianças até 6 anos. Este estudo mostrou uma subnotifição importante do registro dos óbitos, principalmente no SINAN, onde mais da metade dos casos de intoxicação exógena não tinha desfecho final, o que levou a um baixo número de óbitos confirmados no sistema. O principal problema identificado nos casos do IML foram deficiências no preenchimento da declaração de óbito, que leva a um número muito grande de fatalidades de causa violenta sem identificação do agente.

Em resumo, a avaliação dos casos de intoxicação exógena reportados aos sistemas de vigilância do Distrito Federal nos permitiu descrever um panorama destes casos na região. A limitações identificadas no estudo mostrou ser essencial que as autoridades de saúde reconheçam as deficiências e a importância de melhorar o sistema para que os dados possam subsidiar as ações de vigilância junto à população. 


\section{REFERÊNCIAS BIBLIOGRÁFICAS}

AGROFIT (Sistemas de Agrotóxicos Fitossanitários). Ministério da Agricultura Pecuária e Abastecimento. 2017. Disponível em: $<$ http://agrofit.agricultura.gov.br/agrofit_cons/principal_agrofit_cons>. Acesso em: fev. 2017

ALBUQUERQUE, P.C.C.D.; GURGEL, I.G.D.; GURGEL, A.D.M.; AUGUSTO L.G.D.; DE SIQUEIRA, M.T.D. Health information systems and pesticide poisoning at Pernambuco. Revista Brasileira de Epidemiologia, São Paulo, v. 18, n. 3, p. 666-78, 2015.

ALCÂNTARA, H. R. Perícia médica judicial. 2. ed. Rio de Janeiro: Guanabara Koogan, 2006. 510 p.

ALMEIDA, M. R.; CASTRO, L. L. C; CALDAS, E. D. Conhecimentos, práticas e percepção de risco do uso de medicamentos no Distrito Federal. Revista de Ciências Farmacêuticas Básica e Aplicada, São Paulo, v.32, p.225 - 232, 2011.

ALVES, S. R. Toxicologia forense e saúde pública: desenvolvimento e avaliação de um sistema de informações como potencial ferramenta para a vigilância e monitoramento de agravos decorrentes da utilização de substâncias químicas. 2005. 132 f. Tese (Doutorado em Saúde Pública) Escola Nacional de Saúde Pública, Fundação Oswaldo Cruz, Rio de Janeiro, 2005.

AMORIM, L. C. A. O uso dos biomarcadores na avaliação da exposição ocupacional a substâncias químicas. Revista Brasileira de Epidemiologia, São Paulo, v. 6, n. 2, p. 158-170, 2003.

ANDRADE FILHO, A.; CAMPOLINA, D.; DIAS, M.B. Toxicologia na prática clínica. 2. ed. Belo Horizonte: Folium, 2013. 700p.

ANVISA. (Agencia Nacional de Vigilância Sanitária). Disque-intoxicação [online], ANVISA, Brasília, 2006. Disponível em: <http://portal.anvisa.gov.br/disqueintoxicacao>. Acesso em: fev. 2016.

ANVISA (Agência Nacional de Vigilância Sanitária). Resolução RDC no 19, de 03 de fevereiro de 2005. Cria a Rede Nacional de Centros de Informação e Assistência toxicológica (RENACIAT). Diário Oficial da União, 04 fev. 2005. Disponívelem:<http://portal2.saude.gov.br/saudelegis/leg_norma_pesq_consult a.cfm>. Acesso em: set. 2016.

ARAÚJO, A. J.; LIMA, J.S.; MOREIRA, J.C.; JACOB, S.C.; SOARES, M.O.; MONTEIRO, M. C. M. et al. Exposição múltipla a agrotóxicos e efeitos à saúde: estudo transversal em amostra de 102 trabalhadores rurais, Nova Friburgo, RJ. Ciência e Saúde Coletiva, Rio de Janeiro, v. 12, n. 1, p. 115-30, 2007. 
ARGENTINA. El Hospital de Niños Ricardo Gutierrez. Toxicologia [online]. Buenos Aires. Disponível em: <http://guti.gob.ar/servicios-medicos/36toxicologia.html\#detalles $>$. Acesso em: out. 2016.

ARSHAD, M.; SIDDIQA, M.; RASHID, S.; HASHMI, I.; AWAN, M. A.; ALI, M. A. Biomonitoring of toxic effects of pesticides in occupationally exposed individuals. Safety and Health at Work, Korea (South), v. 7, n. 2, p. 156-160, 2016.

ATSDR (Agency for Toxic Substances and Disease Registry). The priority list of hazardous substances that will be the candidates for toxicological profiles. 2014. Disponível em: <https://www.atsdr.cdc.gov/spl/>. Acesso em: set. 2016.

AZKUNAGA, B.; MINTEGI, S.; SALMÓN, N.; ACEDO, Y.; DEL ARCO, L.; Y GRUPO DE TRABAJO DE INTOXICACIONES DE LA SOCIEDAD ESPAÑOLA DE URGENCIAS DE PEDIATRÍA. Poisoning in children under age 7 in Spain: areas of improvement in the prevention and treatment [in Spanish]. Anales de Pediatría, Barcelona, v. 78, p. 355-360, 2013.

AZIZPOUR,Y.;ASADOLLAHI,K.;SAYEHMIRI,K.;,S.;ABANGAH,G.Epidemiologic al survey of intentional poisoning suicide during 1993-2013 in Ilam Province, Iran. BMC Public Health, London, v. 16, n. 1, 2016.

BAPTISTA, M. N.; GOMES, M.A.B. Suicídio: Análise Epidemiológica na Região de Cara-tinga (MG) entre 2003 e 2010. Psicologia Argumento, Paraná, v. 34, n. 85, 2016.

BAROUD, R. Concepção e organização de um Centro de Controle de Intoxicações. Revista de Saúde Pública, São Paulo, v. 19, n. 6, p. 556-65, 1985.

BENTUR, Y.; LURIE, L.; CAHANA, A.; LAVON, O.; BLOOM-KRASIK, A.; KOVLER, N.; GUREVYCH, B.; RAIKHLIN-EISENKRAFT, B. Poisoning in Israel: anual report to the Israel Poison Information Center, 2007. Israel Medical Association Journal, Jerusalem, v. 11, p. 749-756, 2008.

BERNSTEIN, I. L.; BERNSTEIN, J. A.; MILLER, M.; TIERZIEVA, S.; BERNSTEIN, D. I.; LUMMUS, Z.; SELIGY, V. L. Immune responses in farm workers after exposure to Bacillus thuringiensis pesticides. Environmental Health Perspectives, United States, v.107, n. 7, p. 575-582, 1999.

BLANC, P. D.; HIATT, P. H.; OLSON, K. R. The toxic hazards of industrial and occupational chemicals. In: OLSON, K. R. (Ed.). Poisoning \& drug overdose. 6. ed. New York: McGraw-Hill Companies, c2012. 832 p. Chapter 241. Disponível em:<http://accessmedicine. $m$ hmedical.com/content.aspx?bookid=391\&Sectioni $d=42070057$ > . Acesso em: set. 2016. 
BLEECKER, J.; NEUCKER, K.; COLARDYN, F. Intermediate syndrome in organophosphorus poisoning: a prospective study. Critical Care Medicine, New York, v.21, n. 11, p. $1706-1711,1993$.

BOCHNER, R. Informação sobre intoxicações e envenenamentos para a gestão do SUS: um panorama do Sistema Nacional de Informações TóxicoFarmacológicas - SINITOX. Revista Eletrônica de Comunicação Informação e Inovação em Saúde, Rio de Janeiro, v. 7, n. 2, jun. 2013. Disponível em: $<$ http://www.reciis.icict.fiocruz.br/index.php/reciis/article/view/472/1123>.

Acesso em: set. 2016

BOCHNER, R. Óbito ocupacional por exposição a agrotóxicos utilizado como evento sentinela: quando pouco significa muito. Vigilância Sanitária em Debate: sociedade, ciência e tecnologia. Rio de Janeiro, v. 3, n. 4, p. 39-49, 2015.

BOCHNER, R. Sistema Nacional de Informações Tóxico-Farmacológicas SINITOX e as intoxicações humanas por agrotóxicos no Brasil. Ciência e Saúde Coletiva, Rio de Janeiro, v. 12, n. 1, p. 73-89, 2007.

BOCHNER, R.; SOUZA, V. M. F. A. Panorama das intoxicações e envenenamentos registrados no Brasil pelo Sistema Nacional de Informações Tóxico-Farmacológicas (SINITOX). Revista Racine, São Paulo, v. 18, p. 44-58, 2008.

BOLOGNESI, C. Genotoxicity of pesticides: a review of human biomonitoring studies. Mutation Research, Netherlands, v. 543, n. 3, p. 251-272, 2003.

BONNER, M. R.; BEANE FREEMAN, L. E.; HOPPIN, J. A.; KOUTROS, S.; SANDLER, D. P.; LYNCH, C. F., ALAVANJA, M. C. Occupational exposure to pesticides and the incidence of lung cancer in the agricultural health study. Environmental Health Perspectives. 2016 [Epubaheadofprint].

BORTOLETTO, M.E. Tóxicos, civilização e saúde: contribuição à análise dos sistemas de informações tóxico-farmacológicas no Brasil.1990. $142 \mathrm{f}$. Monografia (Mestrado em Administração Pública) - Fundação Oswaldo Cruz, Rio de Janeiro, 1990.

BOX, S. A.; LEE, M.R. A systemic reaction following exposure to a pyrethroid insecticide. Human and Experimental Toxicology, England, v.15, n. 5, p. 389390, 1996.

BRADBERRY, S. M.; CAGE, S. A.; PROUDFOOT, A. T.; VALE, J. A. Poisoning due to pyrethroids. Toxicological reviews. New Zealand, v. 24, n. 2, p. 93-106, 2005.

BRASIL. Câmara dos Deputados. Projeto de Lei $n^{\circ}$ 530/2003. Cria a embalagem especial de proteção à criança, para medicamentos, produtos químicos ou inflamáveis de uso doméstico que oferecem risco à saúde. Relator: Deputado Jorge Gomes. Arquivado. Projetos de lei, Brasília, 2008. 
Disponível

em:

$<$ http://www.camara.gov.br/proposicoesWeb/fichadetramitacao $>$. Acesso em: fev. 2014.

BRASIL. Lei no 7.802, de 11 de julho de 1989. Dispõe sobre a pesquisa, a experimentação, a produção, a embalagem e rotulagem, o transporte, 0 armazenamento, a comercialização, a propaganda comercial, a utilização, a importação, a exportação, o destino final dos resíduos e embalagens, 0 registro, a classificação, o controle, a inspeção e a fiscalização de agrotóxicos, seus componentes e afins, e dá outras providências. Diário Oficial da União. Brasília, 12 jul. 1989. p. 11459.

BRASIL. Ministério da Saúde. Portaria Ministerial no 104, de 25 de janeiro de 2011 [online]. Define as terminologias adotadas em legislação nacional, conforme o disposto no Regulamento Sanitário Internacional 2005 (RSI 2005), a relação de doenças, agravos e eventos em saúde pública de notificação compulsória em todo o território nacional e estabelece fluxo, critérios, responsabilidades e atribuições aos profissionais e serviços de saúde. Diário Oficial da União. Brasília, 26 jan. 2011. Seção 1, p. 37. Disponível em: $<$ http://portal2.saude.gov.br/saudelegis/leg_norma_pesq_consulta.cfm>. Acesso em: nov. 2016.

BRASIL. Ministério da Saúde. Secretaria de Vigilância em Saúde. Departamento de Análise de Situação de Saúde. Manual de Instruções para o preenchimento da declaração de óbito. Brasília: MS, 2011, 54p.

BRASIL. Ministério da Saúde. Secretaria Nacional de Vigilância Sanitária. Portaria no 03, de 16 de janeiro de 1992. Brasília, [1992]. Disponível em:<http://www.fcav.unesp.br/Home/departamentos/fitossanidade/JOAQUIMG ONCALVESMACHADONETO/port_\%200392_anvisa_class_toxicol.pdf>. Acesso em: set. 2016.

BRASIL. Ministério da Saúde. Sistema Único de Saúde. Centro de Referência em Saúde do Trabalhador. Locais de atendimento. 2016. Disponível em: $<$ https://www.ribeiraopreto.sp.gov.br/cerest/index.php?pagina=/cerest/i16locais. htm>. Acesso em: set. 2016.

BRASIL. Ministério do Trabalho e Emprego. Norma regulamentadora 7. Programa de Controle Médico de Saúde Ocupacional, 2013. Disponível em: <http://trabalho.gov.br /images/Documentos/SST/NR/NR7.pdf>. Acesso em: set. 2016.

BRASIL. Ministério do Trabalho e Previdência Social. Anuário estatístico da previdência social (AEPS) [referente ao ano de 2014]. Brasília: MTPS, 2016. Disponível em <http://trabalho.gov.br/noticias/3192-anuario-estatistico-daprevidencia -social-aeps-2014-ja-esta-disponivel-para-consulta>. Acesso em: set. 2016. 
BRASIL. O que devemos saber sobre medicamentos. Anvisa, Brasília. Brasil: ANVISA, 2010. Disponível em: <http://portal.anvisa.gov.br/medicamentos>. Acesso em: out. 2016.

BRASIL. Portaria no 1823, de 23 de setembro de 2012. Institui a Política Nacional de Saúde do Trabalhador e da Trabalhadora. Diário Oficial da União. 24 ago. 2012.

BRENT, J. Critical care toxicology: diagnosis and management of the critically poisoned patient. St. Louis: Mosby, 2005. 1690 p.

BUCARETCHI, F.; PRADO, C.C.; BRANCO, M.M.; SOUBHIA, P.; METTA, GM.; MELLO, S. M.; DE CAPITANI, E.M. et al. Poisoning by illegal rodenticides containing acetylcholinesterase inhibitors (chumbinho): a prospective case series. Clinical Toxicology, New York, v. 50, n. 1, p. 44-51, 2012.

BUDAVARI, S. The Merck index: an encyclopedia of chemicals, drugs, and biologicals. 12th ed. Whitehouse Station, NJ: Merck, 1996. 1741 p.

BUTINOF, M.; FERNANDEZ, R. A.; STIMOLO, M. I.; LANTIERI, M. J.; BLANCO, M.; MACHADO, A. L. Pesticide exposure and health conditions of terrestrial pesticide applicators in Córdoba Province, Argentina. Cadernos de Saúde Pública, Rio de Janeiro, v. 31, n. 3, p. 633-646, 2015.

CALDAS, E. D. Pesticide poisoning in Brazil: reference module in earth systems and environmental sciences. 1. ed. [s.I.]: Elsevier, 2016, p. 1-9.

CALDAS, E.D.; REBELO, F. M.; HELIODORO, V.O.; MAGALHÃES, A.F.A.; REBELO, R.M. Poisonings with pesticides in the Federal District of Brazil. Clinical Toxicology, Philadelphia, v. 46, n. 10, p. 1058 - 1063, 2008.

CALDAS, L. Q. A.; MORAES, A. C. L.; UNES, A. Toxicologia médica: a desinformação é alarmante. Ciência Hoje, Rio de Janeiro, v. 21, n. 124, p. 6670, 1996.

CALVERT, G. M., PETERSEN, A. M., SIEVERT, J., MEHLER, L. N., DAS, R., HARTER, L. C., SCHWARTZ, A. Acute Pesticide Poisoning in the U.S. Retail Industry,1998-2004. Public Health Reports, Washington, v. 122, n. 2, p. 23244, 2007

CAMPELO, E. L.; CALDAS, E. D. Postmortem data related to drug and toxic substance use in the Federal District, Brazil, from 2006 to 2008. Forensic Science International, Ireland, v. 200, n. 1-3, p. 136-140, 2010.

CAMPOS, É.; DOS SANTOS, P.S.V.; SARPA, C. M. M.; BARROS, O.U. Exposure to pesticides and mental disorders in a rural population of Southern Brazil. Neurotoxicology, Netherlands, v. 56, p. 7-16, 2016. 
CAPCC (CANADIAN ASSOCIATION OF POISON CONTROL CENTRES). History of poison control. [site]. Canada. 2016. Disponível em: <http://www.capcc.ca/en> Acesso em: out. 2016.

CDC (CENTERS FOR DISEASE CONTROL AND PREVENTION). Emergency preparedness and response: facts about Paraquat [online]. 2013. Disponível em: <https://emergency.cdc.gov/agent/paraquat/basics/facts.asp >. Acesso em: set. 2016.

CDC (CENTERS FOR DISEASE CONTROL AND PREVENTION). Fourth national report on human exposure to environmental chemicals, 2009 [online]. 2009. Disponível em: <https://www.cdc.gov/exposurereport/>. Acesso em: set. 2016.

CHIBISHEV, A.; PERESKA, Z.; CHIBISHEVA, V.; SIMONOVSKA, N. Corrosive poisonings in adults. Materia Socio-medica, Saravejo, v. 24, n. 2, p. 125-30, 2012.

CIT/RS. Relatório anual 2014: dados de atendimento. Centro de Informação Toxicológica do Rio Grande do Sul (CIT/RS), Fundação Estadual de Produção e Pesquisa em Saúde (FEPPS), Secretaria Estadual da Saúde do Rio Grande do Sul (SES/RS), Porto Alegre, RS.

CLARKE, A.; WALTON, W. W. Effect of safety packaging on aspirin ingestion by children. Pediatrics, United States, v. 63, n. 5, p. 687-693, 1979.

CNM (Confederação Nacional dos Municípios). Mortes causadas pelo uso de substâncias em psicotrópicas no Brasil. Estudos Técnicos, Brasil,2012.

COMSTOCK, E. G. et al. Toxicology and clinical toxicology in Uruguay. Clinical Toxicology, New York, v.18, n. 5, p. 635-641, 1981.

CORRÊA, L. M. L. Saneantes domissanitários e saúde: um estudo sobre a exposição de empregadas domésticas. 2005. 94 f. Dissertação (Mestrado em Saúde Coletiva) - Núcleo de Estudos em Saúde Coletiva, Universidade Federal do Rio de Janeiro, Rio de Janeiro, 2005.

CORTÉS-GENCHI, P.; VILLEGAS-ARRIZÓN, A.; AGUILAR-MADRID, G.; PAZROMÁN, M.P.; MARURIS-REDUCINDO, M.; JUÁREZ-PÉREZ, C.A. Sintomas ocasionados por plaguicidas entra bajadores agrícolas. Revista Médica del Instituto Mexicano del Seguro Social, México, v. 46, n. 2, p. 145-152, 2008.

COSTA, D.; LACAZ, F. A. D. C.; JACKSON FILHO, J. M.; VILELA, R. A. G. Saúde do trabalhador no SUS: desafios para uma política pública. Revista Brasileira de Saúde Ocupacional, São Paulo, v. 38, p. 11-30, 2013.

COSTA, L. G. Toxic effects of pesticides. In: KLAASEN, C. D. (Ed.) Casarett and Doull'sToxicology: the basic science of poisons. 8th ed. New York:McGrawHill, 2013. 1454 p. Chapter 22. 
CRUZ, C.C.; CARVALHO, F.N.; COSTA, V.Í.B.; SARCINELLI, P.N.; SILVA, J.J. O.; MARTINS, T.S.; BOCHNER, R.; ALVES, S. R. Perfil epidemiológico de intoxicados por Aldicarb registrados no Instituto Médico Legal no Estado do Rio de Janeiro durante o período de 1998 a 2005. Cadernos Saúde Coletiva (UFRJ), v. 21, p. 63-70, 2013.

CRUZ, C. C.; SARCINELLI, P. N.; OLIVEIRA-SILVA, J. J. A.; MARTINS, T. S.; BOCHNER, R.; ALVES, S. R. Causas externas relacionadas à alcoolemia registradas pelo Instituto Médico Legal no município do Rio de Janeiro. Cadernos Saúde Coletiva (UFRJ), v. 22, p. 8-15, 2014.

DA SILVA NÓBREGA, H. O.; SILVA, E. L.; MARIZ, S. R.; BRAGAGNOLLI, G.; FOOK, S. M. L. Perfil das intoxicações notificadas na Paraíba, de 2009 a 2013. Revista Cereus, Tocantins, v. 7, n. 2, p. 78-87, 2015.

DATASUS (Ministério da Saúde. Sistema Único de Saúde. Departamento de informática). Classificação estatística internacional de doenças e problemas relacionados à saúde: CID-10. [online]. 2008. Disponível em: <http://www.datasus.gov.br/cid10/V2008/cid10.htm>. Acesso em: set. 2016.

DE COCK, J.; WESTVEER, K.; HEEDERIK, D.; TE VELDE, E.; VAN KOOIJ, R. Time to pregnancy and occupational exposure to pesticides in fruit growers in the Netherlands. Occupational and Environmental Medicine, London, v.51, n. 10, p. 693-699, 1994.

DE DUFFARD, E. A. M.; DUFFARD, R. Behavioral toxicology, risk assessment, and chlorinated hydrocarbons. Environmental Health Perspectives, United States, v.104, p. 353-360, 1996. Supplement 2.

DE FRANÇA, G. V. A medicina legal como norteadora na busca da verdade real. Derecho y Cambio Social, Perú, v. 10, n. 31, p. 27, 2013.

DELGADO, I.F; PAUMGARTTEN, F.J.R. Intoxicações e uso de pesticidas por agricultores no município de Paty do Alferes. Cadernos de Saúde Pública, Rio de Janeiro, v.20, n. 1, p. 180-186, 2004.

DIALLO, T.; HAMI, H.; MAIGA, A.; COULIBALY, B.; MAIGA, D.; MOKHTARI, A.; SOULAYMANI, A. Epidemiology and risk factors for voluntary intoxication in Mali. Sante Publique, France, v. 25, n. 3, p. 359-66, 2013.

DIAS, E. P. F.; ARAÚJJO, R. S. Toxinformes: a toxicologia ao alcance da comunidade. João Pessoa: UFPB, 1997. 215 p.

DISTRITO FEDERAL. Secretaria de Saúde. Subsecretaria de Vigilância à Saúde. Centro de Informações Toxicológicas (CIT-DF). Informativo semestral sobre intoxicações exógenas. Brasília, ano 1, n. 2, 2012. 
DUNA, G. F., COTCH, M. F., GALPERIN, C., HOFFMAN, D. B., HOFFMAN, G. $S$. Wegener's granulomatosis: role of environment exposures. Clinical and Experimental Rheumatology, Italy, v.16, n. 6, p. 669-676, 1997.

EATON, D.L.; GILBERT, S.G. Principles of Toxicology.In: KLAASSEN, C. D. Casarett and Doull'stoxicology: the basic science of poisons. 8th ed. New York:McGraw-Hill Education, 2013. 1454 p. Chapter 2.

FAREED, M. et al. Adverse respiratory health and hematological alterations among agricultural workers occupationally exposed to organophosphate pesticides: a cross-sectional study in North India. PLoSOne, San Francisco, CA, v. 8, n. 7, 2013.

FARIA, N. M. X.; FASSA, A. G.; FACCHINI, L. A. Intoxicação por agrotóxicos no Brasil: os sistemas oficiais de informação e desafios para a realização de estudos epidemiológicos. Ciências Saúde Coletiva, Rio de Janeiro, v.12, n. 1, p. 25-38, 2007.

FARIA, N. M. X.; ROSA, J. A. R.; FACCHINI, L. A. Intoxicações por agrotóxicos entre trabalhadores rurais de fruticultura, Bento Gonçalves, RS. Revista de Saúde Pública, São Paulo, v.43, n. 2, p. 335-344, 2009.

FERRAZ, H. B.; BERTOLUCCI, P. H. F.; PEREIRA, J. S.; LIMA, J. G. C.; ANDRADE, L. A. F. Chronic exposure to the fungicide maneb may produce symptom sandsigns of CNS manganese intoxication. Neurology, Minneapolis, v.38, n. 4 , p. 550-553, 1988.

FERREIRA-DE-SOUSA, F.N.; SANTANA, V.S. Mortality from work-related acidentes among agricultural workers in Brazil, 2000-2010.Cadernos de Saúde Pública. Cadernos de Saúde Pública, Rio de Janeiro, v.32, n.4, 2016.

FERREIRA FILHO, L. I. P. Estudo das alterações citogenômicas na medula óssea de trabalhadores rurais expostos à agrotóxicos.2013. 84 f. Dissertação (Mestrado em Ciências Médicas) - Programa de Mestrado Acadêmico em Ciências Médicas, Universidade Federal do Ceará, Fortaleza, 2013.

FIGUEIREDO, G. M.; TRAPÉ, A. Z.; ALONZO, H. A. Exposição a múltiplos agrotóxicos e prováveis efeitos a longo prazo à saúde: estudo transversal em amostra de 370 trabalhadores rurais de Campinas (SP). Revista Brasileira de Medicina do Trabalho, São Paulo, v. 9, n. 1, p. 1-9, 2011.

FIOCRUZ. Fundação Oswaldo Cruz. Centro de Informação Científica e Tecnológica. Sistema Nacional de Informações Tóxico-Farmacológicas. Casos registrados de intoxicação humana por agente tóxico e circunstância. 2009. Disponível em: <http://sinitox.icict.fiocruz.br/dados-nacionais>. Acesso em: set. 2016.

FIOCRUZ. Fundação Oswaldo Cruz. Centro de Informação Científica e Tecnológica. Sistema Nacional de Informações Tóxico-Farmacológicas. 
Estatística anual de casos de intoxicação e envenenamento. Brasil, 2016. Disponível em: <http://sinitox.icict.fiocruz.br/dados-nacionais $>$. Acesso em: set. 2016.

FIOCRUZ. Fundação Oswaldo Cruz. Centro de Informação Científica e Tecnológica. Sistema Nacional de Informações Tóxico-Farmacológicas. Estatística anual de casos de intoxicação e envenenamento. Brasil, 2017. Disponível em: <http://sinitox.icict.fiocruz.br/dados-nacionais >. Acesso em: fev. 2017.

FLEMING, L.; MANN, J. B.; BEAN, J.; BRIGGLE, T.; SANCHEZ-RAMOS, J. R. Parkinson's disease and brain levels of organochlorine pesticides. Annals of Neurology, Boston, v.36, n. 1, p. 100-103, 1994.

FOSTER, P. M. D. ; GRAY, J. R. Toxicresponses of the reproductive system. In: KLAASSEN, C. D. Casarett and Doull'stoxicology: the basic science of poisons. 8th ed. New York:McGraw-Hill Education, 2013. 1454 p. Chapter 20.

FUORTES, L. Urticaria due to airborne permethrin exposure. Veterinary and Human Toxicology, Manhattan, v.41, n. 2, p. 92-93, 1999.

GALVÃO, T. F.; SILVA, E. N.; SILVA, M. T.; BRONSTEIN, A. C.; PEREIRA, M. G. Economic evaluation of poison centers: a systematic review. International Journal of Technology Assessment in Health Care, England, v. 28, n. 2, p. 8692, 2012.

GARCÍA-RODRÍGUEZ, J.; GARCÍA-MARTÍN, M.; NOGUERAS-OCAÑA, M.; DE DIOS LUNA-DEL-CASTILLO, J.; GARCIA, M. E.; OLEA, N., LARDELLICLARET, P. Exposure to pesticides and crytorchidism: geographical evidence of a possible association. Environmental Health Perspectives, United States, v.104, n. 10, p. 1090-1095, 1996.

GAVIOLI, I. L.; NICOLELLA, A. Medicamento controlado: o personagem clandestino das intoxicações. In: RIO GRANDE DO SUL. Secretaria da Saúde. Centro de Informação Toxicológica (CIT). Toxicovigilância: toxicologia clínica: dados e indicadores selecionados, Rio Grande do Sul: 2006. Porto Alegre: CIT/RS, 2007. p. 31-40.

GOES, F. C.; HOMEM-DE-MELLO, M.; CALDAS, E. D. Access to medicines in Brazil based on monetary and non-monetary acquisition data obtained from the 2008/2009 Household Budget Survey. Revista de Saúde Pública, São Paulo,v. 50, p. 79, 2016.

GOVAERTS, M. Poison control in Europe. Pediatric Clinics of North America, Philadelphia, v.17, n. 3, p. 729-739, 1970.

GUNNEL, D.; EDDLESTON, M.; PHILLIPS, MR.; KONRADSEN, F. The global distribution of fatal pesticide self-poisoning: systematic review. BMC Public Health, London, v.7, p. 357, 2007. 
GUNNEL, D., FERNANDO, R., HEWAGAMA, M., PRIYANGIKA, W.D.D., KONRADSEN, F.; EDDLESTON, M. The impact of pesticide regulations on suicide in Sri Lanka. International Journal of Epidemiology, London, v. 36, n. 6, p. 1235-1242, 2007a.

GREGUS, Z. Mechanisms of Toxicity. In: KLAASEN, C. D. (Ed.) Casarett and Doull'sToxicology: the basic science of poisons. 8th ed. New York:McGraw-Hill, 2013. 1454 p. Chapter 3.

GUYTON, K. Z.; LOOMIS, D.; GROSSE, Y.; EL GHISSASSI, F.; BENBRAHIMTALLAA, L.; GUHA, N; STRAIF, K. International Agency for Research on Cancer Monograph Working Group. Carcinogenicity of tetrachlorvinphos, parathion, malathion, diazinon, and glyphosate. The Lancet Oncology. London, v. 16 , n. 5 , p. $490-1,2015$.

HANDLEY, S. A.; FLANAGAN, R. J. Drugs and other chemicals involved in fatal poisoning in England and Wales during 2000 - 2011. Clinical Toxicology, Philadelphia, v. 52, n. 1, p. 1-12. 2014.

HARRISON, V.; MACKENZIE ROSS, S. Anxiety and depression following cumulative low-level exposure to organophosphate pesticides. Environmental Research, New York, v. 151, p. 528-536, 2016.

HOLDER, Y.; MATZOPOULOS, R.; SMITH, N. Poisons In: PEDEN, M. et al. (Ed.). World report on child injury prevention. Geneva, Switzerland: World Health Organization, 2008. p. 123-146. Chapter 6.

HOYER, P. B.; FLAWS, J. A. Toxicresponses of the endocrine system. In: KLAASSEN, C. D. Casarett and Doull'stoxicology: the basic science of poisons. 8th ed. New York:McGraw-Hill Education, 2013. 1454 p. Chapter 21.

HUBBLE, J. P.; KURTH, J. H.; GLATT, S. L.; KURTH, M. C.; SCHELLENBERG, G. D.; HASSANEIN, R. E. S.; KOLLER, W. C. Gene-toxin interaction as a putative risk factor for Parkinson's disease with dementia. Neuroepidemiology, New York,v.17, n. 2, p. 96 -104, 1998.

HUDSON, N. L.; KASNER, E. J.; BECKMAN, J.; MEHLER, L.; SCHWARTZ, A.; HIGGINS, S.; LARIOS, L. Characteristics and magnitude of acute pesticiderelated illnesses and injuries associated with pyrethrin and pyrethroid exposures -11 states, 2000-2008. American Journal of Industrial Medicine, New York, v. 57, n. 1, p. 15-30, 2014.

HUNGRIA. National Institute of Chemical Safety [site]. Hungria: OKIBI, [2016]. Disponível em: <http://www.okbi.hu/>. Acesso em: out. 2016.

IBAMA (Instituto Brasileiro do Meio Ambiente e dos Recursos Naturais Renováveis). Relatórios de Comercialização de Agrotóxicos. Boletim anual de produção, importação, exportação e vendas de agrotóxicos no Brasil, 2016. 
Disponível em: <http://www.ibama.gov.br/areas-tematicas-qa/relatorios-decomercializacao-de-agrotoxicos/pagina-3>. Acesso em: set. 2016.

IBGE. Censo demográfico 2010: educação e deslocamento. Disponível em: $<$ http://www.ibge.gov.br/home/estatistica/populacao/censo2010/educacaoe deslocamento/>. Acesso em: set. 2016.

IBGE. Cidades [site]. Brasil: IBGE, 2016. Disponível em: <http://www.cidades.ibge.gov.br>. Acesso em: 07 set. 2016.

IBGE. Contas Regionais do Brasil - 2002 - 2012: Tabela 1 - Produto Interno Bruto - PIB e participação das Grandes Regiões e Unidades da Federação 2002 - 2012. <http://www.cidades.ibge.gov.br>. Acesso em: 20 mar. 2017.

IPCS (INTERNATIONAL PROGRAMME ON CHEMICAL SAFETY). Guidelines for poison control [online]. c1997. Disponível em:

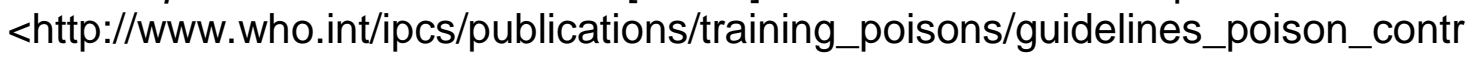
ol/en/>. Acessoem: set. 2016.

IPCS (INTERNATIONAL PROGRAMME ON CHEMICAL SAFETY). Guidelines on the prevention of toxic exposures: education and public awareness activities. World Health Organization, 2004.2 Disponívelem: $<$ http://www.who.int/ipcs/features/en/prevention guidelines.pdf?ua=1/>.

Acessoem: fev. 2017.

JAMAL, F.; HAQUE, Q. S.; SINGH, S. Interrelation of glycemic status and neuropsychiatric disturbances in farmers with organophosphorus pesticide toxicity. The Open Biochemistry Journal, Netherlands, v. 10, p. 27-34, 2016.

JOKANOVIĆ, M.; KOSANOVIĆ, M.; BRKIĆ, D.; VUKOMANOVIĆ, P. Organophosphate induced delayed polyneuropathy in man: an overview. Clinical Neurology and Neurosurgery, Holanda, v. 113, n. 1, p. 7-10, 2011.

KACHURI, L.; DEMERS, P. A.; BLAIR, A.; SPINELLI, J. J.; PAHWA, M.; MCLAUGHLIN, J. R; HARRIS, S. A. Multiple pesticide exposures and the risk of multiple myeloma in Canadian men. International Journal of Cancer, New York, v. 133 , n. 8, p. 1846-58, 2013.

KAYSER, K.; PLODZISZEWSKA, M.; WAITR, E.; SLODKOWSKA, J.; ALTINER, M.; GABIUS, H. J.et al. Diffuse pulmonary hemosiderosis after exposure to pesticides: a case report. Respiration, New York, v.65. n. 3, p. 214 $-8,1998$.

KIM, J.; KO, Y.; LEE, W. J. Depressive symptoms and severity of acute occupational pesticide poisoning among male farmers. Occupational and Environmental Medicine, London, v. 70, n. 5, p. 303-09, 2013. 
$\mathrm{KOCH}, \mathrm{P}$. Occupational allergic contact dermatitis and airborne contact dermatitis from fungicides in a vineyard worker: cross-reactions between fungicides of the dithiocarbamate group. Contact Dermatitis, Copenhagen, v. 34, n. 5, p. 324-9, 1996.

KOSSMANN, S.; KONIECZNY, B.; HOFFMANN, A. The role of respiratory muscles in the impairment of the respiratory system function in the workers of a chemical plant division producing pesticides. PrzegladLekarski, Kraków, v. 54, n. 10, p. 702-6, 1997.

KRISTENSEN, P.; IRGENS, L. M.; ANDERSEN, A., BYE, A. S., SUNDHEIM, L. Birth defects among offspring of Norwegian farmers, 1967-1991.Epidemiology, Cambridge, v.8, n. 5, p. 537- 41, 1997.

LAGUARDIA, J.; DOMINGUES, C. M. A.; CARVALHO, C.; LAUERMAN, C. R.; MACÁRIO, E.; GLATT, R. Sistema de informação de agravos de notificação em saúde (SINAN): desafios no desenvolvimento de um sistema de informação em saúde. Epidemiologia e Serviços de Saúde, Brasília, v. 13, n. 3, p. 135-147, 2004.

LAHTI, R.A.; SAJANTILA, A.; KORPI, H.; POIKOLAINEN, K.; VUORI, E. Underrecording of ethanol intoxication and poisoning in cause-of-death data: causes and consequences. Forensic Science International, Ireland, v. 212, n. 1-3, p. 121-5, 2011.

LAI, M. W.; KLEIN-SCHWARTZ, W.; RODGERS, G.C.; ABRAMS, J.Y.; HABER, D.A.; BRONSTEIN, A.C.; WRUK, K.M.2005 Annual Report of the American Association of Poison Control Centers national poisoning and exposure database. Clinical Toxicology, Philadelphia, v.44, n. 6-7, p. 803-932, 2006.

LANGSTON, J. W. Epidemiology versus genetics in Parkinson's disease: progress in resolving an age-old debate. Annals of Neurology, Boston, v.44, n. 3, p. 45- 52, 1998. Supplement 1.

LAURENCE, L.B.; KEITH, L.P.; BLUMENTHAL, D.K. GOODMAN \& GILMAN'S Manual of Pharmacology and Therapeutics. Porto Alegre: ARTMED; McGrawHill Education, 2010.

LEIKAUF, G. D. Toxicresponses of respiratory system. In: KLAASSEN, C. D. Casarett and Doull'stoxicology: the basic science of poisons. 8th ed. New York:McGraw-Hill Education, 2013. 1454 p. Chapter 15.

LESSA, M. A.; BOCHNER, R. Análise das internações hospitalares de crianças menores de um ano relacionadas a intoxicações e efeitos adversos de medicamentos no Brasil. Revista Brasileira de Epidemiologia, São Paulo, v. 11, n. 4, p. 660-674, 2008. 
LI, R.; HU, L.; HU, L.; ZHANG, X.; PHIPPS, R.; FOWLER, D.R.; CHEN, F.; LI, L. Evaluation of Acute Alcohol Intoxication as the Primary Cause of Death: A Diagnostic Challenge for Forensic Pathologists. J Forensic Sci. Jan 25,2017.

LIMA, C. R. A. Gestão da qualidade dos dados e informações dos sistemas de informação em saúde: subsídios para a construção de uma metodologia adequada ao Brasil. 2010. 156 f. Tese (Doutorado em Ciências na Área de Saúde Pública) - Escola Nacional de Saúde Pública Sergio Arouca, Fundação Oswaldo Cruz. Rio de Janeiro: Ensp, 2010.

MAGALHÃES, A. F. A. Avaliação clínico-ocupacional de trabalhadores assistidos no Ambulatório de Toxicologia Ocupacional - Brasília. 2005. [107f.]. Dissertação (Mestre em Ciências da Saúde) - Programa de Pós-graduação em Ciências da Saúde, Universidade de Brasília. Brasília: UnB, 2005.

MAGALHÃES, A. F. A. Intoxicações por "Chumbinho": etiologia e epidemiologia dos casos notificados pelo Centro e Informações Toxicológicas de Belém. Monografia- Universidade Federal do Pará. Belém: UFPA, 2001.

MAGAUZI, R.; MABAERA, B.; RUSAKANIKO, S.; CHIMUSORO, A.; NDLOVU, N.; TSHIMANGA, M. Health effects of agrochemicals among farm workers in commercial farms of Kwekwe district, Zimbabwe. The Pan African Medical Journal, Uganda, v. 9, n. 1, 2011.

MALASPINA, F. G.; ZINILISE, M. L.; BUENO, P. C. Perfil epidemiológico das intoxicações por agrotóxicos no Brasil, no período de 1995 a 2010. Cadernos de Saúde Coletiva, Rio de Janeiro, v.19, n. 4, p. 425-34, 2011.

MARQUES, M. B.; BORTOLETTO, M. É.; BEZERRA, M. C. C.; DE SANTANA, R. A. Avaliação da Rede Brasileira de Centros de Controle de Intoxicações a Envenenamento (CCIEs). Cadernos de Saúde Pública, Rio de Janeiro, v. 11, n. 4, p. 560-78, 1995.

MATOS, E. L; LORIA, D.J.; ALBIANO, N.; SOBEL, N.; DE BUJAN, E.C. Efectos de losplaguicidas em trabajadores de cultivos intensivos. Revista Médica del Instituto Mexicano del Seguro Social, v. 46, n. 2, p. 145-152, 2008.

MEDEIROS, H. L. V.; MONTEIRO, D. C.; MEDEIRO, C. F. Perfil epidemiológico das tentativas de suicídio por autointoxicação no Estado da Paraíba. Neurobiologia, Pernambuco, v.75, p. 1-2, 2012.

MELLO JORGE, M. H. P.; LAURENTI, R.; DI NUBILA, H. B. V. O óbito e sua investigação: reflexões sobre alguns aspectos relevantes. Revista Brasileira de Epidemiologia, São Paulo, v.13, n. 4, p. 561-76, 2010.

MELO-SANTOS, C.; BERTOLOTE, J. M.; WANG, Y. P. Epidemiology of suicide in Brazil (1980-2000): characterization of age and gender rates of suicide. Revista Brasileira Psiquiatria, São Paulo, v.27, n. 2, p. 131-134, 2005. 
MENDES, R.; OLIVEIRA, D.E. Patogêneses do adoecimento relacionado ao trabalho. In: Mendes, R. Patologia do trabalho. 3. ed. São Paulo: Atheneu, 2013. p. $50-120$. v. 1.

MENDONÇA, D.R.; MENEZES, M.S.; MATOS, A.M.A.; REBOUÇAS, D.S.; CONCEIÇẪO FILHO, J.N.; ASSIS, R.S; CARNEIRO, L. Acutepoisoning in children in Bahia, Brazil. Global Pediatric Health, California, v. 3, p. 1-7, 2016.

MENDONÇA, F. M.; DRUMOND, E.; CARDOSO, A. M. P. Problemas no preenchimento da Declaração de Óbito: estudo exploratório. Revista Brasileira de Estudos Populacionais, Belo Horizonte, v. 27, n. 2, p. 285-95, 2010.

MENEGON, A.; BOARD, P. G.; BLACKBURN, A. C.; MELLICK, G. D.; LE COUTEUR, D. G. Parkinson's disease, pesticides, and glutathione transferase polymorphisms. The Lancet, London, v.352, n. 9137, p. 1344-6, 1998.

MESNAGE, R.; DEFARGE, N.; DE VENDOMOIS, J. S.; SERALINI, G. E. Potential toxic effects of glyphosate and its commercial formulations below regulatory limits. Food and Chemical Toxicology. Oxford, v. 84, p. 133-53, 2015.

MINTEGI, S.; FERNÁNDEZ, A.; ALUSTIZA, J.; CANDUELA, V.; MONGIL, I.; CAUBET, I. et al. Emergency visits for childhood poisoning: a 2-year prospective multicenter survey in Spain. Pediatrics Emergency Care, Maryland, v. 22, n. 5, p. 334-8, 2006.

MITSCHE, T., BORCK, H., HORR, B., BAYAS, N., HOPPE, H. W., \& DIEL, F. Pyrethroid syndrome in an animal keeper. Allergy, Copenhagen, v. 55, n. 1, p. 93-4, 2000.

MONTEIRO, C. N. Perfil das intoxicações fatais registradas no Instituto Médico Legal de Juiz de Fora, Minas Gerais. Revista de APS, v. 13, n. 3, 2010.

MOTA, D. M.; MELO, J. R. R.; DE FREITAS, D. R. C.; MACHADO, M. Perfil da mortalidade por intoxicação com medicamentos no Brasil, 1996-2005: retrato de uma década. Ciência Saúde Coletiva, Rio de Janeiro, v. 17, n. 1, p. 61-70, 2012.

MOSER, V. C. Toxicresponses of the nervous system. In: KLAASSEN, C. D. Casarett and Doull'stoxicology: the basic science of poisons. 8th ed. New York:McGraw-Hill Education, 2013. 1454 p. Chapter 16.

MOSTAFALOU, S.; ABDOLLAHI, M. Pesticides: an update of human exposure and toxicity. Archives of Toxicology, Germany, v. 91, n. 2, p, 549-99, 2017.

MOWRY, J.B.; SPYKER, D.A.; CANTILENA, L.R.; BAILEY, J.E.; FORD,M. Annual Report of the American Association of Poison Control Centers National Poison Data System (NPDS): 32th Annual Report. Clinical Toxicology, Philadelphia, v. 53, n. 10, p. 962-1147, 2015. 
MURPHY, Y.; WILSON, E.; GOLDNER, E. M.; FISCHER, B. Benzodiazepine use, misuse, and harm at the population level in Canada: a comprehensive narrative review of data and developments since 1995. Clinical Drug Investigation, New Zealand, v. 36, n. 7, p. 519-30, 2016.

NEGREIROS, R. L. Agravos provocados por medicamentos em crianças até 12 anos de idade, no Estado do Rio de Janeiro, entre os anos 2000 e 2001. 2006. 61 f. Dissertação (Mestrado em Saúde da criança e do Adolescente) - Pósgraduação em Saúde da Criança e do Adolescente, Universidade Federal Fluminense, Niterói, 2006. Disponível em:

$<$ http://www.uff.br/mestradopediatria/teses/raideline $>$. Acesso em: mar. 2014.

NERILO, S. B.; MARTINS, F. A.; NERILO, L. B.; SALVADEGO, V. E. C.; ENDO, R. Y.; ROCHA, G. H. O.; MACHINSKI JUNIOR, M. Pesticide use and cholinesterase inhibition in small-scale agricultural workers in southern Brazil. Brazilian Journl of Pharmaceutical Sciences. São Paulo, v. 50, n. 4, p. 783-91, 2014.

NICOLELLA, A.; FERREIRA, E. M.; LESSA, C. A. S. Relatório anual 2013: dados de atendimento. Centro de Informação Toxicológica do Rio Grande do Sul (CIT/RS), Fundação Estadual de Produção e Pesquisa em Saúde (FEPPS), Secretaria Estadual da Saúde do Rio Grande do Sul (SES/RS), Porto Alegre, RS. 2014

NICOLELLA, A.; FERREIRA, E. M.; LESSA, C. A. S. Relatório anual 2012: dados de atendimento. Centro de Informação Toxicológica do Rio Grande do Sul (CIT/RS), Fundação Estadual de Produção e Pesquisa em Saúde (FEPPS), Secretaria Estadual da Saúde do Rio Grande do Sul (SES/RS), Porto Alegre, RS.

NPIS (National Poisons Information Service). Report 2013/14. 2014. Disponível em: <http://www.npis.org/NPISAnnualReport2013-14.pdf>. Acesso em: set. 2016.

ILO (International Labour Office). World Day for Safety and Health at Work: A Background Paper. ILO in Focus Programme on Safe Work. International Labour Office, Geneva: International Labor Organization, 2005.

O' MALLEY, M. A. Shin reactions to pesticides. Occupational Medicine, Philadelphia, v.12, n. 2, p. 327-345, 1997.

OMS (Organización Mundial de la Salude). Directrices para la lucha contra las intoxicaciones. Genebra: OMS, $1998 . \quad$ Disponível em:<http://whqlibdoc.who.int/publica tions/1998/9234354487X spa.pdf>. Acesso em: mar. 2014.

OPAS (Organização Pan-Americana da Saúde). Nota de esclarecimento da representação da Opas/OMS no Brasil sobre o uso do larvicida Pyriproxyfen 2016. 2016.

Disponível em: 
$<$ http://www.paho.org/bra/index.php?option=com content\&view=article\&id=500 9:pyriproxyfen\&ltemid=816 $>$. Acesso em: set. 2016.

OSTAPENKO, Y. N.;MATVEEV, S.B.;GASSIMOVA, Z.M.;KHONELIDZE, R.S. Epidemiology and medical aid at acute poisoning in Russia. PrzegladLekarski, Krakóv, v.58, n. 4, p. 293-6, 2001.

PADUNGTOD, C.; LASLEY, B. L.; CHRISTIANI, D. C.; RYAN, L. M.; XU, X. Reproductive hormone profile among pesticide factory workers. Journal of Occupational and Environmental Medicine, Baltimore, v.40, n. 12, p. 1038-47, 1998.

PASIANI, J. O.; TORRES, P.; SILVA, J.R.; DINIZ, B.Z.; CALDAS,E.D. Knowledge, attitudes, practices and biomonitoring of farmers and residents exposed to pesticides in Brazil. International Journal of Environmental Research and Public Health, Switzerland, v. 9, n. 9, p. 3051-68, 2012.

PEDROSA, L. D. C. O.; SARINHO, S. W.; Ordonha, M. R. Análise da qualidade de informação sobre causa básica de óbitos neonatais registrados no Sistema de Informação sobre Mortalidade: um estudo para Maceió, Alagoas, Brasil, 2001-2002. Cadernos de Saúde Pública, Rio de Janeiro,v.23, n. 10, p. 2385-95, 2007.

PEREIRA, C. S. Morte por intoxicação medicamentosa: análise retrospectiva dos casos analisados na Delegação do Centro do Instituto Nacional de Medicina Legal, I.P., entre 1996 e 2007. 2009. 106 f. Dissertação (Mestre em Medicina Legal e Ciências Forenses) - Faculdade de Medicina, Universidade de Coimbra. Coimbra: UC, 2009.

PERRY, L.; ADAMS, R. D.; BENNETT, A. R.; LUPTON, D. J.; JACKSON, G.; GOOD, A. M.; EDDLESTON, M. National toxicovigilance for pesticide exposures resulting in health care contact: an example from the UK's National Poisons Information Service. Clinical Toxicology, Philadelphia, v. 52, n. 5, p. 549-55, 2014.

PICCOLI, C.; CREMONESE, C.; KOIFMAN, R.; KOIFMAN, S.; FREIRE, C. Pesticide exposure and thyroid function in an agricultural population in Brazil. Environmental Research, New York, v. 151, p. 389-98, 2016.

PIRES, D. X.; CALDAS, E. D.; RECENA, M. C. P. Uso de agrotóxicos e suicídios no Estado do Mato Grosso do Sul, Brasil. Cadernos de Saúde Pública, Rio de Janeiro, v.21, n. 2, p. 598-605, 2005.

RAJANAYAGAM, J.; BISHOP, J. R.; LEWINDON, P. J.; EVANS, H. M. Paracetamol-associated acute liver failure in Australian and New Zealand children: high rate of medication errors. Archives of Disease in Childhood, London, v. 100, n. 1, p. 77-80, 2015. 
RAMOS, C. L. J.; TARGA, M. B. M.; STEIN, A. T. Perfil das intoxicações na infância atendidas pelo Centro de Informação Toxicológica do Rio Grande do Sul (CIT/RS), Brasil. Cadernos de Saúde Pública, Rio de Janeiro, v. 21, n. 4, p. 1134-41, 2005.

RAY, D. E. Pesticides derived from plants and other organisms. In: HAYES, W.J.; LAWS, E.R. (Eds). Handbook of Pesticide Toxicology. 2nd ed. San Diego: Academic Press, 1991. p. 585.

REBELO, F. M.; CALDAS, E. D.; HELIODORO, V. O.; REBELO, RM. Intoxicação por agrotóxicos no Distrito Federal, Brasil, de 2004 a 2007: análise da notificação ao Centro de Informação e Assistência Toxicológica. Ciência e Saúde Coletiva, Rio de Janeiro, v.16, n. 8, p.3493 - 502, 2011.

RECENA, M. C.; CALDAS, E. D. Percepção de risco, atitudes e práticas no uso de agrotóxicos entre agricultores de Culturama, MS. Revista de Saúde Pública, São Paulo, v. 42, n. 2, p. 294-301, 2008.

RECENA, M. C.; PIRES, D. X.; CALDAS, E. D. Acute poisoning with pesticides in the state of Mato Grosso do Sul, Brazil. The Science of the Total Environment, Amsterdam, v. 357, n. 1-3, p. 88-95, 2006.

RENAST (Rede Nacional de Saúde do Trabalhador). Renast online. Disponível em: <http://renastonline.ensp.fiocruz.br/cerests>. Acesso em: set. 2016.

RIBEIRO, N. M. Análise dos Sistemas de Informação em Saúde SIM e SINAN em relação ao suicídio na cidade de Uberaba/MG. 2016. 93 f. Dissertação (Mestrado em Atenção à Saúde) - Programa de Pós-Graduação Stricto Sensu em Atenção à Saúde, Universidade Federal do Triângulo Mineiro, 2016.

RICE, R. H.; MAURO, M. T. Toxicresponses of the skin. In: KLAASSEN, C. D. Casarett and Doull'stoxicology: the basic science of poisons. 8th ed. New York:McGraw-Hill Education, 2013. 1454 p. Chapter 19.

ROMERO, D. E; CUNHA, C. B. Avaliação da qualidade das variáveis epidemiológicas e demográficas do Sistema de Informações sobre Nascidos Vivos. 2002. Cadernos de Saúde Pública, Rio de Janeiro. v. 23, n. 3, p. 701-14, 2007.

SANTANA, V. S.; MOURA, M. C. P.; NOGUEIRA, F. F. Mortalidade por intoxicação ocupacional relacionada a agrotóxicos, 2000-2009, Brasil. Revista de Saúde Pública, São Paulo, v. 47, n. 3, p. 598-606, 2013.

SANTOS, J. A. T.; SELEGHIM, M. R.; MARANGONI, S. R.; GONÇALVES, A. M.; BALLANI, T. S. L.; OLIVEIRA, M. L. F. Gravidade de intoxicações por saneantes clandestinos. Texto e Contexto: Enfermagem, Florianópolis, v. 20, p. 247-54, 2011. 
SANTOS, S. A. Suicídios e tentativas de suicídios por intoxicação exógena no Rio de Janeiro: análise dos dados dos sistemas oficiais de informação em saúde, 2006-2008. Revista Brasileira de Epidemiologia, Rio de Janeiro, v. 16, n. 2, p. 376-87, 2013.

SANTOS, S. A. Tentativas e suicídios por intoxicação exógena no Rio de Janeiro, Brasil: análise das informações através do linkage probabilístico. Cadernos de Saúde Pública, Rio de Janeiro, v.30, n. 5, p. 1057-66, 2014.

SÃO PAULO (Município). Centro de Controle de Intoxicações da Prefeitura do Município de São Paulo. Equipe de Assistência do Centro de Controle de Intoxicações. [Divulgação]. $2016 . \quad$ Disponível em $<$ http://www.prefeitura.sp.gov.br/cidade/secretarias/upload/chamadas/cci_1441 745259.pdf>. Acesso em: out. 2016.

SINAN (Sistema de Informação de Agravos de Notificação). SINAN NET 4.0/Patch 4.2 (Versão em uso). Fichas. Intoxicação Exógena. 2013. Disponível em: <http://sinan.saude.gov.br/sinan/login/login.jsf >. Acesso em: mar. 2014.

SINAN (Sistema de Informação de Agravos de Notificação).Normas e rotinas [online]. Brasília: Ministério da Saúde, 2005. Disponível em: $<$ http://bvsms.saude.gov.br/bvs/publicacoes/sistema_informacao_agravos_notif icacao_sinan.pdf>. Acesso em: jan. 2014.

SIM (Sistema de informação sobre mortalidade), Portal da saúde [online]. Brasil, [2014]. Disponível em: <http://svs.aids.gov.br/cgiae/sim/>. Acesso em: jun. 2014.

SCHWARTZMAN, S. Prefácio. In: KOTAKA, E.T.; ZAMBRONE, F.A. D. Contribuições para a construções de diretrizes de avaliação do risco toxicológico de agrotóxicos. Campinas, SP: Ilsi Brasil, 2001. 160 p.

SENTHILSELVAN, A.; MCDUfFIE, H. H.; DOSMAN, J. A. Association of asthma with use of pesticides. The American Review of Respiratory Disease, Baltimore, v.146, n. 4, p. 884-7, 1992.

SHANNON, M. Ingestion of toxic substances by children. The New England Journal of Medicine, Boston, v.342, n. 3, p. 186-91, 2000.

SILVA, A. C. C. Estudo da demanda atendida no Centro de Referência Regional em Saúde do Trabalhador-CEREST/Jequié-BA. Revista Saúde. com. v. 2, n. 1, p. 39-49, 2006.

SILVA, A. M.; ALVES, S. M. F. Análise dos registros de intoxicação por agrotóxicos em Goiás, no período de 2001 a 2004. Revista Eletrônica de Farmácia. v. 4, n. 2, p. 194-201, 2007. Disponível em: <https://revistas.ufg.br/REF/article/view/3055/3091>. Acesso em: fev. 2014. 
SILVA, J. J. O.; ALVES, R. S.; DELLA ROSA, H. V. Avaliação da exposição humana a agrotóxicos. In: PERES, F.; MOREIRA, J. C. (Org.). É veneno ou remédio? agrotóxicos, saúde e ambiente. Rio de Janeiro: Fiocruz, 2003.p. 121124.

SILVEIRA, A. M.; LUCCA, R. S. Estabelecimento de nexo causal entre adoecimento e trabalho: a perspectiva clínica e individual. In: MENDES, R. (Org.). Patologia do Trabalho. 3. ed. São Paulo: Atheneu, 2013.

SILVEIRA, R. M. J. O atestado médico falso. São Paulo: Centro Brasileiro de Classificação de Doenças, 2001. (Série Divulgação, ํํ9).

SIMÕES, E. M. S.; REICHENHEIM, M. E. Confiabilidade das informações de causa básica nas declarações de óbito por causas externas em menores de 18 anos no Município de Duque de Caxias, Rio de Janeiro, Brasil. Cadernos de Saúde Pública, Rio de Janeiro, v. 17, n. 3, p. 521-531, 2001.

SIMONSEN, K.W.; EDVARDSEN, H.M.; THELANDER, G.; OJANPERÄ, I.; THORDARDOTTIR, S.; ANDERSEN, L.V.; KRIIKKU, P.; VINDENES, V.; CHRISTOFFERSEN, D.; DELAVERIS, G.J.; FROST, J. Fatal poisoning in drug addicts in the Nordic countries in 2012. Forensic Science International, Ireland, v. 248, p. $172-80,2015$.

SINITOX (Sistema Nacional de Informações Tóxico-Farmacológicas) FIOCRUZ. Fundação Oswaldo Cruz. Centro de Informação Científica e Tecnológica. Estatística anual de casos de intoxicação e envenenamento. Brasil, 2016. Disponível em: <http://sinitox.icict.fiocruz.br/dados-nacionais>. Acesso em: set. 2016.

SINITOX (Sistema Nacional de Informações Tóxico-Farmacológicas) FIOCRUZ. Fundação Oswaldo Cruz. Centro de Informação Científica e Tecnológica. Estatística anual de casos de intoxicação e envenenamento. Brasil, 2017. Disponível em: <http://sinitox.icict.fiocruz.br/dados-nacionais>. Acesso em: fev. 2017.

SOARES, W. L.; FREITAS, E. A. V.; COUTINHO, J. A. G. Trabalho rural e saúde: intoxicações por agrotóxicos no município de Teresópolis, RJ. Revista de Economia e Sociologia Rural. Brasília, v. 43, n. 4, p. 685-701, 2005.

SOLOMON, G. Pesticides and human health: a resource for health care professionals. California: Physicians for Social Responsibility. Californians for Pesticide Reform, 2000. p. 5-59.

SOUSA, F. N.; SANTANA, V. S. Mortalidade por acidentes de trabalho entre trabalhadores da agropecuária no Brasil, 2000-2010. Cadernos de Saúde Pública, Rio de Janeiro, v. 32, n. 4, p. 1-13, 2016.

SOUZA, T. T.; GODOY, R.R.; ROTTA.I.; PONTAROLO, R.; FERNANDEZLLIMOS, F.; CORRER, C.J. Morbidade e mortalidade relacionadas a 
medicamentos no Brasil: revisão sistemática de estudos observacionais. Revista de Ciências Farmacêuticas Básica e Aplicada, São Paulo, v. 35, n. 4, p. 519-32, 2014.

THORNE, P. S. Occupationaltoxicology. In: KLAASSEN, C. D. Casarett and Doull'stoxicology: the basic science of poisons. 8th ed. New York:McGraw-Hill Education, 2013. 1454 p. Chapter 34.

TIELEMANS, E.; BURDORF, A.; TE VELDE, E. R.; WEBER, R. F.; VAN KOOIJ, R. J.; VEULEMANS, H.;HEEDERIK, D. J.Occupationally related exposures and reduced semen quality: a case-control study. Fertility and Sterility, New York, v. 71, n. 4, p. 690-96, 1999.

TOWNER, E.; SCOTT, I. Child injuries in context. In: PEDEN, M. et al. (Ed.). World report on child injury prevention. Geneva, Switzerland: World Health Organization, 2008. p. 123-46. Chapter 1.

UGES, D. R. What is the definition of a poisoning? Journal of Clinical Forensic Medicine, Edinburgh, v. 8, n. 1, p. 30-3, 2001.

USEPA (United States Environmental Protection Agency). Program National Center for Environmental Research. Biomarkers for the assessment of exposure and toxicity in children science to achieve results (STAR) [online]. USA, 2002. Disponível em: <https://www.epa.gov/science-andtechnology/pesticides-science>. Acesso em: jun. 2014.

URUGUAI. Universidad de la República. Hospital de Clínicas Dr. Manuel Quintela. Departamento de Toxicología. Centro de Información y Asesoramiento Toxicológico (CIAT) [online]. Disponível em: $<$ http://www.ciat.hc.edu.uy/index.php?option=com_content\&view=article\&id=72: ciat\&catid=42\&ltemid=75>. Acessoem: out. 2016.

VALE, A.; LOTTI, M. Organophosphorus and carbamate insecticide poisoning. Handbook of Clinical Neurology, Amsterdam, v. 131, p. 149-68, 2015.

VAN DEN BERG, K. J. Interaction of chlorinated phenols with thyroxine binding sites of human transthyretin, albumin and thyroid binding globulin. ChemicoBiological Interactions, Amsterdam, v.76, n. 1, p. 63 -75, 1990.

VAN RAAIJ, J. A. G. M.; FRIJTERS, C. M. G.; KONG, L. W. Y.; VAN DEN BERG, K. J.; NOTTEN, W. R. F. Reduction of thyroxine uptake into cerebrospinal fluid and rat brain by hexachlorobenzene and pentachlorophenol. Toxicology, Amsterdam, v. 94, n. 1-3, p. 197-208, 1994.

VEALE, D. J. H.; WIUM, C. A.; G. J. Toxicovigilance I: a survey of acute poisonings in South Africa based on Tygerberg Poison Information Centre data. South African Medical Journal, Cape Town, v. 103, n. 5, 2013. 
VELDMAN, B. A. Genetic and environmental risk factors in Parkinson's disease. Clinical Neurology and Neurosurgery, v.100, n. 1, p. 15 -26, 1998.

VIEIRA, É. L. R. Verificação da ocorrência de óbitos por intoxicação exógena por análise de laudos necroscópicos-IML/PE. 2016. Tese (Doutorado) Universidade Federal de Pernambuco. 2016.

VIEIRA, J. L. F.; SILVA, B. A.; SILVA, E. E. G. Chemical identification of granulated rodenticides market in Belém-Pará. Revista Paraense de Medicina, Belém, v. 20, n. 4, p. 19-21, 2006.

WAICHMAN, A. V.; EVEB, E.; NINA, N. C. S. Do farmers understand the information displayed on pesticide product labels? A key question to reduce pesticides exposure and risk of poisoning in the Brazilian Amazon. Crop Protection. Netherlands, v. 26, n. 4, p. 576-83, 2007.

WANANUKUL, W.; SRIAPHA, C.; TONGPOO, A.; SADABTHAMMARAK, U.; WONGVISAWAKORN, S.; KAOJARERN, S. Human poisoning in Thailand: the Ramathibodi Poison Center's experience (2001-2004). Clinical Toxicology, Philadelphia, v.45, n. 5, p. 582-88, 2007.

WASEEM, M.; PERRY, C.; BOMANN, S.; PAI, M.; GERNSHEIMER, J. Cholinergic crisis after rodenticide poisoning. Western Journal of Emergency Medicine, Orange, CA, v. 11, n. 5, p. 524-7, Dec. 2010.

WERNECK, G. L.; HASSELMANN, M. H.; PHEBO, L.B.; VIEIRA, D.E.; GOMES, V.L.O. Suicide attempts recorded at a general hospital in Rio de Janeiro, Brasil. Cadernos de Saúde Pública, Rio de Janeiro, v.22, n. 10, p. 2201-6, 2006.

WHO (World Health Organization). Public health impact of pesticides used in agriculture. Geneve; 1990

WHO (World Health Organization). Adolescent health [online]. Geneve, 2008. Disponível em: <http://www.who.int/topics/adolescent_health/en/>. Acessoem: set. 2016

WHO (World Health Organization). Collaborating Centre for Drug Statistics Methodology. Guidelines for ATC classification and DDD assignment 2016. 17 ed. Oslo: WHO Collaboration Centre for Drug Statistics Methodology; 2016. Disponível em: <http://www.whocc.no/filearchive /publications/2016 guidelines web.pdf>. Acesso em: set. 2016.

WHO (World Health Organization). Multisite intervetion study on suicidal behaviours. [online]. Geneve, 2002. Disponível em: $<$ http://www.who.int/mental health/media/en/254.pdf>.Acesso em: jun. 2014.

WHO (World Health Organization). Prevention of suicidal behaviors: a task for all. In: WHO. Mental and Behavioral Disorders. Geneve, 2000. 
WHO (World Health Organization). Preventing suicide: a global imperative. Geneve, 2014.2 Disponível em: $<$ http://apps.who.int/iris/bitstream/10665/131056/1/9789241564779 eng.pdf >.

Acessoem: set. 2016.

WHO (World Health Organization).Programme on substance abuse: rational use of benzodiazepines. Copenhagen, 1996.

WHO (World Health Organization). World report on child injury prevention. Geneva, 2008.2 Disponível em: $<$ http://www.who.int/violence_injury_prevention/child/injury/world_report/en/>. Acesso em: set. 2016.

WHO (World Health Organization). Global status report on alcohol and health 2014.Disponivel em: <http://www.who.int/substance_abuse/publications/global_alcohol_report/en/>. Acesso em: set. 2016.

YAN, D.; ZHANG, Y.; LIU, L.; YAN, H. Pesticide exposure and risk of Alzheimer's disease: a systematic review and meta-analysis. Scientific Reports, London, v. 6, p. 32222, 2016.

ZAMBOLIM, C. M.; OLIVEIRA, T.P.; HOFFMANN, A.N.; VILELA C.E.B.; NEVES, D.; ANJOS, F.R.; SOARES, L.M.; TIBURZIO, L.S.; CARDOSO, L.A.F.; MURAD, M.B.; MAGALHÃES,M.G.;OPPERMANN, P. E. R.; GUIMARÃES, S. J. Perfil das intoxicações exógenas em um hospital universitário. Revista de Medicina de Minas Gerais, Minas gerais, v.18, n. 1, p. 5-10, 2008.

ZAMBRONE, F. A. D. Contribuição ao estudo das intoxicações na região de Campinas. 1992. 229 p. Tese (Doutorado) - Faculdade de Ciências Médicas, Universidade Estadual de Campinas, Campinas, 1992.

ZHANG, J.; STEWART, R.; PHILLIPS, M.; SHI, C.; PRINCE, M. Pesticide exposure and suicidal ideation in rural communities in Zhejiang province, China. Bulletin of the World Health Organization, Geneva, v. 87, n. 10, p. 745-53, 2009.

ZHANG, X.; ZHAO, W.; JING, R.; WHEELER, K.; SMITH, G.A.; STALLONES, L.; XIANG, $H$. Work-related pesticide poisoning among farmers in two villages of Southern China: a cross-sectional survey. BMC Public Health, London, v. 11, n. 429, 2011. 


\section{APÊNCIDE 1}

FICHA DE NOTIFICAÇÃO CIT-DF

I- IDENTIFICAÇÃO DO PACIENTE

1- № DO PRONTUÁRIO=

2-DATA DE ATENDIMENTO=

3-IDADE: DIA ( ) MEES ( ), ANO ( )

4-NATURALIDADE:

6-SEXO: $M() F()$

7- GESTANTE: $1^{\circ}{ }^{\circ} T\left(\right.$ ), $2^{\circ} \mathrm{T}\left(\right.$ ) $3^{\circ} \mathrm{T}(\mathrm{T})$, T.DESC. ( ) NÃO( ) IGN ( )

8-ZONA DE OCORRÊNCIA: URBANA ( ) RURAL( )

9-LOCAL DA OCORRÊNCIA:

RESIDENCIA ( ), AMBIENTE DE TRABALHO ( ),SERVIÇOS DE SAÚDE

( ),ESCOLA/CRECHE ( )

LOCAL PÚBLICO ( ) OUTRO ( ) IGN ( )

II- IDENTIFICAÇÃO DO SOLICITANTE DA INFORMAÇÃO

10- INSTITUIÇÂAO SOLICITANTE $=$

11-CATEGORIA = PRÓPRIO ( ), LEIGO（）, MÉDICO （）,OUTRO PROF. SAÚDE （）, ING（）

12-LOCAL DO ATENDIMENTO=

HOSPITAIS/CLÍNICAS ( ),CS/UBS ( ), CONSULTÓRIO/AMBULATÓRIO ( ), OUTROS CIAT'S( )

LOCAL DE TRABALHO ( ),SERVIÇOS DE SAÚDE ( ), ESCOLA/CRECHE ( ) RESIDENCIA,

PRONTO SOCORRO ( ) ENFERMARIA ( ) UTI ( ) PRESENCIAL( )

III- DADOS DA INTOXICAÇÃO

13-VIA DA INTOXICAÇẪO=

ALEITAMENTO MATERNO ( ),CUTANEA ( ),MORDEDURA/PICADA/CONTATO( ),NASAL( ),

OCULAR( ) PARENTERAL( ), RESPIRATÓRIA( ),RETAL( ), TRANSPLACETÁRIA( ), RETAL( ), VAGINAL( ),IGN( ),OUTRA( )

14-LOCAL ATINGIDO/PARTE DO CORPO=

$15-\mathrm{TIPO}=$

AGUDA-ÚNICA (), AGUDA REPETIDA ( ),CRÔNICA( ), AGUDA SOBRE CRÔNICA( ),IGNORADA ()

16-AGENTE TÓXICO=

MEDICAMENTO( ),AGROTÓXICO USO AGRICOLA( ), AGROTÓXICO DE USO DOMÉSTICO( ), PRODUTOS VETERINÁRIOS( ), RATICIDAS( ),DOMISSANITÁRIOS( ), COSMÉTICOS( ), PRODUTO QUÍMICO INDISTRIAL( ),METAIS( ),DROGAS DE ABUSO( ), PLANTAS, ALIMENTOS( ), ANIMAIS PECCONHENTOS/ SERPENTES( ), ANIMAIS PEÇONHENTOS/ARANHAS( ),ANIMAIS PEÇONHENTOS/ ESCORPIÕES( ), ANIMAIS PEÇONHENTOS/LONÔMIA( ), OUTROS ANIMAIS PEÇONHENTOS( ), ANIMAIS NÃO PEÇONHENTOS( ), OUTROS( ),DESCONHECIDO( )

17-GRUPO QUIIMICO=

18-NOME COMERCIAL $=$

19-DOSE $=$

20-CLANDESTINO= SIM ( ) NÃO( )

21-CIRCUNSTÂNCIA=ACIDENTAL ( ), AMBIENTAL( ), OCUPACIONAL( ), ALIMENTAR( ), USO TERAPEUTICO ( ), PRESCRIÇÃO MÉDICA INADEQUADA ( ), ERRO DE ADMINISTRAÇÃO ( ),MEDICINA POPULAR( ),ABSTINÊNCIA( ),USO INDEVIDO( ), OUTRA( ), NÃO INTENCIONAL ( )AUTO-MEDICAÇÃO( ), ABUSO( ),TENTATIVA DE SUICIDIO( ), TENTATIVA DE ABORTO( ), VIOLÊNCIA/HOMICÍDIO( ),OUTRA INTENCIONAL( ), ING ( )

\section{IV- DADOS DO TRATAMENTO}

\section{2-TRATAMENTO INICIAL}

ACIDIFICAÇÃO URINÁRIA

ALCALINIZAÇÃO URINÁRIA

ANTÍDOTO

SORO QUANTAS AMPOLAS

CARVÃO ATIVADO

CARVÃO ATIVADO DOSES MÚLTIPLAS

CATÁRTICOS

DEMULCENTES

DESCONTAMINAC̄̃̃O CUTÂNEA / MUCOSA

DESCONTAMINAÇÃO OCULAR

DILUICEÃO

DIURESE FORÇADA

ENDOSCOPIA DIGESTIVA ALTA

EMESE

EXAMES LABORATORIAS 
EXAMES RADIOLÓGICOS

EXOSAGUINEO TRANSFUSÃO

HEMODIÁLISE

HEMOPERFUSÃO

INTERVENÇÃO CIRÚRGICA

IRRIGAÇÃO INTESTINAL TOTAL

LAVAGEM GASTRICA

LAVAGEM INTESTINAL

NENHUM

OBSERVAÇÃO CLÍNICA

ING

TRATAMENTO DE SUPORTE

TRATAMENTO SINTOMÁTICO

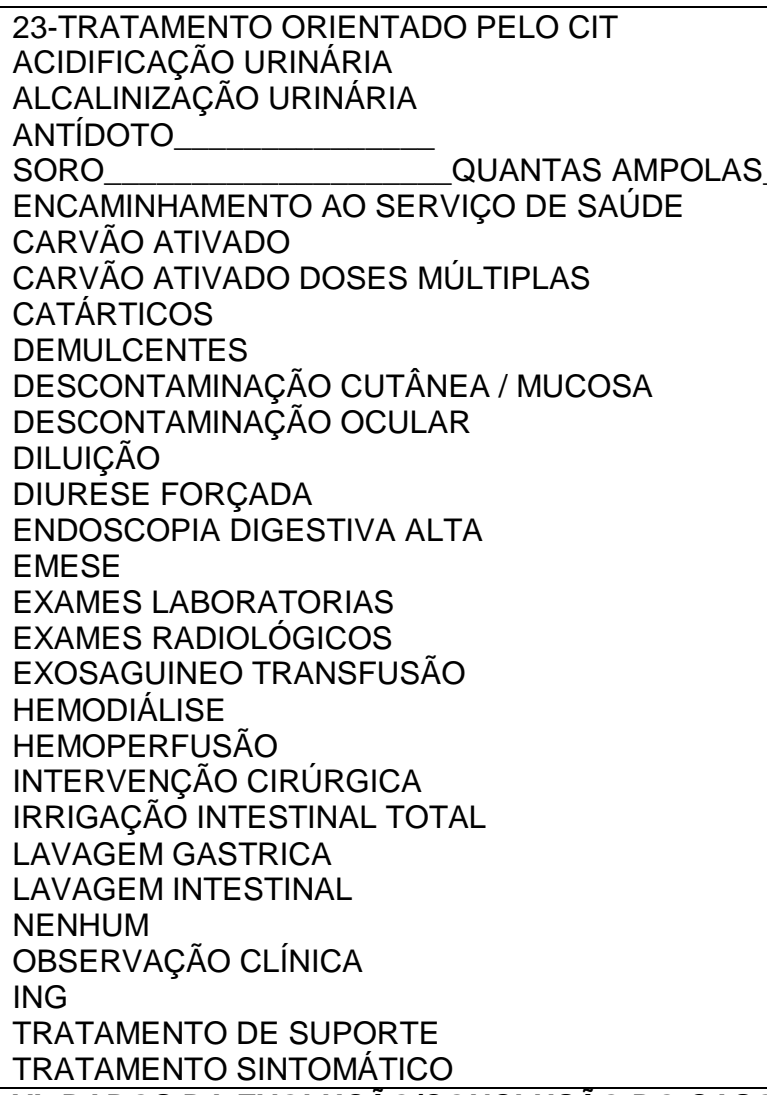




\section{APÊNDICE 2}

\section{Formulário de Investigação CEREST- DF}

\section{Identificação}

№ do Prontuário:
№ do Formulário

Data do atendimento:

Nome

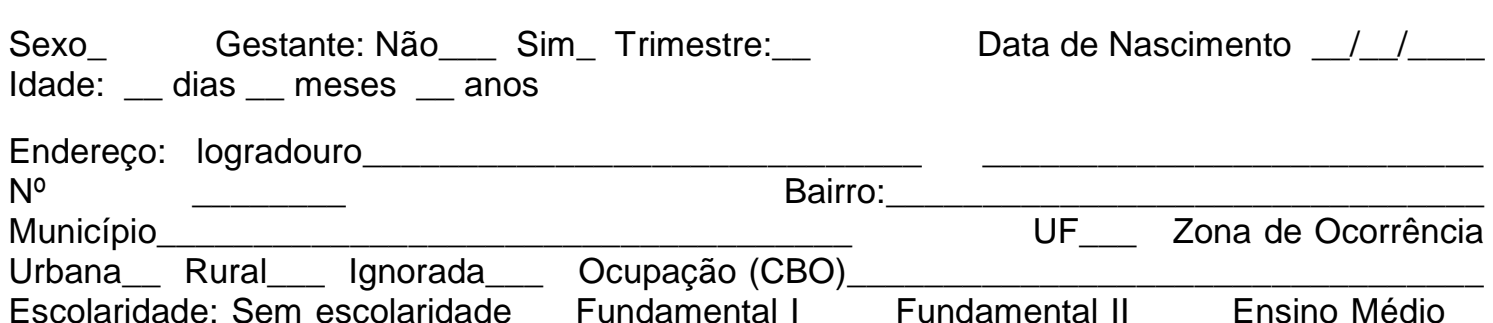
Ensino Superior: completo_ incompleto_ Ignorado

\section{Via de Intoxicação}

Aleitamento materno Parenteral Respiratória

Cutânea Retal
Mordedura /picada/contato Transplacentária_ Vaginal

Nasal Ignorado

3. Agentes Tóxicos: Medicamentos _ Raticidas uso doméstico Agrotóxico uso em saúde pública Agrotóxico uso agrícola Produto Veterinário Agrotóxico uso domiciliar Cosméticos/Higiene pessoal Produto químico de uso industrial Metal _ Drogas de abuso _ Planta tóxica __ Alimento e Bebida_ Animais peçonhentos (ofídios, aranhas, escorpiões, lagartas, lonômias, outros) _ _ Ignorados Tempo de exposição: _ horas _ dias _ meses _ anos

4. Características do Produto Tóxico: Nome comercial Princípio Ativo

5. Circunstâncias da intoxicação: acidental _ ambiental __ocupacional _ alimentar Uso terapêutico___ Prescrição médica inadequada __ Erro de administração __ Medicina popular _ Abstinência __ Uso indevido __ Automedicação ___ Abuso _ Tentativa de suicídio __ Tentativa de aborto ___ Violência/homicídio

6. Locais de ocorrência: Residência Trabalho Serviço de Saúde Escola Local público __ outro___ Uso de EPI: sim _ não _ Tipo de EPI: luva_ máscara _ bota _ avental _ touca árabe _ óculos _ outros _

\section{Dados Clínicos}

Sinais e sintomas:

Dermatológicos: Acne__ Dermatite de contato__ Dermatite seborreica_Eczema_Prurido cutâneo_Queimadura química_Urticária_ Petéquias _ Edema _ Eritema _ Exantema _ Bolhas _ Outros

Neurológicos: Amnésia___ Cefaleia _ Dormência MS e MI_Tonteira_Desmaios Formigamento MMSS__ Incordenação motora_tremores de extremidades_ Marcha atáxica _ outros

Psiquiátricos: Esquecimento__ Insônia__ Irritabilidade__ Labilidade emocional_ Nervosismo_Psicopatologia__Sonolência_

Digestivos: Pirose__ Diarréia__ Dor abdominal_Epigastralgia__ Hepatomegalia Náuseas__ Parestesia na língua__Sialoréia_ Vômitos__ Melena_outros

Ósteo-musculares: Artralgia__ Dor na coluna cervical _ Dor na coluna torácica_ Dor lombar_ Mialgia__ Outros 
Oculares: Diminuição acuidade visual _ Fotofobia _ Hiperemia conjuntival _ Lacrimejamento __ Prurido ocular_ Midríase _ Miose _ Outros

Otorrinolaringológicos: Coriza _ Dor na orofaringe _ Epistaxe _ Diminuição da acuidade auditiva _ Rouquidão __ Zumbido _ outros

Respiratórios: Tosse _ Dispneia _ Dor Torácica ao respirar_ Respiração ofegante

Murmúrio vesicular diminuído _ Sibilos _ Roncos _ Hemoptise_ Incursões

respiratória/minuto Outros

Geniturinários: Dor associada à micção _ Hematúria _ Oligúria _ Poliúria _ Anúria Dor renal__ Impotência sexual Amenorréia Outros

Cardiológicos: Bradicardia _ Taquicardia _ Palpitações $\mathrm{mm} / \mathrm{Hg}$ Batimentos cardíacos /min Outros

PA: Sistólica /diastólica

Endócrinos: Astenia _ Fadiga _ Adinamia _ Apatia _ Sonolência _ Perda de peso _ Diminuição da Libido _ Outros

8. Dados Laboratoriais: Hemograma: Hemácias: Contagem de reticulócitos Hematócrito

Hemoglobina: $\mathrm{g} / \mathrm{dL}$ Leucócitos Fosfatase Alcalina Função Hepática: AST (TGO) Gama GT Lipidograma: Colesterol: total: Função renal: Uréia Creatinina: Ácido Úrico
Triglicécrides_Lipidogram

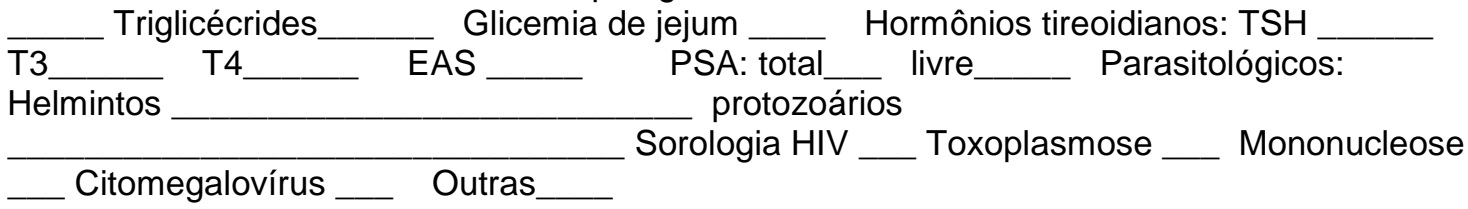

\section{Dados de exames de imagem:}

US Abdome

Raios $\mathrm{X}$ do tórax

10. Dados de exames Toxicológicos: Acetilcolinesterase plasmática

Ácido t-t mucônico ___ Ácido metilhipúrico Dosagem de metais pesados: $\mathrm{Hg}$ $\mathrm{Pb}$ Ácido hipúrico

11. Evolução clínica: Análises toxicológicas Cura com sequela Óbito Ignorado Tipo de alta: Cura Cura suposta

\section{Classificação final do caso conforme CID-10:}

Pesquisador Data: 


\section{COMITÊ DE ÉTICA EM PESQUISA - FEPECS/SES-DF}

\section{PARECER CONSUBSTANCIADO DO CEP}

\section{DADOS DO PROJETO DE PESQUISA}

Título da Pesquisa: PERFIL DAS INTOXICAÇÕES EXÓGENAS NO BRASIL,NO PERÍODO DE 2009 A 2013.

Pesquisador: ANDREA FRANCO AMORAS MAGALHÃES

Área Temática:

Versão: 1

CAAE: 36189714.2 .0000 .5553

Instituição Proponente: Subsecretaria de Vigilância em Saúde

Patrocinador Principal: Financiamento Próprio

\section{DADOS DO PARECER}

Número do Parecer: 1.076 .808

Data da Relatoria: 25/05/2015

\section{Apresentação do Projeto:}

As intoxicações exógenas podem ser definidas como as consequências clínicas e/ou bioquímicas da exposição aguda a substâncias encontradas no ambiente ou isoladas. O risco de um efeito indesejado decorrente de uma exposição a um agente químico depende de vários fatores, incluindo as propriedades intrínsecas e a toxicidade do agente, a via de exposição, a dose, a frequência de exposição e a susceptibilidade individual, que inclui aspectos genéticos, nutricionais e de saúde.

No Brasil, a principal fonte de dados sobre intoxicações exógenas é o Sistema Nacional de Informações Tóxico-Farmacológica (SINITOX), segundo o qual no período de 1998 até 2009 foram notificados 1.166.169 casos de intoxicação humana no Brasil, com produtos como medicamentos, agrotóxicos, produtos químicos industriais, saneantes, cosméticos, alimentos, plantas tóxicas e animais peçonhentos.

\section{Objetivo da Pesquisa:}

Geral:

- Analisar as intoxicações exógenas ocorridas no Brasil e, em especial, no DistritoFederal, no período de 2009 a 2013.

Endereço: SMHN 2 Qd 501 BLOCO A - FEPECS

Bairro: ASA NORTE

CEP: $70.710-904$

UF: DF Município: BRASILIA

Telefone: (61)3325-4955 Fax: (33)3325-4955 E-mail: comitedeetica.secretaria@gmail.com 


\section{COMITÊ DE ÉTICA EM PESQUISA - FEPECS/SES-DF

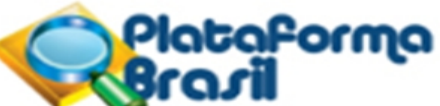

Continuação do Parecer: 1.076.808

\section{Específicos:}

- Avaliar as ocorrências de intoxicações exógenas no Brasil registradas nos sistemas de informação do Sistema de Informação de Agravos Notificáveis (SINAN), Sistema de Informação de Mortalidade (SIM), Sistema Nacional de Informação Tóxico- Farmacológico (SINITOX), a partir do cruzamento das várias fontes de informação, identificar as subnotificações, onde elas mais ocorrem e identificar suas possíveis causas;

- Analisar o perfil epidemiológico das intoxicações exógenas do Distrito Federal baseado nos sistemas de informações nacionais, do Centro de Informação Toxicológica do Distrito Federal (CIT- DF) e Sistema de Informação do Instituto Médico Legal do DF;

- Avaliar a evolução clínica dos casos de intoxicação por agrotóxicos e raticidas atendidos pelo CIT-DF e pelo Ambulatório de Toxicologia do Centro de Referência Estadual em Saúde do Trabalhador (CEREST)DF;

- Identificar os fatores associados ao óbito dos casos de intoxicação atendidos pelo CIT-DFe pelo CERESTDF.

\section{Avaliação dos Riscos e Benefícios:}

Os sujeitos foram adequadamente identificados. Os benefícios apresentam-se com maior magnitude em relação aos riscos para os sujeitos da pesquisa. Os antecedentes científicos que justificam a pesquisa foram apresentados.

\section{Comentários e Considerações sobre a Pesquisa:}

Trata-se de um estudo epidemiológico descritivo do tipo série de casos. Será realizado um estudo epidemiológico, observacional, analítico do tipo caso controle aninhado na coorte clínica, onde os casos serão os óbitos e os controles serão os não óbitos, com 20.000 sujeitos de pesquisa.

Os procedimentos para a coleta de dados será realizado pelo sistema on line do SINAN, SIH/SUS, SIM e SINITOX. Os dados do CIT-DF, CEREST-DF e IML-DF serão coletados dos sistemas de informação in loco. A coleta dos dados clínico-epidemiológicos e laboratoriais terá como fonte primária o prontuário CIT-DF que contempla um vasto elenco de variáveis relacionadas com a intoxicação, como a identificação, circunstância, produto químico, história clínica e laboratorial, assim como a evolução do caso. O diagnóstico de intoxicação será baseado em critérios epidemiológicos, clínicos e laboratoriais. Neste estudo, os tipos de exames laboratoriais considerados relevantes serão os exames toxicológicos.

Para a análise de dados será aplicado o programa Microsoft Office Access 2007, Programa de

Endereço: SMHN 2 Qd 501 BLOCO A - FEPECS

Bairro: ASA NORTE

CEP: $70.710-904$

UF: DF Município: BRASILIA

Telefone: (61)3325-4955

Fax: (33)3325-4955

E-mail: comitedeetica.secretaria@gmail.com 


\section{COMITÊ DE ÉTICA EM PESQUISA - FEPECS/SES-DF}

Continuação do Parecer: 1.076 .808

Linkagem de banco de dados-Reliked, BioEstat 5.0, além disso, serão utilizados os testes estatísticos QuiQuadrado e Fischer.

Considerações sobre os Termos de apresentação obrigatória:

Folha de rosto: Apresentada. Documento assinado pela Diretoria de Vigilância Epidemiológica/SES/DF.

Termo de Concordância: Apresentados. Documentos assinados pelas Responsáveis pelo CIT (Centro de Informações Toxicológicas) e CEREST (Centro de Referência em Saúde do Trabalhador), pela Diretoria da

DIVEP/SES e pelo Diretor do IML (Instituto Médico Legal).

Curriculum Vitae do(s) pesquisador(es): Apresentados.

Cronograma da Pesquisa: Apresentado.

Planilha de orçamento: Apresentada.

Dispensa de TCLE: Apresentado.

\section{Recomendações:}

O pesquisador assume o compromisso de garantir o sigilo que assegure o anonimato e a privacidade dos sujeitos da pesquisa e a confidencialidade dos dados coletados. Os dados obtidos na pesquisa deverão ser utilizados exclusivamente para a finalidade prevista no seu protocolo, que só poderá iniciar após aprovação pelo CEP/FEPECS/SES/DF.

O pesquisador deverá encaminhar relatório parcial e final de acordo com o desenvolvimento do projeto da pesquisa.

\section{Conclusões ou Pendências e Lista de Inadequações:}

- Projeto Aprovado.

\section{Situação do Parecer:}

Aprovado

\section{Necessita Apreciação da CONEP:}

Não

Considerações Finais a critério do CEP:

Endereço: SMHN 2 Qd 501 BLOCO A - FEPECS

Bairro: ASA NORTE

CEP: $70.710-904$

UF: DF Município: BRASILIA

Telefone: (61)3325-4955

Fax: (33)3325-4955

E-mail: comitedeetica.secretaria@gmail.com 


\title{
COMITÊ DE ÉTICA EM PESQUISA - FEPECS/SES-DF
}

BRASILIA, 25 de Maio de 2015

\begin{abstract}
Assinado por:
Helio Bergo

(Coordenador)
\end{abstract}

Endereço: SMHN 2 Qd 501 BLOCO A - FEPECS

Bairro: ASA NORTE

CEP: $\quad 70.710-904$

UF: DF

Município: BRASILIA

Telefone: (61)3325-4955

Fax: (33)3325-4955

E-mail: comitedeetica.secretaria@gmail.com 
República Federativa do Brasil

Ministério da Saúde

1" VIA-SECRETARIA DE SAUDE

\section{Declaração de Óbito}

24523917-0

Hore 3 Cartio sus

(4) Naturalidade

$1 \square$ Fetal

2ФNato Fetal

2. Data do obito

5) Nome do Falecido

6) Nome do $\mathrm{Pa}$

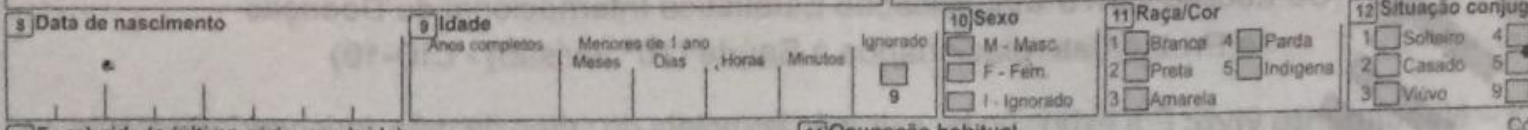

3jDats de nascimento

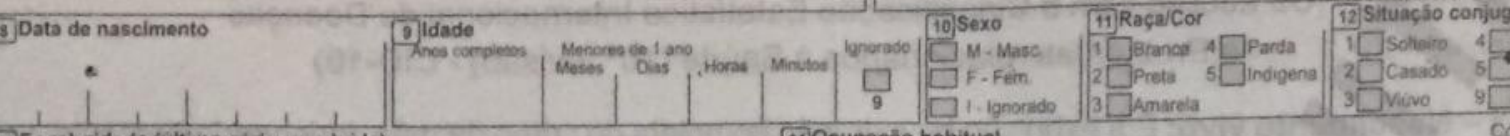

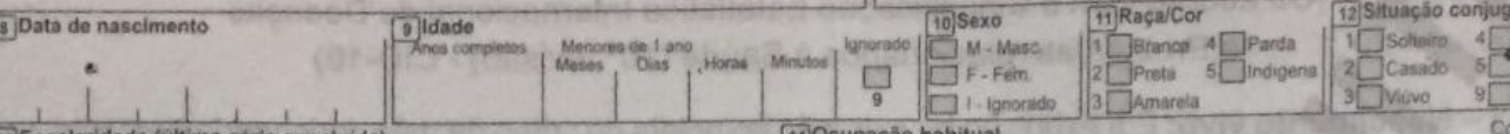

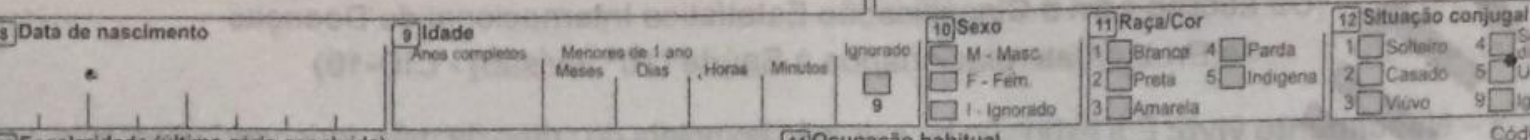
$9 \square$ 1. ignorido 3 3 amarela

(19) Escolaridade (uitima serie concluida)

OL Sem escolaridade $3 \square$ Medio (antigo $2^{\circ}$ grau) ignorado

14. Ocupaçào habitual

Codigo CBO 2002

\begin{tabular}{ll|l}
$1 \square$ Fundamental i $\left(1^{*}\right.$ a $4^{*}$ Série) & $4 \square$ Superior incompleto & $\square$ \\
$2 \square$ Fundamental 11 ( $5^{*}$ a $8^{*}$ Série) & $5 \square$ Supenor completo & 9
\end{tabular}

II

15. Logradouro (rua, praça, avenida, etc.)

17 Bairro/Distrito

(informar anterior, se aposentado / desempregado)

\section{Local de ocorrència do óbito 21] Estabelecimento}

$1 \square$ Hospital $3 \square$ Domiclio $5 \square$ Outros flgnorado

$2 \square$ Outros estab saude $4 \square$ Via publica $6 \square$ indigena $\square$

22. Endereço de ocorréncia (rua, praça, avenida, etc)

(3)

24 Bairro/Distrito

Codigo 25 Municipio de ocorrència

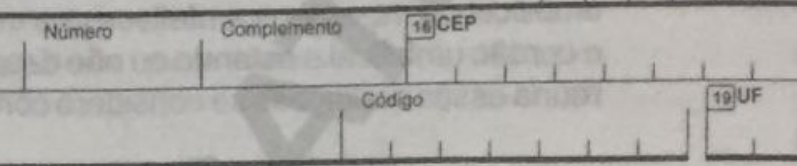

PREENCHIMENTO EXCLUSIVO PARA OBITOS FETAIS E DE MENORES DE 1 ANO - INFORMACOES SOBRE A MĀE

27) Idade 28 Escolaridade (üitima serie concluida)
(anos) Nivel

Nivel
$0 \square$ Sem escolaridade Serie

$1 \square$ Fundamentan (1"a 4 " Série) $4 \square$ Supenor incompleto

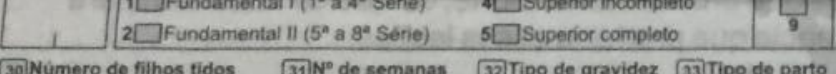

IV

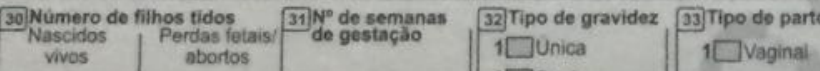

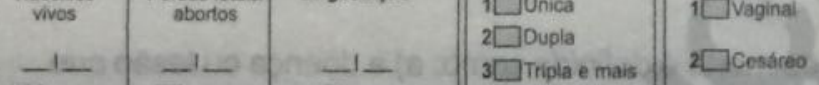

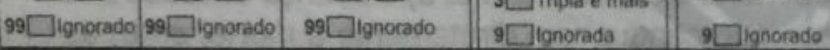

OBITO DE MULHER EM IDADE FÉRTIL

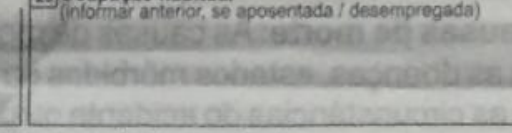

CSdigo CBO 2002 377 A morte ocorret

$1 \square$ Na gravidez $\sqrt[3]{\square}$ No abortamento

$5 \square$ De 43 cias a 1 ano apese o termino da gestacto

34) Morte om relaçăo ao parto

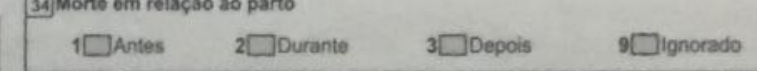

35. Peso ao nascer 30 Nümero da Declaraçăo de Nascido Vivo

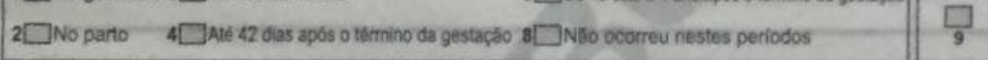

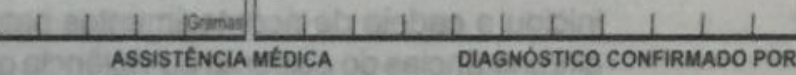

40. CAUSAS DA MORTE

O PARTEI

Doença ou estado marbido que causou divetamente a a
morle.

CAUSAS ANTECEDENTES

Estados morbidos se bxistrem, que produziram a

causa acima reciatrads mencionandose em utime

iugar a causa bisica.

ANOTE SOMENTE UM DIAGNOSTICO POR LINHA

30 Recebeu assist médica durante 39 Necrópsia?

38 Recebeu assist médica durante
a doença que ocasionou a morte?

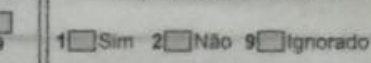

PARTE II

Outras condipbes signilicativas que contrbuiram

para a morte. eque náo entraram, porem, na

cadela acina.

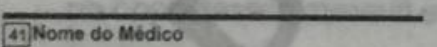

45 Meio de contato (telefone, fax, o-mail, etc.)

46 Data do atestado

42. CRM 43 Obito atestado por Medico 44 Municipio e UF do SVO ou IML.

$1 \square$ Assistente $4 \square$ Svo
$2-$ Substituto

3 - Substim

VII

PROVAVEIS CIRCUNSTANACIAS DE MORTE NÃO NATURAL (Informaçōes de caráter estntamente epidemiológico)

40 Tipo 1 Madente

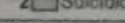

51 Descriçäo sumária do evento

(47) Assinatura

Tempo aproximado

CID

lonanal 


\section{ANEXO 3 \\ Capítulo XX (Causas externas de morbidade e mortalidade)}

Observação: neste capítulo, os subgrupos (0 a 9) se referem ao local onde ocorreu a intoxicação, e são os mesmos em todos os códigos. Por exemplo, para o código X60:

- (X680) na residência

- (X681) em habitação coletiva

- (X682) em escolas, outras instituições e áreas de administração pública

- (X683) em área para a prática de esportes e atletismo

- (X684) em rua e estrada

- (X685) em áreas de comércio e de serviços

- (X686) em áreas industriais e em construção

- (X687) em fazenda

- (X688) em outros locais especificados

- (X689) em local não especificado

$\checkmark$ (X20-X29) Contato com animais e plantas venenosas

- (X26) Contato com animais e plantas marinhos venenosos

- (X28) Contato com outras plantas venenosas especificadas

- (X29) Contato com animais ou plantas venenosos, sem especificação

$\checkmark$ (X40-X49) Envenenamento (intoxicação) acidental por e exposição a substâncias nocivas

- (X40) Envenenamento (intoxicação) acidental por e exposição a analgésicos, antipiréticos e anti-reumáticos, não-opiáceos

- (X41) Envenenamento (intoxicação) acidental por e exposição a anticonvulsivantes (antiepilépticos), sedativos, hipnóticos, antiparkinsonianos e psicotrópicos não classificadas em outra parte

- (X42) Envenenamento (intoxicação) acidental por e exposição a narcóticos e psicodislépticos (alucinógenos) não classificados em outra parte

- (X43) Envenenamento (intoxicação) acidental por e exposição a outras substâncias farmacológicas de ação sobre o sistema nervoso autônomo

- (X44) Envenenamento (intoxicação) acidental por e exposição a outras drogas, medicamentos e substâncias biológicas não especificadas

- (X45) Envenenamento (intoxicação) acidental por e exposição ao álcool

- (X46) Envenenamento (intoxicação) acidental por e exposição a solventes orgânicos e hidrocarbonetos halogenados e seus vapores

- (X47) Intoxicação acidental por e exposição a outros gases e vapores

- (X48) Envenenamento (intoxicação) acidental por e exposição a pesticidas

- (X49) Envenenamento (intoxicação) acidental por e exposição a outras substâncias químicas nocivas e às não especificadas

$\checkmark$ (X60-X84) Lesões autoprovocadas intencionalmente

- (X60) Auto-intoxicação por e exposição, intencional, a analgésicos, antipiréticos e anti-reumáticos, não-opiáceos

- (X61) Auto-intoxicação por e exposição, intencional, a drogas anticonvulsivantes (antiepilépticos) sedativos, hipnóticos, antiparkinsonianos e psicotrópicos não classificados em outra parte 
- (X62) Auto-intoxicação por e exposição, intencional, a narcóticos e psicodislépticos (alucinógenos) não classificados em outra parte

- (X63) Auto-intoxicação por e exposição, intencional, a outras substâncias farmacológicas de ação sobre o sistema nervoso autônomo

- (X64) Auto-intoxicação por e exposição, intencional, a outras drogas, medicamentos e substâncias biológicas e às não especificadas

- (X65) Auto-intoxicação voluntária por álcool

- (X66) Auto-intoxicação intencional por solventes orgânicos,

- (X67) Auto-intoxicação intencional por outros gases e vapores

- (X68) Auto-intoxicação por e exposição, intencional, a pesticidas, incluindo fumigantes, fungicidas, herbicidas, inseticidas, raticidas, preservativo de madeira

- (X69) Auto-intoxicação por e exposição, intencional, a outros produtos químicos e substâncias nocivas não especificadas, incluindo substâncias alcalinas, ácidas, corrosivas, colas e adesivos, metais, tintas, alimentos, fertilizantes, plantas venenosas, sabão e detergentes

$\checkmark$ (X85-Y09) Agressões

- (X85) Agressão por meio de drogas, medicamentos e substâncias biológicas

- (X86) Agressão por meio de substâncias corrosivas

- (X87) Agressão por pesticidas

- (X88) Agressão por meio de gases e vapores

- (X89) Agressão por meio de outros produtos químicos e substâncias nocivas especificados

- (X90) Agressão por meio de produtos químicos e substâncias nocivas não especificado

- (X97) Agressão por meio de fumaça, fogo e chamas

$\checkmark$ (Y10-Y34) Eventos (fatos) cuja intenção é indeterminada

- (Y10) Envenenamento (intoxicação) por e exposição a analgésicos, antipiréticos e anti-reumáticos não-opiáceos, intenção não determinada

- (Y11) Envenenamento (intoxicação) por e exposição a anticonvulsivantes (antiepilépticos), sedativos, hipnóticos, antiparkinsonianos e psicotrópicos não classificados em outra parte, intenção não determinada

- (Y12) Envenenamento (intoxicação) por e exposição a narcóticos e a psicodislépticos (alucinógenos) não classificados em outra parte, intenção não determinada

- (Y13) Envenenamento (intoxicação) por e exposição a outras substâncias farmacológicas de ação sobre o sistema nervoso autônomo, intenção não determinada

- (Y14) Envenenamento (intoxicação) por e exposição a outras drogas, medicamentos e substâncias biológicas e as não especificadas, intenção não determinada

- (Y15) Envenenamento (intoxicação) por e exposição ao álcool, intenção não determinada

- (Y16) Envenenamento (intoxicação) por e exposição a solventes orgânicos e hidrocarbonetos halogenados e seus vapores, intenção não determinada 
- (Y17) Envenenamento (intoxicação) por e exposição a outros gases e vapores, intenção não determinada

- (Y18) Envenenamento (intoxicação) por e exposição a pesticidas, intenção não determinada

- (Y19) Envenenamento (intoxicação) por e exposição a outros produtos químicos e substâncias nocivas e aos não especificados, intenção não determinada

- (Y26) Exposição a fumaça, fogo e chamas, intenção não determinada

$\checkmark$ (Y40-Y59) Efeitos adversos de drogas, medicamentos e substâncias biológicas usadas com finalidade terapêutica

- (Y40) Efeitos adversos de antibióticos sistêmicos

o (Y40.0) Efeitos adversos de penicilinas

- (Y40.1) Efeitos adversos de cefalosporinas e outras betalactaminas

- (Y40.2) Efeitos adversos do grupo do cloranfenicol

- (Y40.3) Efeitos adversos de macrolídeos

- (Y40.4) Efeitos adversos de tetraciclinas

$\circ$ (Y40.5) Efeitos adversos de aminoglicosídeos

- (Y40.6) Efeitos adversos de rifamicinas

- (Y40.7) Efeitos adversos de antibióticos antifúngicos administrados por via sistêmica

- (Y40.8) Efeitos adversos de outros antibióticos administrados por via sistêmica

- (Y40.9) Efeitos adversos de antibiótico sistêmico, não especificado

- (Y41) Efeitos adversos de outros antiinfecciosos e antiparasitários sistêmicos

- (Y41.0) Efeitos adversos de sulfonamidas

- (Y41.1) Efeitos adversos de drogas antimicobacterianas

- (Y41.2) Efeitos adversos de antimaláricos e drogas que atuam sobre outros protozoários parasitas do sangue

- (Y41.3) Efeitos adversos de outras drogas antiprotozoárias

- (Y41.4) Efeitos adversos de anti-helmínticos

- (Y41.5) Efeitos adversos de drogas antivirais

- (Y41.8) Efeitos adversos de outros antiinfecciosos e antiparasitários especificados

- (Y41.9) Efeitos adversos de antiinfecciosos e antiparasitários sistêmicos não especificados

- (Y42) Efeitos adversos de hormônios e seus substitutos sintéticos e antagonistas, não classificados em outra parte

- (Y42.0) Efeitos adversos de glicocorticóides e análogos sintéticos

- (Y42.1) Efeitos adversos de hormônios e substitutos da tireóide

- (Y42.2) Efeitos adversos de drogas antitireoidianas

- (Y42.3) Efeitos adversos da insulina e hipoglicêmicos orais (antidiabéticos)

- (Y42.4) Efeitos adversos de anticoncepcionais (contraceptivos) orais

- (Y42.5) Efeitos adversos de outros estrógenos e progestágenos

- (Y42.6) Efeitos adversos de antigonadotrofinas, antiestrógenos e antiandrógenos, não classificados em outra parte

- (Y42.7) Efeitos adversos de andrógenos e anabolizantes congêneres 
- (Y42.8) Efeitos adversos de outros hormônios e os não especificados e seus substitutos sintéticos

- (Y42.9) Efeitos adversos de outros antagonistas hormonais e os não especificados

- $\quad$ (Y43) Efeitos adversos de substâncias de ação primariamente sistêmica

- (Y43.0) Efeitos adversos de drogas antialérgicas e antieméticas

- (Y43.1) Efeitos adversos de antimetabólicos antineoplásicos

- (Y43.2) Efeitos adversos de produtos naturais antineoplásicos

- (Y43.3) Efeitos adversos de outras drogas antineoplásicas

- (Y43.4) Efeitos adversos de agentes imunossupressores

- (Y43.5) Efeitos adversos de acidificantes e alcalinizantes

- (Y43.6) Efeitos adversos de enzimas, não classificadas em outra parte

- (Y43.8) Efeitos adversos de outras substâncias farmacológicas de ação primariamente sistêmica, não classificadas em outra parte

- (Y43.9) Efeitos adversos de substância farmacológica de ação sistêmica, não especificada

- (Y44) Efeitos adversos de substâncias farmacológicas que atuam primariamente sobre os constituintes do sangue

- (Y44.0) Efeitos adversos de preparações a base de ferro e outros preparações prescritas na anemia hipocrômica

- (Y44.1) Efeitos adversos da vitamina B12, ácido fólico e outros preparações prescritas nas anemias megaloblásticas

- (Y44.2) Efeitos adversos de anticoagulantes

- (Y44.3) Efeitos adversos de antagonistas de anticoagulantes, vitamina $\mathrm{K}$ e outros coagulantes

- (Y44.4) Efeitos adversos de drogas antitrombóticas (inibidores da agregação de plaquetas)

- (Y44.5) Efeitos adversos de trombolíticos

- (Y44.6) Efeitos adversos do sangue natural e produtos do sangue

- (Y44.7) Efeitos adversos de substitutos do plasma

- (Y44.9) Efeitos adversos de outras substâncias farmacológicas que atuam sobre os constituintes do sangue e as não especificadas

- (Y45) Efeitos adversos de substâncias analgésicas, antipiréticas e antiinflamatórias

- (Y45.0) Efeitos adversos de opiáceos e analgésicos correlatos

- (Y45.1) Efeitos adversos de salicilatos

- (Y45.2) Efeitos adversos de derivados do ácido propiônico

- (Y45.3) Efeitos adversos de outras drogas antiinflamatórias nãoesteróides

- (Y45.4) Efeitos adversos de anti-reumáticos

- (Y45.5) Efeitos adversos de derivados do 4-aminofenol

- (Y45.8) Efeitos adversos de outros analgésicos e antipiréticos

- (Y45.9) Efeitos adversos de substâncias analgésicas e antipiréticas não especificadas

- (Y46) Efeitos adversos de drogas anticonvulsivantes (antiepilépticas) e antiparkinsonianas

- (Y46.0) Efeitos adversos de succimidas

- (Y46.1) Efeitos adversos de oxazolidínas

- (Y46.2) Efeitos adversos de derivados da hidantoína 
- (Y46.3) Efeitos adversos de desoxibarbitúricos

- (Y46.4) Efeitos adversos de iminostilbenos

- (Y46.5) Efeitos adversos do ácido valpróico

- (Y46.6) Efeitos adversos de outros anticonvulsivantes (antiepilépticos) e os não especificados

- (Y46.7) Efeitos adversos de drogas antiparkinsonianas

- (Y46.8) Efeitos adversos de substâncias miorrelaxantes (antiespásticas)

- (Y47) Efeitos adversos de sedativos, hipnóticos e tranquilizantes (ansiolíticos)

- (Y47.0) Efeitos adversos de barbitúricos, não classificados em outra parte

- (Y47.1) Efeitos adversos de benzodiazepínicos

- (Y47.2) Efeitos adversos de derivados do cloral

- (Y47.3) Efeitos adversos de paraldeído

- (Y47.4) Efeitos adversos de compostos de bromo

- (Y47.5) Efeitos adversos de sedativos e hipnóticos em associações não classificados em outra parte

- (Y47.8) Efeitos adversos de outros sedativos, hipnóticos e tranquilizantes (ansiolíticos)

- (Y47.9) Efeitos adversos de sedativos, hipnóticos e tranquilizantes (ansiolíticos), não especificados

- (Y48) Efeitos adversos de anestésicos e gases terapêuticos

- (Y48.0) Efeitos adversos de anestésicos por inalação

- (Y48.1) Efeitos adversos de anestésicos por via parenteral

- (Y48.2) Efeitos adversos de outros anestésicos gerais e os não especificados

- (Y48.3) Efeitos adversos de anestésicos locais

- (Y48.4) Efeitos adversos de anestésico, não especificado

- (Y48.5) Efeitos adversos de gases terapêuticos

- (Y49) Efeitos adversos de substâncias psicotrópicas, não classificadas em outra parte

- (Y49.0) Efeitos adversos de antidepressivos triciclos e tetracíclicos

- (Y49.1) Efeitos adversos de antidepressivos inibidores da monoamino-oxidase

- (Y49.2) Efeitos adversos de outros antidepressivos e os não especificados

- (Y49.3) Efeitos adversos de antipsicóticos e neurolépticos fenotiazínicos

- (Y49.4) Efeitos adversos de neurolépticos a base da butirofenona e do tioxanteno

- (Y49.5) Efeitos adversos de outros antipsicóticos e neurolépticos

- (Y49.6) Efeitos adversos de psicodislépticos (alucinógenos)

- (Y49.7) Efeitos adversos de psicoestimulantes que podem provocar dependência

- (Y49.8) Efeitos adversos de outras substâncias psicotrópicas, não classificados em outra parte

- (Y49.9) Efeitos adversos de substância psicotrópica, não especificada 
- (Y50) Efeitos adversos de estimulantes do sistema nervoso central, não classificados em outra parte

- (Y50.0) Efeitos adversos de analépticos

- (Y50.1) Efeitos adversos de antagonistas de receptores dos opiáceos

- (Y50.2) Efeitos adversos de metilxantinas, não classificadas em outra parte

- (Y50.8) Efeitos adversos de outros estimulantes do sistema nervoso central

- (Y50.9) Efeitos adversos de estimulante do sistema nervoso central, não especificado

- (Y51) Efeitos adversos de drogas que atuam primariamente sobre 0 sistema nervoso autônomo

- (Y51.0) Efeitos adversos de agentes anticolinesterásicos

- (Y51.1) Efeitos adversos de outros parasimpaticomiméticos (colinérgicos)

- (Y51.2) Efeitos adversos de ganglioplégicos, não classificados em outra parte

- (Y51.3) Efeitos adversos de outros parassimpaticolíticos (anticolinérgicos e antimuscarínicos) e espasmolíticos, não classificados em outra parte

- (Y51.4) Efeitos adversos de agonistas predominantemente alfaadrenorreceptores, não classificados em outra parte

- (Y51.5) Efeitos adversos de agonistas predominantemente betaadrenorreceptores, não classificados em outra parte

- (Y51.6) Efeitos adversos de antagonistas alfa-adrenorreceptores, não classificados em outra parte

- (Y51.7) Efeitos adversos de antagonistas beta-adrenorreceptores, não classificados em outra parte

- (Y51.8) Efeitos adversos de bloqueadores nervosos de ação central e adrenérgicos, não classificados em outra parte

- (Y51.9) Efeitos adversos de outras drogas que atuam primariamente sobre o sistema nervoso autônomo e as não especificadas

- (Y52) Efeitos adversos de substâncias que atuam primariamente sobre o aparelho cardiovascular

- (Y52.0) Efeitos adversos de glicosídeos estimulantes do coração e substâncias de ação semelhante

- (Y52.1) Efeitos adversos de antagonistas do cálcio (inibidores do cálcio)

- (Y52.2) Efeitos adversos de outras drogas antidisrrítmicas, não classificadas em outra parte

- (Y52.3) Efeitos adversos de vasodilatadores coronarianos, não classificados em outra parte

- (Y52.4) Efeitos adversos de inibidores da enzima de conversão da angiotensina

- (Y52.5) Efeitos adversos de outras drogas anti-hipertensivas, não classificadas em outra parte

- (Y52.6) Efeitos adversos de drogas anti-hiperlipidêmicas e antiarterioscleróticas

- (Y52.7) Efeitos adversos de vasodilatadores periféricos 
- (Y52.8) Efeitos adversos de drogas antivaricosas, incluindo os agentes esclerosantes

- (Y52.9) Efeitos adversos de outras drogas que atuam primariamente sobre o aparelho cardiovascular e as não especificadas

- (Y53) Efeitos adversos de substâncias que atuam primariamente sobre o aparelho gastrointestinal

- (Y53.0) Efeitos adversos de antagonistas dos receptores $\mathrm{H} 2 \mathrm{da}$ histamina

- (Y53.1) Efeitos adversos de outros medicamentos antiácidos e antisecreção gástrica

- (Y53.2) Efeitos adversos de laxativos estimulantes

- (Y53.3) Efeitos adversos de laxativos salinos e osmóticos

- (Y53.4) Efeitos adversos de outros laxativos

- (Y53.5) Efeitos adversos de medicamentos que facilitam a digestão

- (Y53.6) Efeitos adversos de antidiarréicos

- (Y53.7) Efeitos adversos de eméticos

- (Y53.8) Efeitos adversos de outras substâncias que atuam primariamente sobre o aparelho gastrointestinal

- (Y53.9) Efeitos adversos de substâncias que atuam primariamente sobre o aparelho gastrointestinal, não especificadas

- (Y54) Efeitos adversos de substâncias que atuam primariamente sobre o metabolismo da água, dos sais minerais e do ácido úrico

- (Y54.0) Efeitos adversos de mineralocorticóides

- (Y54.1) Efeitos adversos de antagonistas dos mineralocorticóides (antagonistas da aldosterona)

- (Y54.2) Efeitos adversos de inibidores da anidrase carbônica

- (Y54.3) Efeitos adversos de derivados da benzotiadiazína

- (Y54.4) Efeitos adversos de diuréticos de alça

- (Y54.5) Efeitos adversos de outros diuréticos

- (Y54.6) Efeitos adversos de agentes que atuam sobre o equilíbrio eletrolítico, calórico e hídrico

- (Y54.7) Efeitos adversos de medicamentos que atuam sobre o metabolismo de cálcio

- (Y54.8) Efeitos adversos de drogas que atuam sobre o metabolismo de ácido úrico

- (Y54.9) Efeitos adversos de sais minerais não classificados em outra parte

- (Y55) Efeitos adversos de substâncias que atuam primariamente sobre os músculos lisos e esqueléticos e sobre o aparelho respiratório

- (Y55.0) Efeitos adversos de ocitócicos

- (Y55.1) Efeitos adversos de relaxantes da musculatura esquelética (bloqueadores neuromusculares) (curarizantes)

- (Y55.2) Efeitos adversos de outras substâncias que atuam primariamente sobre os músculos e as não especificadas

- (Y55.3) Efeitos adversos de antitússicos

- (Y55.4) Efeitos adversos de expectorantes

- (Y55.5) Efeitos adversos de drogas anti-resfriado comum

- (Y55.6) Efeitos adversos de antiasmáticos, não classificados em outra parte 
- (Y55.9) Efeitos adversos de outras drogas que atuam sobre o aparelho respiratório e as não especificadas

- $\quad$ (Y56) Efeitos adversos de substâncias de uso tópico que atuam primariamente sobre a pele e as membranas mucosas e drogas de uso oftalmológico, otorrinolaringológico e dentário

- (Y56.0) Efeitos adversos de drogas antifúngicas, antiinfecciosas e antiinflamatórias de uso local, não classificadas em outra parte

- (Y56.1) Efeitos adversos de antipruriginosos

- (Y56.2) Efeitos adversos de adstringentes e detergentes locais

- (Y56.3) Efeitos adversos de emolientes, suavizantes e protetores da pele

- (Y56.4) Efeitos adversos de ceratolíticos, ceratoplásticos e outros medicamentos e preparações capilares

- (Y56.5) Efeitos adversos de medicamentos e preparações de uso oftalmológico

- (Y56.6) Efeitos adversos de medicamentos e preparações usados em otorrinolaringologia

- (Y56.7) Efeitos adversos de drogas de uso dentário aplicadas topicamente

- (Y56.8) Efeitos adversos de outras substâncias de uso tópico

- (Y56.9) Efeitos adversos de substância não especificada de uso tópico

- $\quad$ (Y57) Efeitos adversos de outras drogas e medicamentos e as não especificadas

- (Y57.0) Efeitos adversos de depressores do apetite (anoréxicos)

- (Y57.1) Efeitos adversos de lipotrópicos

- (Y57.2) Efeitos adversos de antídotos e agentes quelantes, não classificados em outra parte

- (Y57.3) Efeitos adversos de substâncias para restringir a ingestão de álcool

- (Y57.4) Efeitos adversos de excipientes farmacêuticos

- (Y57.5) Efeitos adversos de substâncias utilizadas como contraste em radiologia

○ (Y57.6) Efeitos adversos de outras substâncias para fins diagnósticos

- (Y57.7) Efeitos adversos de vitaminas, não classificadas em outra parte

- (Y57.8) Efeitos adversos de outras drogas e medicamentos

- (Y57.9) Efeitos adversos de droga e medicamento não especificado

$\checkmark$ (Y90-Y98) Fatores suplementares relacionados com as causas de morbidade e de mortalidade classificados em outra parte

- (Y90) Evidência de alcoolismo determinada por taxas de alcoolemia

- (Y90.0) Alcoolemia inferior a $20 \mathrm{mg} / 100 \mathrm{ml}$

- (Y90.1) Alcoolemia de $20-39 \mathrm{mg} / 100 \mathrm{ml}$

- (Y90.2) Alcoolemia de 40-59 mg/100ml

- (Y90.3) Alcoolemia de $60-79 \mathrm{mg} / 100 \mathrm{ml}$

- (Y90.4) Alcoolemia de 80-99 mg/100ml

- (Y90.5) Alcoolemia de $100-119 \mathrm{mg} / 100 \mathrm{ml}$ 
- (Y90.6) Alcoolemia de $120-199 \mathrm{mg} / 100 \mathrm{ml}$

- (Y90.7) Alcoolemia de $200-239 \mathrm{mg} / 100 \mathrm{ml}$

- (Y90.8) Alcoolemia igual ou superior a $240 \mathrm{mg} / 100 \mathrm{ml}$

- (Y90.9) Presença de álcool no sangue, taxa não especificada

- (Y91) Evidência de alcoolismo determinada pelo nível da intoxicação - (Y91.0) Intoxicação alcoólica leve

- (Y91.1) Intoxicação alcoólica moderada

- (Y91.2) Intoxicação alcoólica grave

- (Y91.3) Intoxicação alcoólica muito grave

- (Y91.9) Envolvimento com álcool não especificado de outra forma 
Caso suspeito: todo aquele indivíduo que, tendo sido exposto a substâncias químicas (agrotóxicos, medicamentos, produtos de uso doméstico, cosméticos e higiene pessoal, produtos químicos de uso industrial, drogas, plantas e alimentos e bebidas), apresente sinais e sintomas clínicos de intoxicação e/ou alterações laboratoriais provavelmente ou possivelmente compatíveis.

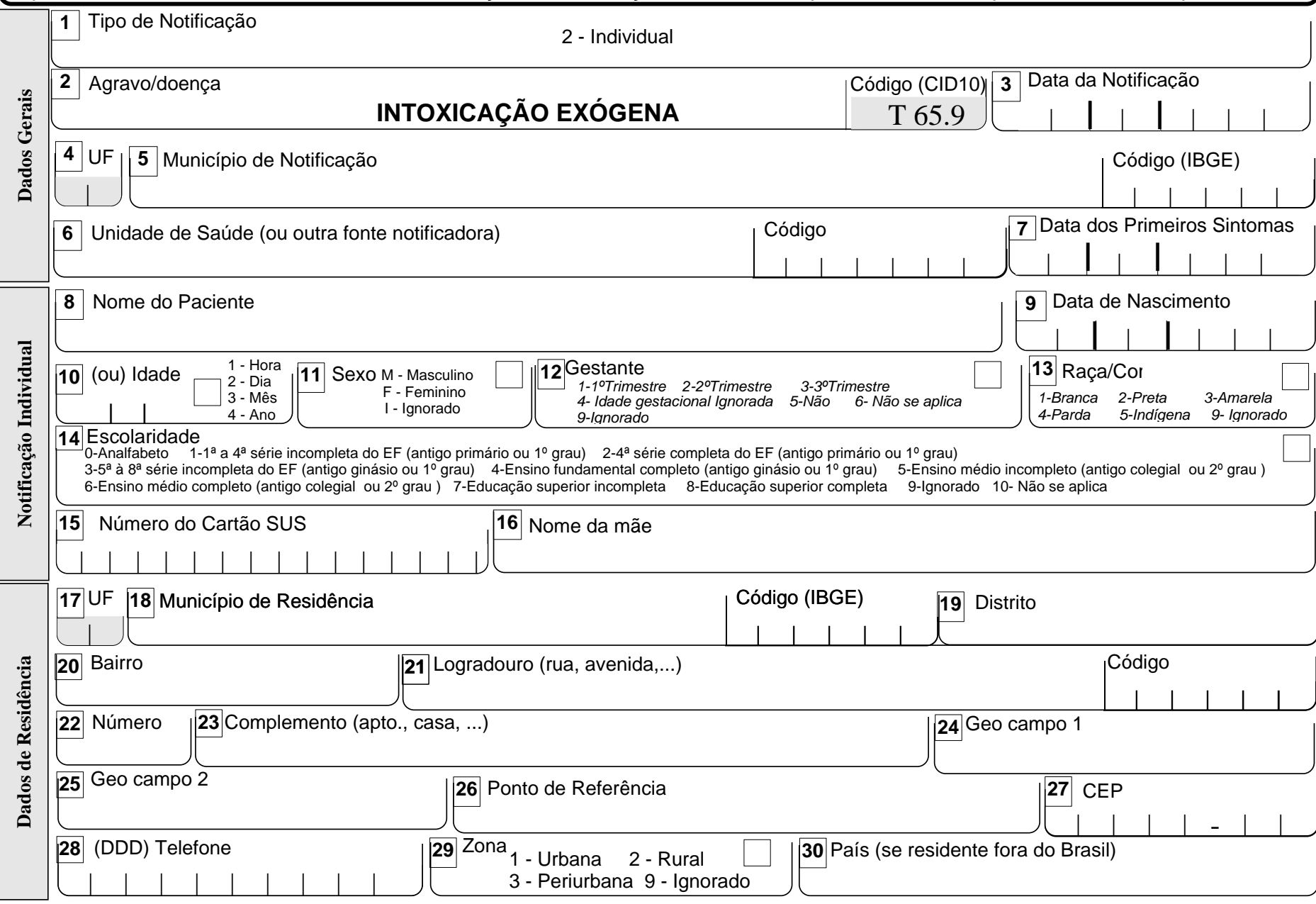

\section{Dados Complementares do Caso}

31 Data da Investigação

33 Situação no Mercado de Trabalho

01- Empregado registrado com carteira assinada

02 - Empregado não registrado

03- Autônomo/ conta própria

04- Servidor público estatuário

05 - Servidor público celetista

06- Aposentado

07- Desempregado

08 - Trabalho temporário
09 - Cooperativado

10- Trabalhador avulso

11- Empregador

12- Outros

99 - Ignorado

34 Local de ocorrência da exposição

2.Ambiente de trabalho 6.Ambiente externo
3.Trajeto do trabalho 7.Outro

\section{Serviços de saúde} 9.Ignorado

35 Nome do local/estabelecimento de ocorrência

(36 Atividade Econômica (CNAE)

37 UF 38 Município do estabelecimento

Código (IBGE)

39 Distrito

40 Bairro

41 Logradouro ( rua, avenida, etc. - endereço do estabelecimento)

42 Número 43 Complemento (apto., casa, ...)

46 (DDD) Telefone

44 Ponto de Referência do estabelecimento

\section{CEP}

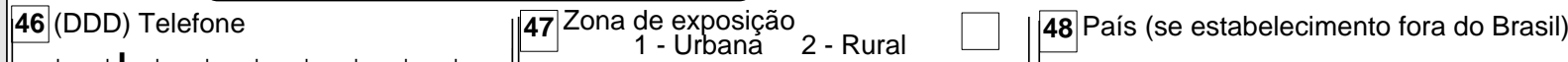


49 Grupo do agente tóxico/Classificação geral

01.Medicamento 02.Agrotóxico;uso agrícola

05.Raticida 06.Produto veterinário

09.Produto químico de uso industrial 10.metal

13.Alimento e bebida 14.Outro

50 Agente tóxico (informar até três agentes)

50 Nome Comercial/popular

1.

2

$3-$
03.Agrotóxico/uso doméstico

07.Produto de uso Domiciliar

11.Drogas de abuso

99.Ignorado

\section{Princípio Ativo}

1 -

2 -

$3-$
51 Se agrotóxico, qual a finalidade da utilização
1.Inseticida
2.Herbicida
6.Preservante para madeira 7.Outro

\section{Carrapaticida 4.Raticida}

9.Ignorado
04.Agrotóxico/uso saúde pública 08.Cosmético/higiene pessoal 12.Planta tóxica
52 Se agrotóxico, quais as atividades exercidas na exposição atual
01- Diluição
05-Colheita
02-Pulverização
06- Transporte
07-Desinsetização
04- Armazenagem
08-Produção/formulação

5.Fungicida
09-Outros

10-Não se aplica

99-Ignorado
1ํOpção:

2ㅇำção:

3Opção:
53 Se agrotóxico de uso agrícola, qual a cultura/lavoura

54 Via de exposição/contaminação

$\begin{array}{lll}\text { 1- Digestiva } & \text { 4-Ocular } & \text { 7-Transplacentária } \\ \text { 2-Cutânea } & \text { 5-Parenteral } & \text { 8-Outra } \\ \text { 3-Respiratória } & \text { 6-Vaginal } & \text { 9-Ignorada }\end{array}$

1ํOpção:

3-Respiratória

6-Vaginal

\section{8-Outra}

2Opção:

3Opção:

55 Circunstância da exposição/contaminação

03-Ambiental 04-Uso terapêutico

09-Ingestão de alimento ou bebida

05-Prescrição médica inadequada

06-Erro de administração 07-Automedicação 08-Abuso

11-Tentativa de aborto 12-Violência/homicídio 13-Outra:

10-Tentativa de suicídio

99-Ignorado

56 A exposição/contaminação foi decorrente do trabalho/ ocupação?

$$
1 \text {-Sim } 2 \text {-Não } 9 \text { - Ignorado }
$$

\begin{tabular}{|c|c|c|}
\hline 57 & Tipo de Exposição & \\
\hline & $\begin{array}{l}1 \text {-Aguda - única } 2 \text {-Aguda - repetida } \\
4 \text { - Aquda sobre Crônica } 9 \text { - lanorado }\end{array}$ & 3 - Crônica \\
\hline
\end{tabular}

\section{Tempo Decorrido entre a Exposição e o Atendimento}

\section{1 - Hora 2 - Dia 3 - Mês 4 - Ano 9- Ignorado}

59 Tipo de atendimento

1 -Hospitalar 2 -Ambulatorial 3 -Domiciliar

4 -Nenhum 9 -Ignorado

60 Houve hospitalização?

1 -Sim 2 -Não

9 - Ignorado

63 Município de hospitalização

Código (IBGE)

64 Unidade de saúde

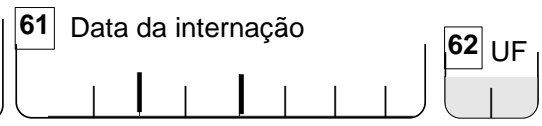

(2)

65 Classificacão final

1 - Intoxicação confirmada

4 -Outro Diagnóstico

2 - Só Exposição

5 -Síndrome de abstinência

3 -Reação Adversa

9 -Ignorado

66 Se intoxicação confirmada, qual o diagnóstico

67 Critério de confirmação

1 - Laboratorial

2 - Clínico-epidemiológico 3 -Clínico

68 Evolução do Caso

1 - Cura sem sequela $\quad 2$ - Cura com sequela 3 - Óbito por intoxicação exógena 4 - Óbito por outra causa 5-Perda de seguimento 9-Ignorado

69 Data do óbito $\quad 70$ Comunicação de Acidente de Trabalho - CAT. Data do Encerramento

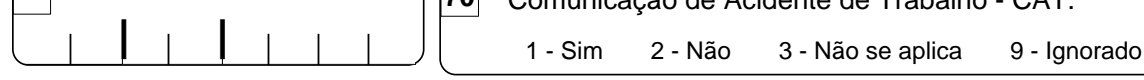

\section{Informações complementares e observações}

\section{Observações:}

